\title{
Al1100 143311
}

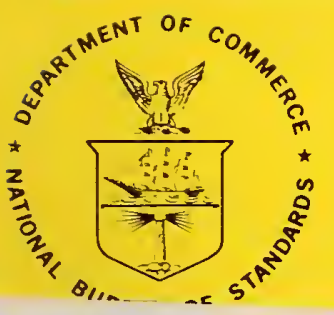

\section{NBS TECHNICAL NOTE 1132}

\section{Al1107 20947 ?}

\section{U.S. ULFARTMENT OF COMMERCE / National Bureau of Standards}

\section{Solar Energy Systems- Standards for Cover Plates For Flat Plate Solar Collectors}




\section{NATIONAL BUREAU OF STANDARDS}

The National Bureau of Standards' was established by an act of Congress on March 3, 1901. The Bureau's overall goal is to strengthen and advance the Nation's science and technology and facilitate their effective application for public benefit. To this end, the Bureau conducts research and provides: (1) a basis for the Nation's physical measurement system, (2) scientilic and technological services for industry and government, (3) a technical basis for equity in trade, and (4) technical services to promote public safety. The Bureau's technical work is performed by the National Measurement Laboratory, the National Engineering Laboratory, and the Institute for Computer Sciences and Technology.

THE NATIONAL MEASUREMENT LABORATORY provides the national system of physical and chemical and materials measurement: coordinates the system with measurement systems of other nations and furnishes essential services leading to accurate and uniform physical and chemical measurement throughout the Nation's scientific community, industry, and commerce; conducts materials research leading to improved methods of measurement, standards, and data on the properties of materials needed by industry, commerce, educational institutions, and Government; provides advisory and research services to other Government agencies; develops, produces, and distributes Standard Reference Materials; and provides calibration services. The Laboratory consists of the following centers:

\section{Absolute Physical Quantities ${ }^{2}$ - Radiation Research - Thermodynamics and}

Molecular Science - Analytical Chemistry - Materials Science.

THE NATIONAL ENGINEERING LABORATORY provides technology and technical services to the public and private sectors to address national needs and to solve national problems; conducts research in engineering and applied science in support of these efforts; builds and maintains competence in the necessary disciplines required to carry out this research and technical service; develops engineering data and measurement capabilities; provides engineering measurement traceability services; develops test methods and proposes engineering standards and code changes; develops and proposes new engineering practices; and develops and improves mechanisms to transfer results of its research to the ultimate user. The Laboratory consists of the following centers:

\footnotetext{
Applied Mathematics - Electronics and Electrical Engineering ${ }^{2}$ - Mechanical Engineering and Process Technology ${ }^{2}$ - Building Technology - Fire Research Consumer Product Technology — Field Methods.
}

THE INSTITUTE FOR COMPUTER SCIENCES AND TECHNOLOGY conducts research and provides scientific and technical services to aid Federal agencies in the selection, acquisition, application, and use of computer technology to improve effectiveness and economy in Government operations in accordance with Public Law 89-306 (40 U.S.C. 759), relevant Executive Orders, and other directives; carries out this mission by managing the Federal Information Processing Standards Program, developing Federal ADP standards guidelines, and managing Federal participation in ADP voluntary standardization activities; provides scientific and technological advisory services and assistance to Federal agencies; and provides the technical foundation for computer-related policies of the Federal Government. The Institute consists of the following centers:

Programming Science and Technology — Computer Systems Engineering.

'Headquarters and Laboratories at Gaithersburg, MD, unless otherwise noted; mailing address Washington, DC 20234.

:Some divisions within the center are located at Boulder, $\mathrm{CO} 80303$. 


\section{Solar Energy Systems-Standards for Cover Plates for Flat Plate Solar Collectors}

Elizabeth J. Clark

Willard E. Roberts

John W. Grimes

Edward J. Embree

Center for Building Technology

National Engineering Laboratory

National Bureau of Standards

Washington, DC 20234

Prepared for:

\section{Department of Energy}

Office of Solar Applications for Buildings

Office of the Assistant Secretary

Conservation and Solar Applications

Washington, DC 20585

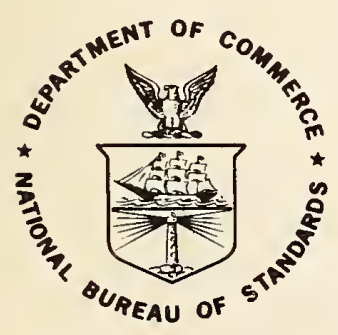

U.S. DEPARTMENT OF COMMERCE, Philip M. Klutznick, Secretary

Jordan J. Baruch, Assistant Secretary for Productivity, Technology and Innovation NATIONAL BUREAU OF STANDARDS, Ernest Ambler, Director Issued December 1980 


\section{National Bureau of Standards Technical Note 1132}

Nat. Bur. Stand. (U.S.), Tech. Note 1132, 157 pages (Dec. 1980)

CODEN: NBTNAL

\section{U.S. GOVERNMENT PRINTING OFFICE}

WASHINGTON: 1980

For sale by the Superintendent of Documents, U.S. Government Printing Office, Washington, D.C. 20402 Price $\$ 5.50$

(Add 25 percent for other than U.S. mailing). 


\section{ABSTRACT}

Laboratory studies were performed to obtain data needed for the development of standards to evaluate the performance and durability of cover plates for flat plate solar collectors used in solar heating and cooling systems. Ten cover plate materials were evaluated to assess their durabilty after exposure to heat aging, natural weathering and accelerated weathering. Laboratory tests included measurement of solar energy transmittance, linear dimensional stability, warpage and the effect of the dirt retention. The temperatures cover plate materials attain on solar collectors were determined by measurement and by computer simulations. A procedure was developed for the natural weathering exposure of cover plate materials at elevated temperatures which aproximate stagnation conditions of solar collectors.

The results of the laboratory tests are presented and draft standards for evaluating cover plate materials for flat plate solar collectors are proposed.

Key words: Cover plate durability; cover plate materials; cover plate standards; standards; weathering of cover plates. 
The primary purpose of the research described in this report was to obtain laboratory data needed to develop the technical basis for standards for solar collector cover plate materials, and not to evaluate commercially available cover plate materials. However, in order to develop the needed data, it was essential that a variety of cover plate materials be tested. No attempt was made to test every type of cover plate material on the market. The materials selected were typical of those commercially available in 1976. Many cover plate materials are marketed and, in order to improve their performance, manufacturers sometimes modify the materials. The properties of a material can be changed by alterations in minor constituents (i.e. iron oxide content, stabilizers, plasticizers, antioxidants) or in processing techniques. The properties of materials currently on the market may differ from those described in this report. The reader is cautioned against direct application of these data to materials currently on the market. 
The authors gratefully acknowledge the contributions of $\mathrm{Mr}$. James Seiler and Ms. Anita Sweigert of NBS for assisting with the laboratory tests described in this report. The authors also thank Mr. Aaron Dawson of Virginia Polytechnic Institute for performing the computer calculations to estimate cover plate temperatures of plastic and glass materials and the calculations of the heat loss coefficients and variable angle exposure in Appendix B. The authors are indebted to Mr. Larry Kaetzel of NBS for his assistance in linking the spectrophotometer with the computer and his computer program development in handling data.

In addition, the valuable review comments on draft standards provided by members of ASTM Committee E44 Solar Energy Conversion are gratefully acknowledged. The authors also thank the personnel at South Florida Test Services, Inc. and at DSET Laboratories, Inc. for their cooperation in maintaining the outdoor exposure boxes. The authors also thank the many manufacturers of cover plate materials who supplied materials utilized in this research. 


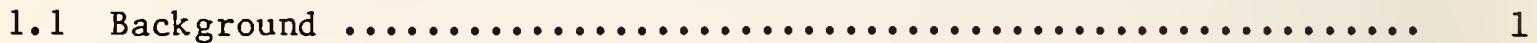

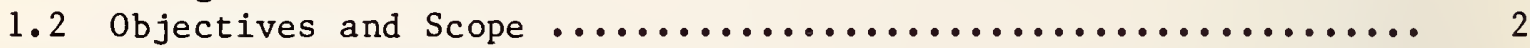

2. PROBLEM ASSESSMENT .................................... 3

2.1 Field Problems ................................... 3

2.2 Performance Requirements ............................ 5

2.3 Cover Plate Properties ............................... 6

2.3.1 Primary Properties ............................ 6

2.3.1.1 Solar Energy Transmittance ................ 6

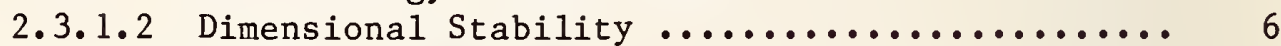

2.3.1.3 Tensile Properties ...................... 7

2.3.1.4 Hail Impact Resistance ................... 7

2.3.2 Secondary Properties .......................... 7

2.3.2.1 Transmittance of Long Wavelength Radiation .... 7

2.3.2.2 Abrasion Resistance ...................... 8

2.3.2.3 Static Electric Charge Buildup ............ 8

2.4 Degradation Factors .............................. 8

2.4 .1 Solar Radiation .............................. 8

2.4 .2 Temperature $\ldots \ldots \ldots \ldots \ldots \ldots \ldots \ldots \ldots \ldots \ldots \ldots \ldots \ldots \ldots \ldots \ldots \ldots \ldots . \ldots \ldots$

2.4 .3 Synergistic Reactions ........................... 10

2.4 .4 other Factors ............................... 10

3. LABORATORY STUDIES and FIELD EXPOSURES ..................... 11

3.1 Introduction ..................................... 11

3.2 Aging Procedures to Simulate Degradation Factors ........... 11

3.2.1 Heat Stability Aging Procedure .................... 11

3.2.2 Artificial Weathering with Xenon Arc Light ........... 12

3.2.3 Natural Weathering Exposure ..................... 12 
Table of Contents (con't)

$\underline{\text { Page }}$

3.3 Property Tests .................................... 14

3.3.1 Solar Energy Transmittance ..................... 14

3.3.1.1 Method A - Integrating Sphere Spectrophoto-

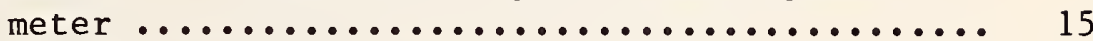

3.3.1.2 Method B - Outdoor with Pyranometer ......... 15

3.3.1.3 Effect of Dirt Accumulation on Solar Energy

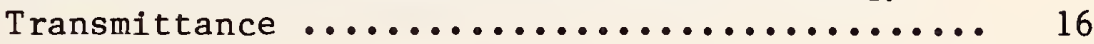

3.3.2 Linear Dimensional Stability ................... 16

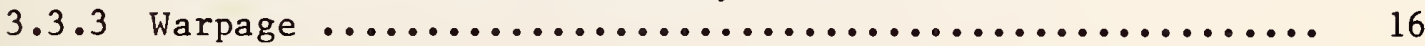

3.4 Materials $\ldots \ldots \ldots \ldots \ldots \ldots \ldots \ldots \ldots \ldots \ldots \ldots \ldots \ldots \ldots \ldots \ldots \ldots \ldots \ldots \ldots \ldots \ldots$

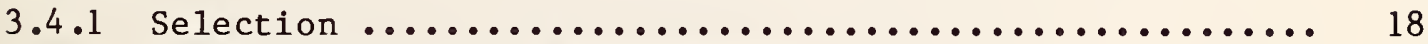

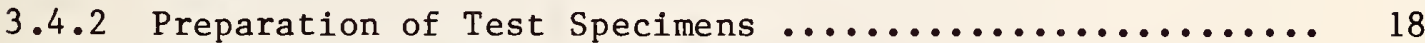

3.4.3 Control Specimens .......................... 18

3.5 Schedule of Aging Procedures and Property Evaluation Tests .... 20

4. RESULTS AND DISCUSSION .................................. 20

4.1 Control Test Specimens ............................... 20

4.1.1 Solar Energy Transmittance ...................... 20

4.1.1.1 Method A - Spectrophotometer .............. 20

4.1.1.2 Method B - Outdoor with Pyranometer .......... 23

4.1.1.3 Comparison of Results of Method $A$ and

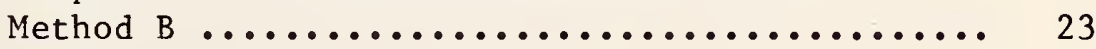

4.1 .2 Infrared Transmittance ....................... 23

4.2 Heat Aging ..................................... 27

4.2 .1 Solar Energy Transmittance .................... 27

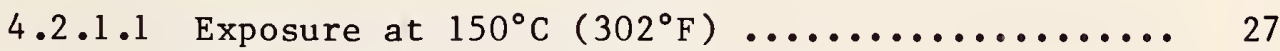

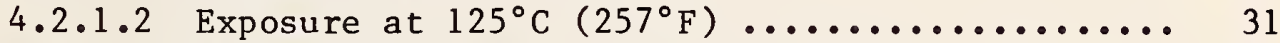

4.2 .1 .3 Exposures at $100^{\circ} \mathrm{C}\left(212^{\circ} \mathrm{F}\right)$ and $75^{\circ} \mathrm{C}\left(167^{\circ} \mathrm{F}\right) \ldots 31$

4.2.1.4 Comparison of Exposures ............... 37

4.2.2 Linear Dimensional Stability .................... 37

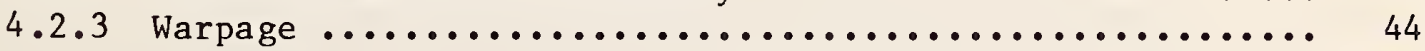


4.3 Artificial Weathering with Xenon Arc Light ............. 46

4.3.1 Solar Energy Transmittance ..................... 46

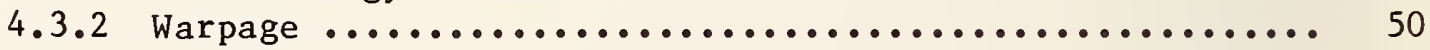

4.4 Natural Weathering $\ldots \ldots \ldots \ldots \ldots \ldots \ldots \ldots \ldots \ldots \ldots \ldots \ldots \ldots . \ldots \ldots$

4.4.1 Temperatures oz Minicollectors ................... 50

4.4.2 Cumulative Solar Radiation ..................... 52

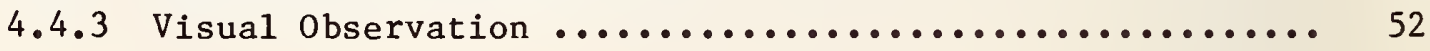

4.4.3.1 Minicollector Boxes ................... 52

4.4 .3 .2 Test Specimens ........................ 52

4.4.4 Solar Energy Transmittance ................... 57

4.4.4.1 Gaithersburg, Maryland Exposures .......... 57

4.4.4.2 Miami, Florida Exposures ................. 63

4.4.4.3 New River, Arizona Exposures .............. 72

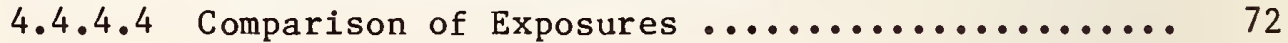

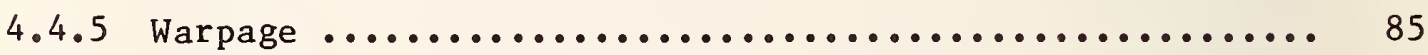

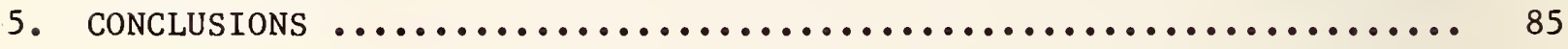

5.1 Measurement of Transmittance ........................ 85

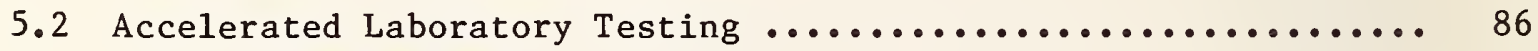

5.3 Outdoor Weathering $\ldots \ldots \ldots \ldots \ldots \ldots \ldots \ldots \ldots \ldots \ldots \ldots \ldots \ldots \ldots \ldots \ldots$

6. ADdITIONAL RESEARCH NEEDS $\ldots \ldots \ldots \ldots \ldots \ldots \ldots \ldots \ldots \ldots \ldots \ldots \ldots \ldots \ldots \ldots \ldots \ldots \ldots$

7. PROPOSED STANDARDS $\ldots \ldots \ldots \ldots \ldots \ldots \ldots \ldots \ldots \ldots \ldots \ldots \ldots \ldots \ldots \ldots \ldots \ldots \ldots \ldots \ldots \ldots \ldots$

7.1 Standard Practice for Exposure of Cover Materials for Solar Collectors to Natural Weathering Under Conditions Simulating

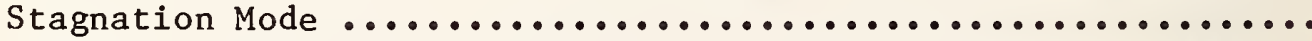

7.2 Standard Practice for Evaluation of Cover Materials for Flat

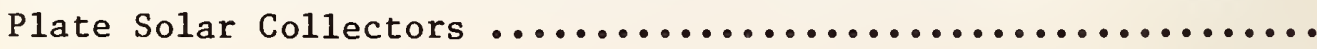

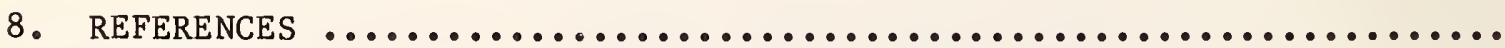

APPENDIX A Determination of Cover Plate Temperatures ................ APPENDIX B Proposed Standard Practice for Exposure of Cover Materials for Solar Collectors to Natural Weathering Under Conditions

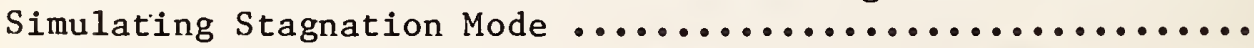
APPENDIX C Proposed Standard Practice for Evaluation of Cover Materials for Flat Plate Solar Collectors ..................... 
1. Damage to $0.13 \mathrm{~mm}$ ( $0.005 \mathrm{in})$ Poly(ethylene terephthalate) Film Caused by Hailstorm in New River, Arizona ..................

2. Spectral Distribution of Sunlight at Air Masses 1,2 and 3...... 9

3. Minicollector for Natural Weathering Exposure $\ldots \ldots \ldots \ldots \ldots \ldots \ldots . . \ldots 13$

4. Apparatus for Warpage Measurement $\ldots \ldots \ldots \ldots \ldots \ldots \ldots \ldots \ldots \ldots . \ldots \ldots$

5a. Spectral Transmittance of Control Test Specimens of Two Glass Materials ..........................................

5b. Spectral Transmittance of Control Test Specimens of Four Plastic Films

5c. Spectral Transmittance of Control Test Specimens of Two Clear Plastic Sheet Materials ...............................

5d. Spectral Transmittance of Control Test Specimens of Two Fiber Reinforced Plastics ..................................

6a. Infrared Transmittance of Control Test Specimens of Two Glass Materials

6b. Infrared Transmittance of Control Test Specimens of Two Plastic Films

6c. Infrared Transmittance of Control Test Specimens of Two Plastic Films

6d. Infrared Transmittance of Control Test Specimens of Two Plastic Sheet Materials

6e. Infrared Transmittance of Control Test Specimens of Two Fiber Reinforced Plastics

7a. Spectral Transmittance of $1.5 \mathrm{~mm}$ (0.06 in) Fiber Reinforced Plastic

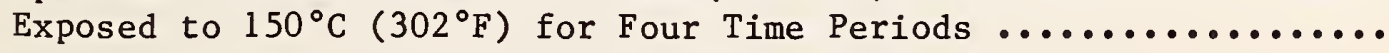

7b. Spectral Transmittance of $0.10 \mathrm{~mm}$ (0.004 in) Poly(vinyl fluoride) Exposed to $150^{\circ} \mathrm{C}\left(302^{\circ} \mathrm{F}\right)$ for Four Time Periods

8. Appearance of Poly(vinyl fluoride) After Exposure at $150^{\circ} \mathrm{C}\left(302^{\circ} \mathrm{F}\right)$ for Various Periods

9a. Rate of Solar Energy Transmittance Loss of Five Cover Plate Materials Exposed at $150^{\circ} \mathrm{C}\left(302^{\circ} \mathrm{F}\right)$ 
9b. Rate of Solar Energy Transmittance Loss of Five Cover Plate Materials Exposed at $125^{\circ} \mathrm{C}\left(257^{\circ} \mathrm{F}\right) \ldots \ldots \ldots \ldots \ldots \ldots \ldots \ldots \ldots \ldots \ldots \ldots \ldots \ldots \ldots \ldots$

10a. Spectral Transmittance of $0.10 \mathrm{~mm}$ (0.004 in) Poly(vinyl fluoride) Exposed to Four Temperatures for Approximately 2000 Hours .......

10b. Spectral Transmittance of $0.13 \mathrm{~mm}$ (0.005 in) Poly(ethylene terephthalate) Exposed to Four Temperatures for Approximately 2000 Hours

10c. Spectral Transmittance of $0.076 \mathrm{~mm}$ (0.003 in) Acrylic Film Exposed to Three Temperatures for Approximately 2000 Hours

10d. Spectral Transmittance of $1.5 \mathrm{~mm}$ (0.06 in) Poly(methyl methacrylate) Exposed to Three Temperatures for Approximately 2000 Hours

10e. Spectral Transmittance of $1.0 \mathrm{~mm}$ (0.04 in) Polycarbonate Exposed at Two Temperatures for Approximately 2000 Hours ...............

10f. Spectral Transmittance of $1.0 \mathrm{~mm}$ (0.04 in) Fiber Reinforced Plastic Exposed at Four Temperatures for Approximately 2000 Hours

10g. Spectral Transmittance of $1.5 \mathrm{~mm}$ (0.06 in) Fiber Reinforced Plastic Exposed at Four Temperatures for Approximately 2000 Hours

1la. Linear Dimensional Changes of Fluorinated(ethylene propylene) Copolymer Exposed at $150^{\circ} \mathrm{C}\left(302^{\circ} \mathrm{F}\right) \ldots \ldots \ldots \ldots \ldots \ldots \ldots \ldots \ldots \ldots$.

1lb. Linear Dimensional Changes of Acrylic Film Exposed at $150^{\circ} \mathrm{C}$ $\left(302^{\circ} \mathrm{F}\right)$

12a. Appearance of Poly(methyl methacrylate) After $150^{\circ} \mathrm{C}\left(302^{\circ} \mathrm{F}\right)$ Heat

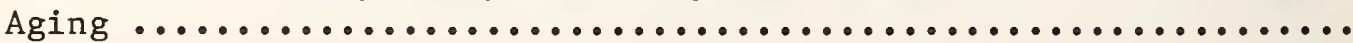

12b. Appearance of Polycarbonate After $150^{\circ} \mathrm{C}\left(302^{\circ} \mathrm{F}\right)$ Heat Aging .......

13a. Spectral Transmittance of $1.0 \mathrm{~mm}$ (0.04 in) Polycarbonate After Exposure in a Xenon Arc Artificial Weathering Device ...........

13b. Spectral Transmittance of $1.0 \mathrm{~mm}(0.04 \mathrm{in})$ Fiber Reinforced Plastic After Exposure in a Xenon Arc Artificial Weathering Device 
13c. Spectral Transmittance of $0.13 \mathrm{~mm}(0.005 \mathrm{in})$ Poly(ethylene terephtalate) After Exposure in a Xenon Arc Artificial Weathering Device

14. Minicollectors Exposed in Gaithersburg, Maryland .............. 54

15. A Double Cover Minicollector with Poly(vinyl fluoride) Covers After 18 Months Exposure at New River, Arizona ................

16. Comparison of the Spectral Transmittance of Control with Washed and Unwashed $0.10 \mathrm{~mm}$ (0.004 in) Poly(vinyl fluoride) Exposed

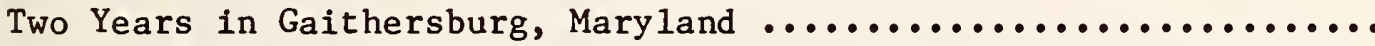

17a. Spectral Transmittance of Washed $3.2 \mathrm{~mm}(1 / 8 \mathrm{in})$ Glass $(0.01 \%$ iron oxide) After Two Years Outdoor Weathering ...............

17b. Spectral Transmittance of Washed $3.2 \mathrm{~mm}(1 / 8)$ Glass $(0.10 \%$ iron oxide) After Two Years Outdoor Weathering ....................

17c. Spectral Transmittance of Washed $0.025 \mathrm{~mm}(0.001$ in) Fluorinated (ethylene propylene) Copolymer After Two Years Outdoor

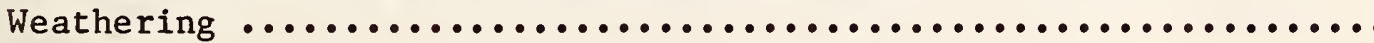

17d. Spectral Transmittance of Washed $0.10 \mathrm{~mm}(0.004 \mathrm{in})$ Poly(vinyl fluoride) After Two Years Outdoor Weathering .................

17e. Spectral Transmittance of Washed $0.13 \mathrm{~mm}(0.005 \mathrm{in})$ Poly(ethylene terephthalate) After Two Years Outdoor Weathering ..............

17f. Spectral Transmittance of Washed $1.5 \mathrm{~mm}(0.06 \mathrm{in})$ Poly(methy 1 methacrylate) After Two Years Outdoor Weathering ...............

17g. Spectral Transmittance of Washed $1.0 \mathrm{~mm}(0.04 \mathrm{in})$ Polycarbonate After Two Years Outdoor Weathering $. . . \ldots \ldots \ldots . . . . . . . . . .$.

17h. Spectral Transmittance of Washed $1.0 \mathrm{~mm}(0.04 \mathrm{in})$ Fiber Reinforced Plastic After Two Years Outdoor Weathering ...........

17i. Spectral Transmittance of Washed $1.5 \mathrm{~mm}(0.06 \mathrm{in})$ Fiber Reinforced Plastic After Two Years Outdoor Weathering ...........

18. Comparison of Spectral Transmittance of $1.0 \mathrm{~mm}(0.04 \mathrm{in})$

Polycarbonate Exposed Two Years in Arizona ..................

19. Comparison of Spectral Transmittance of $1.0 \mathrm{~mm}(0.04 \mathrm{in})$

Polycarbonate Single Covers Exposed in Florida 


\section{List of Figures (con't)}

$\underline{\text { Page }}$

A1. Collector on Which Temperature Measurements Were Made........ A2

A2. Location of Thermocouples on Collector During Stagnation

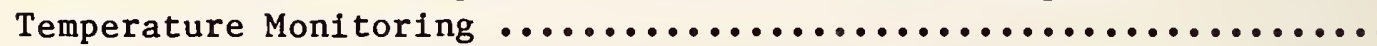

A3. Cover Plate Temperatures Measured June 23, 1977 on Collector in

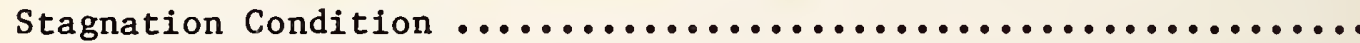

A4. Temperatures Measured September 18, 1977 in Center of Collector in Stagnation Condition .................................

A5a. Maximum Stagnation Temperatures in a Collector with a Flat Black Absorber $(\alpha=0.9, \varepsilon=0.9$ and Two Glass Cover Plates $\left(\mathrm{I}=1070 \mathrm{~W} / \mathrm{m}^{2}\left(340 \mathrm{Btu} / \mathrm{ft}^{2} \cdot \mathrm{h}\right)\right.$, No Wind $) \ldots \ldots \ldots \ldots \ldots \ldots \ldots \ldots$

A5b. Maximum Stagnation Temperatures in a Collector with a Selective Absorber $(\alpha=0.9, \varepsilon=0.1)$ and Two Glass Cover Plates ( $I=1070$ $\mathrm{W} / \mathrm{m}^{2}\left(340 \mathrm{Btu} / \mathrm{ft}^{2} \cdot \mathrm{h}\right)$, No Wind)

A5c. Maximum Stagnation Temperatures in a Collector with Flat Black Absorber $(\alpha=0.9, \varepsilon=0.9)$ and One Glass Cover Plate $\left(\mathrm{I}=1070 \mathrm{~W} / \mathrm{m}^{2}\left(340 \mathrm{Btu} / \mathrm{ft}^{2} \cdot \mathrm{h}\right)\right.$, No Wind $)$

A5d. Maximum Stagnation Temperatures in a Collector with a Selective Absorber $(\alpha=0.9, \varepsilon=0.1)$ and One Glass Cover Plate ( $I=1070$ $\mathrm{W} / \mathrm{m}^{2}\left(340 \mathrm{Btu} / \mathrm{ft}^{2} \cdot \mathrm{h}\right)$, No Wind $)$

B1. Top View of Exposure Test Fixture $\ldots \ldots \ldots \ldots \ldots \ldots \ldots \ldots \ldots \ldots \ldots$ B4

B2. Natural Weathering Box Assembly

Cl. Sequence of Testing $\ldots \ldots \ldots \ldots \ldots \ldots \ldots \ldots \ldots \ldots \ldots \ldots \ldots \ldots$ 


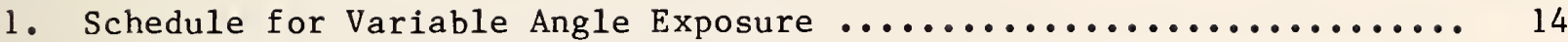

2. Solar Energy Transmittance of Control Test Specimens as Measured with an Integrating Sphere Spectrophotometer .................. 19

3. Solar Energy Transmittance of Control Test Specimens as Measured Outdoors

4. Solar Energy Transmittance of Cover Plate Materials After Heat Aging

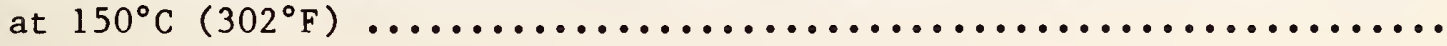

5. Solar Energy Transmittance of Cover Plate Materials After Heat Aging

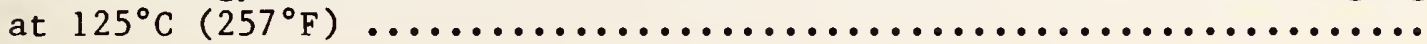

6. Solar Energy Transmittance of Cover Plate Materials After Heat Aging

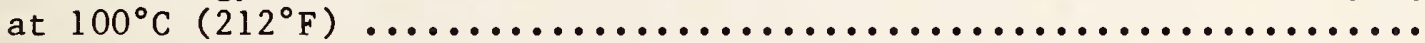

7. Solar Energy Transmittance of Cover Plate Materials After Heat Aging at $75^{\circ} \mathrm{C}\left(167^{\circ} \mathrm{F}\right) \ldots \ldots \ldots \ldots \ldots \ldots$

8. Percent Change in Linear Dimensions of Cover Plate Materials After

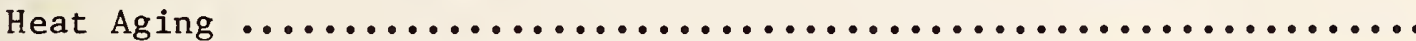

9. Warpage of Test Specimens After Heat Aging $\ldots \ldots \ldots \ldots \ldots \ldots \ldots \ldots$

10. Solar Energy Transmittance of Cover Plate Materials After Artificial

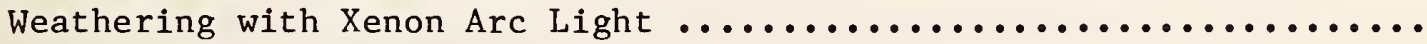

11. Temperatures of Absorber and Cover Plate Materials Exposed to Natural Weathering on Minicollectors in Gaithersburg,

Maryland

12. Natura1 Weathering Exposure Data for Minicollectors .............

13. Solar Energy Transmittance of Cover Plate Materials Exposed as Single Covers to Natural Weathering in Gaithersburg, Maryland ............

14. Solar Energy Transmittance of Cover Plate Materials Exposed as Double Covers to Natural Weathering in Gaithershurg, Maryland .............

15. Solar Energy Transmittance Loss of Cover Plate Materials Exposed as Single Covers to Natural Weathering in Gaithersburg, Maryland ....... 
16. Solar Energy Transmittance Loss of Cover Plate Materials Exposed as Double Covers to Natural Weathering in Gaithersburg, Maryland

17. Solar Energy Transmittance Loss Due to Dirt on the Surface of the Cover Plate Materials After a Single Cover Exposure in Gaithersburg,

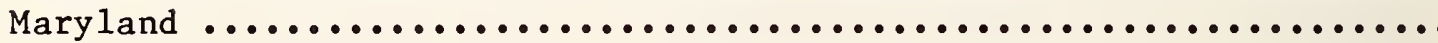

18. Solar Energy Transmittance Loss Due to Dirt on the Surface of the Cover Plate Materials After Double Cover Exposure in Gaithersburg, Maryland ...............................................

19. Solar Energy Transmittance of Cover Plate Materials Exposed as Single Covers to Natural Weathering in Miami, Florida .............

20. Solar Energy Transmittance of Cover Plate Materials Exposed as Double Covers to Natural Weathering in Miami, Florida

21. Solar Energy Transmittance Loss of Cover Plate Materials Exposed as Single Covers to Natural Weathering in Miami, Florida ...

22. Solar Energy Transmittance Loss of Cover Plate Materials Exposed as Double Covers to Natural Weathering in Miami, Florida .............

23. Solar Energy Transmittance Loss Due to Dirt on the Surface of Cover Plate Materials After Single Cover Exposure in Miami, Florida ......

24. Solar Energy Transmittance Loss Due to Dirt on the Surface of Cover Plate Materials After Double Cover Exposure in Miami, Florida .......

25. Solar Energy Transmittance of Cover Plate Materials Exposed as Single Covers to Natural Weathering in New River, Arizona ...

26. Solar Energy Transmittance of Cover Plate Materials Exposed as Double Covers to Natural Weathering in New River, Arizona ...............

27. Solar Energy Transmittance Loss of Cover Plate Materials Exposed as Single Covers to Natural Weathering in New River, Arizona

28. Solar Energy Transmittance Loss of Cover Plate Materials Exposed as Double Covers to Natural Weathering in New River, Arizona .......... 
List of Tables (con't)

$\underline{\text { Page }}$

29. Solar Energy Transmittance Loss Due to Dirt on the Surface of Cover Plate Materials After a Single Cover Exposure in New River,

Arizona

30. Solar Energy Transmittance Loss Due to Dirt on the Surface of Cover Plate Materials After Double Cover Exposure in New River,

Arizona

Al Description of Collector on Which Temperatures Were Measured .....

A2. Properties of Glass Cover Plates Used in Computer Simulation of Maximum Collector Temperatures in Interim Performance Criteria ....

A3. Collector and Weather Parameters Used in Computer Calculations ....

A4. Cover Plate Properties Used in Computer Calculations ...........

A5. Cover Plate and Absorber Plate Temperatures Reached on Stagnating Collectors with an Ambient Air Temperature of $38^{\circ} \mathrm{C}\left(100^{\circ} \mathrm{F}\right)$ and a Solar Irradiance of $1070 \mathrm{~W} / \mathrm{m}^{2}\left(340 \mathrm{Btu} / \mathrm{ft}^{2} \cdot \mathrm{h}\right) \ldots \ldots \ldots \ldots \ldots \ldots \ldots$

A6. Summary of Cover Plate Temperature Data for Stagnation Conditions

A7. Cover Plate and Absorber Plate Temperatures Reached on Stagnating Collectors with an Ambient Air Temperature of $25^{\circ} \mathrm{C}\left(77^{\circ} \mathrm{F}\right)$ and a Solar Irradiance of $945 \mathrm{~W} / \mathrm{m}^{2}\left(300 \mathrm{Btu} / \mathrm{ft}^{2} \cdot \mathrm{h}\right)$

A8. Variation in Cover Plate Temperatures for Stagnating Collectors with No Wind When the Weather Conditions Are Altered

A9. Comparison of Measured Temperatures of Glass Cover Plates on Flat Plate Solar Collectors under Stagnation Conditions with Estimated

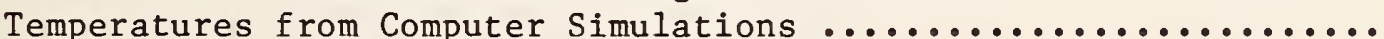

B1. Examples of Exposure Test Fixtures with Combined Heat Loss Coefficient for Back and Edge Losses Less Than $1.5 \mathrm{~W} / \mathrm{m}^{2}{ }^{\circ} \mathrm{C}$ $\left(0.264 \mathrm{Btu} /\left(\mathrm{ft}^{2} \cdot \mathrm{h} \cdot{ }^{\circ} \mathrm{F}\right)\right)$

B2. Variable Angle Rack Adjustment Schedule Utilizing Four Changes per Year .

B3. Variable Angle Rack Adjustment Schedule Utilizing Ten Changes per Year

B4. Variable Angle Rack Adjustment Schedule Utilizing Six Changes per Year 


\section{List of Tables (con't)}

Page

$\mathrm{Cl}$. Summary of Property Tests and Aging Procedures $\ldots \ldots \ldots \ldots \ldots \ldots \ldots$ C4

C2. Total Energy Below $400 \mathrm{~nm}$ for Artificial Weathering Apparatus with

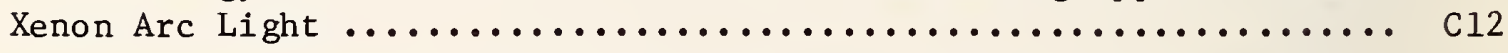

C3. Average Total Energy Below $400 \mathrm{~nm}$ for Natural Solar Irradiance on a South Facing Tilt Angle in Arizona and Florida ............... C13 
1.1 BACKGROUND

Increasing emphasis is being focused on the development of solar collectors to permit solar energy to be utilized for space heating and cooling and to supply domestic hot water. The success of a solar collector is strongly dependent upon the overall performance of the materials $\mathrm{from}$ which it is constructed. Solar collectors should be constructed of durable materials that do not degrade prematurely resulting in decreased collector efficiency. Solar collectors are designed to maximize absorption of solar radiation and minimize heat losses. The principal heat loss mechanisms from the front surface of a collector are by convection and reradiation. These may be controlled by the use of one or more transparent covers [1]*. Cover plates also protect the internal components of the collector from the external environment, i.e., rain and snow. A glazing or cover plate is a major functional element of most solar collectors.

Glass is the most commonly used cover plate material. It is a durable material, highly resistant to deterioration resulting from the thermal and environmental conditions encountered in solar collectors. Its optical properties are well characterized and include a relatively high transmittance of solar radiation which is likely to remain stable for the projected life of the solar collector. The primary disadvantages of glass are its ease of breakage, weight, and cost. Ordinary annealed glass can be strengthened by tempering. This treatment significantly increases the strength and impact resistance of glass.

Alternative materials are constantly being considered in search of the ideal cover plate material. A number of plastics have been employed as cover plate materials; these include thermoplastics and thermosetting resins and range from thin film to rigid sheet. Thermoplastics soften when heat is applied and exhibit considerable creep under load, particularly at elevated temperatures. Thermosetting materials (once cured) do not soften appreciably on the application of heat; they normally exhibit higher strength and have less tendency to creep than thermoplastics. However, they are more brittle. Compared to glass, plastics are generally lower in cost, lighter in weight, easier to fabricate, and some have a higher impact resistance [1, 2]. However, the mechanical properties of plastics are much more time and temperature dependent and their long-term durability is less well known than that of glass. Plastics are more readily affected by environmental factors such as solar radiation, temperature, humidity, airborne abrasive particles, and air pollutants. The degradation resulting from exposure of plastic materials to such environmental factors can reduce transmittance, induce shrinkage and cause other changes, e.g., in mechanical properties such as brittleness and tendency to sag.

*Figures in brackets refer to references in Section 8 . 
Questions frequently arise over which is the best cover plate material, or which should be used in a specific situation. Answers are not simple because many factors are involved. Crucial considerations include optical properties, physical properties, mechanical properties and the durability of the material. However, all too often the optimization of one property of a cover plate material (e.g. impact resistance) occurs at the expense of other properties (e.g•, transmittance and weight).

Ideally the long-term performance of any solar collector material should be assessed in service, $i . e .$, on a solar collector, where it is simultaneously subjected to all aspects of weathering including relatively high temperatures, cyclic variations of temperature between day and night, and variations in humidities and intensities of solar radiation. Due to the time involved in such long-term testing, and the variation in weather conditions, shortterm methods to measure the performance and durability of cover plate materials are needed. The established test methods and standards for glass and plastic used in conventional construction applications, such as windows and doors, seldom adequately evaluate durability or take into account the kind of service conditions encountered by solar collectors. Standards for cover plates must include the weathering factors encountered both in the external environment and within the solar collector. Standards should identify both initial and long-term performance properties and test methods for evaluating these properties to measure the performance of the cover plate materials. Cover plate standards will provide a means of comparing various materials and lead to the development of a uniform data base of materials performance and durability.

\subsection{OBJECTIVES AND SCOPE}

This study, which was sponsored by the Department of Energy (DoE), had the following objectives:

1. To identify performance requirements for cover plate materials used in flat plate nonconcentrating solar collectors,

2. To identify and assess existing test methods for evaluating the performance and durability of cover plate materials and to modify or develop new methods as needed,

3. To obtain data needed as the technical basis for standards by evaluating commercially available cover plate materials according to the performance requirements, and

4. To prepare draft standards for cover plate materials for consideration as consensus standards by the American Society for Testing and Materials (ASTM) and other organizations.

The laboratory and field studies conducted for the project include: the modification and development of aging procedures which simulate environmental degradation factors, the measurement of critical properties of typical cover plate materials, and the assessment of material durability by comparison of 
material property values before and after aging procedures. The environmental degradation factors studied on this project were heat aging and solar radiation. Three aging procedures which simulated these factors were identified and developed. They were heat stability exposure in an oven, artificial solar radiation exposure in a laboratory apparatus, and natural weathering exposure on a minicollector. Both simulated weather exposures and natural weathering exposures were performed to permit comparison of the exposures and to determine if the effects on the materials were independent or synergistic. The material properties that were evaluated were solar energy transmittance, linear dimensional changes, warpage and the effect of dirt retention on solar transmittance.

\section{PROBLEM ASSESSMENT}

\subsection{FIELD PROBLEMS}

The performance of cover plate materials on solar energy systems in the field was reviewed to identify the problems that have been encountered. Many problems have been previously documented in two major studies [3, 4] which address materials performance in solar collector systems.

Breaking, rupturing, and cracking of cover plates has occurred in some systems $[3,4,5,6]$. While such cover plate damage has not been widely observed, it remains a concern. Both glass and plastic materials are susceptible to such damage. Some of the causes of this damage are thermal stresses, accidental impact, and environmentally induced embrittlement. The breakage has ranged from damage on a single collector to failure of 90 percent of the covers in a single solar heating system. Annealed glass was used in the collectors which encountered 90 percent breakage, and the failure was reportedly caused by thermal stress on the glass [5]. In this system reflectors were used on part of the collector array. The incidence of breakage on the collectors subjected to added reflected radiation was higher than the collectors without the reflectors. In recent years most glass cover plates have been tempered glass which is more resistant to failure caused by thermal stresses and impact.

Impact damage can be caused by vandalism, accidents or hail. To date there has been little documented damage resulting from vandalism. Damage incurred during handling or by accidental impact has occurred. Due to the brittle nature of glass, impact damage results in the glass breaking into multiple pieces. Plastic materials, which are more flexible, may crack, tear or rupture. Tears and holes, apparently caused by impact, have been observed in polycarbonate, fiber reinforced plastics, and film cover plate materials [3].

Although there have not been many reports of hail damage to solar collectors [6], the risk of hail damage has been of particular concern. Hail storms occur in most regions of the United States and severe storms have caused considerable damage to roofs and other building elements [7]. Figure 1 shows damage incurred by a $0.13 \mathrm{~mm}$ ( $5 \mathrm{mil}$ ) poly(ethylene terephthalate) cover material exposed 
Figure 1 Damage to 0.13im (0.005 in) Poly(ethylene Terephthalate) film Caused by Hailstorm in New River, Arizona.

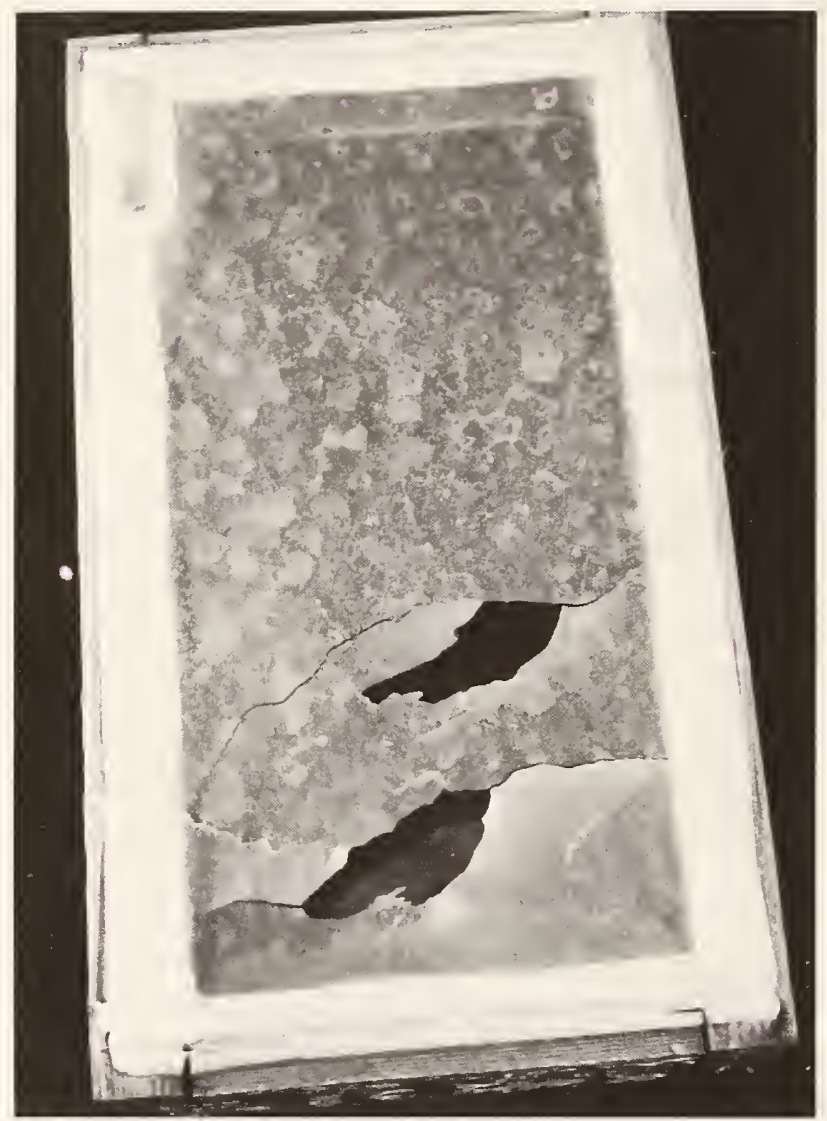


at a test site in New River, Arizona. The material had been exposed 17 months prior to the hail storm. Personnel in the area estimated the hail size to be 13-19 $\mathrm{mm}(1 / 2-3 / 4 \mathrm{in.})$ in diameter.

Embrittlement and cracking, apparently caused by environmenal conditions such as sunlight and elevated temperature, have been reported [3, 4]. Stress cracking was observed in polycarbonate cover plates that had been designed with indented sections to provide structural rigidity. Approximately 60-70 percent of the indentations exhibited stress cracking to some degree. Poly(viny1 fluoride) film exhibited embrittlement and yellowing after exposure on collectors that had been subjected to stagnation conditions for several months due to a system failure. Later laboratory examination of the material indicated approximately a 3.5 percent loss of solar transmittance. Poly (ethylene terephthalate) film also exhibited brittleness after exposure to sunlight, see Figure 1.

Warpage and distortion of cover materials have been reported on several systems [3]. In one case the polycarbonate cover plate had distorted so much that it was touching the absorber at one location while nearby it had buckled above the plane of the collector surface. Sagging of some film materials has also been observed.

Dirt on both the inner and outer surfaces of cover plates, unidentified deposits, and moisture condensation on the inner surfaces have been observed on many solar collector systems [3, 4, 8]. In some cases, the deposits have produced a film over the entire inner surface, apparently due to outgassing from other collector materials.

Field problems mentioned above have been identified through visual examination. Other changes in materials which cannot be detected by visual inspection may also cause reductions in optical, physical and mechanical properties but would require laboratory testing. However, since the cover plate is an integral part of the solar collector, it has been difficult to obtain samples for laboratory evaluation.

\subsection{PERFORMANCE REQUIREMENTS}

The primary purposes of the cover plate are to minimize heat losses from the front surface of the collector and to protect the interior of the collector from the external weather. The cover plate should perform these functions while maintaining the maximum possible transmittance of the incident solar radiation. It reduces heat losses by insulating the absorber from the outside environment with an air gap and by trapping infrared (IR) radiation from the absorber surface (if the glazing is opaque to the reradiated IR energy). It also protects the interior of the collector from elements such as rain and snow, shields the absorber from air pollutants and reduces the amount of ultraviolet (UV) radiation falling on the absorber.

To perform these intended functions, the cover plate should have good optical, physical and mechanical properties when installed on the solar collector and retain these properties after long-term exposure to service conditions. In 
addition, the cover plate should be resistant to deterioration caused by sunlight and the temperatures encountered in use, and it should be compatible with adjacent materials such as sealants, gaskets and framing. In short the cover material must be durable.

\subsection{COVER PLATE PROPERTIES}

Cover plate properties may be divided into primary and secondary properties. Primary properties are those material properties considered critical to the performance of the solar collector which are likely to be affected by weathering on a solar collector. Primary properties of a cover plate included solar energy transmittance, dimensional stability, i.e. linear dimensions and warpage, tensile properties, and hail impact resistance.

Secondary properties are those which have some bearing on the performance of the material as a cover plate but are less critical to collector performance. These included transmittance of long wavelength radiation, abrasion resistance, and static electric charge buildup.

\subsubsection{Primary Properties}

\subsubsection{Solar Energy Transmittance}

Solar energy transmittance is the key factor in the admittance of energy through the cover plate to the absorber of the solar collector. At sea level the incident solar radiation extends from about $300 \mathrm{~nm}$ to $2600 \mathrm{~nm}$ ! . A reduction of the solar energy reaching the absorber can be caused by a change in the transmittance, absorbance or reflectance of the cover plate material, or by dirt or other substances on the cover plate which block the passage of solar energy. A reduction of the energy reaching the absorber decreases the collector efficiency and results in a decline in overall system thermal performance.

\subsubsection{Dimensional Stability}

Dimensional stability is essential if the cover plate is to perform its primary functions. The cover plate should remain intact and maintain its original size and shape. Excessive changes in the linear dimensions such as shrinkage or expansion should not occur. Shrinkage can cause the material to pull away from the edge restraints resulting in a tear or a gap between the edge of the cover plate and the collector frame. This would permit heat losses and allow rain and other weather elements to enter the collector. Expansion of the material can lead to breaking, sagging, or warping, possibly into contact with an inner cover plate or the absorber plate. In addition, deviations from flatness (e.g., by warp, bow, buckle, and sag) reduce the effective insulating value of the air gap between the absorber and the cover material.

1/ $\mathrm{nm}=$ nanometer $=1 \times 10^{-9}$ meters. 


\subsubsection{Tensile Properties}

The tensile stress-strain curve provides an indication of the strength, toughness and elasticity of the material. Changes in the stress-strain behavior also indicate whether a material is becoming more elastic or more brittle.

\subsubsection{Hail Impact Resistance}

The Department of Housing and Urban Development (HUD) Minimum Property Standards [9] and the DoE Interim Performance Criteria [10, 11] require collectors to be resistant to the damage caused by hail expected for the particular geographic location. Other solar collector buyers have also placed hail impact requirements in purchase specifications. The desired level of hail impact resistance must be related to the size of hail reasonably expected at the location of the solar energy system. Climatological data provide an indication of the geographical distribution of hail and some history of the intensity and severity of hail storms. Some regions of the United States rarely have hail storms, while other regions have had an average of eight storms per year in a 20 year period [7]. Not only do the number of storms vary, but the size of hail also has a wide range. While rare, hail stones with a diameter $70 \mathrm{~mm}$ (2-3/4 inches) and larger have occurred in the United States $[6,12,13]$.

The damage to cover plate materials caused by hail is directly related to the size and velocity of the hail at impact. Since cover plate materials may be rigid, semirigid, or flexible materials, the type of damage resulting from hail is dependent upon the material composition. For brittle materials, hail impact may cause the material to break or shatter. For flexible or semirigid materials, hail impact may tear, puncture, or indent the material. Such damage to the material could prevent the cover plate from performing its primary functions. Breakage or rupture of the cover plate would permit heat losses to occur and expose the absorber to the weather elements. Hail impact resistance of cover plates, in particular the polymeric materials, may be reduced by exposure to sunlight and high temperature if the materials become brittle.

\subsubsection{Secondary Properties}

\subsubsection{Transmittance of Long Wavelength Radiation}

The heat losses through the cover plate are related to the long wavelength transmittance, the emittance of the cover material, and the convective heat loss at the cover. The reradiation of thermal energy from the absorber and subsequent heat loss from the collector correspond to the ability of a cover plate material to transmit long wavelength (infrared) radiation (wavelengths greater than $2.8 \mu \mathrm{m}^{1 /}$ ). This radiation will be lost through the cover material to the surrounding cooler sky if the solar collector cover is not opaque to this radiation. The infrared energy absorbed by the cover plate is

1/ $\mu \mathrm{m}=$ micrometer $=1 \times 10^{-6}$ meters $=100 \mathrm{~nm}$. 
also reradiated to the sky and collector as a function of cover plate emittance and its temperature. Convective heat losses are related to wind speed and direction, heat transfer coefficient, and ambient temperature.

\subsubsection{Abrasion Resistance}

Abrasion resistance of a cover plate material is the ability to resist scratching or marring of the surface. Abrasion damage could reduce the transmittance of the cover material due to scatter of the solar energy or an increase in the dirt retained on the roughened surface. Abrasion of thin cover materials may also result in a decrease in the tensile and/or impact properties.

\subsubsection{Static Electric Charge Buildup}

Certain plastic materials, in particular films, develop static electric charge. As a cover plate, such a material may attract or pull dust and dirt particles out of the air and hold the particles on the surface. These particles could interfere with the passage of sunlight and reduce the solar transmittance of the cover plate.

\subsection{DEGRADATION FACTORS}

The durability of a material is related to its ability to resist degradation by its exposure environment. The foremost degradation factors encountered by a solar collector cover plate are solar radiation and elevated temperature (due to the close proximity of the absorber plate). Other factors which may contribute to degradation include synergistic reactions resulting from the combination of solar radiation with moisture or temperature or both. The resulting stress fatigue may induce a gradual impairment of material properties. In addition, thermal cycling, moisture, air pollutants, wind flutter, and particulate matter such as dirt, dust, or sand may also degrade cover plate materials.

\subsubsection{Solar Radiation}

The spectral distribution of sunlight is illustrated in figure 2 , and the ranges of ultraviolet (UV), visible (VIS) and near infrared (NIR) energy are indicated. Degradation due to ultraviolet radiation has long been of great concern to people designing or using products exposed to sunlight. The solar radiation spectrum band below $400 \mathrm{~nm}$ is detrimental to most polymers [14]. The radiation may cause crosslinking, breaking of chemical bonds, and reduction in molecular weight $[15,16]$. The polymer damage may be reflected by changes in appearance or in chemical, physical, mechanical or optical properties [17]. To offset degradation due to UV radiation, UV stabilizers are frequently added to polymers or coated on their surface to absorb the UV radiation and inhibit bond breakage.

\subsubsection{Temperature}

It is unlikely that temperatures reached in a flat plate solar collector would damage glass cover platé materials by degradation, although they could increase 


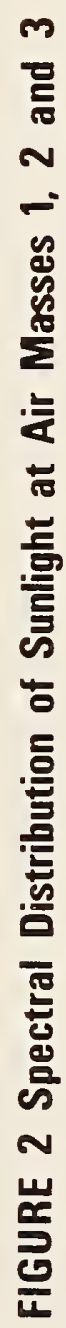

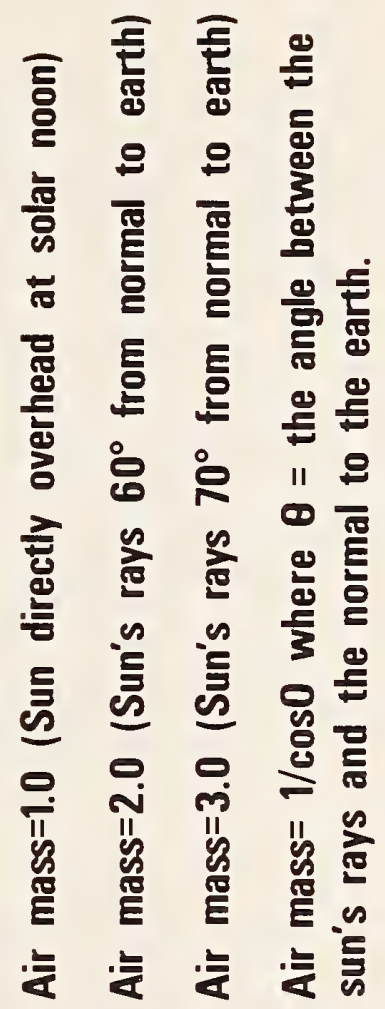

.

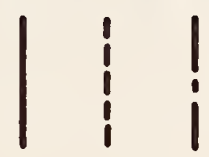

言 
the solarization rate of impure glasses. However, elevated temperatures may cause degradation of plastic cover plates. The temperature conditions which may lead to degradation include extended exposure to operational temperatures and to stagnation $1 /$ temperatures. Cover materials are exposed to operational temperatures for 6-10 hours a day. Stagnation temperatures may occur in several circumstances: 1) after the collector is put in place but prior to system startup, 2) when the system is shutdown for maintenance or repair, or 3 ) when the system is not operated because the heat is not needed (e.g., a space heating system during the summer).

\subsubsection{Synergistic Reactions}

Plastic materials are susceptible to damage caused by the combination of sunlight, heat, oxidation, and moisture [14, 18, 19]. The deterioration of polymers exposed to outdoor weathering is related to bond breakage caused by photooxidation (i.e., UV radiation and oxidation). Heat also aids in the degradation process, but in the presence of UV radiation and oxygen, it seems primarily to increase the rate of photooxidation. "Both 'weathering' at high temperature $\left(\mathrm{i} . \mathrm{e} .>38^{\circ} \mathrm{C}\left(100^{\circ} \mathrm{F}\right)\right.$ ) and photochemical impurities speed the photodegradation of such polymers. Generally, photochemical reaction rates are doubled for each $10^{\circ} \mathrm{C}\left(18^{\circ} \mathrm{F}\right)$ rise in temperature" [20].

\section{4 .4 Other Factors}

Thermal cycling, can affect a cover material in two ways. First, if the material is a composite, the thermal cycling may cause delamination of the components. Second, differences in the thermal expansion coefficients of the cover and adjacent materials may impose cyclic stress at the edges where the cover material is joined to the frame. The resulting damage would be dependent on the method of joining. A cover plate mechanically held in place, such as with a screw, may stress crack at the screw hole. Cover plate/sealant joints may pull apart.

Moisture (e.g., humidity, condensation, or rainfall) and air pollutants (e.g., ozone, oxides of nitrogen, or sulfur dioxide) may cause surface degradation of cover plates. Wind flutter of thin films may fatigue the material and alter mechanical properties. Cleaning with harsh detergents or cleaning agents could subject the outer cover plate surface to abrasive chemical attack. Contact of the cover material with the heat transfer fluids may also initiate chemical attack. However, compatibility between the cover material and the heat transfer fluid is not required unless the collector design permits contact.

1/ Stagnation is a condition obtained when the heat transfer fluid is not flowing through the collector, however, the collector is exposed to the amount of solar radiation that it would receive under normal operational conditions. The heat transfer fluid may be in the collector but it is not flowing. 


\section{LABORATORY STUDIES AND FIELD EXPOSURES}

\subsection{INTRODUCTION}

The laboratory and field studies conducted for the project included: the measurement of critical properties of typical cover plate materials, the exposure of cover plate materials to aging procedures which simulate environmental degradation factors in solar collectors, and the assessment of material durability by comparison of material property values before and after aging procedures. This report addresses the measurement of solar energy transmittance, linear dimensional stability, warpage, and dirt retention, and evaluates the effects of heat aging and solar radiation on these properties. The subjects of hail impact and tensile properties will be described in a later report. This chapter contains a description of the test methods and aging procedures utilized in the project and a description of the cover materials which were studied. Test results and data to evaluate the durability of cover plate materials are incorporated in chapter 4.

\subsection{AGING PROCEDURES TO SIMULATE DEGRADATION FACTORS}

Heat aging and solar radiation were the environmental degradation factors studied on this project. The three aging procedures utilized were: heat aging in an oven, artificial solar radiation in a laboratory apparatus, and natural weathering on a minicollector. In the laboratory the materials were exposed separately to heat and artificial solar radiation, whereas in the natural weathering they were exposed to natural sunlight while the material temperatures were raised by the minicollector. Both simulated and natural weathering exposures were performed to permit comparison of the exposures and to assess the simulated weathering.

\subsubsection{Heat Stability Aging Procedure}

Cover plate temperatures on flat plate solar collectors vary considerably depending on the weather and operating conditions, however, it is the maximum temperature to which materials are exposed that is most important. Studies were performed to determine cover plate temperatures under stagnation conditions. These studies are described in Appendix A, Determination of Cover Plate Temperatures. Temperatures for the heat aging tests were based upon maximum cover plate stagnation temperatures which are summarized in table A9 of Appendix A. Heat aging test temperatures were established as $75^{\circ} \mathrm{C}\left(167^{\circ} \mathrm{F}\right), 100^{\circ} \mathrm{C}$ $\left(212^{\circ} \mathrm{F}\right), 125^{\circ} \mathrm{C}\left(257^{\circ} \mathrm{F}\right)$, and $150^{\circ} \mathrm{C}\left(302^{\circ} \mathrm{F}\right)$.

Test specimens were suspended vertically from a single point at the center of the top edge and were exposed in a mechanical convection oven. Such an oven is described in ASTM Method D 794, Recommended Practice for Determining Permanent Effect of Heat on Plastics [21]. Separate sets of test specimens were used for each of the temperatures. Test specimens were removed at time intervals ranging up to 2,000 hours and were evaluated to determine the effect of the heat exposure. Once a test specimen was removed for evaluation it was not returned to the oven. Properties measured after the heat aging were solar transmittance, warpage, and linear dimensions. One set of test specimens 
( 115 by $230 \mathrm{~mm}$ ( 4.5 by 9 in.)) was used for the solar transmittance and warpage evaluations. A separate set of test specimens of the sizes described in Section 3.3.2 was measured for linear dimensions. These were placed in a horizontal position while in the oven.

\subsubsection{Artificial Weathering with Xenon Arc Light}

Properly filtered xenon arcs have been shown to have a spectral energy distribution which closely simulates the spectral distribution of sunlight at the surface of the earth $[22,23,24]$. The procedure used to expose the cover plate materials to artificial solar radiation was ASTM Method D 2565, Recommended Practice for Operating Xenon Arc-Type (Water-Cooled) Light-Exposure Apparatus With and Without Water for Exposure of Plastics [25]. A Type B apparatus was used with the irradiance controlled through the use of a continuously controlling monitor that automatically maintained uniform intensity at preselected wavelengths of 340,420 and $580 \mathrm{~nm}$. A borosilicate glass filter with suitable transmittance was used to filter the light and to provide radiation which simulated the solar spectrum at sea level. Test specimens were exposed to a continuous light cycle without water spray. The ambient temperature within the chamber was approximately $40^{\circ}-50^{\circ} \mathrm{C}\left(104^{\circ}-122^{\circ} \mathrm{F}\right)$.

Test specimens were mechanically fastened with a clip to a metal backing which was placed in the vertical specimen rack. The test specimen size was about 320 by $75 \mathrm{~mm}$ ( 12.5 by $3 \mathrm{in.}$ ). Periodically, test specimens were repositioned to assure uniform radiation. They were removed for evaluation at time intervals ranging from 250 hours to 4,000 hours and were not replaced in the apparatus.

\subsubsection{Natural Weathering Exposure}

Existing outdoor exposure procedures did not provide for sufficient elevation of the material temperature above ambient conditions. To obtain the elevated temperature, a small box was designed to hold the cover plate materials during natural weathering. The box resembled a small collector. The minicollector consisted of a wooden box containing insulation and an absorber plate. For double cover exposures a spacer was also utilized. Figure 3 illustrates the construction of the minicollector. To minimize outgassing resulting from deterioration of the organic components during exposure to elevated temperatures, the insulation and the wooden boxes and spacers were heated in an oven before the minicollectors were assembled. The wooden components were permitted to regain moisture equilibrium prior to assembly. After this was completed, the minicollectors were assembled. The test specimen size for natural weathering exposure was 115 by $230 \mathrm{~mm}$ ( 4.5 by 9 in.). For single cover exposures, the test specimen was adhered to the box using sealant. For double cover exposures, the inner cover was adhered directly to the box with sealant and then the outer cover was adhered to the double cover spacer which in turn was adhered to the inner cover and box. Staples were used to provide mechanical fastening of the spacer to the side of the box. Sealant was then used to fill any voids such as between the spacer and the box, and to coat remaining unpainted areas. The weep and drain holes were not filled. 
FIGURE 3 Minicollector for Natural Weathering Exposure

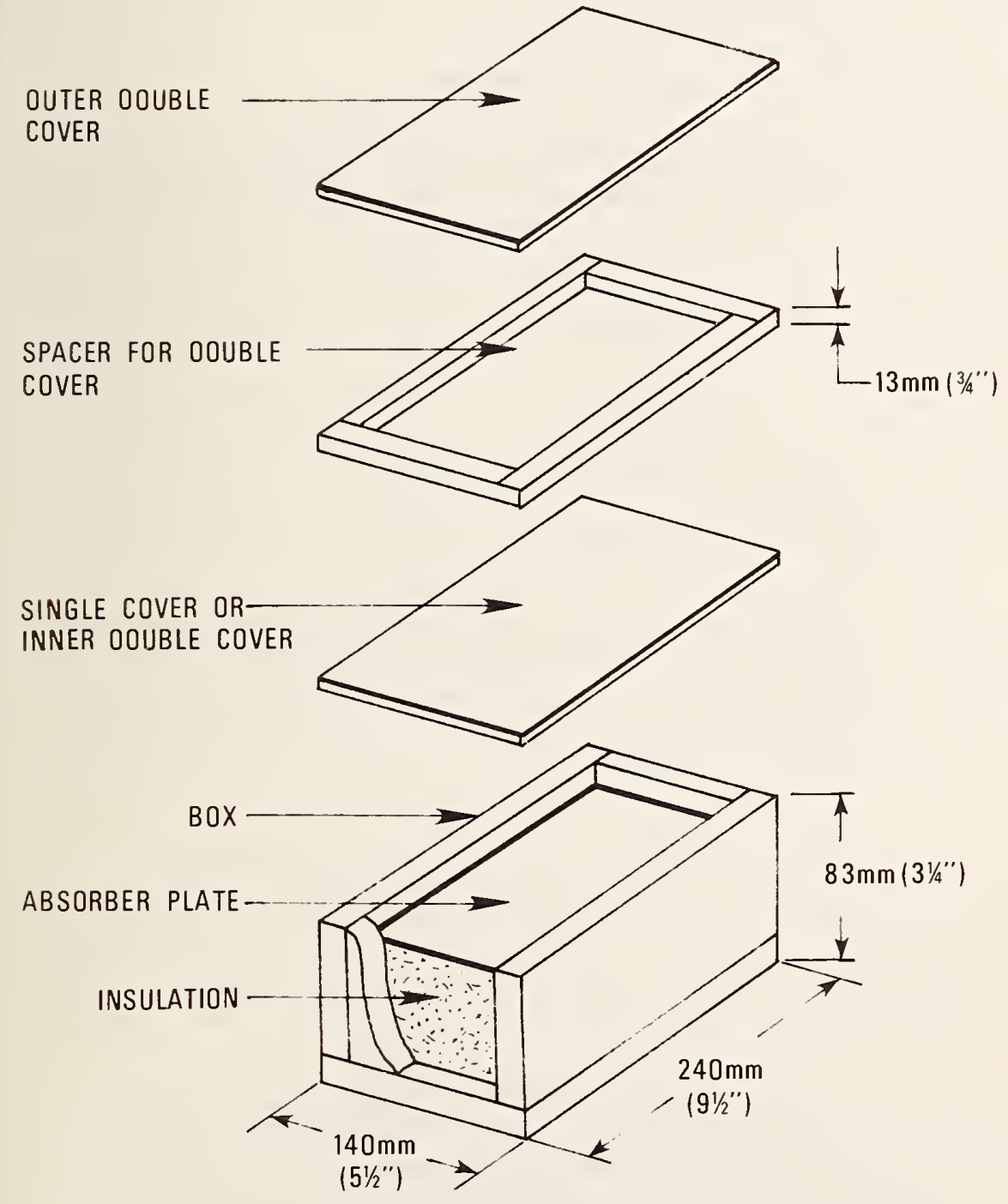

MATERIALS:

BOX AND SPACER:

$19 \mathrm{~mm}(3 / 3 / 4)$ WOOO PAINTEO

WHITE ON OUTSIOE

INSULATION

$50 \mathrm{~mm}\left(2^{\prime \prime}\right)$ FIBERGLASS BLANKET

ABSORBER:

BLACK PORCELAIN ENAMEL

ON STEEL, $\alpha=.93, \epsilon=.85$

SEALANT:

RTV SUITABLE FOR OUTDOOR EXPOSURE.

NOTE:

VENT HOLES WERE DRILLED IN THE BOTTOM OF THE BOX ANO THE ENO OF THE SPACER TO MINIMIZE MOISTURE ACCUMULATION 
The minicollectors were weathered at three sites: New River, Arizona; Miami, Florida; and Gaithersburg, Maryland. The minicollectors were mounted in an unbacked condition on weathering racks such as those described in ASTM D 1435 Recommended Practice for Outdoor Weathering of Plastics [26]. They were mounted side by side with the long sides touching and the a narrow end of the box toward the ground. A variable angle exposure was utilized to maximize solar radiation incident upon the minicollector. The schedule used for the variable angle exposure is contained in table 1. The exposures were initiated September 1, 1977 on seven sets of minicollectors. (A set of minicollectors consisted of one single cover and one double cover minicollector for each of ten materials.) A set of test specimens was removed for evaluation at 3,6 , 12,18 , and 24 month intervals.

Table 1

Schedule for Variable Angle Exposure

\begin{tabular}{|l|c|c|c|}
\cline { 2 - 4 } \multicolumn{1}{c|}{} & Miami & New River & Gaithersburg \\
\hline $5^{\circ}$ & April-August & $33^{\circ}$ latitude & $39^{\circ}$ 1atitude \\
\hline 1atitude & April-August & May-August \\
$45^{\circ}$ & September & September & September \\
1atitude & October-February & October-February & October-March \\
& March & March & April \\
\hline
\end{tabular}

After removal of the first sets of specimens, new test specimens were placed on the minicollectors to obtain exposures for similar time intervals. At this time (August, 1980), two of the original sets of minicollectors remain on exposure at each location.

\subsection{PROPERTY TESTS}

The material properties evaluated in this project were solar energy transmittance, the effect of dirt retention on solar energy transmittance, linear dimensional stability, and warpage.

\subsubsection{Solar Energy Transmittance}

Two methods for the measurement of solar energy transmittance are included in ASTM E 424-71, Standard Test Methods for Solar Energy Transmittance and Reflectance (Terrestrial) of Sheet Materials [27]. Method A is performed in a laboratory utilizing an integrating sphere spectrophotometer. Method B is conducted outdoors where the transmittance is measured using a pyranometer 
in an enclosure and the sun as the energy source. Test specimens for Method A are limited in size by the geometry of the spectrophotometer while Method B requires a specimen $0.61 \mathrm{~m}$ ( $2 \mathrm{ft}$ ) square.

\subsubsection{Method A - Integrating Sphere Spectrophotometer}

The spectral transmittance of the cover plate materials was measured utilizing a Cary 17D Spectrophotometerl/ with a $76 \mathrm{~mm}$ (3 in) diameter integrating sphere. Measurements of spectral transmittance relative to air were made over the spectral range from 300 to $2150 \mathrm{~nm}$. The illumination and viewing mode were normal-diffuse. The transmittance measurements were made by placing the test specimen in direct contact with the sphere aperture so that the incident monochromatic radiation was normal to the plane of the specimen. The sphere aperture had approximate dimensions of 25 by $10 \mathrm{~mm}$ ( 1 by $3 / 8 \mathrm{in.}$ ). The incident beam was approximately 24.4 by $6.2 \mathrm{~mm}(0.96$ by $0.24 \mathrm{in}$.) and it intersected the test specimen near the center. The solar energy transmitted was obtained by integrating over the solar energy distribution, as reported by Parry Moon [28], for sea level and air mass 2 (AM 2). The weighted ordinates calculation method from ASTM E 424 was used to integrate the solar energy distribution at $50 \mathrm{~nm}$ intervals, normalized to 100. The spectral transmittance data were digitized by the spectrophotometer and fed directly into a computer which performed the integration calculations after correcting for the baseline. Due to the optics associated with the integrating sphere and moisture in the atmosphere, the 100 percent baseline contained several absorption bands for which corrections were made.

A change in an integrated solar transmittance of a material does not indicate how the material changed, however the spectral transmittance curve provides this information. Most commonly, solar transmittance losses result from increased absorption (i.e. transmittance decrease) in the UV-VIS region, although in some cases a fairly uniform transmittance loss across the full spectrum occurs. Increased absorption in the UV-VIS range is due to damage to the bulk material as caused by heat or solar radiation, while a loss across the spectrum indicates changes in surface properties. Dirt, surface deposits, a change in refractive index, and delamination of the fibers in fiber reinforced plastic are examples of such changes in surface properties.

\subsubsection{Method B - Outdoor with Pyranometer}

Method B of ASTM E 424 was utilized to measure the total transmittance of selected sets of cover plate test specimens. The apparatus included a box having an open side with outside dimensions of $0.66 \mathrm{~m}$ (26 in) square. This side of the box supported a $0.61 \mathrm{~m}$ (24 in) square test specimen. The interior

1/ Certain trade names and company products are identified in order to adequately specify the experimental procedure. In no case does such identification imply recommendation or endorsement by the National Bureau of Standards, nor does it imply that the products are necessarily the best available for the purpose. 
of the box was painted flat black. A Class 1 pyranometer, as classified by the World Meteorological Organization, was placed in the center of the box about $50 \mathrm{~mm}$ ( $2 \mathrm{in}$ ) below the bottom plane of the test specimen. Film materials were placed in a frame which held the material taut. During the transmittance measurements the box was positioned so that the plane of the test specimen was essentially perpendicular to the incident solar radiation. The solar energy transmittance of the test specimens was the ratio of the energy measured when the test specimen was in place on the box between the sun and the pyranometer to the energy measured with no test specimen in place.

\subsubsection{Effect of Dirt Accumulation on Solar Energy Transmittance}

To determine the solar transmittance loss due to dirt accumulated on the surface of a cover plate and to differentiate this from the loss due to degradation of the material caused by the weathering, the transmittance of the test specimens from the natural weathering minicollectors was measured twice. After removal of the cover plates from the minicollectors, the transmittance was measured as described in Section 3.3.1.1, the test specimens were washed and the transmittance was remeasured using the same method.

The cleaning procedure consisted of immersing the test specimens in a 0.1 percent solution of detergent in distilled water. A soft brush was used to clean both sides of the test specimen which was then rinsed with distilled water and air dried. Care was taken to avoid scratching or stretching the plastic materials.

\subsubsection{Linear Dimensional Stability}

Linear dimensional changes were determined according to the procedures in ASTM D 1042, Test for Linear Dimensional Changes of Plastics [29], and ASTM D 1204, Test for Linear Dimensional Changes of Nonrigid Thermoplastic Sheeting or Film at Elevated Temperatures [30]. ASTM D 1204 was used for four film materials which had a thickness of $0.25 \mathrm{~mm}(0.01 \mathrm{in})$ or less. The other materials were measured in both the length and width directions using ASTM D 1042. The size of test specimens was about 120 by $150 \mathrm{~mm}$ ( 4.75 by 6 in) for ASTM D 1042 and $254 \mathrm{~mm}$ (10 in) square for ASTM D 1204. A set of triplicate test specimens was used for each test.

\subsubsection{Warpage}

For sheet materials, deviation from flatness was measured and reported as warpage. The test specimens were 115 by $230 \mathrm{~mm}$ ( 4.5 by $9 \mathrm{in}$ ). The apparatus consisted of a table with a movable platform, a probe which scanned the profile of the test specimen, and graph paper to record the profile. Figure 4 illustrates the apparatus. The heavy framed table had a motorized aluminum platform with variable speed control. An inverted L-shaped support frame extended upward from one side of the platform. A plastic shaft with a small wheel on the lower end extended from an end of the support frame. The shaft was positioned above the center of the platform with a manually operated gear rod. A pen was mounted on the vertical shaft and positioned in contact with the graph paper. 
FIgURE 4 Apparatus for Warpage measurement

graph of profile of test specimen

movable

platform

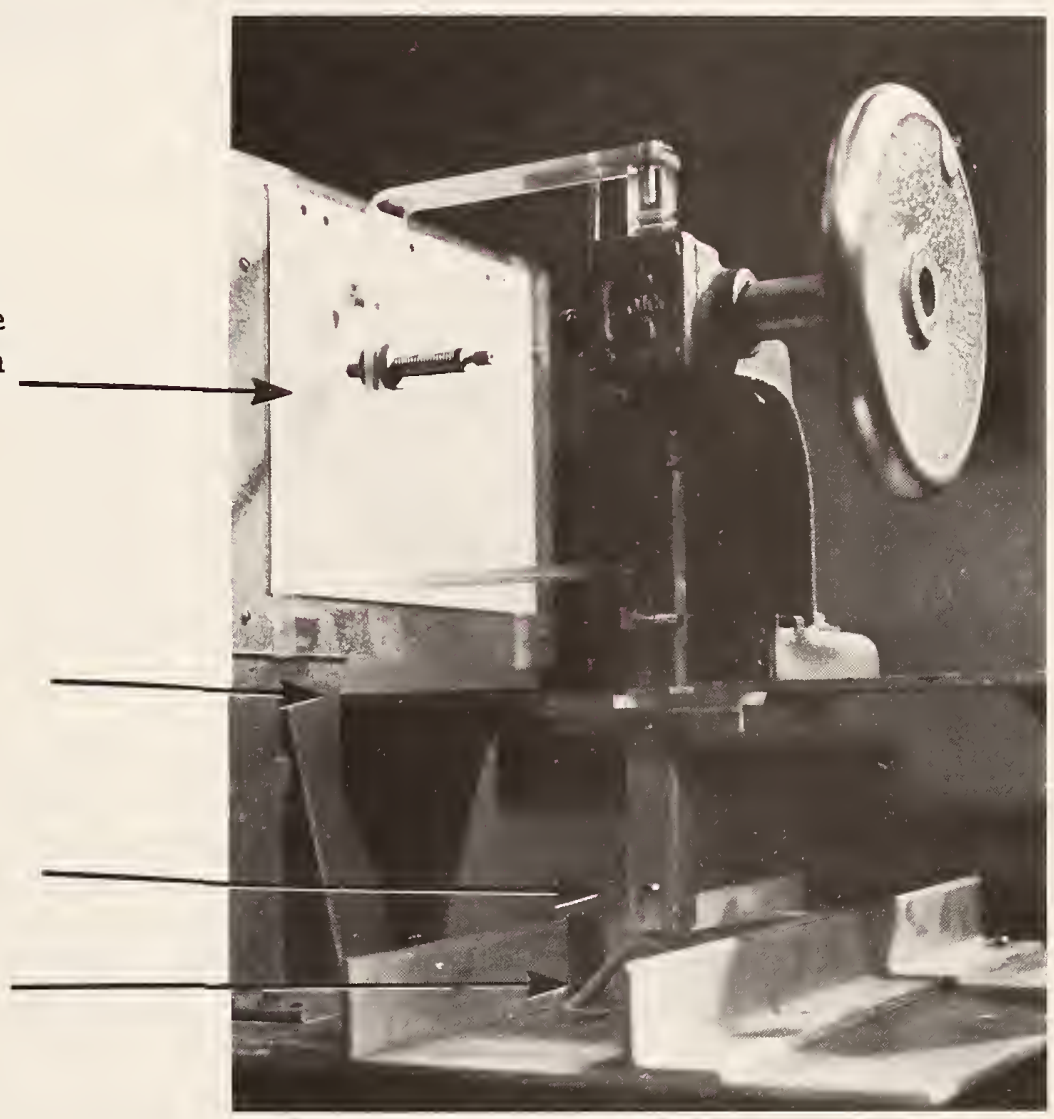


The procedure was as follows: 1. The graph paper was placed in the proper location and the plane of the platform surface was drawn on the paper, 2. The test specimen was placed concave side down on the platform with one end against the positioning bar and in a position to assure the shaft would pass over the location with the maximum warpage, 3. The platform was adjusted and the shaft was lowered until the small wheel came in contact with one end of the upper surface of the test specimen, 4. The platform was activated which slowly moved the wheel over the surface of the specimen as the pen graphed a profile of the test specimen.

The maximum warpage was determined by measuring the distance between the plane of the platform surface and the profile of the test specimen. The distance was corrected for the thickness of the test specimen.

\subsection{MATERIALS}

\subsubsection{Selection}

The cover plate materials utilized in this study were typical of those commercially availatle in 1976. The properties of materials currently on the market may differ from those described in this report. Properties of cover plate materials can be altered by changes in minor constituents (i.e. iron oxide content, stabilizers, plasticizers, antioxidants) or in processing techniques. Many cover plate materials are marketed, and in order to improve their performance, manufacturers sometimes modify the materials. The reader is cautioned against direct application of the data in this report to materials currently marketed.

The cover plate materials selected for testing were representative of the materials and thicknesses used in solar collectors. The ten materials are listed in Table 2. Two of the materials were glass sheet. They differ in iron oxide content which directly affects the solar energy transmittance. Four of the materials were plastic films, and four materials were plastic sheet, two of which were fiber reinforced plastics (FRP). These FRP materials were from separate manufacturers and contained different resins. They will be distinguished in this report by their thicknesses. All of the materials had smooth surfaces, except the glass with the lower iron oxide content. On this material one surface was textured.

\subsubsection{Preparation of Test Specimens}

Test specimens were cut from either sheet or rolls of material. Prior to initiation of aging procedures, all test specimens were cut to the dimensions required for the tests. A random number selection procedure was used to assign test specimens to each aging procedure. This precaution was taken to minimize any bias in test results for a particular test due to material inhomogenieties.

\subsubsection{Control Specimens}

A set of three test specimens ( 115 by $230 \mathrm{~mm}$ ( 4.5 by 9 in)) was utilized as control specimens for all tests except the Method B transmittance test. The 


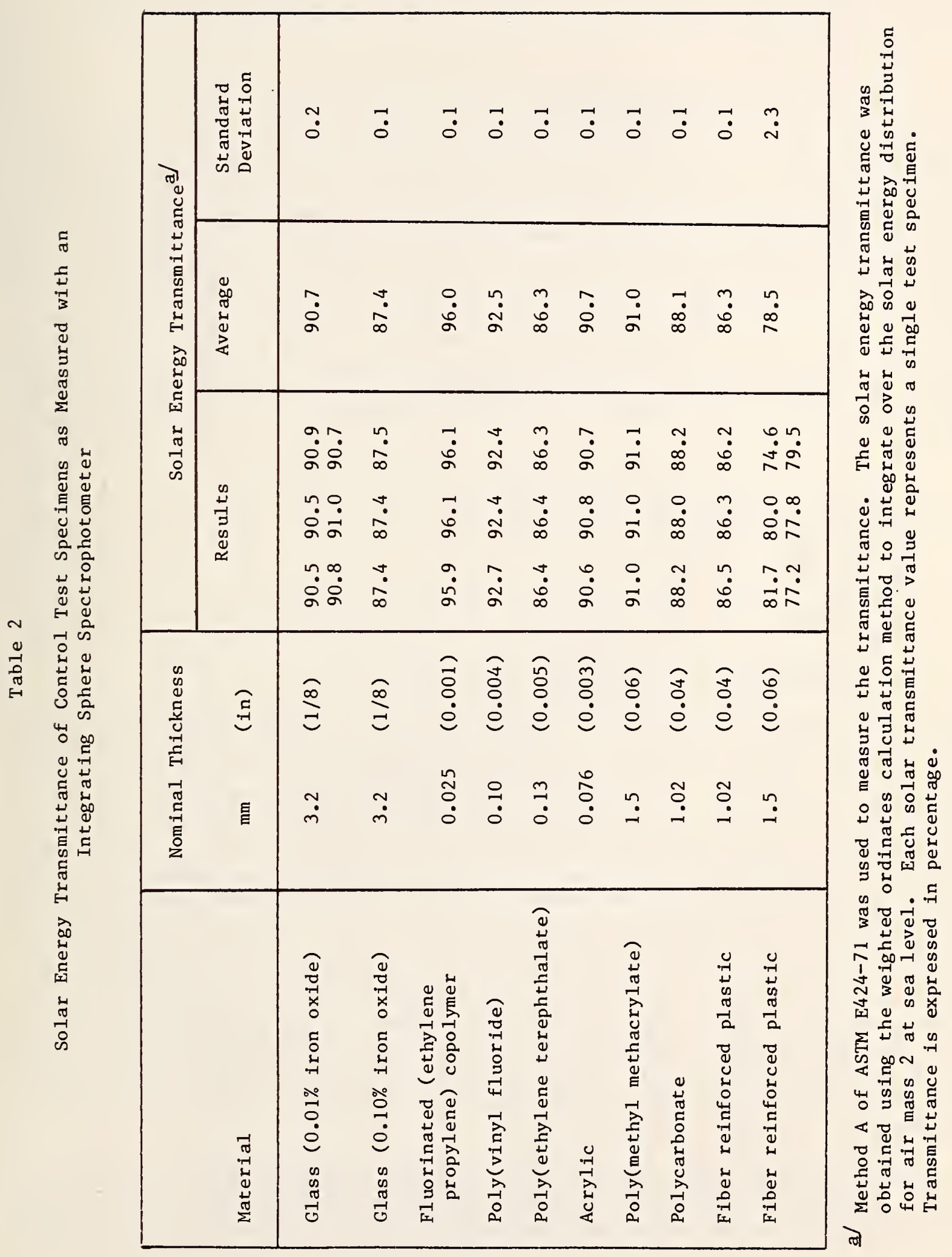


control test specimens for Method B transmittance measurements were $0.61 \mathrm{~m}$ (24 in) square. The control test specimens were stored in the dark under typical laboratory conditions of $23 \pm 2^{\circ} \mathrm{C}\left(74 \pm 4^{\circ} \mathrm{F}\right)$ with $50 \pm 10$ percent relative humidity.

\subsection{SCHEDULE OF AGING PROCEDURES AND PROPERTY EVALUATION TESTS}

To establish the initial material properties for unaged materials, the solar transmittance and warpage properties were measured on sets of control test specimens. Then to evaluate durability, sets of test specimens were exposed in each aging procedure followed by remeasurement of material properties. After the heat aging the solar transmittance was measured on each test specimen while linear dimensions were measured on test specimens from the $100^{\circ}$ and $150^{\circ} \mathrm{C}$ $\left(212^{\circ}\right.$ and $\left.302^{\circ} \mathrm{F}\right)$ exposures. Selected test specimens from $125^{\circ}$ and $150^{\circ} \mathrm{C}\left(257^{\circ}\right.$ and $302^{\circ} \mathrm{F}$ ) exposures were evaluated for changes in warpage. Test specimens exposed in the xenon arc artificial weathering had solar tansmittance measured after the aging. The test specimens exposed to natural weathering were evaluated by measurement of solar energy transmittance and the effect dirt retention on solar transmittance. Method A of E 424 was used to measure transmittance after aging.

4. RESULTS AND DISCUSSION

4.1 CONTROL TEST SPECIMENS

4.1.1 Solar Energy Transmittance

4.1.1.1 Method A - Spectrophotometer

The solar energy transmittance for the control set of test specimens for air mass 2 at sea level is listed in table 2. The average solar energy transmittance of the control test specimens was used when comparing aged and unaged materials. For all but two materials the standard deviation of the three control test specimens was 0.1 percent or less. Therefore three additional test specimens of the glass ( 0.01 percent iron oxide) and the $1.5 \mathrm{~mm}$ FRP were measured to establish a better basis for their averages. At least two factors may have contributed to the variation in solar transmittance: first, material thickness; and second, material inhomogeneities. The thickness of a number of pieces of the glass ( 0.01 percent iron oxide) was measured and found to vary from 3.02 to $3.43 \mathrm{~mm}(0.119$ to $0.135 \mathrm{in})$, a difference of more than 10 percent. There were no apparent inhomogeneities in the glass other than the textured surface. The solar transmittance of the $1.5 \mathrm{~mm}$ FRP material varied by 7.1 percent among the six test specimens. Their thickness ranged from 1.37 to $1.52 \mathrm{~mm}$ ( 0.054 to $0.060 \mathrm{in})$, greater than a 10 percent difference. An irregular fiber distribution was evident upon visual inspection and undoubtedly contributed to transmittance variations.

The spectral transmittance curves from 300 to $2150 \mathrm{~nm}$ are shown in figures $5 a-5 d$ for control specimens. The differences between the two types of glass are illustrated in figure $5 \mathrm{a}$, while the four films are displayed in figure $5 \mathrm{~b}$. 
Figure 5a Spectral Transmittance of Control Test Specimens of Two GLASS Materials

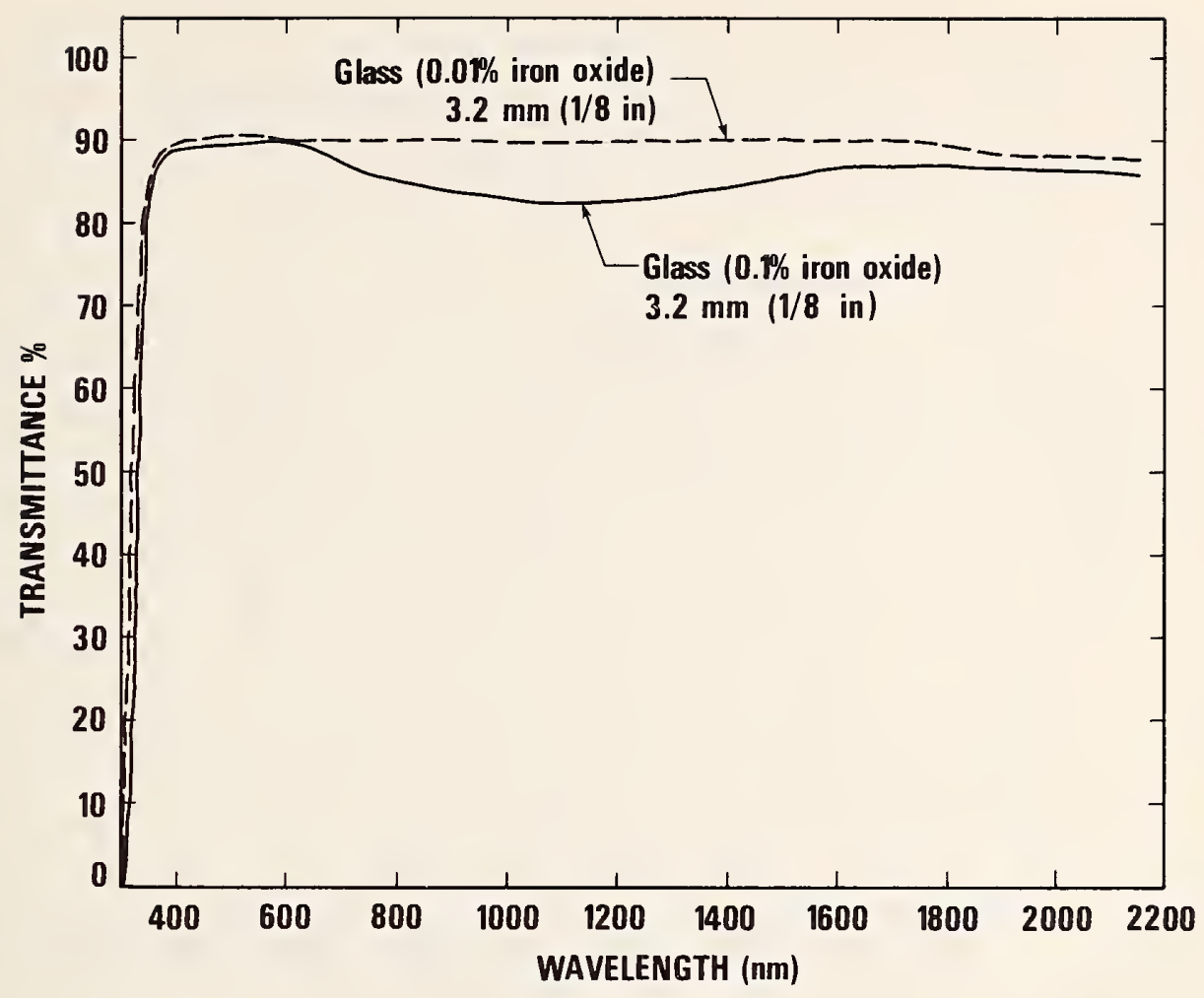

Figure 5B Spectral Transmittance of Control Test Specimens of Four Plastic Films

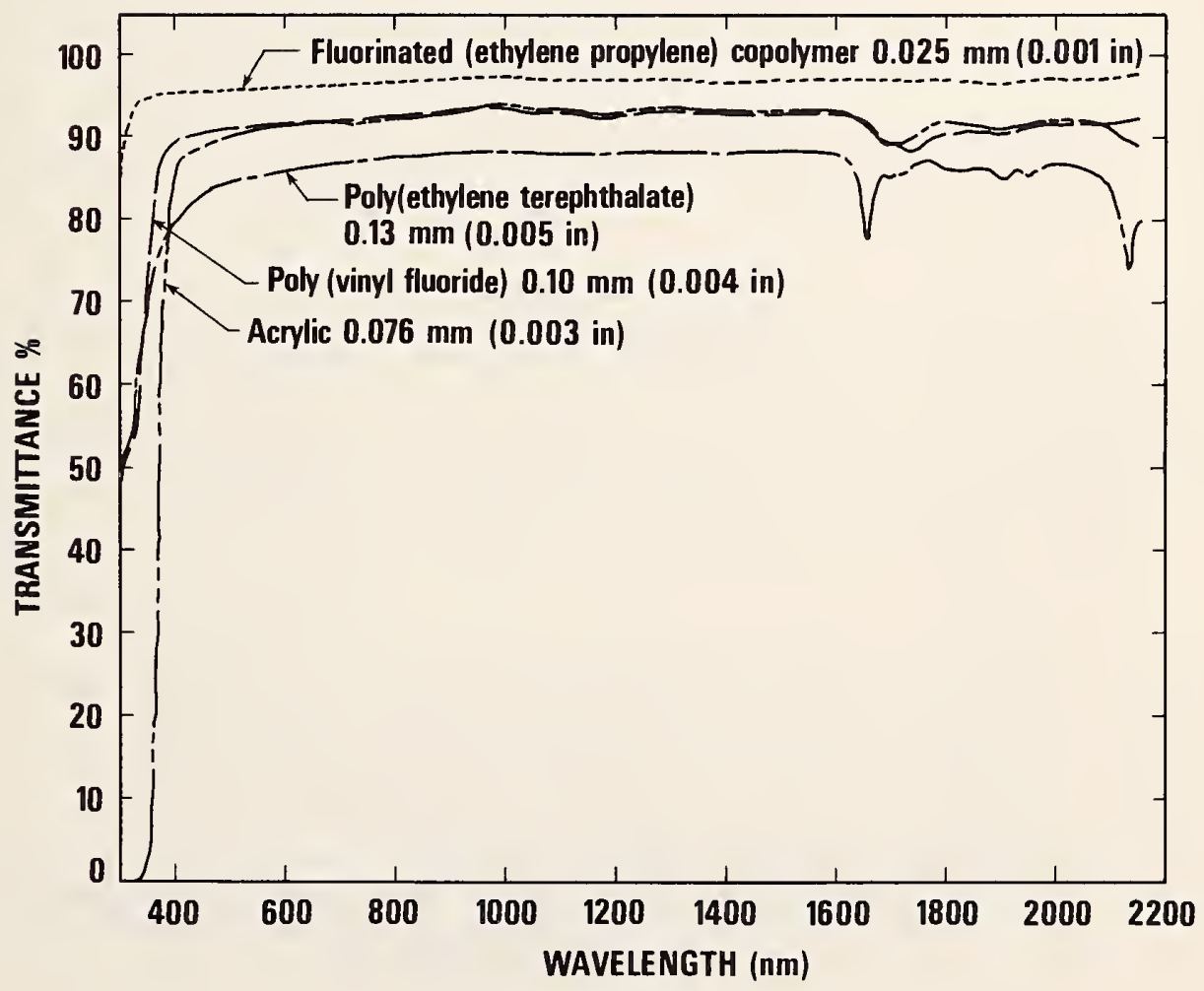


Figure 5 C Spectral Transmittance of Control Test Specimens of Two Clear Plastic Sheet Materials

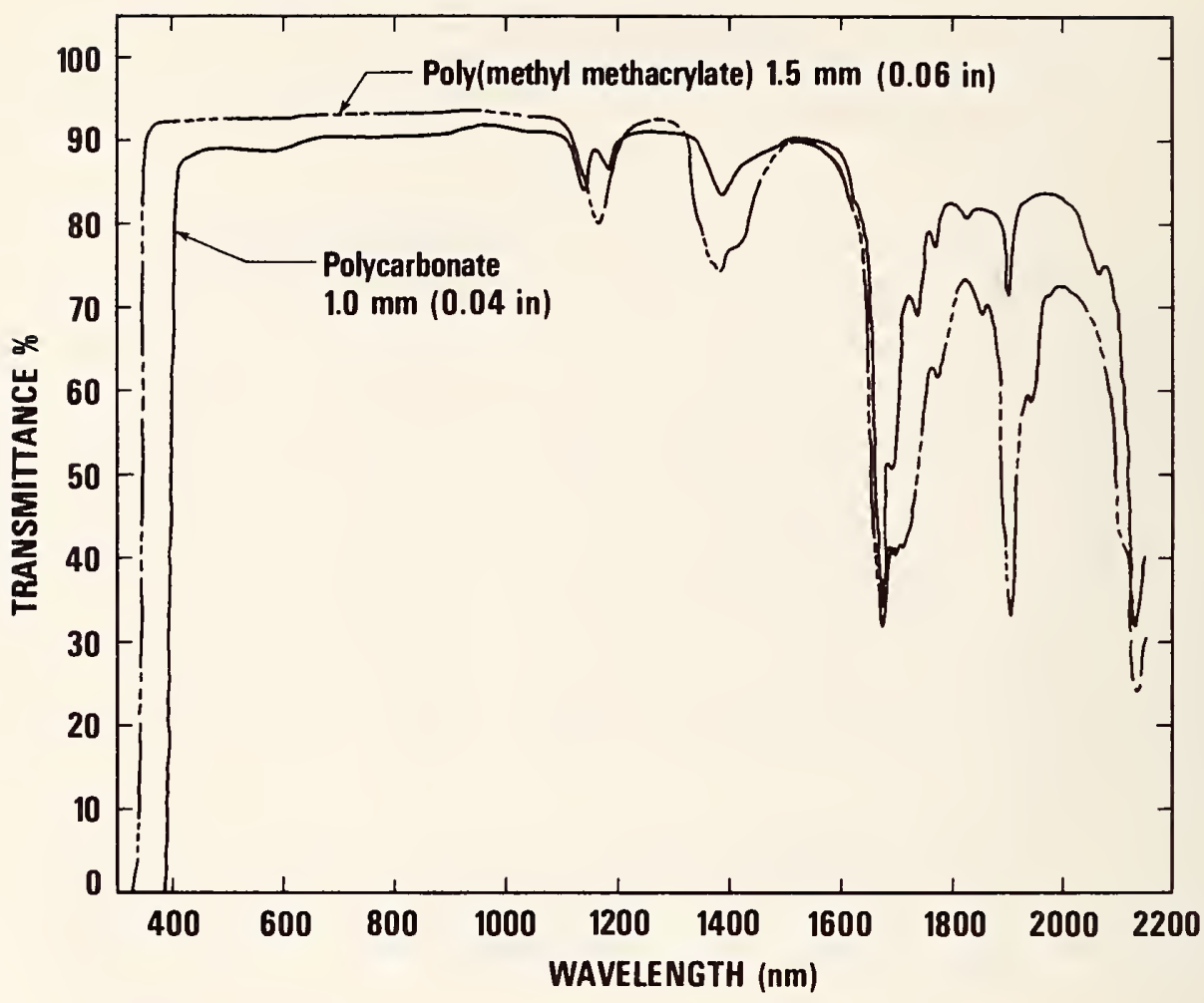

Figure 5d Spectral Transmittance of Control Test Specimens of Two

Fiber Reinforced Plastics

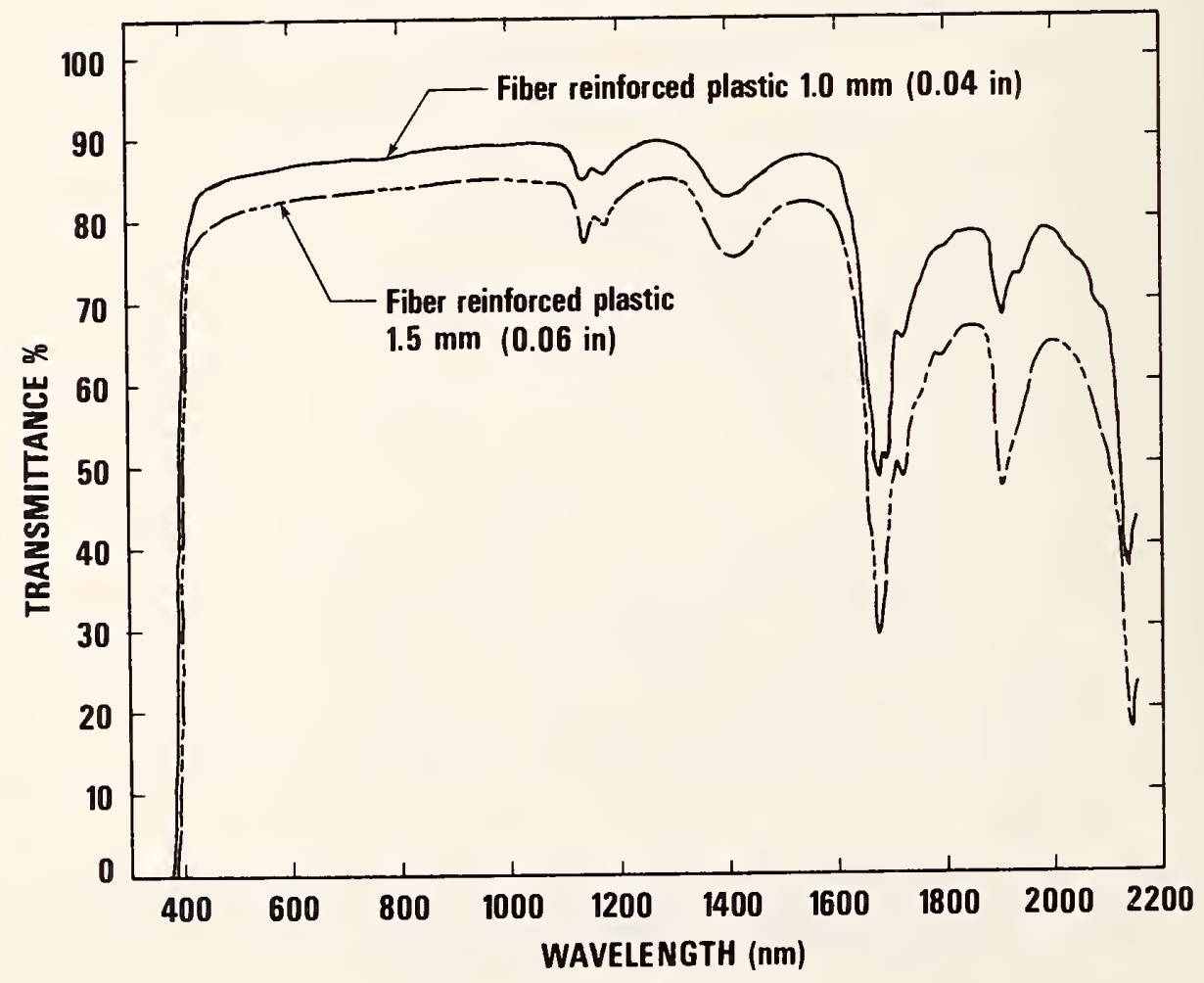


The two clear rigid plastic sheet materials, are shown in figure $5 c$, whereas, the two fiber reinforced plastics are compared in figure $5 \mathrm{~d}$. Among the various materials it is noteworth to observe the differences in the location of the absorption band in the ultraviolet region (below $400 \mathrm{~nm}$ ). Absorbing the ultraviolet portion of solar energy can result in deterioration of the material.

4.1.1.2 Method B - Outdoor with Pyranometer

The solar energy transmittance for a control set of test specimens as measured outdoors is listed in table 3. The table lists the solar transmittance of each control specimen, their average, and the standard deviation. The standard deviation of the $1.5 \mathrm{~mm}$ fiber reinforced plastic was 4.6 percent. For the other materials it ranged from $0.2-0.9$ percent.

\subsubsection{Comparison of Results of Method A and Method B}

The solar energy transmittance values in tables 2 and 3 were used to compare Methods A and B. With Method B, the standard deviation was greater for each material. Also with Method B, the average solar transmittance values for six materials (i.e. both glasses, fluorinated (ethylene propylene) copolymer, poly(vinyl fluoride), poly(ethylene terephthalate), and $1.5 \mathrm{~mm}$ fiber reinforced plastic) were higher than with Method A. An explanation for this may 1ie with the fact that with Method A (spectrophotometer) the calculations were made using AM 2, while with Method B (outdoor) the air mass was about 1.2. Figure 2 illustrates the differences in energy distribution for the air masses. Air mass 1 has more energy in the ultraviolet (below $400 \mathrm{~nm}$ ). Consequently materials having their absorption band well below $400 \mathrm{~nm}$ (Figures $5 \mathrm{a}-5 \mathrm{~d}$ ) have a higher transmittance with Method B compared to Method A. Conversely, materials having their absorption band closest to $400 \mathrm{~nm}$ (i.e. acrylic film, poly(methyl methacrylate), polycarbonate and the fiber reinforced plastics) do not transmit the additional energy contained in AM 1 and consequently have a lower solar energy transmittance when comparing the values obtained from Method $B$ with Method A.

The solar energy transmittance determined by Method B may vary from day to day due to atmospheric conditions, changes in the spectral distribution of sunlight, and variation in the direct/diffuse ratio of sunlight. Method $A$ has a constant energy source and a high degree of precision, consequently small changes in transmittance can be detected. For these reasons, Method A was used to evaluate the changes in transmittance caused by aging procedures.

\subsubsection{Infrared Transmittance}

Near normal infrared transmittance measurements from 2.5 to $40 \mu \mathrm{m}$ were made to characterize the cover plate materials and to determine if the materials would transmit the long wavelength energy reradiated by the absorber. Figures $6 \mathrm{a}$ to 6e contain the spectral transmittance curves in the infrared region for control test specimens. The poly(methyl methacrylate) and the two fiber reinforced plastics, figures $6 \mathrm{~d}$ and $6 \mathrm{e}$, transmit almost no infrared (IR) energy. The two types of glass, figure $6 \mathrm{a}$, and the polycarbonate, figure $6 \mathrm{~d}$, have some IR transmittance below $4.5 \mathrm{\mu m}$ but overall the IR transmittance is low. Conversely, 


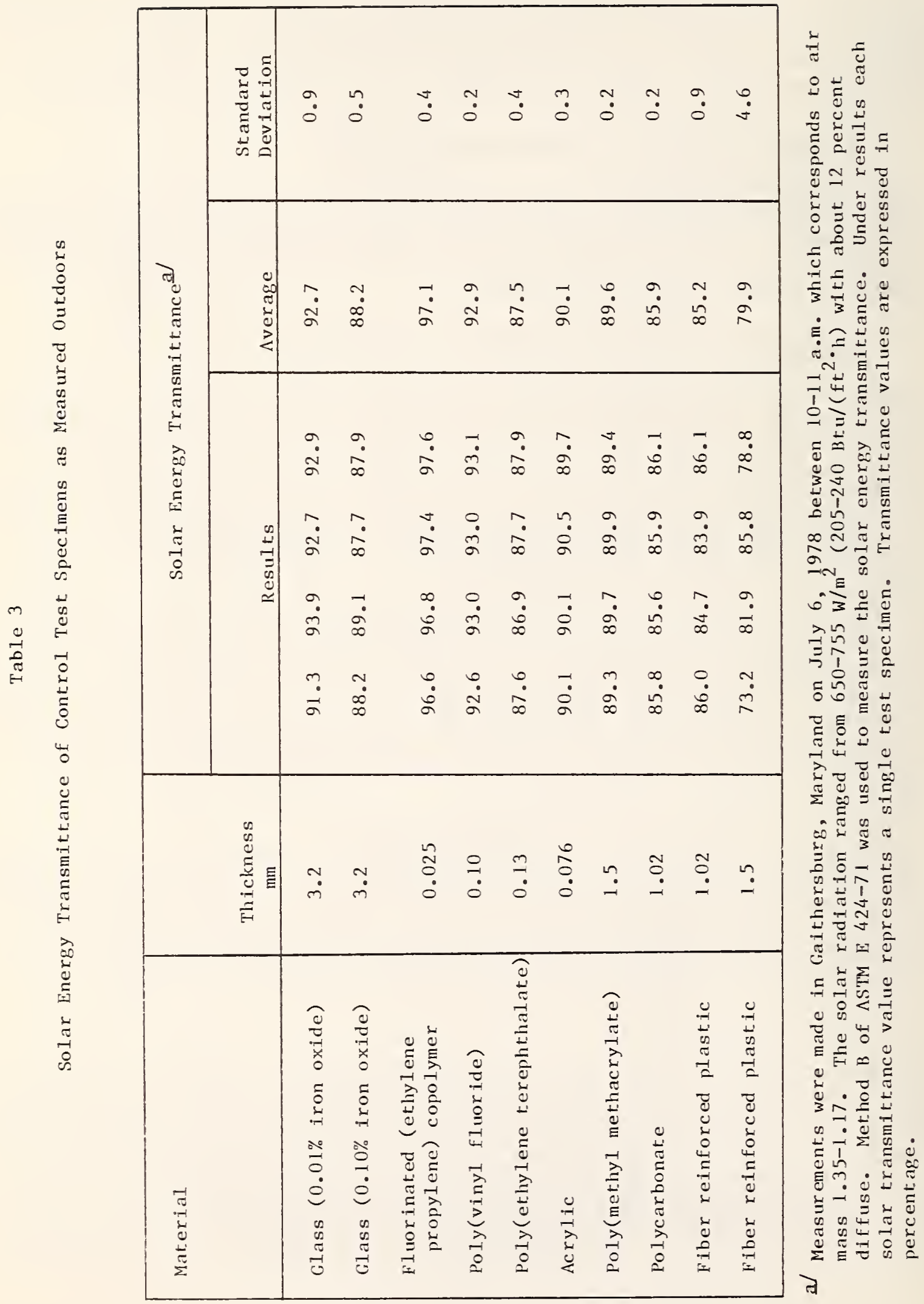



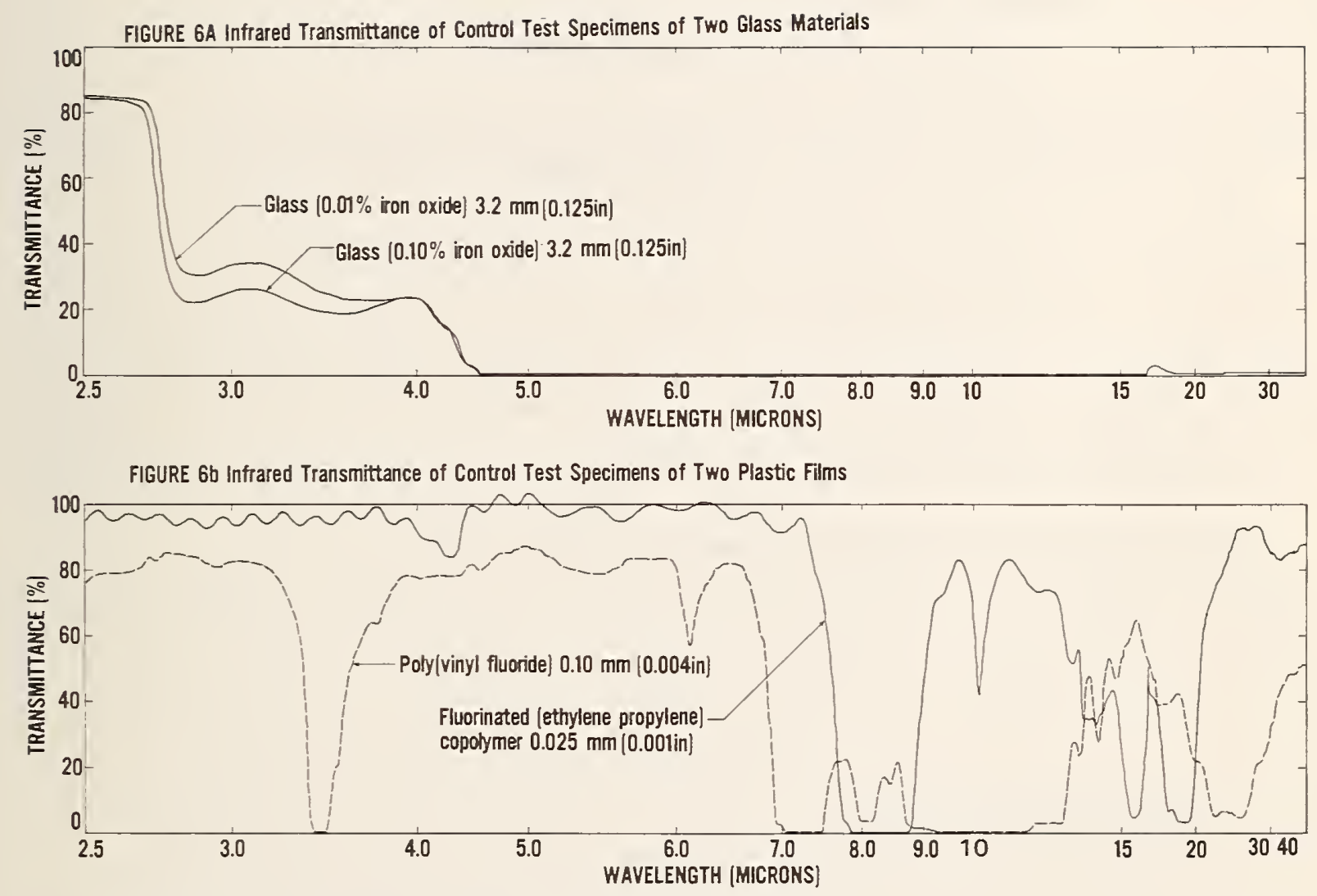

FIGURE 6c Infrared Transmittance of Control Test Specimens of Two Plastic Films

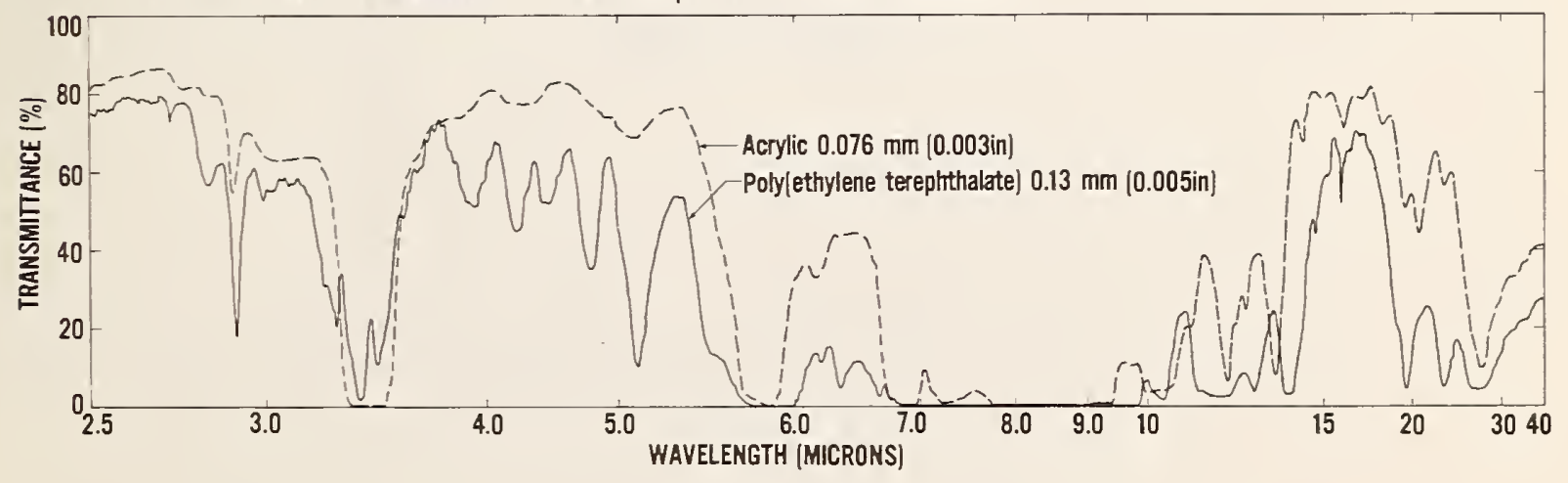



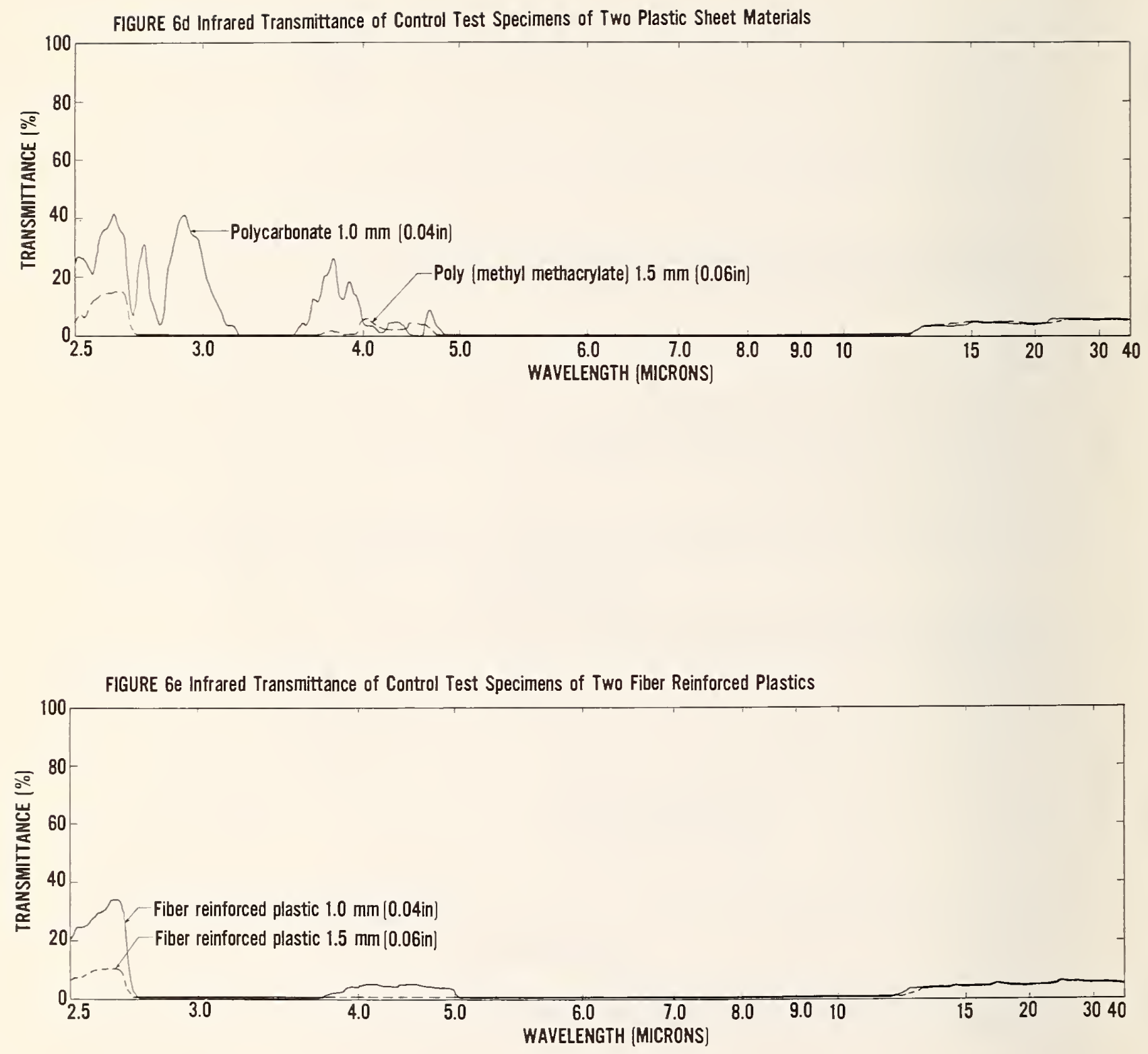
the four film materials, figures $6 \mathrm{~b}$ and $6 \mathrm{c}$, (i.e., fluorinated (ethylene propylene) copolymer, poly(vinyl fluoride), poly(ethylene terephthalate), and acrylic) transmit significant portions of the infrared energy.

IR transmittance measurements were made on selected film test specimens after some of the aging procedures. No significant changes relating to the IR long wavelength transmittance or emittance were observed.

\subsection{HEAT AGING}

\subsubsection{Solar Energy Transmittance}

4.2.1.1 Exposure at $150^{\circ} \mathrm{C}\left(302^{\circ} \mathrm{F}\right)$

The test specimens exposed to heat aging at $150^{\circ} \mathrm{C}\left(302^{\circ} \mathrm{F}\right)$ were removed at time intervals ranging from 10 to 1825 hours. From visual inspection it was evident that many materials were affected by the heat. Some materials (i.e., poly (vinyl fluoride) and the fiber reinforced plastics) visibly yellowed while other materials were dimensionally unstable. Table 4 contains the solar energy transmittance for air mass 2 at sea level. The greatest decrease occurred in the $1.5 \mathrm{~mm}$ fiber reinforced plastic which lost approximately half of the initial transmittance. The decrease occurred rapidly and took place across the entire spectrum from 375 to $2150 \mathrm{~nm}$, as is shown in figure $7 \mathrm{a}$. The solar transmittance of the $1 \mathrm{~mm}$ fiber reinforced plastic also dropped significantly during the exposure i.e. 13.5 percent. Like the $1.5 \mathrm{~mm}$ fiber reinforced plastic, this material lost transmittance across the entire spectrum, although the decrease was greatest below $700 \mathrm{~nm}$ for both materials.

The solar energy transmittance of the poly(vinyl fluoride) declined about 20 percent during the exposure. The transmittance loss occurred primarily below $900 \mathrm{~nm}$, as is shown in figure $7 \mathrm{~b}$. The test specimens gradually darkened during the exposure until they were nearly brown. Figure 8 provides a comparison of the appearance of the poly(vinyl fluoride) after various times at $150^{\circ} \mathrm{C}$ $\left(302^{\circ} \mathrm{F}\right)$. The poly(ethylene terephthalate) showed a slow but steady decrease in transmittance resulting in about 5 percent loss during the exposure. The gradual decrease took place across the entire spectrum. The heat aging caused a 2.5 percent decline in the polycarbonate. Although this is relatively small, it was caused by increasing absorption below $600 \mathrm{~nm}$.

The poly(methyl methacrylate) was seriously distorted and the acrylic film was so shrunken by the heat such that it was difficult to find an adequate flat area on which to make the measurement. The solar energy transmittance of both the poly(methyl methacrylate) and acrylic film decreased. In part, this was caused by increasing absorption in the ultraviolet-visible region, although the distortion of the test specimens and the resulting thickness deviations may also have contributed. After 10 hours, the fluorinated (ethylene propylene) copolymer had a decrease of about 1 percent which remained relatively constant for the remainder of the exposure. Examination of the transmittance curves showed little, if any, absorption change in the ultraviolet region. 
Table 4

Solar Energy Transmittance of Cover Plate Materials After Heat Aging at $150^{\circ} \mathrm{C}\left(302^{\circ} \mathrm{F}\right) \stackrel{\mathrm{a}}{ }$

\begin{tabular}{|c|c|c|c|c|c|c|c|c|c|c|}
\hline Material Exposure Time (hours) & 0 & 10 & 100 & 225 & 500 & 750 & 1000 & 1250 & 1500 & 1825 \\
\hline Glass $(0.01 \%$ iron oxide) & 90.7 & $\begin{array}{l}91.1 \\
89.9\end{array}$ & $\begin{array}{l}90.0 \\
90.2\end{array}$ & $\begin{array}{l}89.9 \\
89.7\end{array}$ & 89.8 & 89.8 & 88.8 & 90.1 & 91.6 & $\begin{array}{l}89.3 \\
91.6\end{array}$ \\
\hline Glass $(0.10 \%$ iron oxide) & 87.4 & $\begin{array}{l}86.9 \\
86.5\end{array}$ & $\begin{array}{l}86.9 \\
88.9\end{array}$ & $\begin{array}{l}86.7 \\
86.6\end{array}$ & 86.7 & 86.8 & 86.5 & 86.2 & 87.1 & $\begin{array}{l}86.9 \\
87.0\end{array}$ \\
\hline $\begin{array}{l}\text { Fluorinated (ethylene } \\
\text { propylene) copolymer }\end{array}$ & 96.0 & $\begin{array}{l}95.0 \\
95.0\end{array}$ & $\begin{array}{l}95.1 \\
94.9\end{array}$ & $\begin{array}{l}94.9 \\
95.2\end{array}$ & 95.2 & 94.9 & 95.0 & 95.2 & 94.5 & $\begin{array}{l}94.8 \\
94.8\end{array}$ \\
\hline Poly(vinyl fluoride) & 92.5 & $\begin{array}{l}91.2 \\
91.2\end{array}$ & $\begin{array}{l}87.2 \\
87.4\end{array}$ & $\begin{array}{l}87.9 \\
87.9\end{array}$ & 86.8 & 82.4 & 80.5 & 75.0 & 71.7 & $\begin{array}{l}72.0 \\
72.5\end{array}$ \\
\hline Poly(ethylene terephthalate) & 86.3 & $\begin{array}{l}84.9 \\
86.0\end{array}$ & $\begin{array}{l}85.8 \\
86.0\end{array}$ & $\begin{array}{l}85.5 \\
84.8\end{array}$ & 84.0 & 83.1 & 81.5 & 82.4 & 82.3 & $\begin{array}{l}81.6 \\
80.7\end{array}$ \\
\hline Acrylic & 90.7 & $\begin{array}{l}\mathrm{b} / \\
\mathrm{b} /\end{array}$ & b/ & $\begin{array}{l}86.9 \\
87.7\end{array}$ & 88.1 & 87.6 & 88.4 & 88.0 & 87.2 & ${ }_{\mathrm{b}}^{86} j^{0}$ \\
\hline Poly(methyl methacrylate) & 91.0 & $\begin{array}{l}90.1 \\
90.4\end{array}$ & b/ & $\frac{b}{89.9}$ & 89.5 & 89.3 & 89.4 & b/ & b) & b/ \\
\hline Polycarbonate & 88.1 & $\begin{array}{l}87.2 \\
86.8\end{array}$ & $\begin{array}{l}\mathrm{b} / \\
\mathrm{b} /\end{array}$ & $\begin{array}{l}87.2 \\
87.1\end{array}$ & 86.7 & 86.4 & 86.6 & 86.2 & 86.3 & $\begin{array}{l}85.7 \\
85.6\end{array}$ \\
\hline Fiber reinforced plastic $(1.0 \mathrm{~mm})$ & 86.3 & $\begin{array}{l}77.3 \\
74.5\end{array}$ & $\begin{array}{l}76.4 \\
76.1\end{array}$ & $\stackrel{77}{b}]^{2}$ & 77.0 & 75.2 & 74.5 & 72.7 & 70.2 & $\begin{array}{l}74.3 \\
70.9\end{array}$ \\
\hline Fiber reinforced plastic $(1.5 \mathrm{~mm})$ & 78.5 & $\begin{array}{l}64.1 \\
77.2\end{array}$ & $\begin{array}{l}60.1 \\
60.7\end{array}$ & $\begin{array}{l}52.1 \\
56.1\end{array}$ & 52.2 & 43.6 & 39.7 & 39.7 & 44.6 & $\begin{array}{l}39.7 \\
39.4\end{array}$ \\
\hline
\end{tabular}

a Transmittance measurements were made on a Cary 17D integrating sphere spectrophotometer according to ASTM E 424-71, Method A. The solar energy transmittance for air mass 2 at sea level was obtained by integrating over Parry Moon's Standard solar energy distribution curve using weighted ordinates. The initial solar energy transmittance values listed are the average of the control test specimens. Each transmittance value for exposed materials represents

a separate test specimen. Transmittance is expressed in percentage.

b/ Test specimen was too deformed from the heat to make a transmittance measurement. 
Figure 7a Spectral Transmittance $1.5 \mathrm{~mm}(0.06$ in) Fiber Reinforced Plastic EXPOSED tO $150^{\circ} \mathrm{C}\left(302^{\circ} \mathrm{F}\right)$ FOR FOUR TIME PERIODS

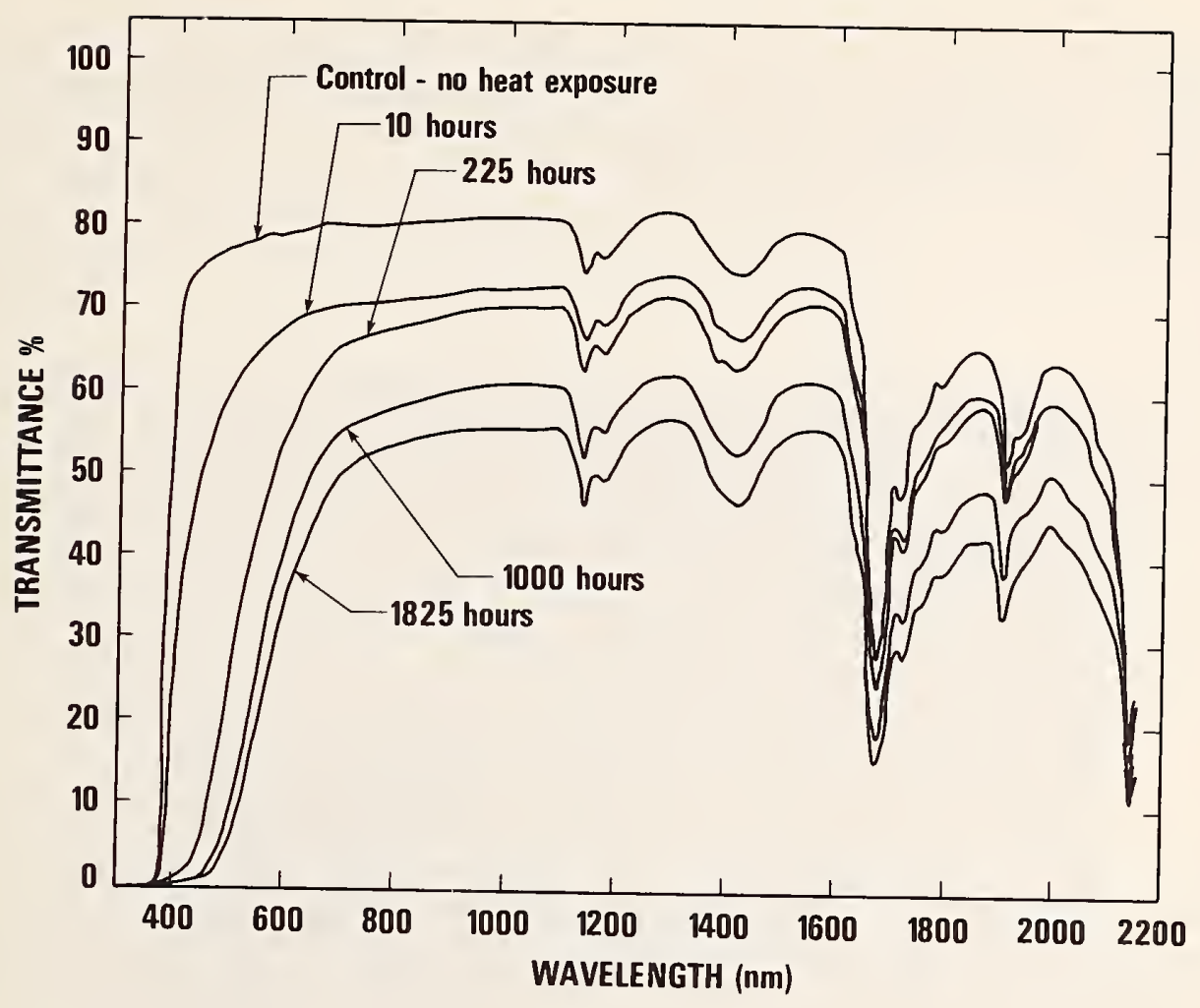

Figure 7b Spectral Transmittance 0.10mm(0.004in) Poly(vinyl fluoride) EXPOSEd TO $150^{\circ} \mathrm{C}\left(302^{\circ} \mathrm{F}\right)$ FOR Four TIME PERIOdS

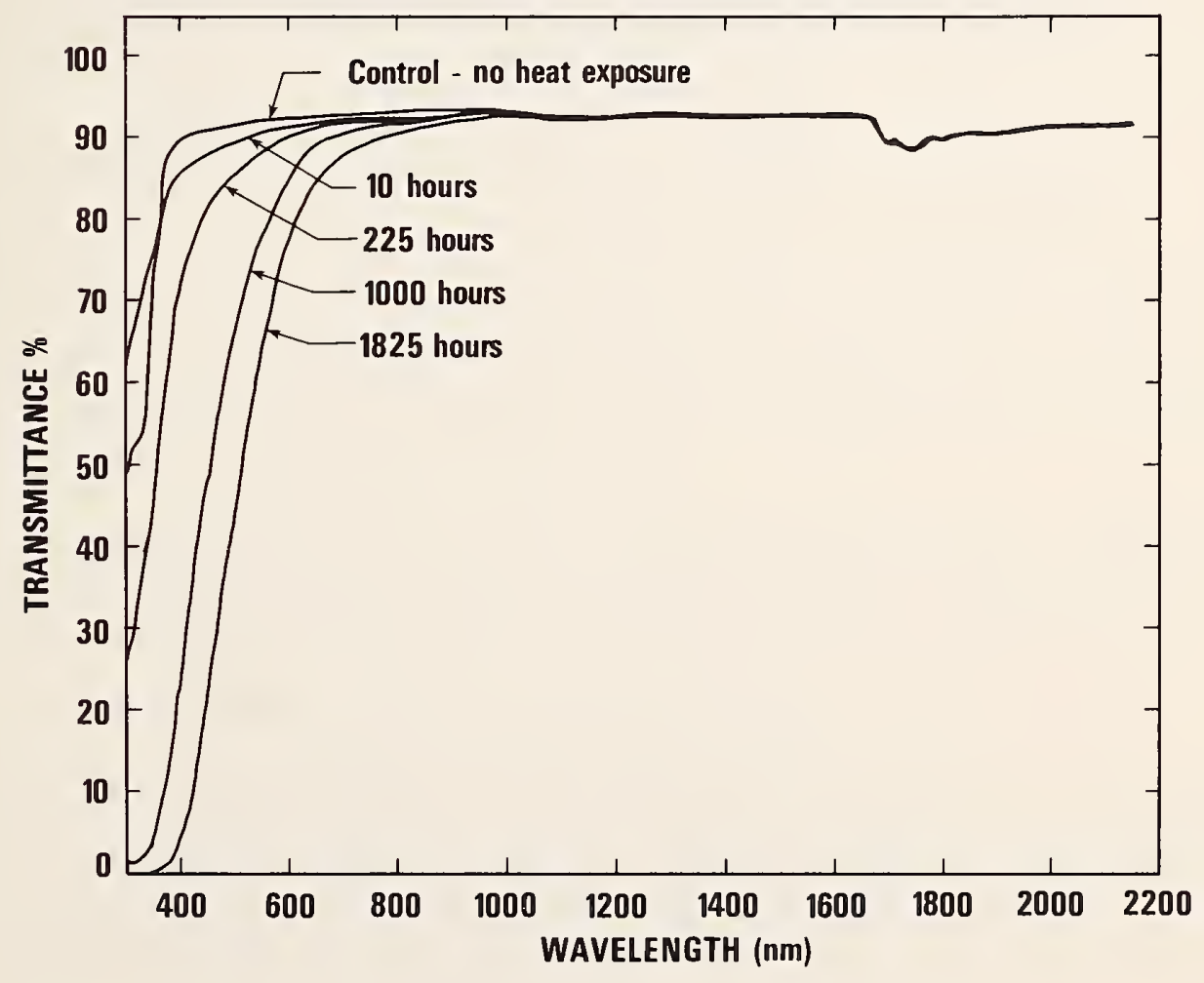


Figure 8 Appearance of Poly(vinyl fluoride) after Exposure at $150^{\circ} \mathrm{C}\left(302^{\circ} \mathrm{F}\right)$ for Various Periods

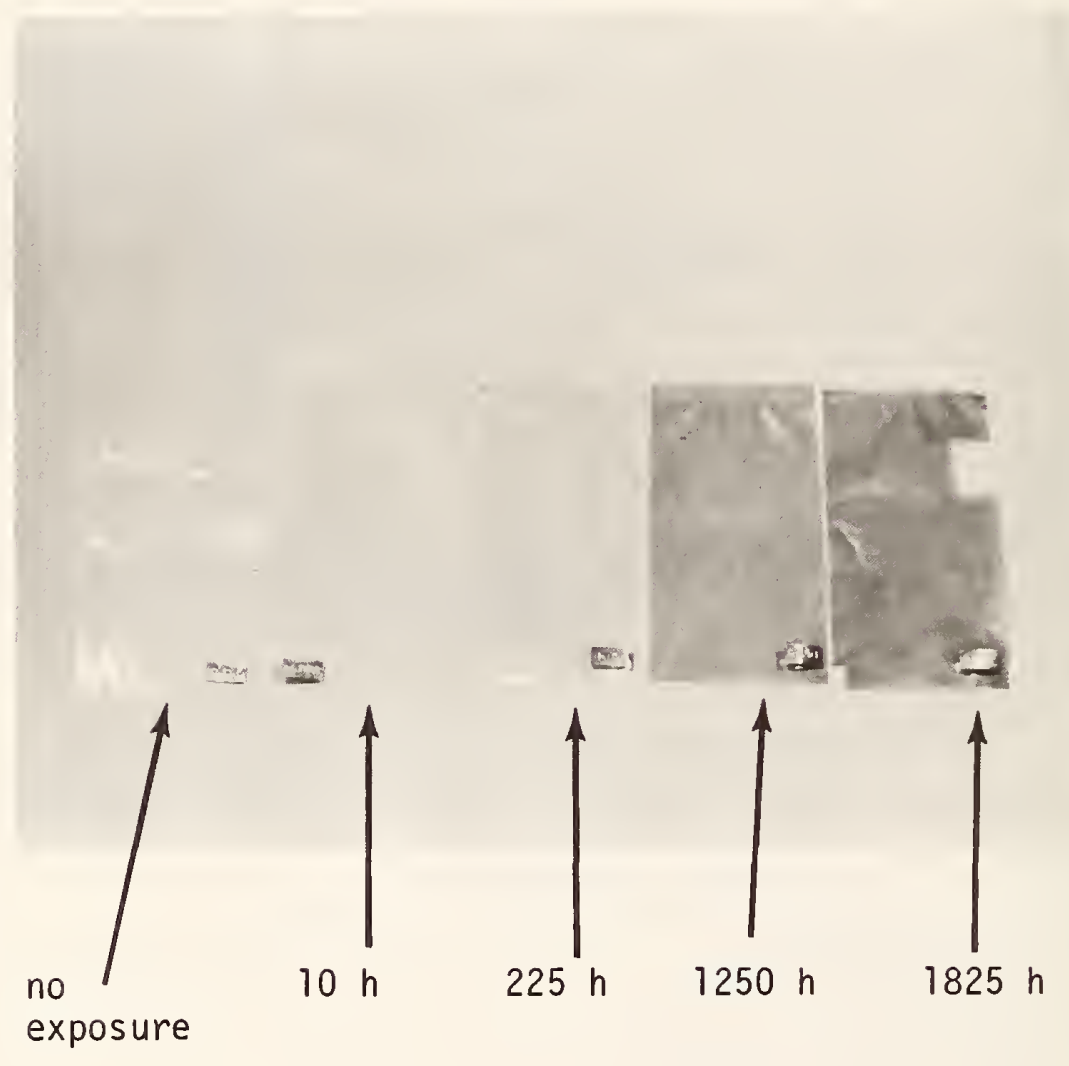


The two glass materials had some scatter in the solar energy transmittance results. The irregularities may be attributed to two causes: 1) slight variations in the thickness of the test specimens; and 2) deposit of a film on the glass. Since glass and plastic test specimens were simultaneously exposed in the same oven, products from outgassing or deterioration of the plastic materials may have been deposited on other materials thereby causing slight changes in transmittance.

The rate of solar energy transmittance loss varied among the materials, as shown in figure 9a. The $1.5 \mathrm{~mm}$ fiber reinforced plastic decreased rapidly until about 1500 hours exposure when it leveled off. For the $1.0 \mathrm{~mm}$ fiber reinforced plastic material, there was a large immediate loss followed by a gradually increasing loss. These two fiber reinforced materials were not the same resin and were produced by different manufacturers which is the reason for the differences in the test results. The poly(vinyl fluoride) had a fairly uniform rate of transmittance loss while the poly(ethylene terephthalate) and polycarbonate changed more slowly.

\section{2 .1 .2 Exposure at $125^{\circ} \mathrm{C}\left(257^{\circ} \mathrm{F}\right)$}

The materials exposed to $125^{\circ} \mathrm{C}\left(257^{\circ} \mathrm{F}\right)$ were removed from the oven at time increments ranging from 100 to 2000 hours. While yellowing and deformation of the materials did occur, it was less pronounced than for the $150^{\circ} \mathrm{C}\left(302^{\circ} \mathrm{F}\right)$ exposure. The solar energy transmittance of the cover plate materials after heat aging at $125^{\circ} \mathrm{C}\left(257^{\circ} \mathrm{F}\right)$ is listed in table 5. As was expected, the transmittance losses were less for the $125^{\circ} \mathrm{C}\left(257^{\circ} \mathrm{F}\right)$ exposure than for the $150^{\circ} \mathrm{C}$ $\left(302^{\circ} \mathrm{F}\right)$ exposure. The $1.5 \mathrm{~mm}$ fiber reinforced plastic again had the greatest solar transmittance loss, declining approximately 30 percent, whereas the $1 \mathrm{~mm}$ fiber reinforced plastic lost 7 percent solar energy transmittance. The poly (vinyl fluoride) decreased an average 8 percent after 2000 hours, whereas the poly(ethylene terephthalate) fell about 2.5 percent. Although the transmittance losses for the polycarbonate and poly(methyl methacrylate) were small, examination of the transmittance curves revealed that absorption had started to increase below $500 \mathrm{~nm}$. Very little difference was observed in the spectra for the fluorinated (ethylene propylene) copolymer. The deviations in the transmittance of the glass materials appear to be due to variations in the actual glass thickness or film deposits caused by deterioration of other materials. The acrylic film test specimens were too deformed from shrinkage to allow transmittance measurements to be made.

The rate of transmittance loss at $125^{\circ} \mathrm{C}\left(257^{\circ} \mathrm{F}\right)$ is plotted for several materials in figure $9 \mathrm{~b}$. Although the rates are lower than for $150^{\circ} \mathrm{C}\left(302^{\circ} \mathrm{F}\right.$ ) (figure $9 \mathrm{a})$, the general trends are the same for both heat aging exposures.

4.2.1.3 Exposures at $100^{\circ} \mathrm{C}\left(212^{\circ} \mathrm{F}\right)$ and $75^{\circ} \mathrm{C}\left(167^{\circ} \mathrm{F}\right)$

The cover materials were exposed to $100^{\circ} \mathrm{C}\left(212^{\circ} \mathrm{F}\right)$ and $75^{\circ} \mathrm{C}\left(167^{\circ} \mathrm{F}\right)$ heat aging for periods of 10 to 2000 hours. The solar energy transmittance for these materials is tabulated in tables 6 and 7. The decreases in solar energy transmittance are less than the decreases caused by the $125^{\circ} \mathrm{C}\left(257^{\circ} \mathrm{F}\right)$ exposures for comparable times. From the data, it was obvious that the two fiber 
figure 9a Rate of Solar Energy Transmittance Loss of Five Cover Plate Materials Exposed at $150^{\circ} \mathrm{C}\left(302^{\circ} \mathrm{F}\right)$

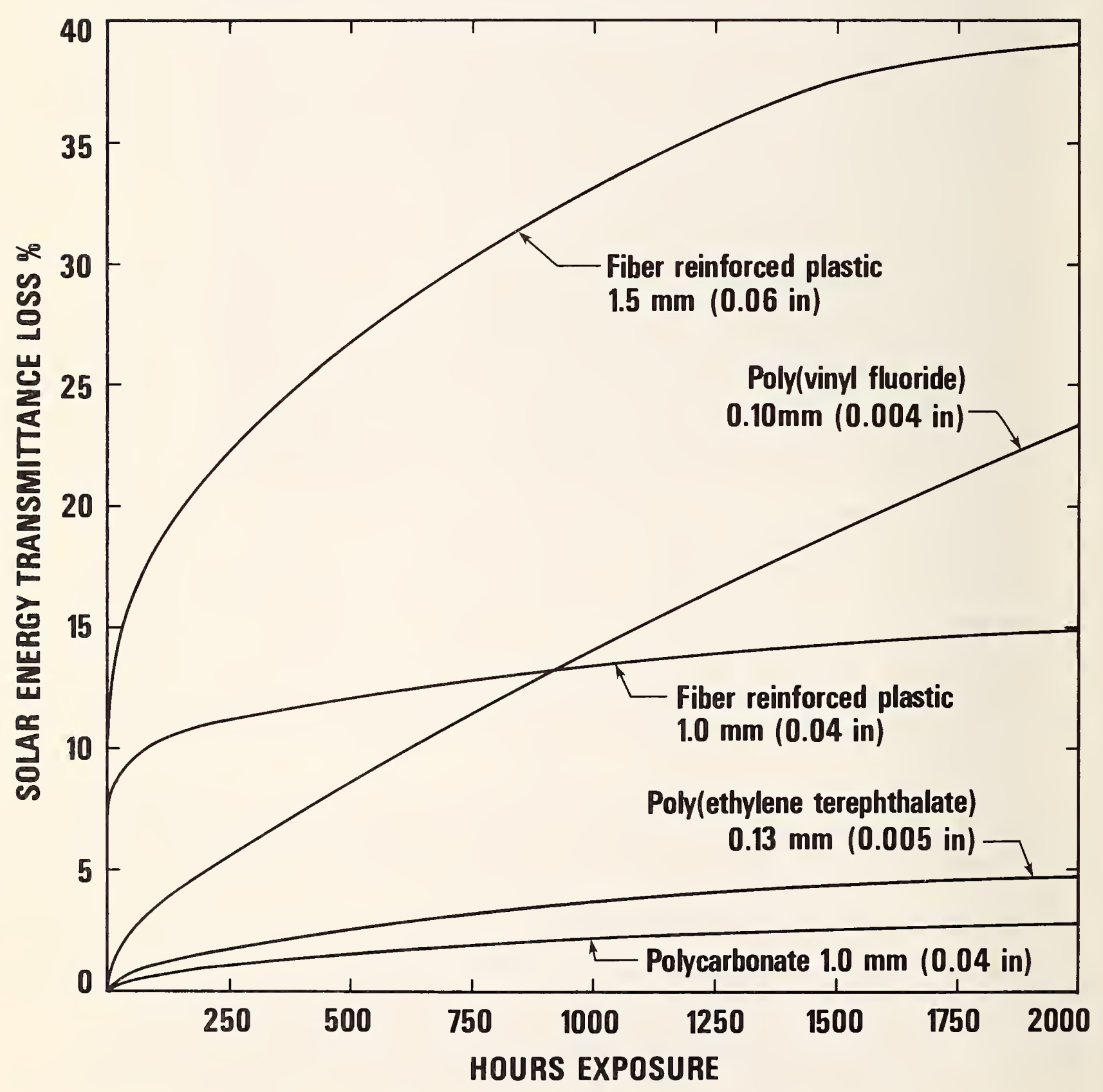


Table 5

Solar Energy Transmittance of Cover Plate Materials After Heat Aging at $125^{\circ} \mathrm{C}\left(257^{\circ} \mathrm{F}\right) \underline{a}$

\begin{tabular}{|c|c|c|c|c|c|c|c|c|}
\hline Material Exposure Time (hours) & 0 & 100 & 250 & 500 & 750 & 1000 & 1500 & 2000 \\
\hline Glass $(0.01 \%$ iron oxide) & 90.7 & $\begin{array}{l}89.4 \\
89.7\end{array}$ & 89.9 & 89.3 & 89.6 & 89.7 & 89.7 & $\begin{array}{l}89.5 \\
89.6\end{array}$ \\
\hline Glass $(0.10 \%$ iron oxide) & 87.4 & $\begin{array}{l}86.9 \\
86.7\end{array}$ & 86.7 & 86.8 & 86.8 & 85.8 & 86.3 & $\begin{array}{l}86.7 \\
86.4\end{array}$ \\
\hline $\begin{array}{l}\text { Fluorinated (ethylene } \\
\text { propylene) copolymer }\end{array}$ & 96.0 & $\begin{array}{l}95.0 \\
95.3\end{array}$ & 95.2 & 95.4 & 95.2 & 95.4 & 95.3 & $\begin{array}{l}95.2 \\
95.1\end{array}$ \\
\hline Poly(viny1 fluoride) & 92.5 & $\begin{array}{l}90.5 \\
90.6\end{array}$ & 90.4 & 90.3 & 86.1 & 88.0 & 85.9 & $\begin{array}{l}87.2 \\
83.4\end{array}$ \\
\hline Poly(ethylene terephthalate) & 86.3 & $\begin{array}{l}86.0 \\
85.7\end{array}$ & 85.0 & 84.6 & 84.7 & 84.9 & 83.7 & $\begin{array}{l}82.3 \\
84.9\end{array}$ \\
\hline Acrylic & 90.7 & $\begin{array}{l}87.4 \\
87.7\end{array}$ & 88.0 & b/ & b/ & b/ & 89.8 & $88 y^{2}$ \\
\hline Poly(methy 1 methacrylate) & 91.0 & 89.3 & 89.7 & 90.3 & 90.2 & 90.1 & 90.2 & $\begin{array}{l}90.4 \\
90.2\end{array}$ \\
\hline Polycarbonate & 88.1 & $\begin{array}{l}87.5 \\
87.5\end{array}$ & 87.5 & 87.3 & 87.7 & 87.1 & 87.0 & $\begin{array}{l}86.9 \\
86.9\end{array}$ \\
\hline Fiber reinforced plastic $(1.0 \mathrm{~mm})$ & 86.3 & $\begin{array}{l}83.2 \\
83.3\end{array}$ & 82.6 & 80.3 & 80.6 & 77.8 & 79.2 & $\begin{array}{l}79.2 \\
79.1\end{array}$ \\
\hline Fiber reinforced plastic $(1.5 \mathrm{~mm})$ & 78.5 & $\begin{array}{l}73.7 \\
68.1\end{array}$ & 63.8 & 56.9 & 51.2 & 55.8 & 47.0 & $\begin{array}{l}55.7 \\
45.5\end{array}$ \\
\hline
\end{tabular}

a) Transmittance measurements were made on a Cary 17D integrating sphere spectrophotometer according to ASTM E 424-71, Method A. The solar energy transmittance for air mass 2 at sea level was obtained by integrating over Parry Moon's Standard solar energy distribution curve using weighted ordinates. The initial solar energy transmittance values listed are the average of the control test specimens. Each transmittance value for exposed materials represents a separate test specimen. Transmittance is expressed in percentage.

b/ Test specinens too deformed from the heat to make a transmittance measurement. 


\section{figure 9b Rate of Solar Energy Transmittance loss of Five Cover Plate Materials Exposed at $125^{\circ} \mathrm{C}\left(257^{\circ} \mathrm{F}\right)$}

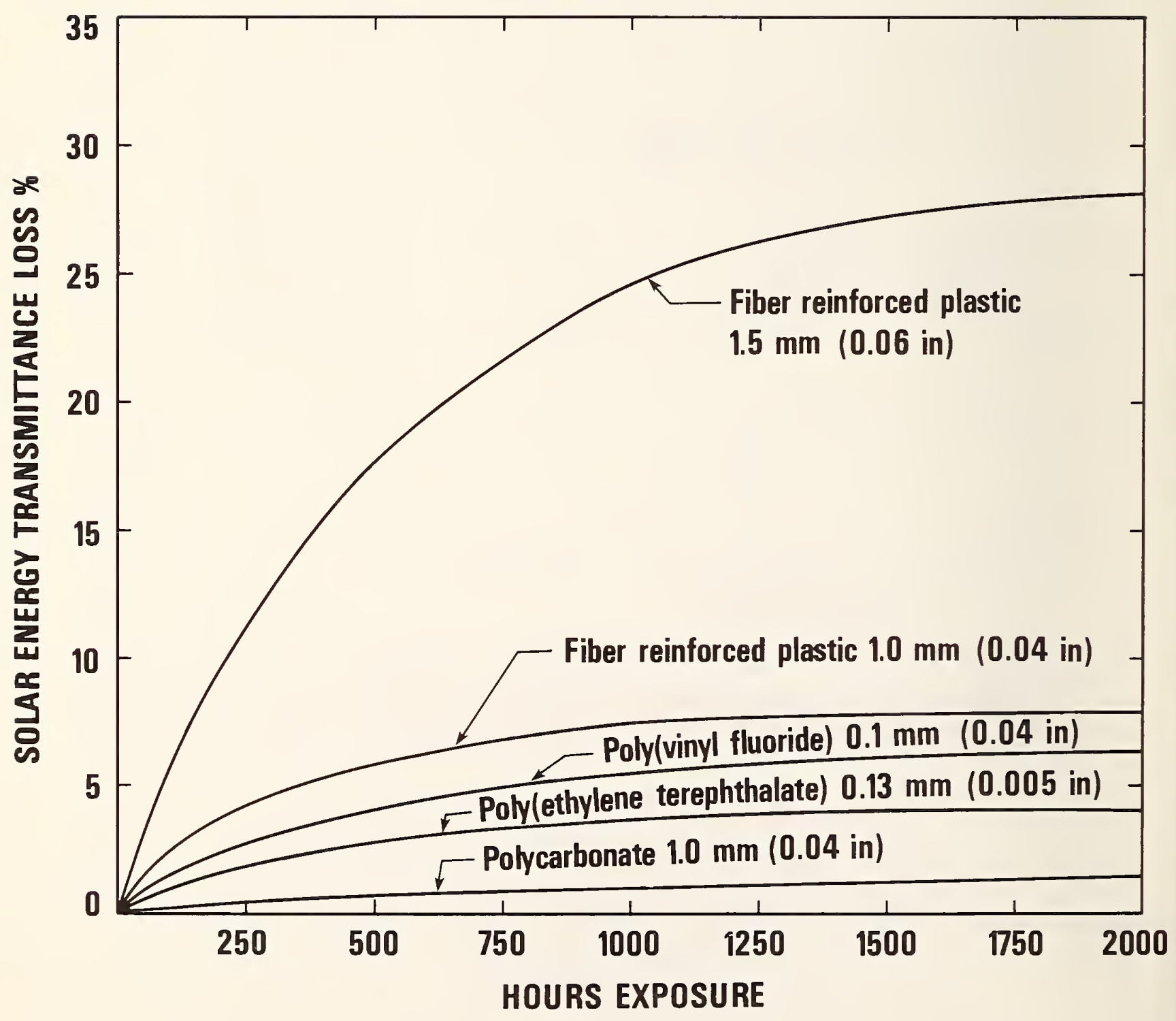


Table 6

Solar Energy Transmittance of Cover Plate Materials After Heat Aging at $100^{\circ} \mathrm{C}\left(212^{\circ} \mathrm{F}\right) \stackrel{\mathrm{a}}{ }$

\begin{tabular}{|c|c|c|c|c|c|c|c|c|c|c|}
\hline Material & 0 & 10 & 100 & 250 & 550 & 750 & 1050 & 1300 & 1700 & 2000 \\
\hline Glass $(0.01 \%$ iron oxide) & 90.7 & $\begin{array}{l}89.8 \\
89.9\end{array}$ & $\begin{array}{l}90.0 \\
89.8\end{array}$ & 89.7 & 88.7 & 89.4 & 89.5 & 88.8 & 88.6 & $\begin{array}{l}89.4 \\
89.9\end{array}$ \\
\hline Glass $(0.10 \%$ iron oxide) & 87.4 & $\begin{array}{l}86.5 \\
86.6\end{array}$ & $\begin{array}{l}86.9 \\
86.8\end{array}$ & $\begin{array}{l}86.7 \\
86.2\end{array}$ & 86.4 & 86.5 & 86.7 & 86.1 & 86.9 & $\begin{array}{l}87.3 \\
86.9\end{array}$ \\
\hline Poly(vinyl fluoride) & 92.5 & $\begin{array}{l}91.2 \\
91.0\end{array}$ & $\begin{array}{l}91.3 \\
89.4\end{array}$ & $\begin{array}{l}91.5 \\
91.3\end{array}$ & 91.5 & 91.6 & 91.5 & 90.6 & 90.7 & $\begin{array}{l}90.5 \\
90.4\end{array}$ \\
\hline Poly(methyl methacrylate) & 91.0 & $\begin{array}{l}90.2 \\
90.0\end{array}$ & $\begin{array}{l}90.4 \\
90.0\end{array}$ & $\begin{array}{l}89.9 \\
89.8\end{array}$ & 90.2 & 90.3 & 90.3 & 89.7 & 90.1 & $\begin{array}{l}89.9 \\
90.0\end{array}$ \\
\hline Polycarbonate & 88.1 & $\begin{array}{l}86.9 \\
87.2\end{array}$ & $\begin{array}{l}86.8 \\
87.1\end{array}$ & $\begin{array}{l}87.6 \\
88.1\end{array}$ & 87.1 & 87.0 & 87.0 & 87.0 & 87.3 & $\begin{array}{l}87.3 \\
87.7\end{array}$ \\
\hline Fiber reinforced plastic $(1.0 \mathrm{~mm})$ & 86.3 & $\begin{array}{l}81.4 \\
82.3\end{array}$ & $\begin{array}{l}82.9 \\
83.0\end{array}$ & $\begin{array}{l}83.3 \\
84.0\end{array}$ & 84.0 & 84.3 & 83.6 & 82.7 & 79.6 & $\begin{array}{l}81.0 \\
79.7\end{array}$ \\
\hline
\end{tabular}

a/ Transmittance measurements were made on a Cary 17D integrating sphere spectrophotometer according to ASTM E 424-71, Method A. The solar energy transmittance for air mass 2 at sea level was obtained by integrating over Parry Moon's Standard solar energy distribution curve using weighted ordinates. The initial solar energy transmittance values

listed are the average of the control test specimens. Each transmittance value for exposed materials represents

a separate test specimen. Transmittance is expressed in percentage. 
Table 7

Solar Transmittance of Cover Plate Materials After Heat Aging at $75^{\circ} \mathrm{C}\left(167^{\circ} \mathrm{F}\right) \mathrm{a} /$

\begin{tabular}{|c|c|c|c|c|c|c|c|c|c|}
\hline Material Exposure Time (hours) & 0 & 10 & 100 & 250 & 500 & 750 & 1000 & 1500 & 2000 \\
\hline Glass $(0.01 \%$ iron oxide) & 90.7 & $\begin{array}{l}89.9 \\
90.0\end{array}$ & $\begin{array}{l}90.1 \\
90.3\end{array}$ & 90.3 & 90.2 & 90.6 & 90.2 & 90.2 & $\begin{array}{l}90.5 \\
90.4\end{array}$ \\
\hline Glass $(0.10 \%$ iron oxide) & 87.4 & $\begin{array}{l}86.1 \\
86.2\end{array}$ & $\begin{array}{l}86.5 \\
87.2\end{array}$ & 86.6 & 86.7 & 86.6 & 87.1 & 86.6 & $\begin{array}{l}87.1 \\
87.0\end{array}$ \\
\hline $\begin{array}{l}\text { Fluorinated (ethylene } \\
\text { propylene) copolymer }\end{array}$ & 96.0 & $\begin{array}{l}96.0 \\
96.0\end{array}$ & $\begin{array}{l}95.6 \\
95.4\end{array}$ & 95.5 & 95.7 & 95.4 & 95.5 & 95.1 & $\begin{array}{l}95.1 \\
95.1\end{array}$ \\
\hline Poly(vinyl fluoride) & 92.5 & $\begin{array}{l}91.6 \\
91.2\end{array}$ & $\begin{array}{l}90.2 \\
91.4\end{array}$ & 90.3 & 91.3 & 91.2 & 91.5 & 90.1 & $\begin{array}{l}91.0 \\
91.0\end{array}$ \\
\hline Poly(ethylene terephthalate) & 86.3 & $\begin{array}{l}85.6 \\
85.9\end{array}$ & $\begin{array}{l}86.0 \\
85.1\end{array}$ & 84.4 & 85.9 & 85.5 & 84.8 & 84.5 & $\begin{array}{l}85.0 \\
85.0\end{array}$ \\
\hline Acrylic & 90.7 & $\begin{array}{l}89.4 \\
90.4\end{array}$ & $\begin{array}{l}88.6 \\
89.0\end{array}$ & 89.8 & 89.9 & 89.2 & 89.3 & 89.7 & $\begin{array}{l}89.5 \\
90.2\end{array}$ \\
\hline Poly(methyl methacrylate) & 91.0 & $\begin{array}{l}90.3 \\
90.5\end{array}$ & $\begin{array}{l}90.4 \\
90.4\end{array}$ & 90.2 & 90.7 & 90.4 & 90.4 & 90.4 & $\begin{array}{l}90.8 \\
90.6\end{array}$ \\
\hline Polycarbonate & 88.1 & $\begin{array}{l}87.4 \\
87.3\end{array}$ & $\begin{array}{l}87.2 \\
87.4\end{array}$ & 87.1 & 87.2 & 88.1 & 86.8 & 86.9 & $\begin{array}{l}87.1 \\
87.3\end{array}$ \\
\hline Fiber reinforced plastic $(1.0 \mathrm{~mm})$ & 86.3 & $\begin{array}{l}81.3 \\
87.3\end{array}$ & $\begin{array}{l}85.3 \\
83.4\end{array}$ & 83.3 & 81.0 & 83.8 & 83.8 & 82.5 & $\begin{array}{l}83.4 \\
82.4\end{array}$ \\
\hline Fiber reinforced plastic $(1.5 \mathrm{~mm})$ & 78.3 & $\begin{array}{l}74.2 \\
74.6\end{array}$ & $\begin{array}{l}75.3 \\
77.3\end{array}$ & 79.9 & 69.3 & 72.1 & 69.3 & 66.6 & $\begin{array}{l}71.8 \\
71.4\end{array}$ \\
\hline
\end{tabular}

Transmittance measurements were made on a Cary 17D integrating sphere spectrophotometer according to ASTM E 424-71 Method A. The solar energy transmittance for air mass 2 at sea level was obtained by integrating over Parry Moon's Standard solar energy distribution curve using weighted ordinates. The initial solar energy transmittance values listed are the average of the control test specimens. Each transmittance value for exposed materials represents a separate test specimen. Transmittance is expressed in percentage. 
reinforced materials suffered deterioration which had caused a loss in transmittance, however, decreases in the transmittance of the other materials were generally less than 2 percent. To determine if the losses were caused by the heat, the spectral transmittance graphs were inspected. They indicated that absorption had increased in the ultraviolet-visible region for poly(vinyl fluoride), acrylic film, poly(ethylene terephthalate), and poly(methyl methacrylate). The increased absorption observed in the graphs for these materials indicated that the solar energy transmittance losses, though small, were caused by deterioration of the material. For polycarbonate, small variations in transmittance existed across the entire spectrum, however, there was little change in the location of the absorption band in the ultraviolet region. The spectral transmittance curves for the fluorinated (ethylene propylene) copolymer showed minor variations when compared with the control test specimens. The transmittance variations of the glass materials were irregular and did not appear to be caused by the heat.

\subsubsection{Comparison of Exposures}

Except for glass and fluorinated (ethylene propylene) copolymer, two conclusions can be made from the data in tables 4-7. First, the solar energy transmittance decreased as the cover material was exposed to longer periods in a heat aging, and second, as the temperature was increased, the solar energy transmittance decreased. The rate of transmittance loss was related to the exposure temperature. Figures $10 \mathrm{a}-10 \mathrm{~g}$ provide a comparison of the transmittance curves of the control test specimens and the plastic materials after approximately 2000 hours in the four heat aging exposures. The 2000 hours is roughly equivalent to one year with the temperature elevated six hours per day. Since only relatively small changes were observed with glass and fluorinated (ethylene propylene) copolymer, their transmittance curves are not compared.

\subsubsection{Linear Dimensional Stability}

Linear dimensional stability was evaluated after 10 and 100 hours of heat aging at $100^{\circ} \mathrm{C}\left(212^{\circ} \mathrm{F}\right)$ and $150^{\circ} \mathrm{C}\left(302^{\circ} \mathrm{F}\right)$. Table 8 contains the results of the measurements. The data are the average from three test specimens. As was expected, no change was observed for the glass materials or the fiber reinforced plastic materials (which were thermosets). However, the other six plastic materials exhibited anisotropy, i.e., unequal changes in length and width. Although the film test specimens were square prior to exposure, examination of the exposed test specimens indicated that the changes were not proportional across the material. Figures $1 \mathrm{la}$ and $1 \mathrm{lb}$ illustrate the irregular shape of some film test specimens after heat aging. The dimensional measurements were made on the centerline in each direction.

Only small differences were observed in the data for the 10 and 100 hour exposure. Comparing the 100 hour data for the two temperatures showed that the materials behaved similarly at both temperatures although greater expansions or contractions took place at $150^{\circ} \mathrm{C}\left(302^{\circ} \mathrm{F}\right)$. Poly(vinyl fluoride) and polycarbonate were exceptions to this. At $100^{\circ} \mathrm{C}\left(212^{\circ} \mathrm{F}\right.$ ) poly (vinyl fluoride) 
Figure 10a Spectral Transmittance 0.10mm(0.004in) Poly(vinyl fluoride)

EXPOSEd to Four Temperatures for Approximately 2000 HoURS
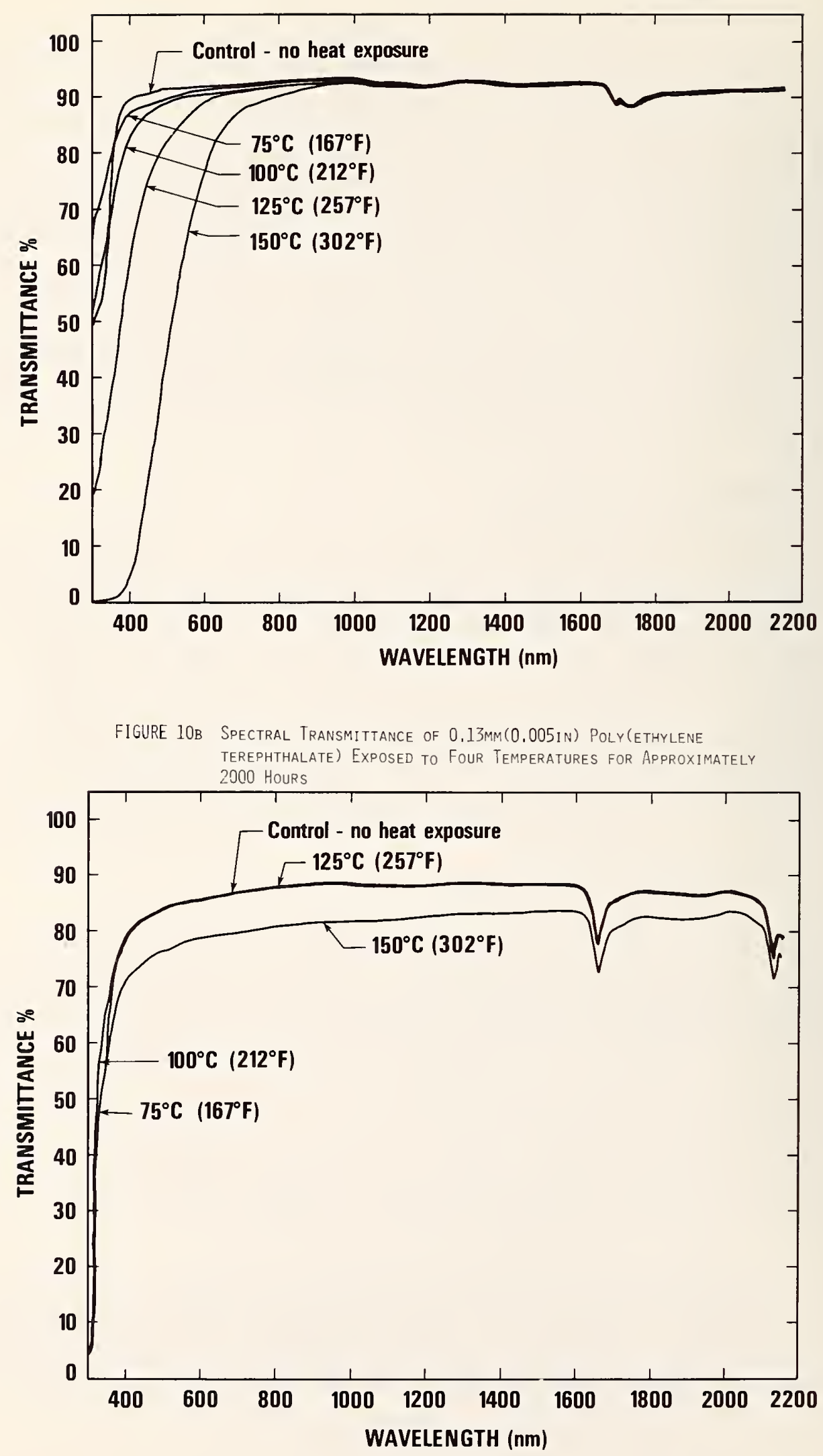
Figure 10c Spectral Transmittance of 0.076mm(0.003in) Acrylic Film

Exposed to Three Temperatures for Approximately 2000 Hours

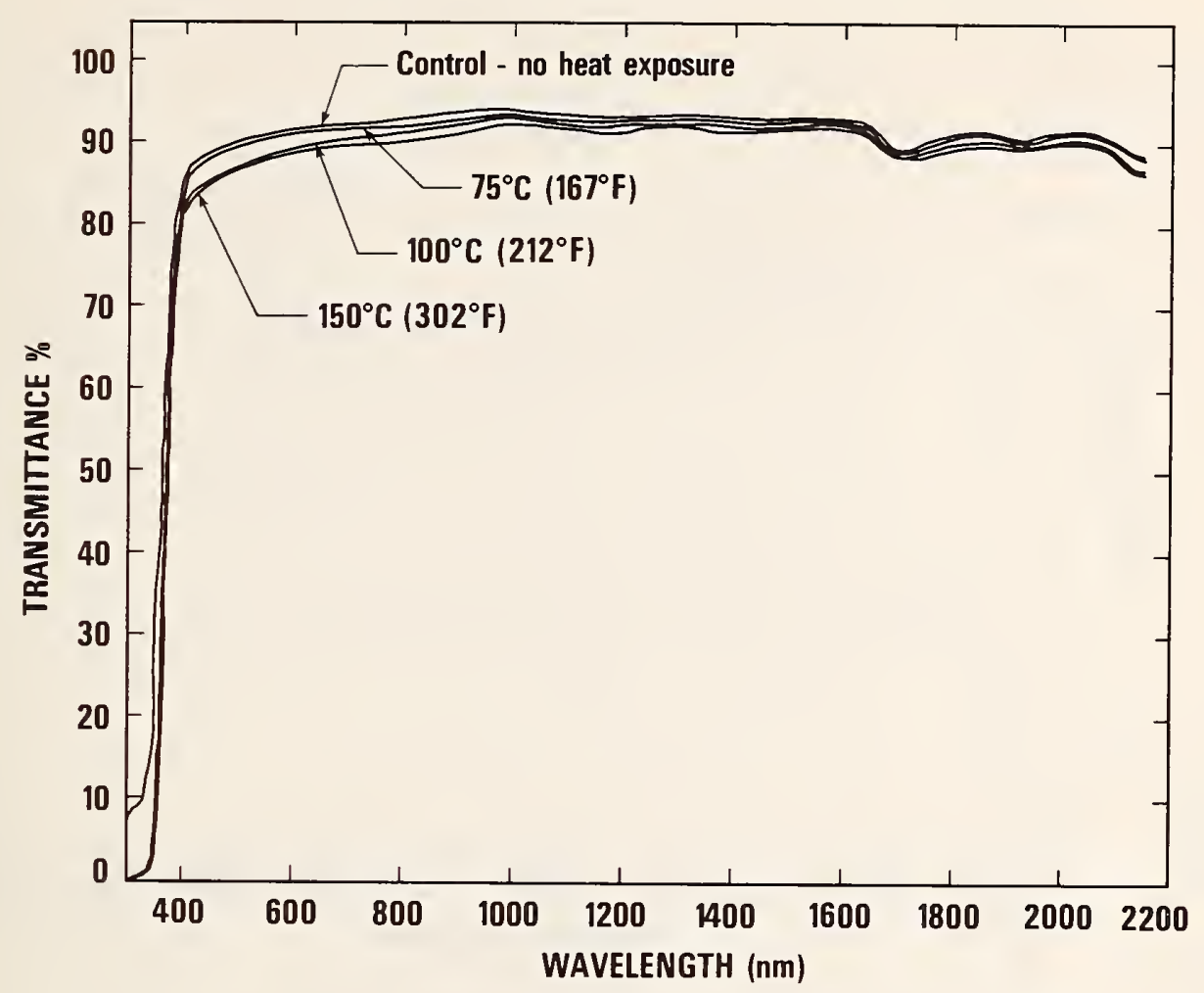

FIGURE 10d Spectral Transmittance af $1.5 \mathrm{~mm}(0.06 \mathrm{in})$ Paly (methyl methacrylate) Expased to Three Temperaturesfar Appraximately 2000 Haurs

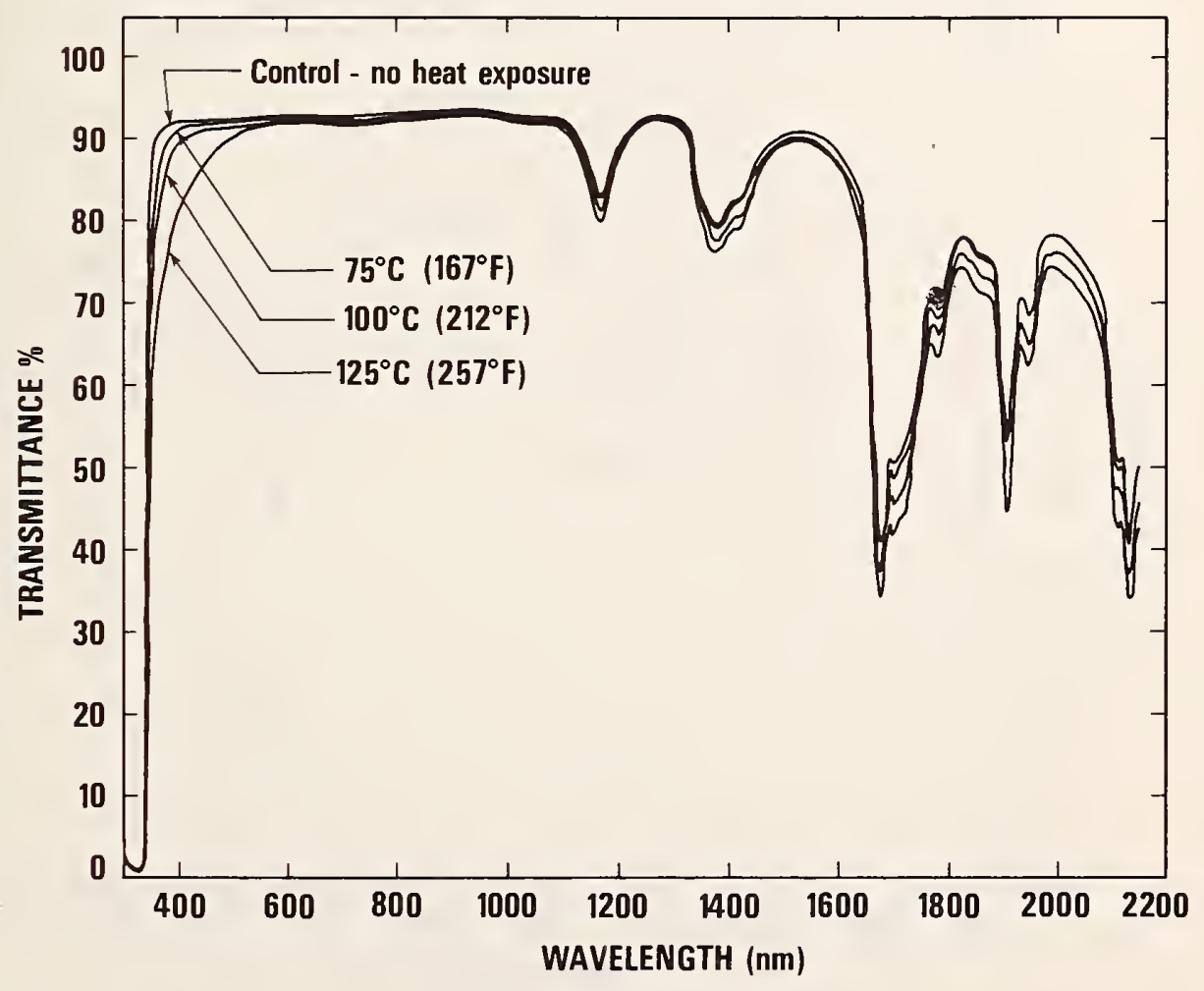


FIgure 10e Spectral Transmittance of 1. Omm(0.04in) Polycarbonate

EXPosed at TWo Temperatures for ApproXimately 2000 Hours

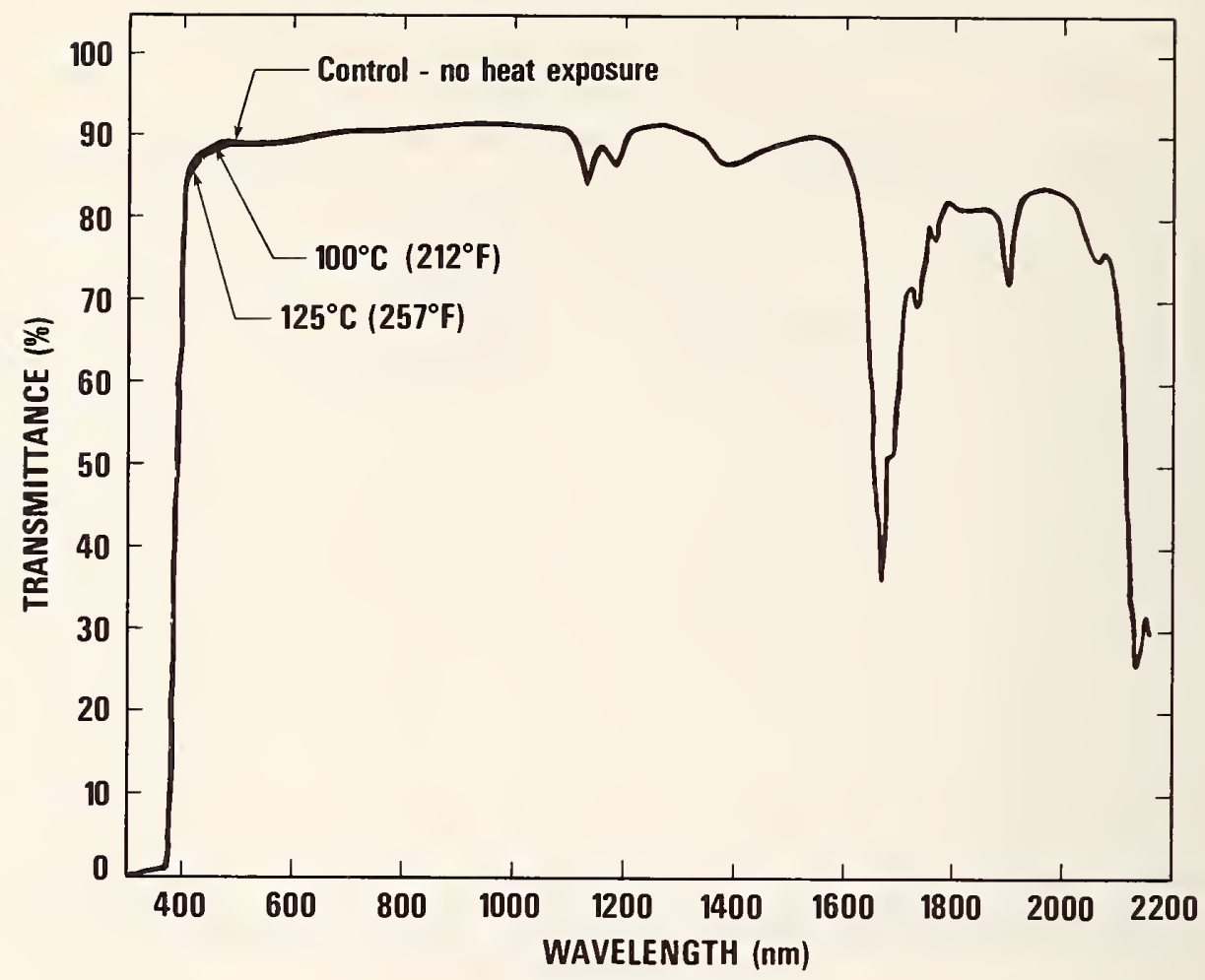

Figure 10F Spectral Transmittance 1.0mm(0.04in) Fiber Reinforced

Plastic Exposed at Four Temperatures for Approximately

2000 HOURS

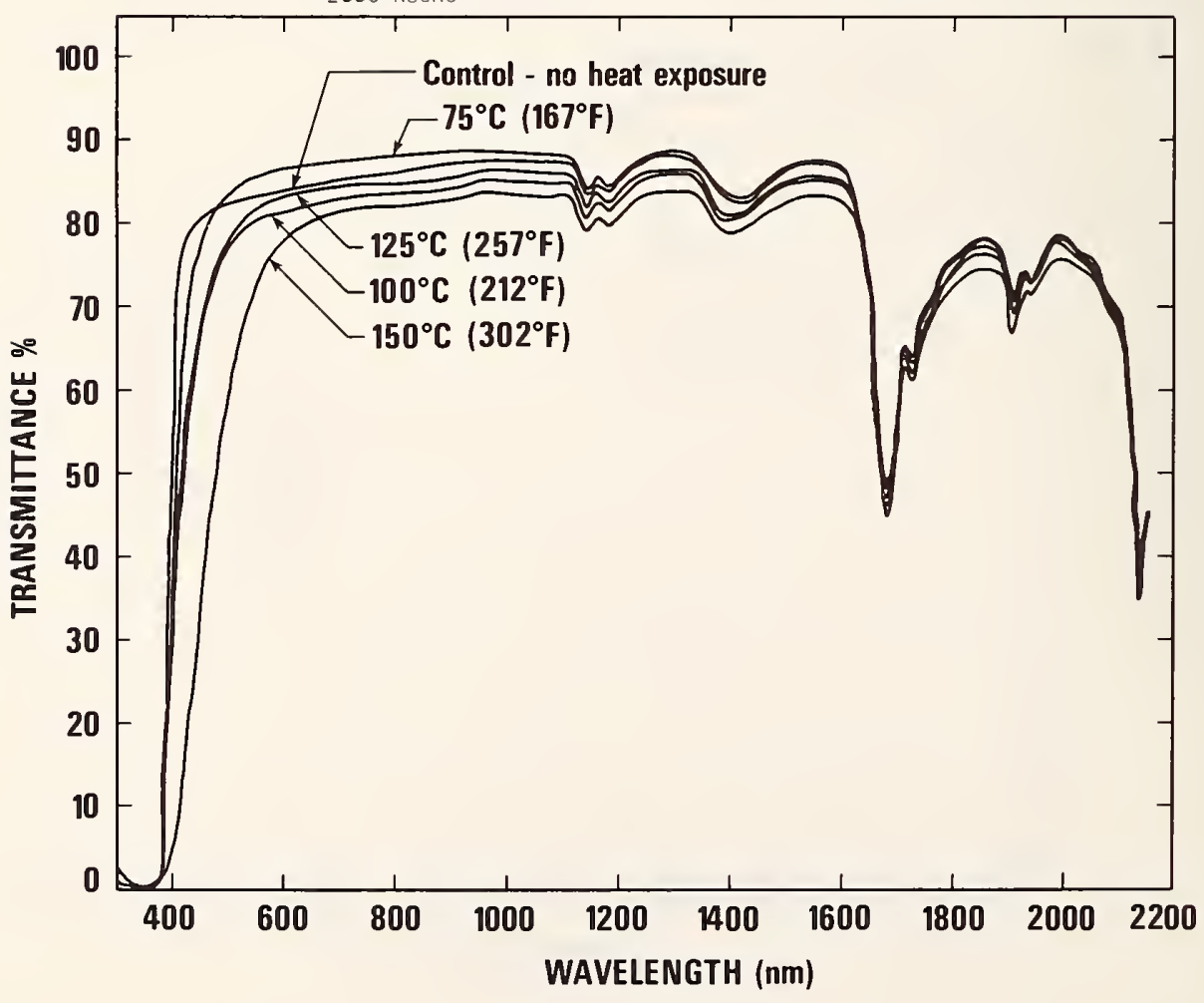


Figure 10 Spectral Transmittance of $1.5 \mathrm{~mm}(0.06$ in) Fiber Reinforced Plastic Exposed at Four Temperatures for Approximately 2000 HOURS

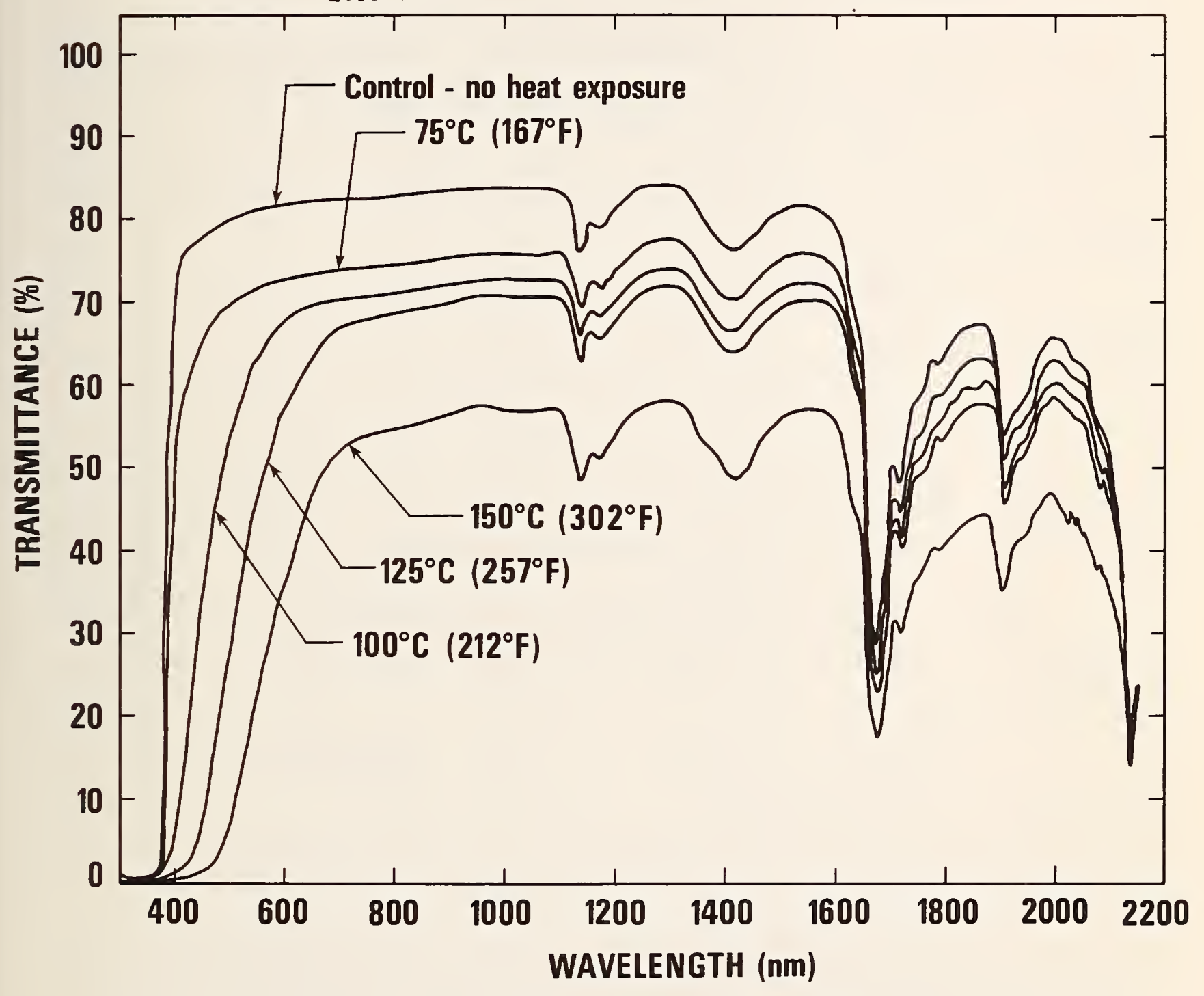


Table 8

Percent Change in Linear Dimensions of Cover Plate Materials After Heat Aging

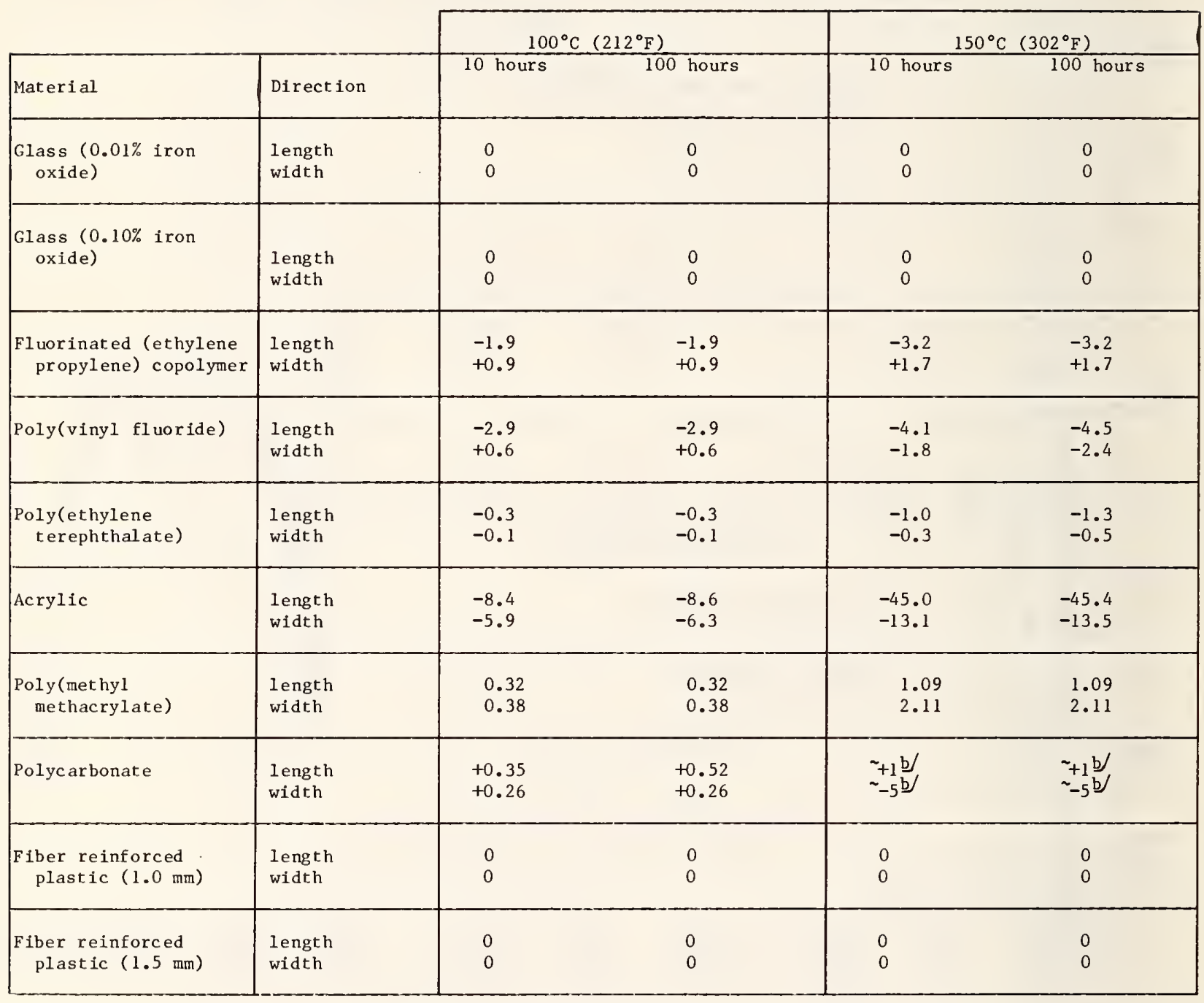

a/ The fluorinated(ethylene propylene) copolymer, poly(vinyl fluoride), poly(ethylene terephthalate) and acrylic film were measured using ASTM D 1204. The other materials were measured with ASTM D 1042. The values in the table are an average of three test specimens.

b/ Polycarbonate warped and deformed during the heat exposure. Although the test specimens were flattened for measurement, the measurements on these test specimens are approximate due to permanent deformation. 
Figure lla Linear Dimensional Changes of Fluorinated (ethylene propylene) COPOLYMER EXPOSED AT $150^{\circ} \mathrm{C}\left(302^{\circ} \mathrm{F}\right)$

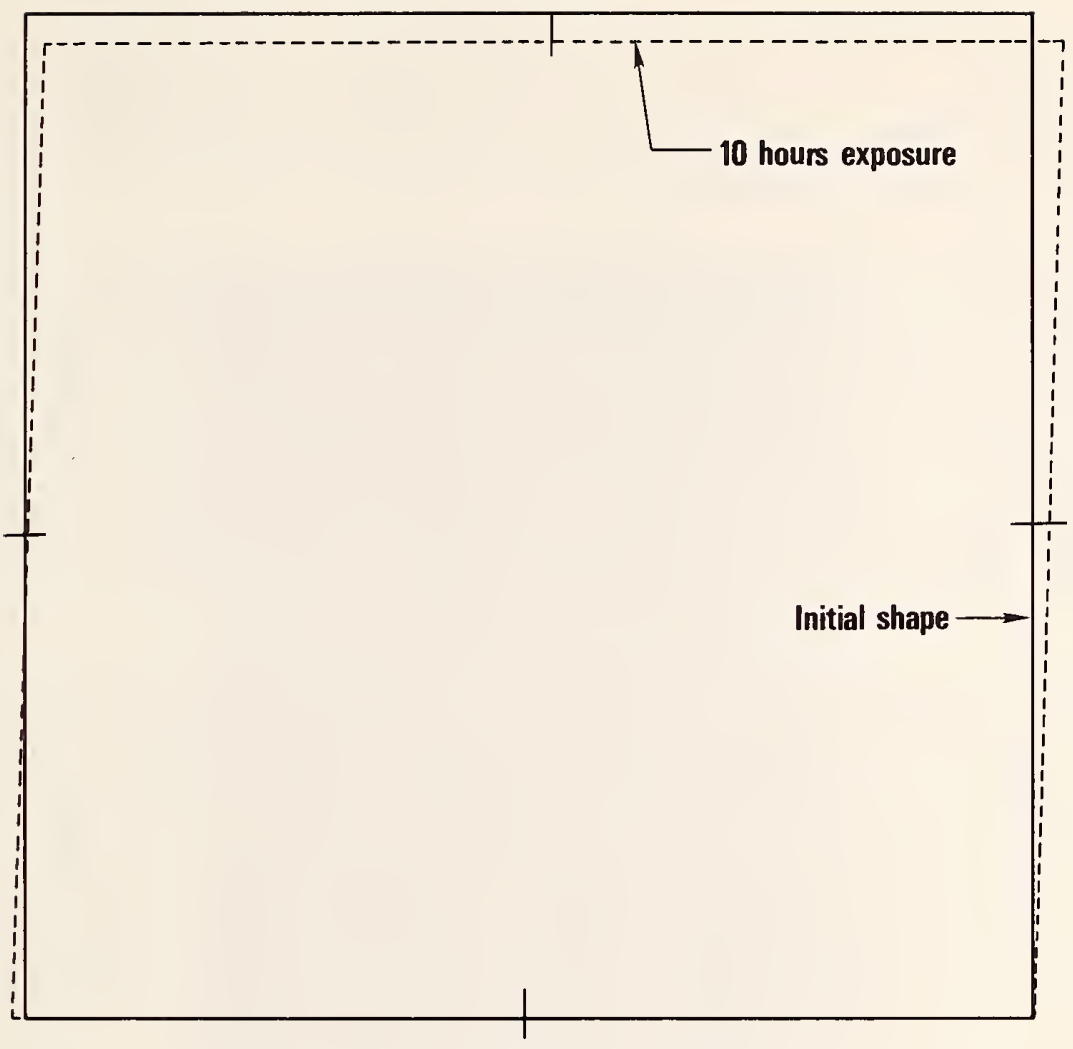

Figure 1 lib Linear Dimensional Changes of Acrylic Film Exposed at $150^{\circ} \mathrm{C}\left(302^{\circ} \mathrm{F}\right)$

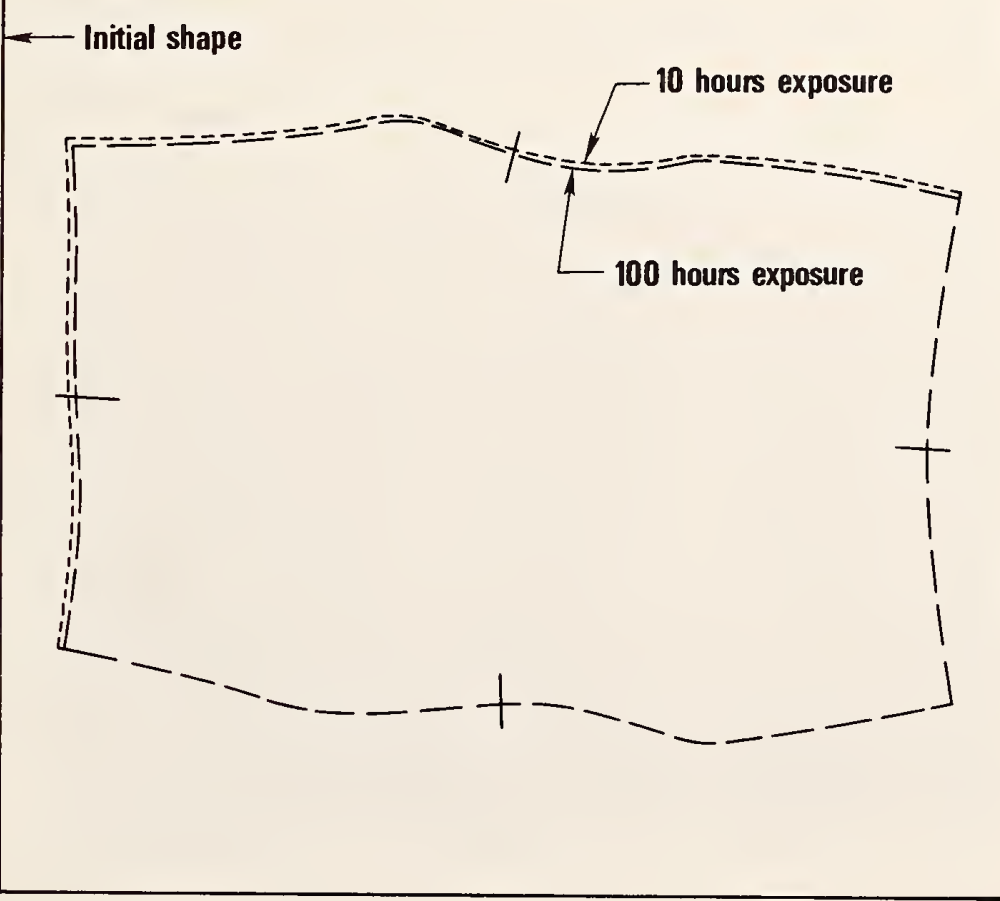


expanded 0.6 percent in the width direction, whereas, it contracted 2.4 percent at $150^{\circ} \mathrm{C}\left(302^{\circ} \mathrm{F}\right)$. The polycarbonate was similar although the contraction was greater (i.e. five percent) at $150^{\circ} \mathrm{C}$.

The acrylic film proved to be the most dimensionally unstable material. It shrank substantially in length and width at both temperatures. After 100 hours at $150^{\circ} \mathrm{C}\left(302^{\circ} \mathrm{F}\right)$ it had contracted 45.4 percent in length and 13.5 percent in width, see figure $11 \mathrm{~b}$. Similar shrinkage, although not as large, occurred at $100^{\circ} \mathrm{C}\left(212^{\circ} \mathrm{F}\right)$. The fluorinated (ethylene propylene) copolymer expanded in width while shrinking in length, but the test specimen was not rectangular after the exposure. Figure $11 \mathrm{a}$ illustrates the shape after $150^{\circ} \mathrm{C}\left(302^{\circ} \mathrm{F}\right)$ aging. The poly(ethylene terephthalate) contracted in both length and width although the shrinkage was not equal in both directions.

Although there are small differences for some materials between the 10 and 100 hour data, it appears that measurement of the linear dimensions after 10 hours exposure at a particular temperature is sufficient to establish trends and determine approximate values for a temperature. The properties of viscoelastic materials such as plastics are a function of the time at a particular temperature because of stress relaxation constants. To determine total change at a given temperature, the dimensions should be measured at increasing time intervals until no additional dimensional change is induced by continued heat exposure.

\subsubsection{Warpage}

Warpage and shape distortion were observed on test specimens from the $150^{\circ} \mathrm{C}$, $125^{\circ} \mathrm{C}$, and $100^{\circ} \mathrm{C}\left(302^{\circ} \mathrm{F}, 257^{\circ} \mathrm{F}\right.$, and $\left.212^{\circ} \mathrm{F}\right)$ heat stability exposures. Films were not evaluated in this test since a material had to be self supporting to measure warpage. Materials exhibiting warpage were poly(methyl methacrylate), polycarbonate, and $1.0 \mathrm{~mm}$ fiber reinforced plastic. The test specimens were suspended vertically during the heat stability test and constrained only by the paper clip in the center of the short edge. As a result, the materials were free to move. Table 9 provides the ranges in warpage measured after the heat aging.

The poly (methyl methacrylate) became extremely distorted during the $150^{\circ} \mathrm{C}$ $\left(302^{\circ} \mathrm{F}\right)$ heat aging and meaningful warpage measurements were not possible on these specimens. Figure $12 \mathrm{a}$ shows the appearance of some of these test specimens. At the lower heat aging temperatures the poly(methyl methacrylate) suffered some warpage, however it was not as drastic. The amount of warpage (i.e. deviation from flatness) was not directly related to exposure time. The heat aging period varied from 100 to 2000 hours. The edges of the polycarbonate test specimens curled up from the heat. The resulting warpage is illustrated in figure 12b. Apparently the elevated temperature soften the polycarbonate enough such that stresses developed during the manufacture of the sheet were relieved. As with the poly(methyl methacrylate), the amount of warpage was not directly related to the exposure time. 
Figure 12A Appearance of Poly (methyl methacrylate) after $150^{\circ} \mathrm{C}$ (302 $\mathrm{F}$ ) HeAt Aging.

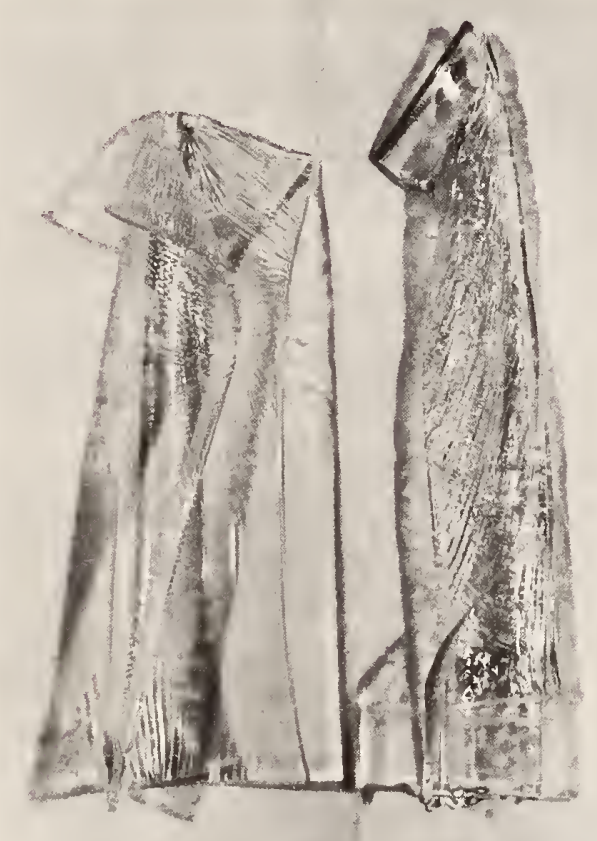

Figure $12 \mathrm{~B}$ Appearance of Polycarbonate after $150^{\circ} \mathrm{C}\left(302^{\circ} \mathrm{F}\right)$ Heat Aging.
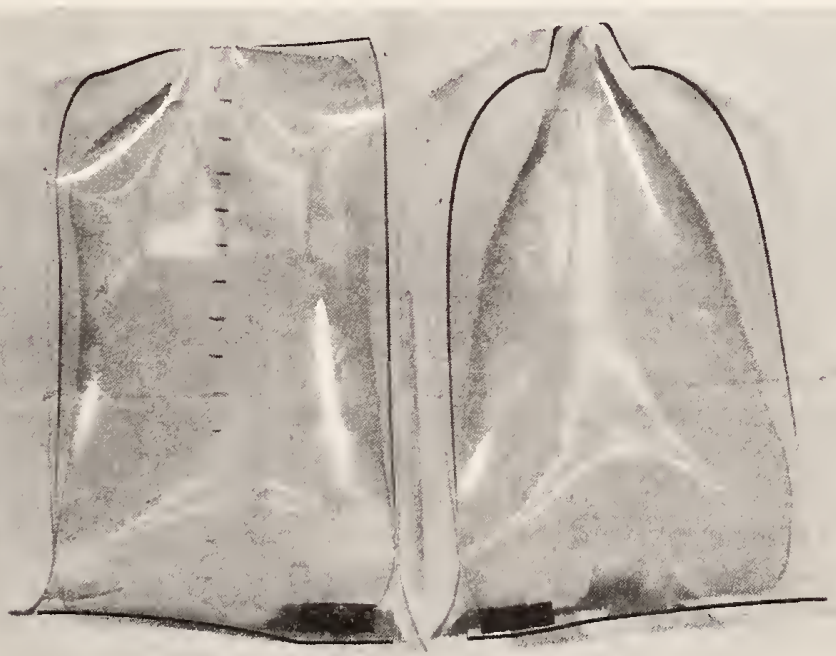
Table 9

Warpage of Test Specimens After Heat Aging

\begin{tabular}{|c|c|c|c|}
\hline Materiala/ & $150^{\circ} \mathrm{C}\left(302^{\circ} \mathrm{F}\right)$ & $125^{\circ} \mathrm{C}\left(257^{\circ} \mathrm{F}\right)$ & $100^{\circ} \mathrm{C}\left(212^{\circ} \mathrm{F}\right)$ \\
\hline poly (methy 1 methacrylate) & $\begin{array}{l}\text { too distorted to } \\
\text { measure }\end{array}$ & $\begin{array}{l}6.4-20.2 \mathrm{~mm} \\
(0.25-0.80 \mathrm{in})\end{array}$ & $\begin{array}{c}4.8-17.5 \mathrm{~cm} \\
(0.19-0.69 \mathrm{in})\end{array}$ \\
\hline $\begin{array}{l}\text { polycarbonate } \\
\text { fiber reinforced } \\
\text { plastic } 1.0 \mathrm{~mm}\end{array}$ & $\begin{array}{l}35.3-56.6 \mathrm{~mm} \\
(1.39-2.23 \mathrm{in}) \\
6.1-11.8 \mathrm{~mm} \\
(0.24-0.46 \mathrm{in})\end{array}$ & $\begin{array}{l}5.1-15.2 \mathrm{~mm} \\
(0.20-0.60 \mathrm{in}) \\
\text { slight }-8.4 \mathrm{~mm} \\
(\mathrm{~s} l i g h t-0.33 \mathrm{in}) \\
\end{array}$ & $\begin{array}{l}8.3-14.0 \mathrm{~mm} \\
(0.33-0.55 \mathrm{in}) \\
\text { slight }-8.3 \mathrm{~mm} \\
\text { (slight }-0.33 \mathrm{in}) \\
\end{array}$ \\
\hline \multicolumn{4}{|c|}{$\begin{array}{l}\text { a Test specimens were about } 115 \mathrm{~mm} \text { by } 230 \mathrm{~mm}(4.5 \text { by } 9 \mathrm{in}) \text { and were suspended verti- } \\
\text { cally from the center of the short edge during the heat aging. Aging periods } \\
\text { ranged from } 100 \text { to } 2000 \text { hours, however the amount of warpage was not directly } \\
\text { related to aging time. Measurement of the warpage is described in Section 3.3.3. }\end{array}$} \\
\hline
\end{tabular}

The $1.0 \mathrm{~mm}$ fiber reinforced plastic exhibited slight distortion after the heat aging. Although the distortion was slight (see table 9), it was observable and can account for the wavy appearance of fiber reinforced plastic glazed collectors reported by some observers.

\subsection{ARTIFICIAL WEATHERING WITH XENON ARC LIGHT}

\subsubsection{Solar Energy Transmittance}

Test specimens were exposed to the xenon arc light in an artificial weathering device for time increments ranging from 250 to 4000 hours. The solar energy transmittance of the materials after this artificial weathering is tabulated in table 10. The integrated solar energy transmittance of the materials changed little due to the exposure. Inspection of the corresponding spectral transmittance curves (e.g. figures $13 \mathrm{a} \& 13 \mathrm{~b}$ ) provided a better indication of the effect of the artificial solar radiation on the materials.

Polycarbonate had the largest solar energy transmittance loss ( 3.7 percent) after 4000 hours. The loss was primarily due to increased absorption in the ultraviolet and the visible region below $700 \mathrm{~nm}$, as shown in figure 13a. A 2.5 percent solar energy transmittance decrease for the $1.0 \mathrm{~mm}$ fiber reinforced plastic resulted from a decline in transmittance across the entire spectrum, as is illustrated in Figure $13 \mathrm{~b}$. The $1.5 \mathrm{~mm}$ fiber reinforced plastic also had transmittance variations across the entire spectrum, however, except for the 4000 hour data, the solar energy transmittance values are within the range of the variation seen in the control test specimens (table 2). As the exposure 
Table 10

Solar Energy Transmittance of Cover Plate Materials After Artificial Weathering with Xenon Arc Light

\begin{tabular}{|c|c|c|c|c|c|c|c|c|}
\hline Material Exposure Time (hours) & 0 & 250 & 500 & 750 & 1000 & 2000 & 3000 & 4000 \\
\hline Glass $(0.01 \%$ iron oxide $)$ & 90.7 & $\begin{array}{l}89.9 \\
90.1\end{array}$ & 90.0 & 90.2 & 89.2 & 89.1 & 87.6 & $\begin{array}{l}88.9 \\
87.5\end{array}$ \\
\hline Glass $(0.10 \%$ iron oxide) & 87.4 & $\begin{array}{l}87.0 \\
87.0\end{array}$ & 87.0 & 87.0 & 87.0 & 86.9 & 86.1 & $\begin{array}{l}85.9 \\
86.3\end{array}$ \\
\hline $\begin{array}{l}\text { Fluorinated (ethylene } \\
\text { propylene) copolymer }\end{array}$ & 96.0 & $\begin{array}{l}95.1 \\
95.4\end{array}$ & 95.5 & 95.4 & 95.4 & 95.0 & 95.0 & $\begin{array}{l}95.2 \\
94.8\end{array}$ \\
\hline Poly(vinyl fluoride) & 92.5 & $\begin{array}{l}91.4 \\
91.6\end{array}$ & 91.4 & 91.4 & 91.4 & 91.1 & 91.4 & $\begin{array}{l}91.5 \\
91.3\end{array}$ \\
\hline Poly(ethylene terephthalate) & 86.3 & $\begin{array}{l}85.9 \\
85.1\end{array}$ & 85.5 & 85.3 & 85.4 & 85.5 & 85.3 & $\begin{array}{l}84.9 \\
84.9\end{array}$ \\
\hline Acrylic & 90.7 & $\begin{array}{l}90.0 \\
90.0\end{array}$ & 89.9 & 90.3 & 90.1 & 90.0 & & $\begin{array}{l}89.2 \\
89.8\end{array}$ \\
\hline Poly(methyl methacrylate) & 91.0 & $\begin{array}{l}89.3 \\
89.4\end{array}$ & 89.2 & 89.1 & 88.9 & 89.2 & 88.7 & $\begin{array}{l}89.0 \\
88.9\end{array}$ \\
\hline Polycarbonate & 88.1 & $\begin{array}{l}87.8 \\
87.5\end{array}$ & 87.0 & 86.6 & 86.4 & 85.3 & 85.6 & $\begin{array}{l}84.5 \\
84.3\end{array}$ \\
\hline Fiber reinforced plastic $(1.0 \mathrm{~mm})$ & 86.3 & $\begin{array}{l}85.5 \\
85.1\end{array}$ & 86.6 & 85.5 & 86.2 & 84.7 & 85.2 & $\begin{array}{l}84.0 \\
83.6\end{array}$ \\
\hline Fiber reinforced plastic $(1.5 \mathrm{~mm})$ & 78.5 & $\begin{array}{l}79.7 \\
76.4\end{array}$ & 77.7 & 79.0 & 81.3 & 79.8 & 79.3 & $\begin{array}{l}71.6 \\
70.2\end{array}$ \\
\hline
\end{tabular}

a/ Transmittance measurements were made on a Cary I7D integrating sphere spectrophotometer according to ASTM E 424-71 Method A. The solar energy transmittance for air mass 2 at sea level was obtained by integrating over Parry Moon's standard solar energy distribution curve using weighted ordinates. The initial solar energy transmittance values listed are the average of the control test specimens. Each transmittance value for exposed materials represents a separate test specimen. Transmittance is expressed in percentage. 

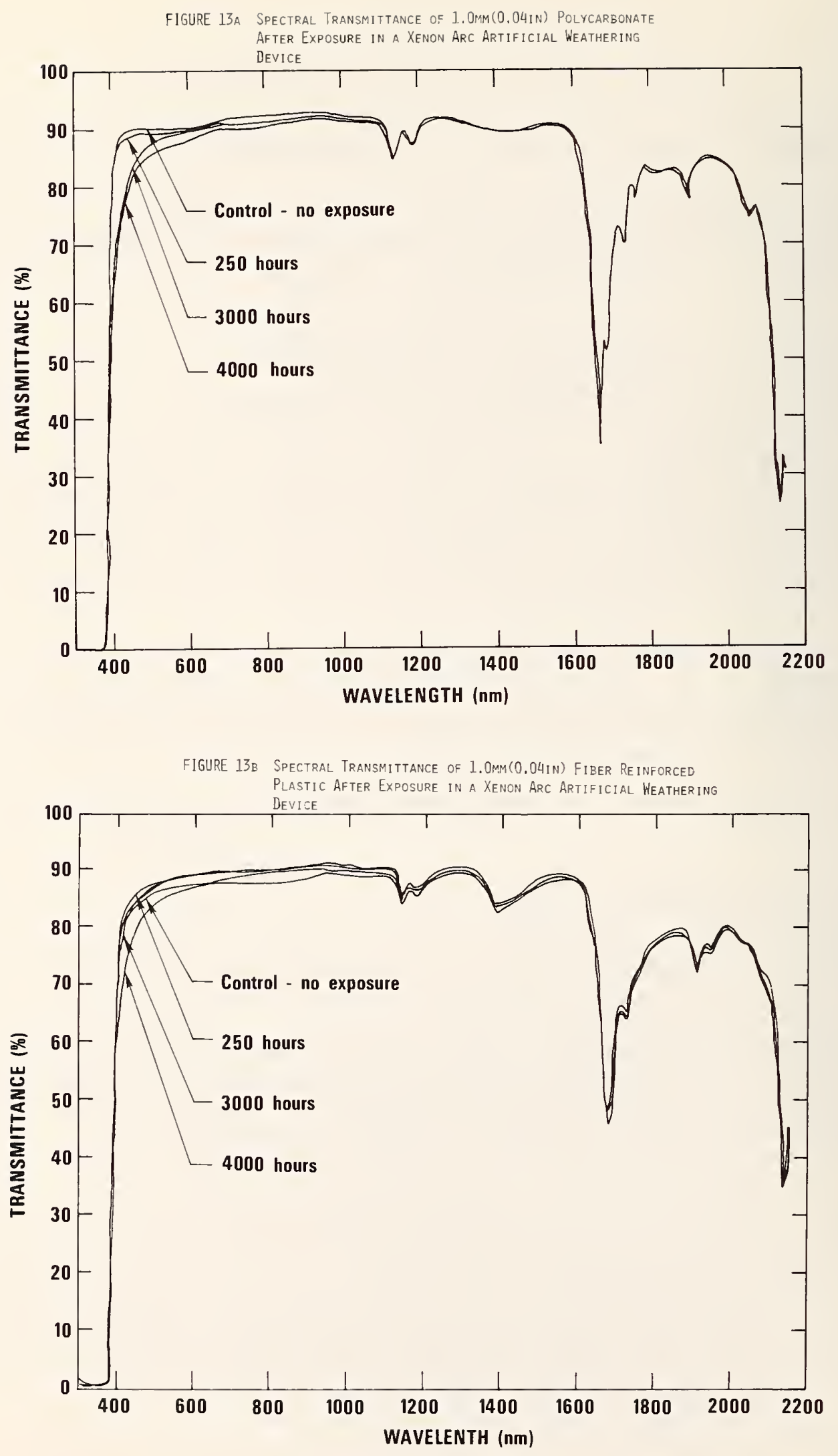


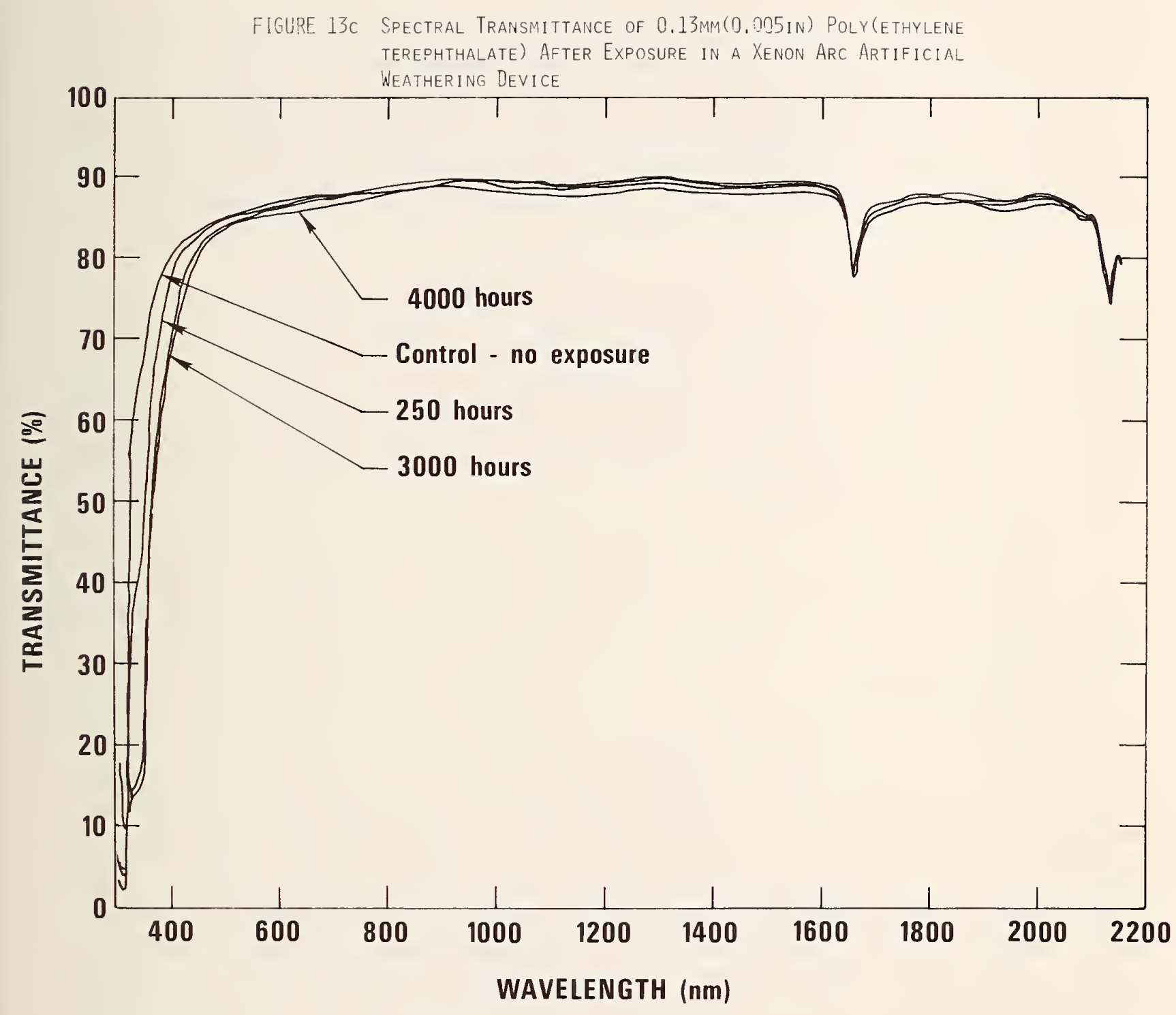


time increased, the transmittance below $500 \mathrm{~nm}$ declined. The integrated solar energy transmittance data mask the increased absorption at the ultraviolet end of the spectrum.

During the artificial weathering exposure the poly(ethylene terephthalate) suffered a small but definite decline in the transmittance below $700 \mathrm{~nm}$ and the absorption band moved toward the visible range. This change is displayed in figure 13c. For poly(methyl methacrylate) the absorption band shifted more than $50 \mathrm{~nm}$ toward the visible region in the first 250 hours; after this, decreases in transmittance were small. The acrylic film also had observable absorption increases along the absorption band in the ultraviolet-visible region.

The transmittance of the fluorinated(ethylene propylene) copolymer fell off slightly below $700 \mathrm{~nm}$ but the absorption band remained below $325 \mathrm{~nm}$. The transmittance of the poly(vinyl fluoride) dropped somewhat from 375 to $700 \mathrm{~nm}$ but increased in the region of the absorption band between 300 and $375 \mathrm{~nm}$. The glass with the 0.10 percent iron oxide content showed no significant change in the transmittance curves whereas the low iron glass had small deviations in the transmittance across the spectrum. This seemed to indicate possible variations in the glass thickness.

\subsubsection{Warpage}

No significant warpage was observed in the test specimens after artificial weathering.

\section{4 NATURAL WEATHERING}

\subsubsection{Temperatures of Minicollectors}

The temperatures of the cover plate and absorber materials were measured on one set of minicollectors exposed in Gaithersburg, Maryland. Thermocouples were installed in the center of the back of the absorber of a complete set of minicollectors. In addition, thermocouples were installed on one cover plate of the minicollectors having cover plates made of glass $(0.01$ percent iron oxide), poly(vinyl fluoride), poly(methyl methacrylate), and both fiber reinforced materials. For the double cover minicollectors this thermocouple was on the inner cover plate. The thermocouples on the cover plates were shielded from direct radiation from the sun and the absorber. The choice of the cover materials for temperature measurement was based upon optical properties, (i.e. initial solar and infrared transmittance) which affect temperature. The set of minicollectors had approximately 80 days weathering prior to the measurements. The temperatures of the materials are tabulated in table 11. The absorber temperatures range from $95-109^{\circ} \mathrm{C}\left(203-228^{\circ} \mathrm{F}\right)$ for single cover exposures and $99-117^{\circ} \mathrm{C}\left(210-243^{\circ} \mathrm{F}\right)$ for the double cover exposures. The cover plate temperatures varied from $59-63^{\circ} \mathrm{C}\left(138-145^{\circ} \mathrm{F}\right)$ for single covers and $78-85^{\circ} \mathrm{C}$ $\left(172-185^{\circ} \mathrm{F}\right)$ for the inner double cover. In comparing these temperatures to those calculated for similar cover plates on stagnating collectors (tables A6 and A7 in Appendix A), it was observed that these were lower. However, since these temperatures were measured three hours after solar noon, when the solar 


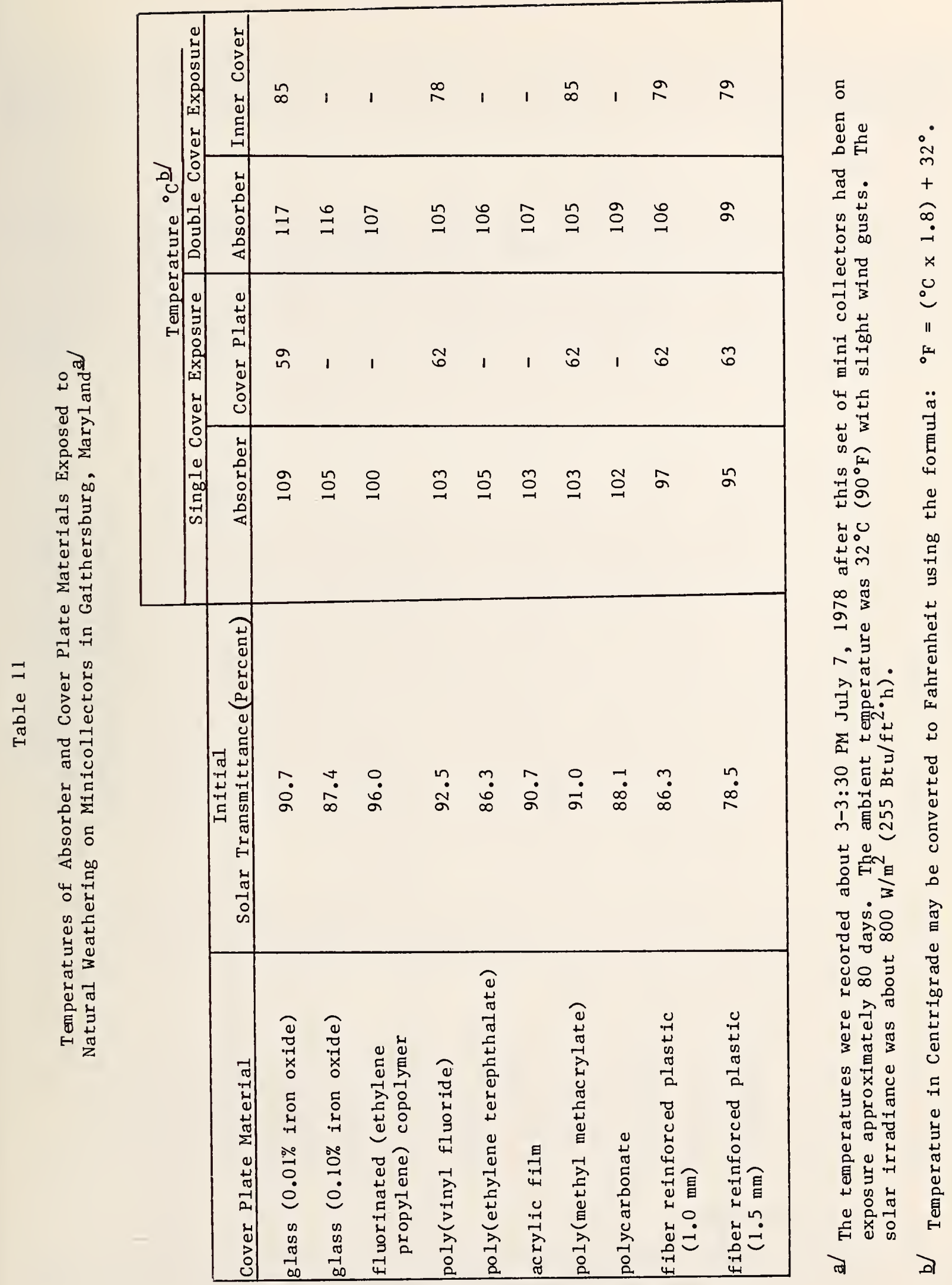


irradiance was lower than that used for the calculated temperatures, it is likely that the temperatures reached near solar noon by the materials on these minicollectors would have been in the range of stagnation temperatures in solar collectors.

\subsubsection{Cumulative Solar Radiation}

The exposure schedule and the solar radiation accumulated by the test specimens during exposure are summarized in table 12. Comparing the solar radiation accumulated at the three sites during simultaneous exposure, it is observed that the test specimens received approximately 50 percent more solar radiation at New River than at Gaithersburg, and about 25 percent more solar radiation at New River than at Miami. Similarly, the test specimens at Miami received about 20 percent more solar radiation than those at Gaithersburg.

\subsubsection{Visual Observation}

\subsubsection{Minicollector Boxes}

The minicollector boxes were examined as they were returned to the lab after the exposures. Although the boxes had been sealed prior to exposure, problems did occur. From the first set returned, it was evident that there were problems with the boxes, i.e. peeling paint, water accumulation in some boxes, swelled and cracked wood. The problems occurred at all three exposure sites and were apparently initiated by moisture intrusion into the box. Whether the initial moisture penetration occurred through the paint or through voids is uncertain; however, once the moisture began to accumulate in the box, peeling paint and swelled wood followed. Expansion and contraction of the wood caused it to crack and, in some cases, the bottom of the boxes split. Weep holes were drilled in the bottom of the boxes to prevent accumulation of water, and additional efforts were made to seal the boxes, where possible. Nevertheless, deterioration of the boxes has continued to be a problem. Wood rot has occurred on some of the boxes exposed in Miami.

It is probable that these problems could be reduced in a number of ways: 1) Extending the test specimen to the edges of the box; 2) Placing an " $L$ " shaped molding over the edge of the test specimen and sealing it to the box; 3) Using paints or sealants that are impervious to moisture; 4) Using metal or plastic for the box instead of wood.

Examination of the boxes during exposure determined that some of the test specimens, in particular poly(methyl methacrylate) and polycarbonate, partially lost adhesion to the sealant and lifted up. When this occurred, the test specimens were reattached to the boxes. The minicollectors on exposure in Gaithersburg are pictured in figure 14. For many of the minicollectors it is evident that there is moisture on the interior of the cover plates.

\subsubsection{Test Specimens}

The test specimens were examined prior to removal from the minicollector boxes. Some of each type of glass test specimen had broken during the exposure. This 


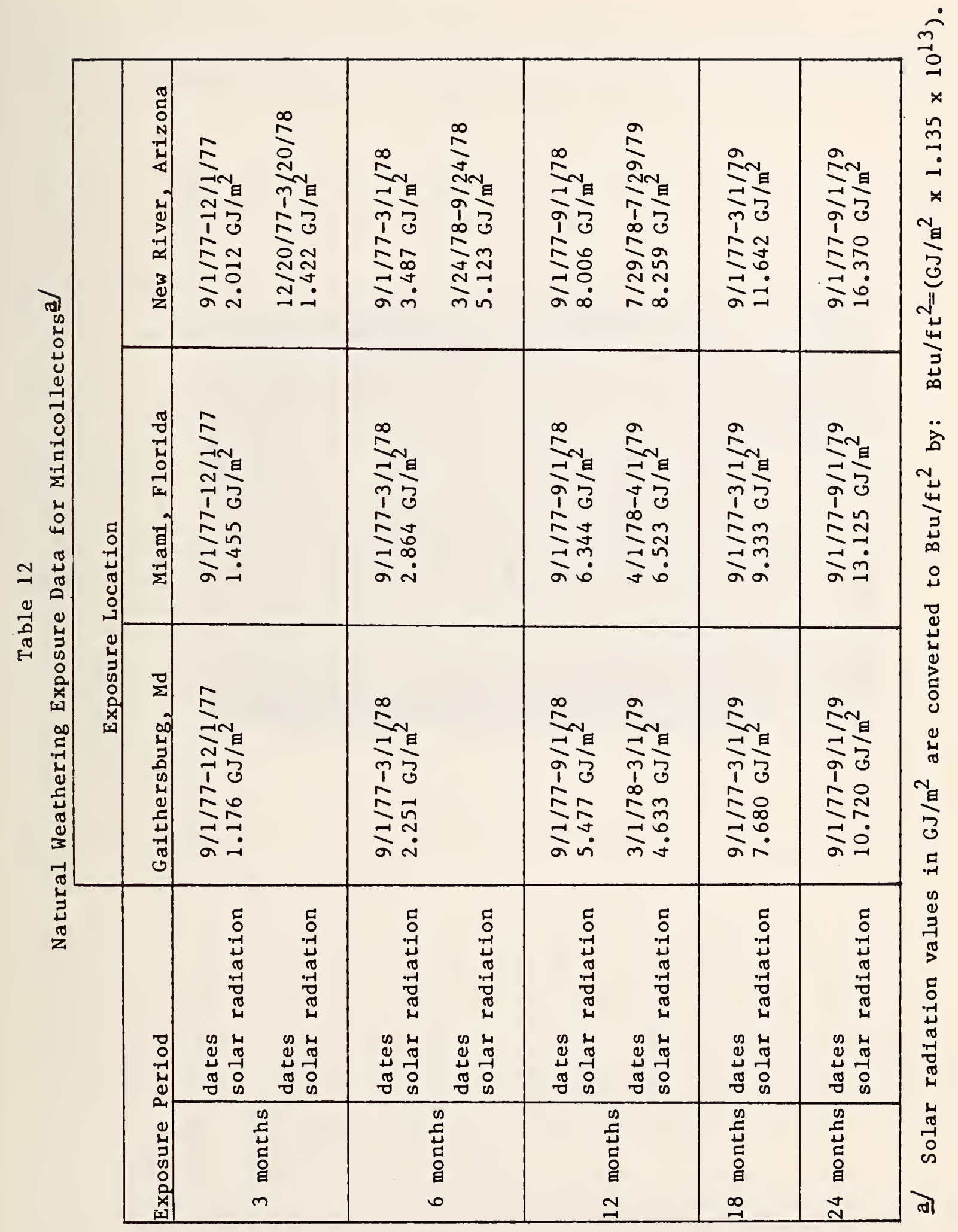


Figure 14 Minicollectors exposed in Gaithersburg, Maryland.

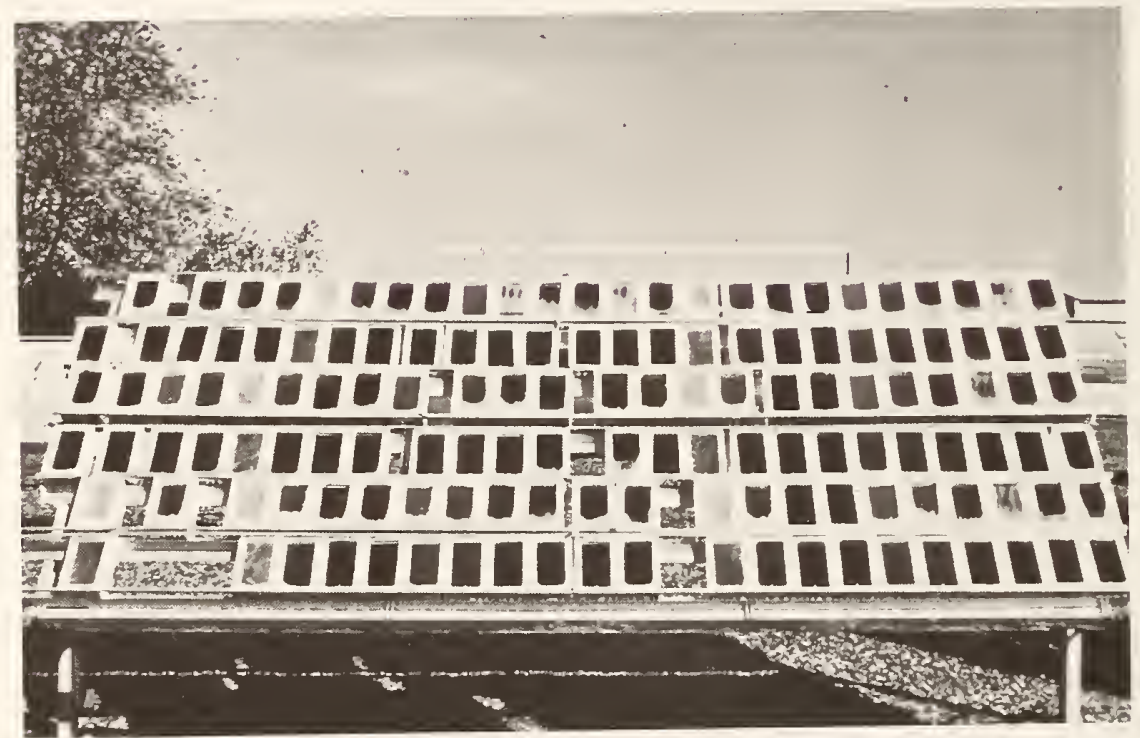


breakage was apparently due to the manner in which the boxes were held on the exposure rack. It was not due to impact. One test specimen did crack during a hail storm in Arizona. Both types of glass were annealed. The test specimens had been cut from large sheets and the edges had not been treated to reduce the stress levels. It is doubtful cracking would have occurred with tempered glass.

With the fluorinated (ethylene propylene) copolymer, there was little change in appearance other than an accumulation of dirt. However, several of the double cover minicollectors (some from Miami and some from Gaithersburg) developed small holes $20-40 \mathrm{~mm}(0.75-1.5 \mathrm{in})$ from the edge. The holes were reported to be caused by birds pecking at the cover plates. The minicollectors in Arizona suffered damage due to a hail storm during the 29 th month of exposure. Damage ranged from dents to holes of $13-20 \mathrm{~mm}(0.5-0.75 \mathrm{in})$ diameter.

The poly(vinyl fluoride) became extremely taut across the boxes, apparently caused by shrinkage of the material The test specimens gradually yellowed as the exposure continued. In addition, the inner cover of the double cover minicollectors exposed for 18 and 24 months in Arizona and for 24 months in Florida became so brittle that they ruptured in place. Figure 15 shows the appearance of one of these minicollectors. The behavior of this material is similar to the deterioration of poly(vinyl fluoride) cover materials exposed on stagnating collectors near Denver, Colorado [3]. One of the four minicollectors in Arizona at 29 months exposure developed dents, but not holes, during a hail storm.

The poly(ethylene terephthalate) outer covers exposed for one year and longer in Miami developed a white, opaque appearance. Although the material was transparent prior to exposure, it became a milky white. Closer examination of the test specimens found that the white material was present only on the exterior surface. Apparently the environmental factors in Miami, e.g. more moisture and an industrial atmosphere, caused changes in the surface of the poly (ethylene terephthalate) exposed directly to the weather. The white material was not present on the interior side of the outer cover nor on the inner cover. Examination of outer surface with a scanning electron microscope indicated minute cracking on the surface.

The poly(ethylene terephthalate) test specimens from Arizona were damaged apparently by a hailstorm during the 17th month of exposure (see figure 1). All of the outer double cover and single cover poly(ethylene terephthalate) test specimens on exposure at that time had holes and cracks in them. The material had become extremely brittle. The inner cover remained intact. All but one of the minicollectors with poly(ethylene terephthalate) from Arizona were terminated after 18 months due to this damage. The remaining minicollector suffered similar serious damage in a hail storm during the 29 th month of exposure. None of the other cover plate materials were damaged by the hailstorm during the 17 th month of exposure.

The acrylic film was the first material to physically deteriorate during the exposure. It cracked and broke into pieces at all three exposure sites. The material failed most rapidly in Arizona, followed by Florida and Maryland. 
Figure 15 A Double Cover Minicollector with Poly (vinyl fluoride) Covers after 18 Months Exposure at New River, Arizona,

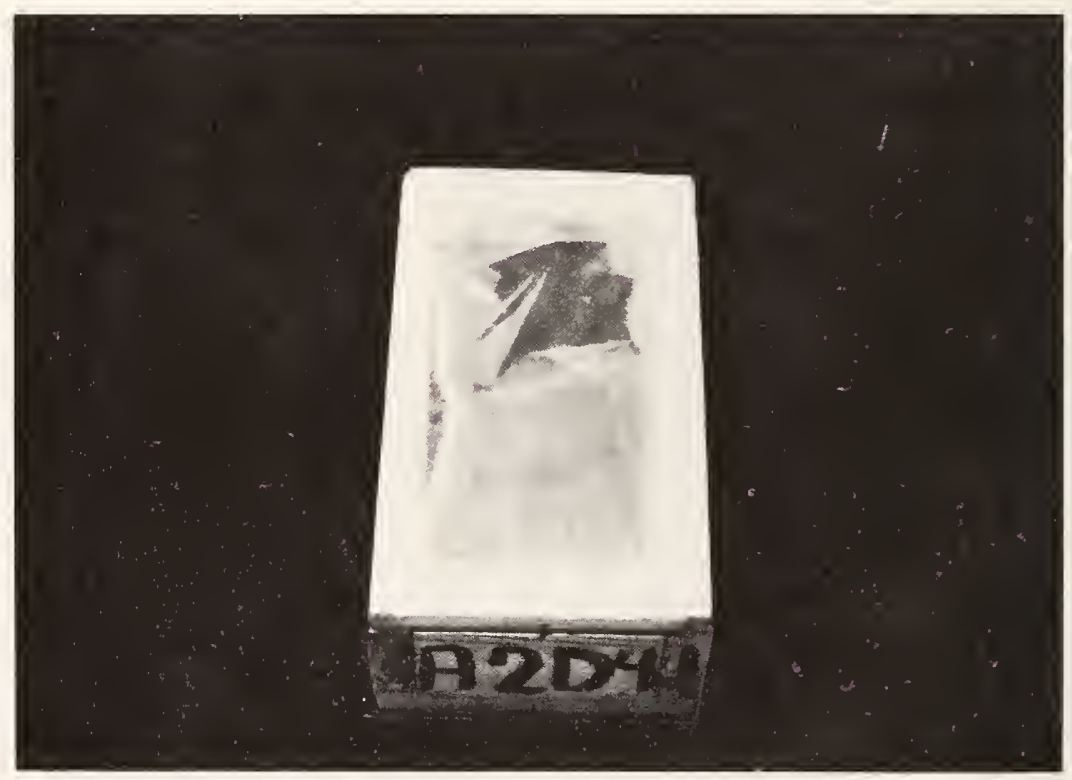

THE INNER COVER HAS RUPTURED, 
The outer cover test specimen deteriorated more rapidly than the inner one. After 18 months exposure in Arizona and Florida, the outer covers had completely disintegrated and blown away. The inner cover and single cover test specimens exhibited somewhat less damage. All minicollectors with the acrylic film have been terminated due to material failure.

The poly(methyl methacrylate) appeared to be somewhat less dirty than most of the rest of the materials after 24 months. On the minicollectors from Arizona, the inner cover sagged in the center, apparently due to the elevated temperature.

The polycarbonate material visibly yellowed as it was exposed. In addition, the test specimens exposed in Florida developed deposits on the outer surface. The deposits were not washed off during the cleaning and were apparently due to the industrial atmosphere near the exposure site.

Both of the fiber reinforced materials yellowed during the outdoor exposure, with the $1.5 \mathrm{~mm}$ FRP changing the most. The resin of this material also progressively developed a whitish appearance when weathered in Florida. This change may be attributed to either moisture or the industrial atmosphere. After 24 months exposure the $1.5 \mathrm{~mm}$ fiber reinforced material also exhibited a significant amount of "fiber bloom" on the outer covers while the $1.0 \mathrm{~mm} \mathrm{fiber}$ reinforced material showed a small amount. "Fiber bloom" occurs when fibers break away from the resin and protrude from the surface. The "fiber bloom" occurred most on the test specimens from Arizona.

\subsubsection{Solar Energy Transmittance}

\subsubsection{Gaithersburg, Mary land Exposures}

The solar energy transmittance after the natural weathering in Gaithersburg is tabulated in table 13 for the single cover test specimens and table 14 for the double cover test specimens. In all cases, the solar energy transmittance declined; however the loss varied among the materials. The solar transmittance loss had two causes: 1) material deterioration due to weathering, and 2) dirt accumulation on the cover plate. The combined solar energy transmittance loss due to both weather and dirt can be determined by comparison of the average value for the controls with the data in tables 13 and 14 . Differentration between the causes was accomplished by measurement of the transmittance before and after washing the materials. The spectral transmittance of a control and a test specimen before and after washing are given in figure 16 to illustrate these differences. The solar energy transmittance loss due to weathering was determined by comparison of the average solar energy transmittance of the controls with the value of the washed test specimen. The solar energy transmittance loss due to dirt was obtained by comparing the values obtained before and after washing.

The solar energy transmittance losses due to weathering in Gaithersburg are tabulated in tables 15 and 16. The transmittance losses for the single covers and outer double covers followed the same general trend for all the materials. However, for the inner double covers the losses were much lower for all 
Table 13

Solar Energy Transmittance of Cover Plate Materials Exposed as Single Covers to Natural Weathering in Gaithersburg, Maryland

\begin{tabular}{|c|c|c|c|c|c|c|c|}
\hline Exposure Period (months) & 0 & 3 & 6 & 12 b/ & $12^{\mathrm{b} /}$ & 18 & 24 \\
\hline Material $>$ Solar Radiation $\left(\mathrm{GJ} / \mathrm{m}^{2}\right) \mathrm{c}$ & 0 & 1.176 & 2.251 & 4.633 & 5.477 & 7.680 & 10.720 \\
\hline glass $(0.01 \%$ iron oxide) & 90.7 & 90.4 & 90.5 & 87.7 & 85.5 & 86.2 & 84.0 \\
\hline glass $(0.10 \%$ iron oxide) & 87.4 & 86.1 & 85.3 & 81.6 & 82.9 & 84.4 & 81.2 \\
\hline $\begin{array}{c}\text { fluorinated (ethylene propylene) } \\
\text { copolymer }\end{array}$ & 96.0 & 92.0 & 93.8 & 83.3 & 84.8 & 84.0 & 86.0 \\
\hline poly(vinyl fluoride) & 92.5 & 89.5 & 86.9 & 80.8 & 86.1 & 87.3 & 85.8 \\
\hline poly (ethylene terephthalate) & 86.3 & 84.7 & 82.7 & 75.8 & 80.9 & 80.4 & 75.3 \\
\hline acrylic & 90.7 & 87.7 & 85.7 & 79.0 & 83.2 & d] & d/ \\
\hline poly(methyl methacrylate) & 91.0 & 88.1 & 86.5 & 80.4 & 85.4 & 84.9 & 81.9 \\
\hline polycarbonate & 88.1 & 87.3 & $=$ & 78.3 & 83.0 & 80.3 & 78.5 \\
\hline fiber reinforced plastic $1.0 \mathrm{~mm}$ & 86.3 & 85.1 & 82.3 & 74.7 & 80.0 & 80.0 & 77.4 \\
\hline fiber reinforced plastic $1.5 \mathrm{~mm}$ & 78.5 & 75.0 & 69.9 & 66.2 & 64.9 & 70.8 & 65.6 \\
\hline
\end{tabular}

a/ Materials were exposed on minicollectors. Transmittance measurements were made on a Cary 17D integrating sphere spectrophotometer according to ASTM E 424-71, Method A. The solar energy transmittance for air mass 2 at sea level was obtained by integrating over Parry Moon's standard solar energy distribution curve using weighted ordinates. Transmittance was measured after exposure but before washing. Each transmittance value represents a separate test specimen. Average solar transmittance of the control test specimens is given for comparison. Transmittance is expressed in percentage.

b/ Two sets of minicollectors were exposed for the same length of time but different dates.

c/ Solar radiation values in $\mathrm{GJ} / \mathrm{m}^{2}$ are converted to $\mathrm{Btu} / \mathrm{ft}^{2}$ by: $\mathrm{Btu} / \mathrm{ft}^{2}=\left(\mathrm{GJ} / \mathrm{m}^{2} \mathrm{x} 1.135 \mathrm{x} 10^{13}\right)$.

d Material failed prior to this time. 
Table 14

Solar Energy Transmittance of Cover Plate Materials Exposed as, Double Covers to Natural Weathering in Gaithersburg, Maryland

\begin{tabular}{|c|c|c|c|c|c|c|c|}
\hline \multirow[b]{2}{*}{ Exposure Period (months) } & \multicolumn{7}{|c|}{ Outer Cover } \\
\hline & 0 & 3 & 6 & $12 \mathrm{~b} /$ & $12 \mathrm{~b}$ & 18 & 24 \\
\hline Material $>$ Solar Radiation $\left(\mathrm{GJ} / \mathrm{m}^{2}\right) \mathrm{c}$ & 0 & 1.176 & 2.251 & 4.633 & 5.477 & 7.680 & 10.720 \\
\hline glass $(0.01 \%$ iron oxide) & 90.7 & 89.3 & 88.3 & 82.3 & 88.8 & 87.9 & 85.2 \\
\hline glass $(0.10 \%$ iron oxide) & 87.4 & 86.6 & 85.4 & 79.2 & 84.2 & 86.1 & 83.1 \\
\hline $\begin{array}{r}\text { fluorinated(ethylene propylene) } \\
\text { copolymer }\end{array}$ & 96.0 & 94.5 & 92.4 & 82.3 & 86.7 & 86.9 & 84.7 \\
\hline poly(vinyl fluoride) & 92.5 & 89.6 & 83.3 & 82.2 & 86.0 & 88.7 & 83.6 \\
\hline poly(ethylene terephthalate) & 86.3 & 84.8 & 80.1 & 79.7 & 81.4 & 82.0 & 74.1 \\
\hline acrylic & 90.7 & 88.1 & 84.2 & 82.9 & 84.5 & 83.5 & d/ \\
\hline poly(methyl methacrylate) & 91.0 & 88.6 & 86.3 & 81.9 & 86.3 & 86.0 & - \\
\hline polycarbonate & 88.1 & 86.6 & 85.0 & 81.1 & 82.0 & 81.3 & 77.1 \\
\hline fiber reinforced plastic $1.0 \mathrm{~mm}$ & 86.3 & 84.4 & 81.6 & 76.6 & 80.9 & 79.0 & 77.8 \\
\hline fiber reinforced plastic $1.5 \mathrm{~mm}$ & 78.5 & 71.5 & 76.6 & 71.1 & 71.9 & 65.5 & 67.3 \\
\hline
\end{tabular}

\begin{tabular}{|c|c|c|c|c|c|c|c|}
\hline & \multicolumn{7}{|c|}{ Inner Cover } \\
\hline Exposure Period (months) & 0 & 3 & 6 & $12 \mathrm{~b} /$ & $12 \underline{b} /$ & 18 & 24 \\
\hline Material $\triangle$ Solar Radiation $\left(\mathrm{GJ} / \mathrm{m}^{2}\right) \mathrm{c}$ & 0 & 1.176 & 2.251 & 4.633 & 5.477 & 7.680 & 10.720 \\
\hline glass $(0.01 \%$ iron oxide) & 90.7 & 89.3 & - & 89.3 & 91.8 & 90.1 & 89.8 \\
\hline glass $(0.10 \%$ iron oxide) & 87.4 & 87.0 & - & 86.5 & 86.3 & 86.8 & 85.7 \\
\hline $\begin{array}{c}\text { fluorinated(ethylene propylene) } \\
\text { copolymer }\end{array}$ & 96.0 & 95.5 & 94.9 & 95.2 & 95.5 & 95.1 & 94.4 \\
\hline poly(vinyl fluoride) & 92.5 & 90.6 & 89.7 & 91.5 & 91.5 & 91.9 & 91.7 \\
\hline poly (ethylene terephthalate) & 86.3 & 85.7 & 85.5 & 84.6 & 85.3 & 85.1 & 85.5 \\
\hline acrylic & 90.7 & 90.0 & 89.2 & 89.6 & 89.9 & 89.6 & d/ \\
\hline poly(methyl methacrylate) & 91.0 & 90.2 & 89.6 & 90.1 & 89.8 & 91.1 & - \\
\hline polycarbonate & 88.1 & 88.0 & 86.9 & 87.1 & 87.4 & 87.6 & 87.3 \\
\hline fiber reinforced plastic $1.0 \mathrm{~mm}$ & 86.3 & 86.0 & 84.7 & 81.0 & 82.8 & 84.8 & 84.5 \\
\hline fiber reinforced plastic $1.5 \mathrm{~mm}$ & 78.5 & 75.0 & 67.8 & 67.0 & 70.4 & 67.1 & 62.8 \\
\hline
\end{tabular}

a/ Materials were exposed on minicollectors. Transmittance was measured after exposure but before washing. Transmittance measurements were made on a Cary 17D integrating sphere spectrophotometer according to ASTM E 424-71, Method A. The solar energy transmittance for air mass 2 at sea level was obtained by integrating over Parry Moon's standard solar energy distribution curve using weighted ordinates. Each transmittance value represents a separate test specimen. Average solar transmittance of the control test specimens is given for comparison. Both the inner and outer covers on each minicollector were the same material. Transmittance is expressed in percentage.

b/ Two sets of minicollectors were exposed for the same length of time but different dates.

cJ Solar radiation values in $\mathrm{GJ} / \mathrm{m}^{2}$ are converted to $\mathrm{Btu} / \mathrm{ft}^{2}$ by: $\mathrm{Btu} / \mathrm{ft}^{2}=\left(\mathrm{GJ} / \mathrm{m}^{2} \times 1.135 \times 10^{13}\right)$. d) Material failed prior to this time. 


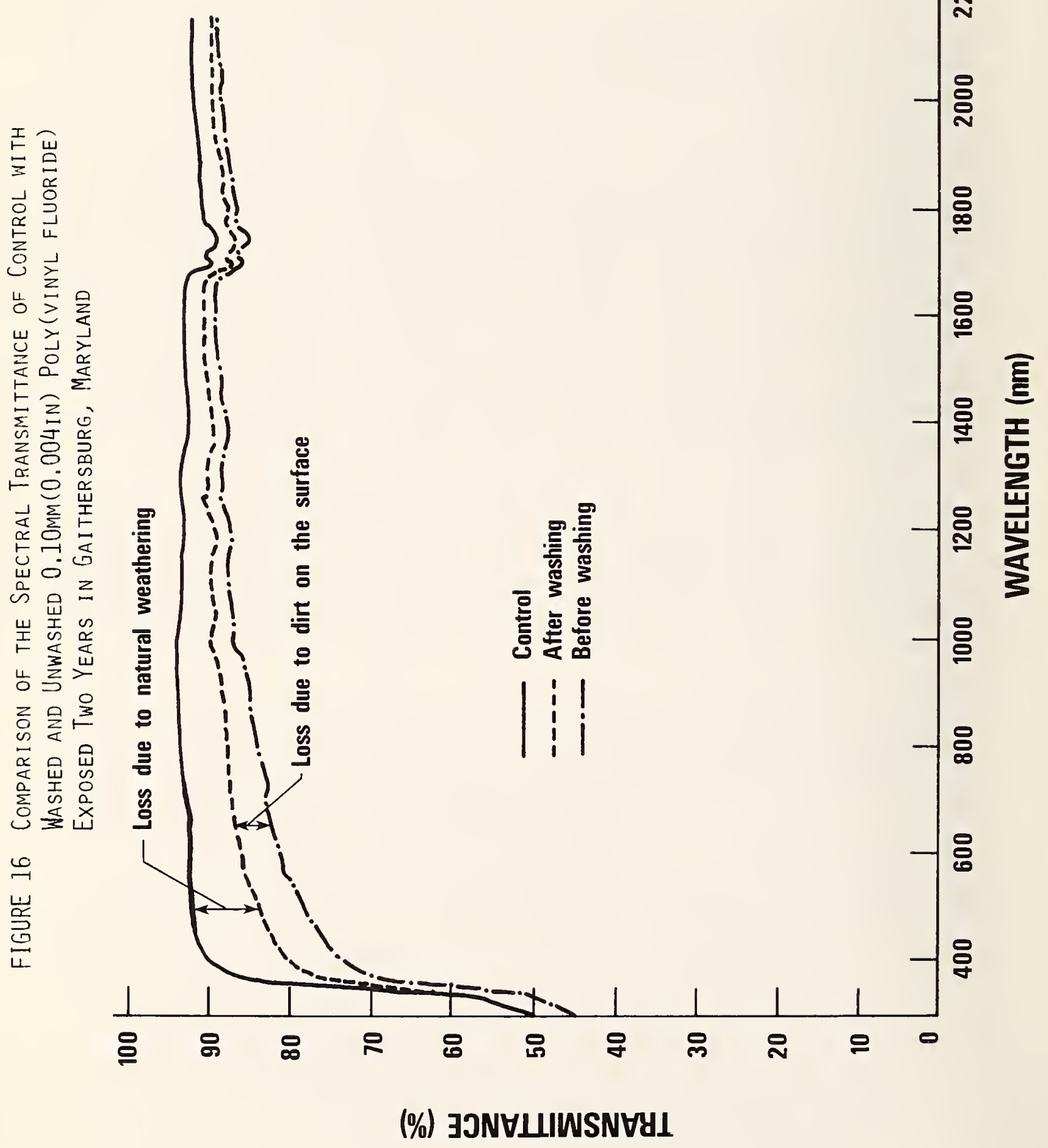


Table 15

Solar Energy Transmittance Loss of Cover Plate Materials Exposed as Single Covers to Natural Weathering in Gaithersburg, Maryland

\begin{tabular}{|c|c|c|c|c|c|c|}
\hline Exposure Period (months) & 3 & 6 & 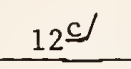 & $12 \stackrel{\mathfrak{c} J}{ }$ & 18 & 24 \\
\hline Material Solar Radiation $\left(\mathrm{GJ} / \mathrm{m}^{2}\right)$ d/ & 1.176 & 2.251 & 4.663 & 5.477 & 7.680 & 10.720 \\
\hline glass $(0.01 \%$ iron oxide) & 1.6 & 0.6 & -0.6 & 0.5 & -0.4 & 2.6 \\
\hline glass (0.10\% iron oxide) & -0.8 & 0.6 & -0.1 & -0.4 & 0.3 & 1.5 \\
\hline $\begin{array}{c}\text { fluorinated (ethylene propylene) } \\
\text { copolymer }\end{array}$ & -0.3 & 0.8 & 0.4 & 0 & 2.6 & 2.4 \\
\hline poly(vinyl fluoride) & 3.0 & 3.0 & 5.2 & 0.6 & 3.3 & 4.9 \\
\hline poly(ethylene terephthalate) & 1.1 & 3.3 & 3.5 & 0.6 & 1.7 & 9.7 \\
\hline acrylic & 0.6 & 3.4 & 4.7 & 3.4 & e/ & e/ \\
\hline poly(methy1 methacrylate) & 1.5 & 1.9 & 1.8 & 1.7 & 2.9 & 5.2 \\
\hline polycarbonate & -0.1 & - & 1.1 & 0.9 & 2.5 & 6.5 \\
\hline fiber reinforced plastic $1.0 \mathrm{~mm}$ & 0.6 & 2.1 & 1.8 & 1.9 & 3.8 & 6.0 \\
\hline fiber reinforced plastic $1.5 \mathrm{~mm}$ & 3.5 & 6.6 & 1.9 & 9.0 & 4.0 & 12.9 \\
\hline
\end{tabular}

a) Materials were exposed on minicollectors. Transmittance measurements were made on a Cary 17D integrating sphere spectrophotometer according to ASTM E 424-71, Method A. The solar energy transmittance for air mass 2 at sea level was obtained by integrating over Parry Moon's standard solar energy distribution curve using weighted ordinates. Each transmittance value represents a separate test specimen. Transmittance is expressed in percentage.

b/ The solar energy transmittance loss is the difference between the average for the control test specimens (Table 11) and the values obtained after the test specimen was washed. Negative values represent a gain in comparison with the average for the controls. This solar energy transmittance loss does not include the loss due to dirt on the surface. Losses due to dirt are tabulated in Table 17.

c) Two sets of minicollectors were exposed for the same length of time but different dates.

d Solar radiation values in $\mathrm{GJ} / \mathrm{m}^{2}$ are converted to $\mathrm{Btu} / \mathrm{ft}^{2}$ by: $\mathrm{Btu} / \mathrm{ft}^{2}=$ $\left(\mathrm{GJ} / \mathrm{m}^{2} \times 1.135 \times 10^{13}\right)$.

ef Material failed prior to this time. 
Table 16

Solar Energy Transmittance Loss of Cover Plate Materials Exposed as Double Covers to Natural Weathering in Gaithersburg, Maryland a, b

\begin{tabular}{|c|c|c|c|c|c|c|}
\hline \multirow{2}{*}{ Exposure Period (months) } & \multicolumn{6}{|c|}{ Outer Cover } \\
\hline & 3 & 6 & $12^{\mathrm{c} J}$ & 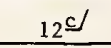 & 18 & 24 \\
\hline Material $>$ Solar Radiation $\left(\mathrm{GJ} / \mathrm{m}^{2}\right) \mathrm{d}$ & 1.176 & 2.251 & 4.633 & 5.477 & 7.680 & 10.720 \\
\hline glass $(0.01 \%$ iron oxide) & 1.1 & 0.6 & 0.0 & -0.8 & 0.4 & 1.5 \\
\hline glass (0.10\% iron oxide) & -0.4 & 0.2 & 0.0 & -1.6 & -0.5 & -0.5 \\
\hline $\begin{array}{c}\text { fluorinated(ethylene propylene) } \\
\text { copolymer }\end{array}$ & 0.2 & 0.7 & 0.2 & 0.5 & 2.9 & 4.3 \\
\hline poly(vinyl fluoride) & 2.0 & 3.2 & 4.8 & -0.3 & 0.3 & 5.9 \\
\hline poly(ethylene terephthalate) & 0.7 & 1.7 & 2.8 & 0.6 & 1.0 & 15.0 \\
\hline acrylic & 1.6 & 3.1 & 2.9 & 2.9 & 3.0 & e \\
\hline poly(methy1 methacrylate) & 0.4 & 2.0 & 1.2 & 1.4 & 2.3 & - \\
\hline polycarbonate & -0.8 & 1.5 & 0.4 & 1.1 & 1.7 & 6.9 \\
\hline fiber reinforced plastic $1.0 \mathrm{~mm}$ & 1.1 & 2.4 & 3.0 & 2.8 & 5.8 & 8.2 \\
\hline fiber reinforced plastic $1.5 \mathrm{~mm}$ & 5.2 & 0.9 & 1.7 & 5.5 & 9.7 & 9.8 \\
\hline
\end{tabular}

\begin{tabular}{|c|c|c|c|c|c|c|}
\hline \multirow{3}{*}{ Exposure Period (months) } & & & & & & \\
\hline & \multicolumn{6}{|c|}{ Inner Cover } \\
\hline & 3 & 6 & $12 \mathrm{c}$ & $12 \mathrm{c}$ & 18 & 24 \\
\hline Material Solar Radiation $\left(\mathrm{GJ} / \mathrm{m}^{2}\right) \mathrm{d} /$ & 1.176 & 2.251 & 4.633 & 5.477 & 7.680 & 10.720 \\
\hline glass $(0.01 \%$ iron oxide) & 1.4 & 2.9 & -0.3 & -1.1 & 0.4 & 0.6 \\
\hline glass $(0.10 \%$ iron oxide) & -0.9 & 0.5 & 0.2 & -1.5 & 0.4 & -0.7 \\
\hline $\begin{array}{c}\text { fluorinated(ethylene propylene) } \\
\text { copolymer }\end{array}$ & 0.1 & 0.4 & 0.2 & 0.0 & 0.1 & -0.5 \\
\hline poly(vinyl fluoride) & 1.1 & 1.8 & 0.8 & 0.7 & -0.3 & 0.5 \\
\hline poly(ethylene terephthalate) & 0.3 & 1.4 & 0.7 & 0.4 & 0.6 & 0.3 \\
\hline acrylic & 0.4 & 0.7 & 1.2 & 0.4 & 0.8 & e \\
\hline poly(methyl methacrylate) & 0.1 & 1.2 & 0.0 & 0.3 & 0.2 & - \\
\hline polycarbonate & 0.2 & 1.0 & -0.2 & 0.2 & -0.2 & 0.2 \\
\hline fiber reinforced plastic $1.0 \mathrm{~mm}$ & 1.7 & 1.2 & 4.7 & 3.2 & 2.7 & 3.6 \\
\hline fiber reinforced plastic $1.5 \mathrm{~mm}$ & 3.8 & 11.0 & 11.4 & 10.4 & 12.7 & 16.8 \\
\hline
\end{tabular}

a/ Materials were exposed on minicollectors. Transmittance measurements were made on a Cary $17 D$ integrating sphere spectrophotometer according to ASTM E 424-71, Method A. The solar energy transmittance for air mass 2 at sea level was obtained by integrating over Parry Moon's standard solar energy distribution curve using weighted ordinates. Each transmittance value represents a separate test specimen. Transmittance is expressed in percentage.

b/ The solar energy transmittance loss is the difference between the average for the control test specimens (Table li) and the value obtained after the test specimen was washed. Negative values represent a gain in comparison with the average for the controls. This solar energy transuittance loss does not include the loss due to dirt on the surface. Losses due to dirt are tabulated in table 18.

c/ Two sets of minicollectors were exposed for the same length of time but different dates.

d Solar radiation values in $\mathrm{GJ} / \mathrm{m}^{2}$ are converted to $\mathrm{Btu} / \mathrm{ft}^{2}$ by: $\mathrm{Btu} / \mathrm{ft}^{2}=\left(\mathrm{GJ} / \mathrm{m}^{2} \mathrm{x} 1.13510^{13}\right)$.

e Material failed prior to this time. 
materials except the $1.5 \mathrm{~mm}$ fiber reinforced plastic. The damage suffered by this material was most likely caused by the temperature encountered in the inner cover exposure.

The smallest transmittance losses occurred with the two glass materials, the fluorinated (ethylene propylene) copolymer, and the acrylic film. The $1.5 \mathrm{~mm}$ fiber reinforced plastic suffered the greatest loss as both an outer and inner cover. This indicates the material is susceptable to damage by both solar radiation and temperature. The losses in the poly(vinyl fluoride), poly (ethylene terephthalate), poly(methyl methacrylate), polycarbonate, and $1.0 \mathrm{~mm}$ fiber reinforced plastic were due to a reduction in transmittance across the entire solar spectrum but were greatest below $700 \mathrm{~nm}$ as the absorption band in the UV-VIS moved toward the visible region. Between 18 and 24 months, significant transmittance losses occurred with the single and outer cover test specimens.

The solar energy transmittance losses due to dirt are listed in table 17 for single covers and table 18 for double covers. All materials lost transmittance due to dirt accumulation on the surface. In most cases the dirt on the inner cover plates reduced transmittance less than one percent. For outer and single covers the transmittance losses generally ranged from three to five percent, although in one case the fluorinated (ethylene propylene) copolymer lost 12.3 percent. It appeared that after the first 12 months the losses did not increase significant $1 y$.

\subsubsection{Miami, Florida Exposures}

The solar energy transmittance after natural weathering on the minicollector in Miami is tabulated in table 19 for the single cover test specimens and in table 20 for the double cover test specimens. Transmittance losses due to weathering (not dirt retention) are listed in tables 21 and 22 . In the inner cover application the solar transmittance changes were generally less than one percent, except for the fiber reinforced materials which were more susceptible to damage caused by the temperature of the inner cover application. For the outer double cover and the single cover applications the greatest losses also occurred in the fiber reinforced materials. The glass materials showed only small changes. The other plastic materials exhibited transmittance losses across the entire spectrum and the absorption band in the UV-VIS region shifted toward the visible, an indication of material degradation.

The solar energy transmittance losses due to dirt on the surface of the cover plate materials are given in tables 23 and 24 . For the outer and single covers, the transmittance losses were generally three to seven percent although the poly (ethylene terephthalate) lost more than ten percent in three cases. For the inner covers, the dirt caused decreases of one to two percent for the exposures 12 months and less. However for the 18 and 24 month exposures, the transmittance losses were three to four percent with the losses for several materials exceeding five percent. This increase in transmittance loss due to dirt on the inner cover is probably resulting from decomposition of the wooden boxes and from dirt leaking in when the covers had loosened. 
Solar Energy Transmittance Loss Due to Dirt on the Surface of the Cover Plate Materials After a Single Cover Exposure in Gaithersburg, Maryland

\begin{tabular}{|l|cccccc|}
\hline & & & & & & \\
\hline Material Exposure Period (months) & 3 & 6 & $12 \mathrm{~b} /$ & $12 \mathrm{~b} /$ & 18 & 24 \\
\hline glass (0.01\% iron oxide) & -1.3 & -0.2 & 3.6 & 4.7 & 4.9 & 4.1 \\
\hline glass (0.10\% iron oxide) & 2.1 & 1.5 & 5.9 & 5.9 & 2.3 & 4.7 \\
\hline $\begin{array}{c}\text { fluorinated (ethylene propylene) } \\
\text { copolymer }\end{array}$ & 4.3 & 1.4 & 12.3 & 1.2 & 9.4 & 7.6 \\
\hline poly (vinyl fluoride) & 1.2 & 2.6 & 6.5 & 5.8 & 1.9 & 1.8 \\
\hline poly(ethylene terephthalate) & 0.5 & 0.4 & 8.0 & 4.8 & 4.2 & 1.3 \\
\hline acrylic & 2.4 & 1.6 & 7.0 & 4.1 & 8.6 & 3.7 \\
\hline poly (methyl methacrylate) & 1.4 & 2.6 & 8.8 & 3.9 & 3.2 & 3.9 \\
\hline polycarbonate & 0.9 & - & 8.7 & 4.2 & 5.3 & 3.1 \\
\hline fiber reinforced plastic $1.0 \mathrm{~mm}$ & 0.6 & 1.9 & 9.8 & 4.4 & 2.5 & 2.9 \\
\hline fiber reinforced plastic $1.5 \mathrm{~mm}$ & 0 & 2.4 & 10.4 & 4.6 & 3.9 & 4.3 \\
\hline
\end{tabular}

a/ Materials were exposed to natural weathering on minicollectors. Transmittance measurements were made on a Cary 17D integrating sphere spectrophotometer according to ASTM E 424-71, Method A. The solar energy transmittance for air mass 2 at sea level was obtained by integrating over Parry Moon's standard solar energy distribution curve using weighted ordinates. Each transmittance value represents a separate test specimen. The solar energy transmittance loss due to dirt is the difference between the values obtained before and after washing the test specimen. Negative values represent a loss in transmittance after washing. Transmittance is expressed in percentage.

b/ Two sets of minicollectors were exposed for the same length of time but different dates. 
Solar Energy Transmittance Loss Due to Dirt on the Surface of the Cover Plate Materials After Double Cover Exposure in Gaithersburg, Maryland

\begin{tabular}{|c|c|c|c|c|c|c|}
\hline & \multicolumn{6}{|c|}{ Outer Cover } \\
\hline Material Exposure Period (Months) & 3 & 6 & $12^{\mathrm{b}} /$ & $12 \underline{b}$ & 18 & 24 \\
\hline glass $(0.01 \%$ iron oxide) & 0.3 & 1.8 & 8.4 & 2.7 & 3.2 & 4.0 \\
\hline glass $(0.10 \%$ iron oxide) & 1.2 & 1.8 & 8.2 & 4.8 & 1.8 & 4.8 \\
\hline $\begin{array}{c}\text { fluorinated(ethylene propylene) } \\
\text { copolymer }\end{array}$ & 1.3 & 2.9 & 3.5 & 8.8 & 6.2 & 7.0 \\
\hline poly(vinyl fluoride) & 0.9 & 6.0 & 5.5 & 6.8 & 3.5 & 3.0 \\
\hline poly(ethylene terephthalate) & 0.8 & 4.5 & 3.8 & 4.3 & 3.3 & 2.8 \\
\hline acrylic & 1.0 & 3.4 & 4.9 & 3.3 & 4.2 & $\underline{c}$ \\
\hline poly(methyl methacrylate) & 2.0 & 2.7 & 7.9 & 3.3 & 2.7 & - \\
\hline polycarbonate & 2.3 & 1.6 & 6.6 & 5.0 & 5.1 & 4.1 \\
\hline fiber reinforced plastic $1.0 \mathrm{~mm}$ & 0.8 & 2.3 & 6.7 & 2.6 & 1.5 & 0.3 \\
\hline fiber reinforced plastic $1.5 \mathrm{~mm}$ & 1.8 & 1.0 & 5.7 & 1.0 & 3.3 & 1.4 \\
\hline
\end{tabular}

\begin{tabular}{|c|c|c|c|c|c|c|}
\hline & \multicolumn{6}{|c|}{ Inner Cover } \\
\hline Material Exposure Period (months) & 3 & 6 & 12 b/ & $12 \underline{b} /$ & 18 & 24 \\
\hline glass $(0.01 \%$ iron oxide) & 0 & - & 1.7 & 0 & 0.2 & 0.3 \\
\hline glass $(0.10 \%$ iron oxide) & 1.3 & - & 0.7 & 2.6 & 0.2 & 2.4 \\
\hline $\begin{array}{c}\text { fluorinated(ethylene propylene) } \\
\text { copolymer }\end{array}$ & 0.4 & 0.7 & 0.6 & 0.5 & 0.8 & 2.9 \\
\hline poly(vinyl fluoride) & 0.8 & 1.0 & 0.2 & 0.3 & 0.9 & 0.3 \\
\hline poly(ethylene terephthalate) & 0.3 & -0.6 & 1.0 & 0.6 & 0.6 & 0.5 \\
\hline acrylic & 0.3 & 0.8 & -0.1 & 0.4 & 0.3 & c J \\
\hline poly(methyl methacrylate) & 0.8 & 0.2 & 0.9 & 0.9 & -0.3 & - \\
\hline polycarbonate & -0.1 & 0.2 & 1.2 & 0.5 & 0.7 & 0.6 \\
\hline fiber reinforced plastic $1.0 \mathrm{~mm}$ & -1.4 & 0.5 & 0.6 & 0.3 & -0.8 & -1.8 \\
\hline fiber reinforced plastic $1.5 \mathrm{~mm}$ & -0.3 & -0.2 & 0.1 & -2.3 & 0.3 & -1.1 \\
\hline
\end{tabular}

a Materials were exposed to natural weathering on minicollectors. Transmittance measurements were made on a Cary 17D integrating sphere spectrophotometer according to ASTM E 424-71, Method A. The solar energy transmittance for air mass 2 at sea level was obtained by integrating over Parry Moon's standard solar energy distribution curve using weighted ordinates. Each transmittance value represents a separate test specimen. The solar energy transmittance loss due to dirt is the difference between the solar energy transmittance measurements made before and after washing the test specimen. Negative values represent a loss in transmittance after washing. Transmittance is expressed in percentage.

b/ Two sets of minicollectors were exposed for the same length of time but different dates.

c) Material failed prior to this time. 
Table 19

Solar Energy Transmittance of Cover Plate Materials Exposed as Single Covers to Natural Weathering in Miami, Floridaa

\begin{tabular}{|c|c|c|c|c|c|c|c|}
\hline Exposure Period (months) & $\underline{0}$ & 3 & 6 & $12 \mathrm{~b} /$ & $12 \mathrm{~b} /$ & 18 & 24 \\
\hline Material $\searrow$ Solar Radiation $\left(\mathrm{GJ} / \mathrm{m}^{2}\right) \subseteq /$ & 0 & 1.455 & 2.864 & 6.344 & 6.523 & 9.333 & 13.125 \\
\hline glass $(0.01 \%$ iron oxide) & 90.7 & 87.0 & 87.8 & 87.2 & 86.2 & 85.0 & 84.9 \\
\hline glass $(0.10 \%$ iron oxide) & 87.4 & 86.4 & 85.2 & 82.2 & 84.1 & 81.9 & 82.9 \\
\hline $\begin{array}{c}\text { fluorinated(ethylene propylene) } \\
\text { copolymer }\end{array}$ & 96.0 & 93.2 & 88.2 & 86.4 & 89.0 & 86.5 & 84.0 \\
\hline poly(vinyl fluoride) & 92.5 & 89.5 & 89.6 & 84.6 & 86.7 & 84.4 & 85.7 \\
\hline poly (ethylene terephthalate) & 86.3 & 83.8 & 82.5 & 71.5 & 78.0 & 71.3 & 75.8 \\
\hline acrylic & 90.7 & 87.2 & 84.9 & 84.8 & 84.5 & 85.4 & $d /$ \\
\hline poly (methyl methacrylate) & 91.0 & 88.6 & 86.9 & 84.5 & 87.3 & 81.7 & 83.5 \\
\hline polycarbonate & 88.1 & 85.9 & 85.1 & 78.2 & 81.7 & 77.6 & 75.4 \\
\hline fiber reinforced plastic $1.0 \mathrm{~mm}$ & 86.3 & 82.6 & 82.4 & 77.7 & 79.8 & 74.3 & 76.6 \\
\hline fiber reinforced plastic 1.5 & 78.5 & 69.2 & 71.0 & 66.3 & 63.8 & 53.0 & 56.5 \\
\hline
\end{tabular}

a/ Materials were exposed on minicollectors. Transmittance measurements were made on a Cary 17D integrating sphere spectrophotometer according to ASTM E 424-71, Method A. The solar energy transmittance for air mass 2 at sea level was obtained by integrating over Parry Moon's standard solar energy distribution curve using weighted ordinates. Transmittance was measured after exposure but before washing. Each transmittance value for the exposed materials represents a separate test specimen. Average solar transmittance of the control test specimens is given for comparison. Transmittance is expressed in percentage.

b/ Two sets of minicollectors were exposed the same length of time but different dates.

c/ Solar radiation values in $\mathrm{GJ} / \mathrm{m}^{2}$ are converted to $\mathrm{Btu} / \mathrm{ft}^{2}$ by: $\mathrm{Btu} / \mathrm{ft}^{2}=\left(\mathrm{GJ} / \mathrm{m}^{2} \mathrm{x} 1.135 \mathrm{x} 10^{13}\right)$. d/ Material failed prior to this time. 
Table 20

Solar Energy Transmittance of Cover Plate Materials Exposed as Double Covers to Natural Weathering in Miami, Florida

\begin{tabular}{|l|cccccccc|}
\cline { 2 - 8 } & \multicolumn{7}{c|}{ Outer Cover } \\
\hline Material Exposure Period (months) & 0 & 3 & 6 & 12 b & $12 \mathrm{~b}$ & 18 & 24 \\
\hline Solar Radiation $\left(\mathrm{GJ} / \mathrm{m}^{2}\right)$ & $\mathrm{c}$ & 0 & 1.455 & 2.864 & 6.344 & 9.333 & 9.333 & 13.125 \\
\hline glass (0.01\% iron oxide) & 90.7 & 87.6 & 89.3 & 89.0 & 83.6 & 83.6 & 87.0 \\
\hline glass (0.10\% iron oxide) & 87.4 & 86.0 & 85.4 & 81.1 & 82.6 & 82.6 & 84.5 \\
\hline fluorinated(ethylene propylene) \\
copolymer
\end{tabular}

\begin{tabular}{|c|c|c|c|c|c|c|c|}
\hline & \multicolumn{7}{|c|}{ Inner Cover } \\
\hline Exposure Period (months) & 0 & 3 & 6 & 12 b & 12 b/ & 18 & 24 \\
\hline Material Solar Radiation $\left(\mathrm{GJ} / \mathrm{m}^{2}\right) \mathrm{d}$ & 0 & 1.455 & 2.864 & 6.344 & 6.523 & 9.333 & 13.125 \\
\hline glass $(0.01 \%$ iron oxide) & 90.7 & 87.9 & 89.1 & 89.1 & 88.2 & 82.1 & 88.5 \\
\hline glass (0.10\% iron oxide) & 87.4 & 87.1 & 85.8 & 86.1 & 86.2 & 83.0 & 73.1 \\
\hline $\begin{array}{c}\text { fluorinated(ethylene propylene) } \\
\text { copolymer }\end{array}$ & 96.0 & 95.4 & 95.2 & 95.9 & 95.4 & 94.9 & 93.4 \\
\hline poly(vinyl fluoride) & 92.5 & 90.6 & 91.3 & 88.5 & 91.1 & 89.1 & 89.1 \\
\hline poly(ethylene terephthalate) & 86.3 & 85.6 & 85.5 & 85.3 & 85.4 & 85.4 & 85.0 \\
\hline acrylic & 90.7 & 90.0 & 89.6 & 89.6 & 89.5 & 86.8 & d/ \\
\hline poly (methy1 methacrylate) & 91.0 & 93.0 & 89.8 & 87.9 & 90.0 & 81.2 & 89.5 \\
\hline polycarbonate & 88.1 & 89.9 & 87.4 & 81.8 & 87.2 & 81.7 & 82.0 \\
\hline fiber reinforced plastic $1.0 \mathrm{~mm}$ & 86.3 & 85.1 & 85.0 & 84.4 & 81.8 & 77.7 & 71.2 \\
\hline fiber reinforced plastic $1.5 \mathrm{~mm}$ & 78.5 & 64.8 & 69.9 & 58.8 & 67.3 & 64.5 & 63.7 \\
\hline
\end{tabular}

a Materials were exposed on minicollectors. Transmittance measurements were made on a Cary 17D integrating sphere spectrophotometer according to ASTM E 424-71, Method A. The solar energy transmittance for air mass 2 at sea level was obtained by integrating over Parry Moon's standard solar energy distribution curve using weighted ordinates. Each transmittance value represents a separate test specimen. Average solar transmittance of the control test specimens is given for comparison. Both inner and outer covers on each minicollector were the same material. Transmittance is expressed in percentage.

b/ Two sets of minicollectors were exposed for the same legth of time but different dates.

c) Solar radiation values in $\mathrm{GJ} / \mathrm{m}^{2}$ are converted to $\mathrm{Btu} / \mathrm{ft}^{2}$ by: $\mathrm{Btu} / \mathrm{ft}^{2}=\left(\mathrm{GJ} / \mathrm{m}^{2} \times 1.135 \times 10^{13}\right)$. d) Material failed prior to this time. 
Table 21

Solar Energy Transmittance Loss of Cover Plate Materials Exposed as Single Covers to Natural Weathering in Miami, Florida a,b

\begin{tabular}{|c|c|c|c|c|c|c|}
\hline Exposure Period (months) & 3 & 6 & $12 \mathrm{~d}$ & $12 \subseteq$ & 18 & 24 \\
\hline Material $>$ Solar Radiation $\left(\mathrm{GJ} / \mathrm{m}^{2}\right) \underline{\mathrm{d}} /$ & 1.455 & 2.864 & 6.344 & 6.523 & 9.333 & 13.125 \\
\hline glass $(0.01 \%$ iron oxide) & 0.6 & 0.7 & 0.9 & 0.2 & 1.6 & 0.3 \\
\hline glass $(0.10 \%$ iron oxide) & -0.6 & 0.4 & -1.2 & 0.4 & 1.5 & 0.1 \\
\hline $\begin{array}{c}\text { fluorinated(ethylene propylene) } \\
\text { copolymer }\end{array}$ & 0.3 & 0.7 & 0.8 & 1.1 & 3.6 & 4.3 \\
\hline poly(viny1 fluoride) & 0.6 & 1.1 & 4.0 & 0.8 & 5.2 & 4.6 \\
\hline poly (ethylene terephthalate) & 0 & 0.2 & 4.9 & 7.7 & 4.8 & 4.8 \\
\hline acrylic & 1.9 & 1.0 & 3.2 & 2.0 & 3.4 & ef \\
\hline poly (methy1 methacrylate) & 0.7 & 1.9 & 2.2 & 2.3 & 4.1 & 4.9 \\
\hline polycarbonate & -0.3 & 0.1 & 2.5 & 3.5 & 4.6 & 7.9 \\
\hline fiber reinforced plastic $1.0 \mathrm{~mm}$ & 1.4 & 1.3 & 4.1 & 1.9 & 9.1 & 0.9 \\
\hline fiber reinforced plastic $1.5 \mathrm{~mm}$ & 5.6 & 7.0 & 8.5 & 7.9 & 19.6 & 15.9 \\
\hline
\end{tabular}

a/ Transmittance measurements were made on a Cary 17D integrating sphere spectrophotometer according to ASTM E 424-71, Method A. The solar energy transmittance for air mass 2 at sea level was obtained by integrating over Parry Moon's standard solar energy distribution curve using weighted ordinates. Each transmittance value represents a separate test specimen. Transmittance is expressed in percentage.

b/ The solar energy transmittance loss is the difference between the average for the control test specimens (Table 11) and the values obtained after the test specimen was washed. Negative values represent a gain in comparison with the average for the controls. This solar energy transmittance loss does not include the loss due to dirt on the surface. Losses due to dirt are tabulated in table 23.

c/ Two sets of minicollectors were exposed for the same length of time but different dates. d/ Solar radiation values in $\mathrm{GJ} / \mathrm{m}^{2}$ are converted to $\mathrm{Btu} / \mathrm{ft}^{2}$ by: $\mathrm{Btu} / \mathrm{ft}^{2}=\left(\mathrm{GJ} / \mathrm{m}^{2} \times 1.135 \times 10^{13}\right)$. e) Material failed prior to this time. 
Solar Energy Transmittance Loss of Cover Plate Materials Exppsed as Double Covers to Natural Weathering in Miami, Florida

\begin{tabular}{|c|c|c|c|c|c|c|}
\hline \multirow[b]{2}{*}{ Exposure Period (months) } & \multicolumn{6}{|c|}{ Outer Cover } \\
\hline & 3 & 6 & $12^{\mathrm{C} J}$ & $12 \mathrm{c}$ & 18 & 24 \\
\hline Material Solar Radiation $\left(\mathrm{GJ} / \mathrm{m}^{2}\right) \stackrel{d}{d}$ & 1.455 & 2.864 & 6.344 & 6.523 & 9.333 & 13.125 \\
\hline glass $(0.01 \%$ iron oxide) & -0.3 & 0.4 & -1.7 & 0.6 & 1.4 & 1.5 \\
\hline glass $(0.10 \%$ iron oxide) & -0.3 & 0 & 0.8 & 0.6 & 0.9 & 0.9 \\
\hline $\begin{array}{c}\text { fluorinated(ethylene propylene) } \\
\text { copolymer }\end{array}$ & -0.5 & 0 & 1.3 & 0.1 & 4.5 & 1.4 \\
\hline poly(vinyl fluoride) & 0.9 & 1.4 & 3.0 & 1.0 & 0 & 4.4 \\
\hline poly(ethylene terephthalate) & -0.4 & 0.9 & 7.7 & 5.2 & 5.2 & 3.9 \\
\hline acrylic & 3.2 & 2.6 & 2.1 & 2.7 & ef & el \\
\hline poly(methyl methacrylate) & 1.0 & 1.8 & 2.8 & 2.0 & 3.3 & 3.1 \\
\hline polycarbonate & -0.1 & 0.8 & 2.4 & 2.5 & 5.0 & 5.1 \\
\hline fiber reinforced plastic $1.0 \mathrm{~mm}$ & -2.2 & 0.8 & 7.3 & 9.1 & 8.5 & 15.0 \\
\hline fiber reinforced plastic $1.5 \mathrm{~mm}$ & -2.4 & 0.3 & 19.7 & 10.6 & 24.3 & 24.8 \\
\hline
\end{tabular}

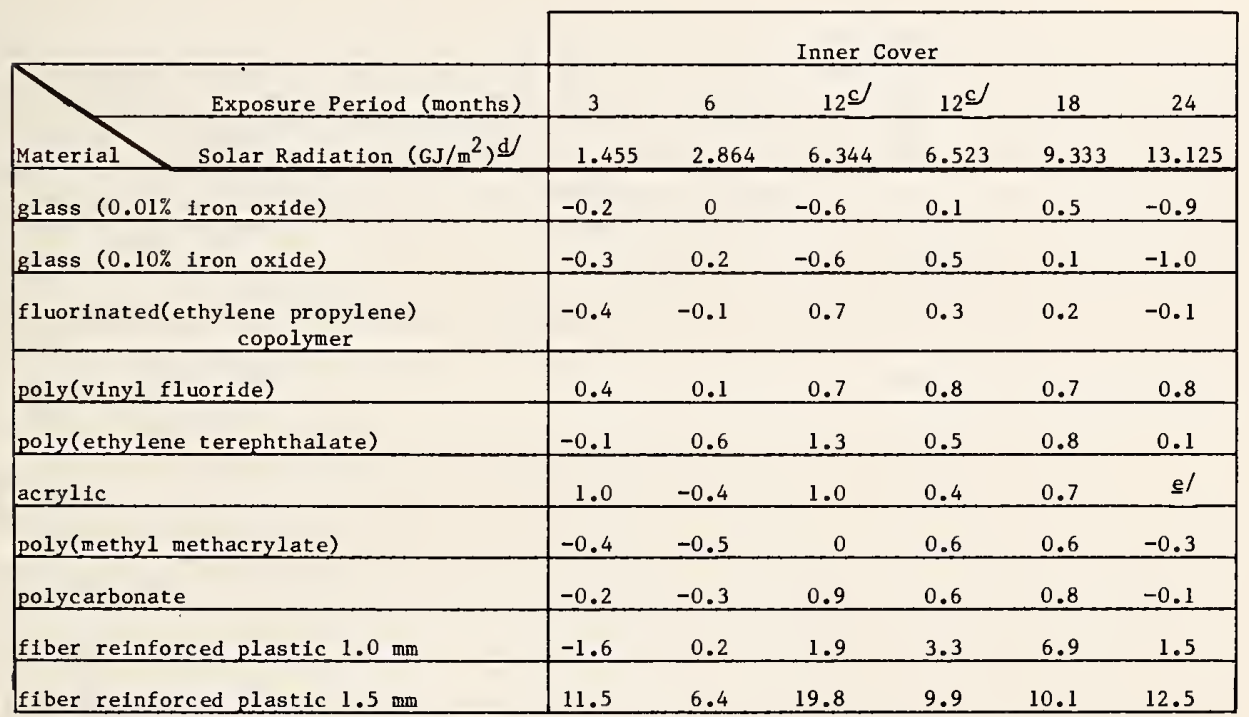

a/ Materials were exposed on minicollectors. Transmittance measurements were made on a Cary 17D integrating sphere spectrophotometer according to ASTM E 424-71, Method A. The solar energy transmittance loss for air mass 2 at sea level was obtained by integrating over Parry Moon's standard solar energy distribution curve using weighted ordinates. Each transmittance value represents a separate test specimen. Transmittance is expressed in percentage.

b/ The solar energy transmittance loss is the difference between the average for the control test specimens (Table 11 ) and the value obtained after the test specimen was washed. Negative values represent a gain in comparison with the average for the controls. This solar energy transmittance does not include the loss due to dirt on the surface. Losses due to dirt are tabulated in table 24.

c/ Two sets of minicollectors were exposed for the same length of time but different dates.

d/ Solar radiation values in $\mathrm{GJ} / \mathrm{m}^{2}$ are converted to $\mathrm{Btu} / \mathrm{ft}^{2}$ by: $\mathrm{Btu} / \mathrm{ft}^{2}=\left(\mathrm{GJ} / \mathrm{m}^{2} \times 1.135 \times 10^{13}\right)$. e/ Material failed prior to this time. 
Table 23

Solar Energy Transmittance Loss Due to Dirt on the Surface of Cover Plate Materials After Single Cover Exposure

in Miami, Florida

\begin{tabular}{|c|c|c|c|c|c|c|}
\hline Material Exposure Period (months) & 3 & 6 & $12 \underline{\mathrm{b}}$ & $12 \mathrm{~b} /$ & 18 & 24 \\
\hline glass $(0.01 \%$ iron oxide) & 3.1 & 2.2 & 2.6 & 3.3 & 4.1 & 5.5 \\
\hline glass $(0.10 \%$ iron oxide) & 1.6 & 1.9 & 3.5 & 3.8 & 4.0 & 4.4 \\
\hline $\begin{array}{c}\text { fluorinated(ethylene propylene) } \\
\text { copolymer }\end{array}$ & 2.5 & 7.1 & 6.2 & 8.5 & 5.9 & 7.7 \\
\hline poly(vinyl fluoride) & 2.4 & 1.8 & 1.8 & 7.1 & 2.9 & 2.2 \\
\hline poly (ethylene terephthalate) & 2.5 & 3.6 & 3.4 & 7.1 & 10.2 & 5.7 \\
\hline acrylic & 1.6 & 4.8 & 3.0 & 3.9 & 1.9 & s/ \\
\hline poly(methy1 methacrylate) & 1.7 & 2.2 & 1.5 & 4.2 & 5.2 & 2.6 \\
\hline polycarbonate & 2.5 & 2.9 & 3.9 & 6.4 & 5.9 & 4.8 \\
\hline fiber reinforced plastic $1.0 \mathrm{~mm}$ & 2.3 & 2.6 & 3.4 & 6.7 & 2.9 & -1.1 \\
\hline fiber reinforced plastic $1.5 \mathrm{~mm}$ & 3.9 & 0.5 & 6.2 & 4.3 & 5.9 & 6.5 \\
\hline
\end{tabular}

a Materials were exposed to natural weathering on minicollectors. Transmittance measurements were made on a Cary 17D integrating sphere spectrophotometer according to ASTM E 424-71, Method A. The solar energy transmittance for air mass 2 at sea 1 evel was obtained by integrating over Parry Moon's standard solar energy distribution curve using weighted ordinates. Each transmittance value represents a separate test specimen. The solar energy transmittance loss due to dirt is the difference between the value obtained before and after washing the test specimen. Negative values represent a loss in transmittance after washing. Transmittance is expressed in percentage.

b/ Two sets of minicollectors were exposed for the same length of time but different dates.

C Material failed prior to this time. 
Solar Energy Transmittance Loss Due to Dirt on the Surface of Cgver Plate Materials After Double Cover Exposure in Miami, Florida

\begin{tabular}{|c|c|c|c|c|c|c|}
\hline Exposure Period (months) & 3 & 6 & $12 \mathrm{~b} /$ & $12 \mathrm{~b} /$ & 18 & 24 \\
\hline glass $(0.01 \%$ iron oxide) & 3.4 & 1.0 & 3.3 & 1.1 & 5.7 & 2.2 \\
\hline glass $(0.10 \%$ iron oxide) & 1.7 & 2.1 & 1.8 & 5.7 & 3.9 & 2.1 \\
\hline $\begin{array}{c}\text { fluorinated(ethylene propylene) } \\
\text { copolymer }\end{array}$ & 6.2 & 5.8 & 6.2 & 7.4 & 2.9 & 0.9 \\
\hline poly(vinyl fluoride) & 2.0 & 0.5 & 1.4 & 7.2 & 6.6 & 1.7 \\
\hline poly (ethylene terephthalate) & 2.3 & 1.9 & 1.0 & 10.9 & 10.9 & 4.5 \\
\hline acrylic & 0.1 & 0.7 & 2.5 & 2.7 & d & d \\
\hline poly(methyl methacrylate) & -1.1 & 2.2 & 1.0 & 5.0 & 3.7 & 3.4 \\
\hline polycarbonate & -0.5 & 2.1 & 5.8 & 6.3 & 6.1 & 5.1 \\
\hline fiber reinforced plastic $1.0 \mathrm{~mm}$ & 2.6 & 2.5 & 2.1 & 6.7 & 4.4 & 2.2 \\
\hline fiber rainforced plastic $1.5 \mathrm{~mm}$ & 4.7 & 1.6 & 6.3 & 4.6 & 4.0 & 6.1 \\
\hline
\end{tabular}

Inner Cover

\begin{tabular}{|c|c|c|c|c|c|c|}
\hline Exposure Period (months) & 3 & 6 & $12 \mathrm{~b} /$ & $12 \mathrm{~b} /$ & 18 & 24 \\
\hline glass $(0.01 \%$ iron oxide) & 3.0 & 1.6 & 3.2 & 2.4 & 8.1 & 3.1 \\
\hline glass $(0.10 \%$ iron oxide) & 0.6 & 1.4 & 1.9 & 0.7 & 4.3 & 15.3 \\
\hline $\begin{array}{c}\text { fluorinated(ethylene propylene) } \\
\text { copolymer }\end{array}$ & 1.0 & .9 & -0.6 & 0.2 & 0.9 & 2.7 \\
\hline poly(vinyl fluoride) & 1.5 & 1.1 & 2.3 & 0.6 & 2.7 & 2.6 \\
\hline poly(ethylene terephthalate) & 0.8 & 0.2 & -0.3 & 0.4 & 0.1 & 1.2 \\
\hline acrylic & -0.3 & 1.5 & 0.1 & 0.8 & 3.2 & $\underline{c} /$ \\
\hline poly (methyl methacrylate) & -1.6 & 1.7 & 3.1 & 0.4 & 9.2 & 1.8 \\
\hline polycarbonate & -1.6 & 1.0 & 7.2 & 0.3 & 5.6 & 6.2 \\
\hline fiber reinforced plastic $1.0 \mathrm{~mm}$ & 2.8 & 1.1 & 0 & 1.2 & 1.7 & 3.6 \\
\hline fiber reinforced plastic $1.5 \mathrm{~mm}$ & 2.2 & 2.2 & -0.1 & 1.3 & 3.9 & 2.3 \\
\hline
\end{tabular}

a/ Materials were exposed to natural weathering in minicollectors. Transmittance measurements were made on a Cary 17D integrating sphere spectrophotometer according to ASTM E 424-71, Method A. The solar energy transmittance for air mass 2 at sea level was obtained by integrating over Parry Moon's standard solar energy distribution curve using weighted ordinates. Each transmittance value represents a separate test specimen. The solar energy transmittance loss due to dirt is the difference between the solar energy transmittance measurements made before and after washing the test specimen. Negative values represent a loss in transmittance af ter washing. Transmittance is expressed in percentage.

b/ Two sets of minicollectors were exposed for the same length of time but different dates.

d Material failed prior to this time. 
The solar energy transmittance of the materials exposed in New River, Arizona is provided in table 25 for single cover applications and table 26 for double covers. The solar energy transmittance losses caused by weathering (not dirt retention) are given in tables 27 and 28 . In the inner cover applications the only materials to have significant solar transmittance losses were the two fiber reinforced plastics. These same materials suffered the greatest losses in applications as outer and single covers. The glass materials and the fluorinated (ethylene propylene) copolymer exhibited changes of generally less than one percent. Losses for the other plastic materials were in the range of one to three percent.

The loss of solar energy transmittance due to dirt retention on the cover plate materials is listed in tables 29 and 30 . The outer and single cover losses varied from two to five percent in the first 12 months. The transmittance loss increased for the 18 and 24 month exposures. The increase may be due to surface roughess caused by material deterioration or abrasion from wind blown sand. The inner covers generally had losses less than two percent until the 24 month exposure when most of the losses exceeded this.

\subsubsection{Comparison of Exposures}

The materials followed the same general trends at all three locations. The greatest solar energy transmittance losses due to weathering occurred at either Florida or Maryland, with specimens exposed in Arizona showing the least transmittance loss. This is probably due to deterioration caused by the combination of moisture and sunlight. Figures $17 a-17 i$ illustrate the spectral transmittance of the outer double covers after 24 months at the three exposure sites. After weathering the transmittance of the single covers was similar to that of the outer double covers but the inner double covers generally showed little change. A comparison of the transmittance of inner and outer double covers and single covers after 24 months exposure in Arizona is shown in figure 18 for polycarbonate. The gradual loss of transmittance over time occurred for both single and outer double covers. A typical example of the decrease is represented in figure 19 which illustrates the transmittance of polycarbonate exposed in Florida for periods up to two years. For the inner cover application, the two fiber reinforced materials appear to be the only materials having significant transmittance losses due to weathering (not dirt). The other materials changed very little. The fiber reinforced plastic materials also had significant losses in outer cover and single cover applications.

The solar energy transmittance losses caused by dirt seemed to be slightly greater at Miami than Gaithersburg with the losses being least at New River. The amount of dirt retained on the surface is directly related to the most recent rain or snow fall. Consequently, comparisons should be limited to materials simultaneously exposed at a single location. In evaluating the data, it appears that after about one year the solar energy transmittance losses due to dirt do not increase significantly except in Arizona. Solar energy transmittance losses of three to five percent due to dirt are common for all cover 
Solar Energy Transmittance of Cover Plate Materials Exposed as Single Covers to Natural Weathering in New River, Arizona

\begin{tabular}{|c|c|c|c|c|c|c|c|c|c|}
\hline Exposure Period (months) & 0 & $3 \underline{b}$ & $3 \mathrm{~b} /$ & $6 \mathrm{~b} /$ & $6 \mathrm{~b} /$ & $12 \mathrm{~b}$ & $12 \mathrm{~b} /$ & 18 & 24 \\
\hline Material $\backslash$ Solar Radiation $\left(\mathrm{GJ} / \mathrm{m}^{2}\right) \mathrm{c} /$ & 0 & 1.422 & 2.012 & 3.487 & 5.123 & 8.006 & 8.259 & 11.642 & 16.370 \\
\hline glass $(0.01 \%$ iron oxide) & 90.7 & 89.4 & 89.5 & 88.5 & 87.5 & 89.6 & 85.5 & 87.5 & 86.8 \\
\hline glass $(0.10 \%$ iron oxide) & 87.4 & 85.5 & 87.6 & 85.4 & 85.7 & 86.6 & 85.9 & 84.0 & 82.6 \\
\hline $\begin{array}{c}\text { fluorinated(ethylene propylene) } \\
\text { copolymer }\end{array}$ & 96.0 & 93.3 & 93.5 & 92.9 & 94.5 & 91.6 & 90.9 & 91.6 & 90.1 \\
\hline poly(vinyl fluoride) & 92.5 & 91.0 & 89.4 & 90.2 & 90.6 & 89.6 & 86.7 & 87.7 & 87.5 \\
\hline poly(ethylene terephthalate) & 86.3 & 84.6 & 83.2 & 83.9 & 83.9 & 82.5 & 71.0 & 76.8 & d) \\
\hline acrylic & 90.7 & 89.1 & 87.9 & 88.8 & 88.8 & 88.1 & 79.0 & d/ & d/ \\
\hline poly (methy 1 methacrylate) & 91.0 & 88.7 & 88.6 & 87.1 & 86.8 & 86.8 & 85.1 & 84.7 & 83.9 \\
\hline polycarbonate & 88.1 & 87.2 & 86.1 & 85.9 & 84.2 & - & 84.1 & 80.9 & 84.0 \\
\hline fiber reinforced plastic $1.0 \mathrm{~mm}$ & 86.3 & 83.5 & 84.3 & 83.8 & 82.3 & 80.9 & 81.2 & 75.0 & 77.2 \\
\hline fiber reinforced plastic $1.5 \mathrm{~mm}$ & 78.5 & 73.8 & 72.4 & 68.5 & 66.7 & 68.6 & 63.0 & 64.7 & 61.2 \\
\hline
\end{tabular}

a/ Materials were exposed on minicollectors. Transmittance measurements were made on a Cary 170 integrating sphere spectrophotometer according to ASTM E 424-71, Method A. The solar energy transmittance for air mass 2 at sea level was obtained by integrating over Parry Moon's standard solar energy distribution curve using weighted ordinates. Transmittance was measured after exposure but before washing. Each transmittance value represents a separate test specimen. Average solar transmittance of the control test specimens is given for comparison. Transmittance is expressed in percentage.

b/ Two sets of minicollectors were exposed for the same length of time but different dates.

S Solar radiation values in $\mathrm{GJ} / \mathrm{m}^{2}$ are converted to $\mathrm{Btu} / \mathrm{ft}^{2}$ by: $\mathrm{Btu} / \mathrm{ft}^{2}=\left(\mathrm{GJ} / \mathrm{m}^{2} \times 1.135 \times 10^{13}\right)$.

d Material falled prior to this time. 
Table 26

Solar Energy Transmittance of Cover Plate Materials Exposed as Double Covers to Natural Weathering in New River, Arizona

\begin{tabular}{|c|c|c|c|c|c|c|c|c|c|}
\hline \multirow[b]{2}{*}{ Exposure Period (months) } & \multicolumn{9}{|c|}{ Outer Cover } \\
\hline & 0 & $3^{\mathrm{b} /}$ & $3 \mathrm{~b}$ & $6 \mathrm{~b}$ & $6 \mathrm{~b}$ & $12^{\mathrm{b} /}$ & $12^{\mathrm{b} /}$ & 18 & 24 \\
\hline Material Solar Radiation $\left(\mathrm{GJ} / \mathrm{m}^{2}\right) \mathrm{C}$ & 0 & 1.422 & 2.012 & 3.487 & 5.123 & 8.006 & 8.259 & 11.642 & 16.370 \\
\hline glass $(0.01 \%$ iron oxide) & 90.7 & 90.4 & 89.7 & 89.2 & 86.3 & 96.7 & 88.1 & 87.2 & 85.2 \\
\hline glass $(0.10 \%$ iron oxide) & 87.4 & 86.9 & 86.1 & 86.1 & 84.8 & 87.1 & 83.6 & 84.3 & 83.8 \\
\hline $\begin{array}{c}\text { fluorinated (ethylene propylene) } \\
\text { copolymer }\end{array}$ & 96.0 & 93.1 & 93.6 & 93.5 & 94.4 & 93.1 & 91.8 & 91.5 & 94.4 \\
\hline poly(vinyl fluoride) & 92.5 & 91.0 & 90.4 & 89.0 & 90.5 & 88.7 & 87.5 & 88.3 & 87.2 \\
\hline poly (ethylene terephthalate) & 86.3 & 85.6 & 84.6 & 84.1 & 83.8 & 83.8 & d/ & 77.2 & d $/$ \\
\hline acrylic & 90.7 & 88.2 & 88.2 & 89.5 & 88.4 & 88.8 & $d$ & $\mathrm{~d} /$ & d \\
\hline poly(methy 1 methacrylate) & 91.0 & 89.3 & 87.4 & 87.9 & 87.4 & 86.5 & 86.3 & 86.1 & 84.5 \\
\hline polycarbonate & 88.1 & 86.5 & 86.2 & 86.4 & 84.5 & 83.9 & 84.8 & 82.6 & 82.5 \\
\hline fiber reinforced plastic $1.0 \mathrm{~mm}$ & 86.3 & 85.7 & 83.4 & 84.0 & 80.5 & 83.3 & 77.6 & 79.5 & 78.0 \\
\hline fiber reinforced plastic $1.5 \mathrm{~mm}$ & 78.5 & 77.5 & 76.7 & 74.0 & 69.1 & 70.1 & 72.7 & 68.2 & 61.8 \\
\hline
\end{tabular}

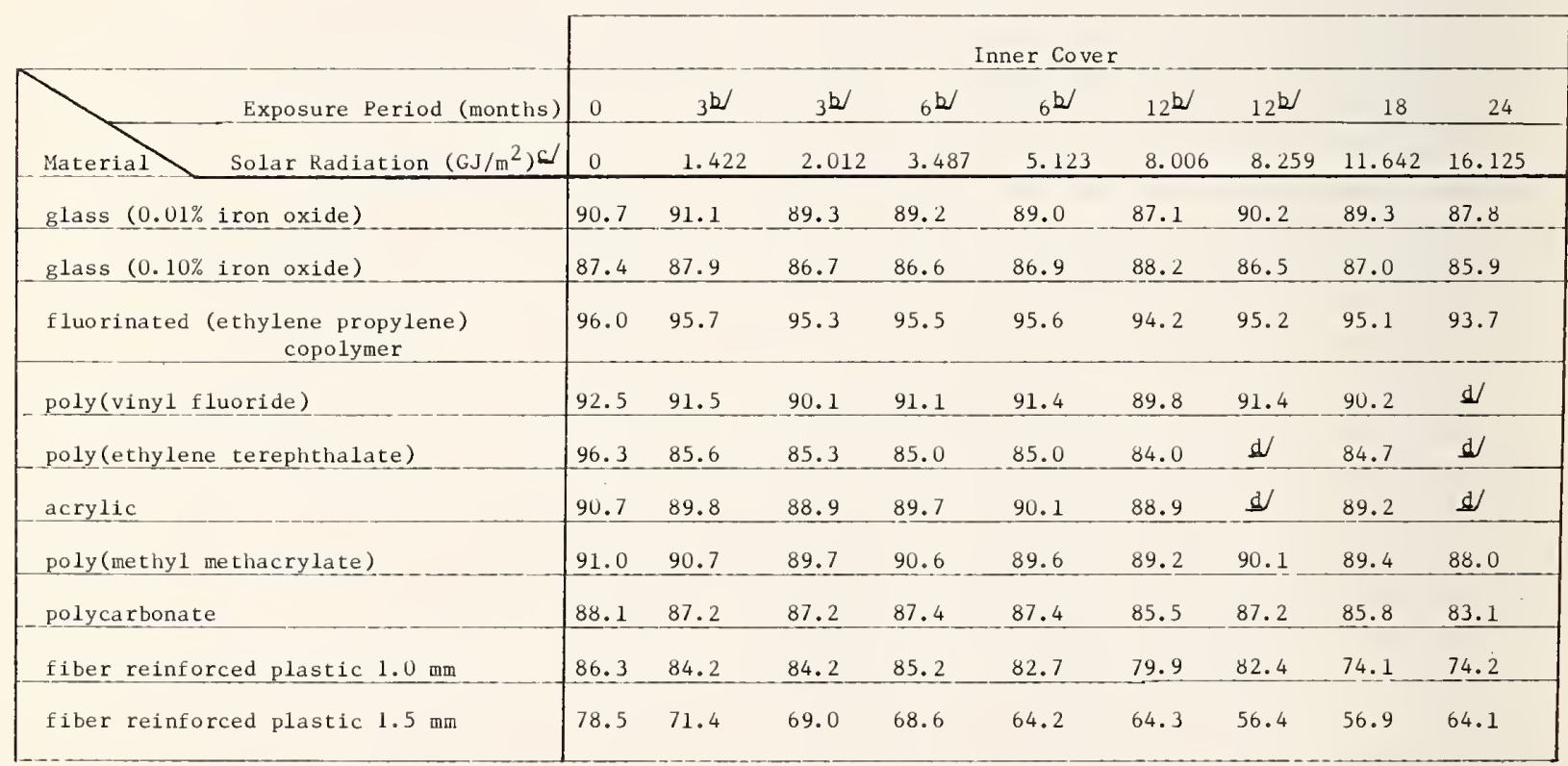

a Materials were exposed on minicollectors. Transmittance was measured after exposure but before washing. Transmittance measurements were made on a Cary 17D integrating sphere spectrophotometer according to ASTM E 424-71, Method A. The solar energy transmittance for air mass 2 at sea level was obtained by integrating over Parry Moon's standard solar energy distribution curve using weighted ordinates. Each transmittance value represents a separate test specimen. Average solar tramsmittance of the control test specimens is given for comparison. Both the inner and outer covers on each minicollector were the same material.

Transmittance is expressed in percentage.

b/ Two sets of minicollectors were exposed for the same length of time but different dates.

c/ Solar radiation values in $\mathrm{GJ} / \mathrm{m}^{2}$ are converted to $\mathrm{Btu} / \mathrm{ft}^{2}$ by: $\mathrm{Btu} / \mathrm{ft}^{2}=\left(\mathrm{GJ} / \mathrm{m}^{2} \times 1.135 \times 10^{13}\right)$.

d/ Material failed prior to this time. 
Table 27

Solar Energy Transmittance Loss of Cover Plate Materials Exposed as Single Covers to Natural Weathering in New River, Arizona $\underline{a}, \underline{b}$

\begin{tabular}{|c|c|c|c|c|c|c|c|c|}
\hline Exposure Period (months) & 3 & $3 \sqrt{d}$ & $6^{\mathrm{c} /}$ & $6^{\mathrm{c}}$ & $12 \mathrm{c}$ & $12^{\mathrm{c} J}$ & 18 & 24 \\
\hline Material $\longrightarrow$ Solar Radiation $\left(\mathrm{GJ} / \mathrm{m}^{2}\right) \mathrm{d} /$ & 1.422 & 2.012 & 3.487 & 5.123 & 8.006 & 8.259 & 11.642 & 16.370 \\
\hline glass $(0.01 \%$ iron oxide) & -0.1 & 1.6 & 1.0 & -1.7 & -0.8 & 0.7 & 0.9 & 0.7 \\
\hline glass $(0.10 \%$ iron oxide) & 0.5 & 0 & 0.3 & -1.9 & 0.2 & 0.3 & -0.6 & 0.2 \\
\hline $\begin{array}{c}\text { fluorinated (ethylene propylene) } \\
\text { copolymer }\end{array}$ & 0.2 & 0.7 & 0.7 & 0.4 & 1.3 & 0.8 & 0.6 & 0.5 \\
\hline poly(vinyl fluoride) & 1.1 & 1.8 & 1.5 & 1.2 & 2.0 & 1.2 & 1.8 & 1.1 \\
\hline poly(ethylene terephthalate) & 1.4 & 1.0 & 0.4 & 1.4 & -0.5 & 3.2 & 6.6 & e/ \\
\hline acrylic & 1.6 & 0.9 & 0.3 & 0.2 & 1.0 & 3.9 & ef & el \\
\hline poly (methyl methacrylate) & 1.5 & 1.6 & 2.2 & -0.3 & 1.8 & 3.2 & 2.5 & 1.6 \\
\hline polycarbonate & 0.2 & 0.8 & 0.5 & 1.7 & - & 3.2 & 3.1 & 1.8 \\
\hline fiber reinforced plastic $1.0 \mathrm{~mm}$ & 1.0 & 1.9 & 1.8 & 2.7 & 3.7 & 6.1 & 4.7 & 1.9 \\
\hline fiber reinforced plastic $1.5 \mathrm{~mm}$ & 4.6 & 4.2 & 8.6 & 12.5 & 12.7 & 1.9 & 10.3 & 8.9 \\
\hline
\end{tabular}

a/ Materials were exposed on minicollectors. Transmittance measurements were made on a Cary $17 \mathrm{D}$ integrating sphere spectrophotometer according to ASTM E 424-71, Method A. The solar energy transmittance for air mass 2 at sea level was obtained by integrating over Parry Moon's standard solar energy distribution curve using weighted ordinates. Each transmittance value represents a separate test specimen. Transmittance is expressed in percentage.

b/ The solar energy transmittance loss is the difference between the average for the control test specimens (Table 11) and the value obtained after the test specimen was washed. Negative values represents a gain in comparison with the average of the controls. This solar energy transmittance loss does not include loss due to dirt on the surface. Losses due to dirt are tabulated in Table 29.

c) Two sets of minicollectors were exposed for the same length of time but different dates.

$\mathrm{d} /$ Solar radiation values in $\mathrm{GJ} / \mathrm{m}^{2}$ are converted to $\mathrm{Btu} / \mathrm{ft}^{2}$ by: $\mathrm{Btu} / \mathrm{ft}^{2}=\left(\mathrm{GJ} / \mathrm{m}^{2} \times 1.135 \times 10^{13}\right)$.

e Material failed prior to this time. 
Table 28

Solar Energy Transmittance Loss of Cover Plate Materials Exposed as Double Covers to Natural Weathering in New River, Arizonaa,

\begin{tabular}{|c|c|c|c|c|c|c|c|c|}
\hline & & & & & & & & \\
\hline & \multicolumn{8}{|c|}{ Outer Cover } \\
\hline & \multirow{2}{*}{$\frac{3 \mathrm{c}}{1.422}$} & \multirow{2}{*}{$\begin{array}{l}3 \mathrm{C} \\
2.012 \\
\end{array}$} & \multirow{2}{*}{$\begin{array}{l}6 \mathrm{~J} \\
3.487 \\
\end{array}$} & \multirow{2}{*}{$\begin{array}{r}68 \\
5.123 \\
\end{array}$} & \multirow{2}{*}{$\begin{array}{l}12 \mathrm{~J} \\
8.006 \\
\end{array}$} & \multirow{2}{*}{$\begin{array}{l}12^{\mathrm{C} /} \\
8.259 \\
\end{array}$} & \multirow{2}{*}{$\begin{array}{c}18 \\
11.642 \\
\end{array}$} & 24 \\
\hline Exposure Period (months) & & & & & & & & \multirow{2}{*}{$\begin{array}{l}16.370 \\
-0.5 \\
\end{array}$} \\
\hline glass $(0.01 \%$ iron oxide $)$ & 0.1 & 0.9 & -0.4 & -0.4 & -0.3 & -0.5 & -0.5 & \\
\hline glass ( $0.10 \%$ iron oxide) & 0.3 & 0.8 & 0.3 & -2.0 & -1.5 & 0.3 & 0.3 & -0.5 \\
\hline $\begin{array}{c}\text { fluorinated (ethylene propylene) } \\
\text { copolymer }\end{array}$ & 0.4 & 0.8 & 0.3 & 0.4 & 0.1 & 0.2 & 1.1 & 0.5 \\
\hline poly(vinyl fluoride) & 0.7 & 1.1 & 2.8 & 0.8 & 1.8 & 1.2 & - & 3.0 \\
\hline poly (ethylene terephthalate) & 0.6 & 0.8 & 0.3 & 1.3 & 1.1 & e/ & 1.5 & e/ \\
\hline acrylic & 0.9 & 0.7 & -0.1 & 0 & 1.5 & e/ & ef & e/ \\
\hline poly(methyl methacrylate) & 1.7 & 1.6 & 1.7 & -0.5 & 1.0 & 2.7 & 2.0 & 1.7 \\
\hline polycarbonate & 0.5 & 0.2 & 0.3 & 1.6 & 2.2 & 2.3 & 2.1 & 3.0 \\
\hline fiber reinforced plastic $1.0 \mathrm{~mm}$ & -0.2 & 1.8 & 1.8 & 2.1 & 2.3 & 3.2 & 3.3 & 3.5 \\
\hline fiber reinforced plastic $1.5 \mathrm{~mm}$ & 0.2 & 1.0 & 0.7 & 6.5 & 6.3 & 2.8 & 6.5 & 7.6 \\
\hline
\end{tabular}

\begin{tabular}{|c|c|c|c|c|c|c|c|c|}
\hline & \multicolumn{8}{|c|}{ Inner Cover } \\
\hline Exposure Period (months) & $3 \mathrm{c}$ & $3 \mathrm{c}$ & $6 \mathrm{c}$ & $6 \mathrm{c}$ & $12 \mathrm{c}$ & $12 \mathrm{c}$ & 18 & 24 \\
\hline Material Solar Radiation $\left(\mathrm{GJ} / \mathrm{m}^{2}\right) \mathrm{d} /$ & 1.422 & 2.012 & 3.487 & 5.123 & 8.006 & 8.259 & 11.642 & 16.370 \\
\hline glass $(0.01 \%$ iron oxide) & 0.1 & 2.4 & 0.6 & -1.6 & 0.4 & 0.3 & 0.6 & 1.0 \\
\hline glass $(0.10 \%$ iron oxide) & -0.1 & 0 & 0.9 & -2.0 & -2.5 & 0.4 & 0.3 & 0.9 \\
\hline $\begin{array}{c}\text { fluorinated (ethylene propylene) } \\
\text { copolymer }\end{array}$ & 0.3 & 0.3 & 2 & 0.4 & -0.3 & 0 & 0.2 & 0.1 \\
\hline poly(vinyl fluoride) & 0.7 & 1.4 & 0.8 & 1.1 & 0.4 & 0.7 & el & el \\
\hline poly (ethylene terephthalate) & 0.6 & 0.8 & 1.8 & 1.4 & 0.6 & e & 1.2 & e \\
\hline acrylic & 0 & 0.6 & 0.2 & 0.4 & -0.1 & e) & -0.3 & ef \\
\hline poly(methyl methacrylate) & 1.1 & 0.3 & 0.4 & -0.3 & 0.3 & 0.4 & 0.6 & 0.2 \\
\hline polycarbonate & 0.7 & 0.3 & 0.3 & 0 & 0.5 & 0.5 & 0.6 & 0.9 \\
\hline fiber reinforced plastic $1.0 \mathrm{~mm}$ & 2.1 & 3.3 & 1.8 & 3.6 & 5.6 & 3.9 & 8.5 & 6.2 \\
\hline fiber reinforced plastic $1.5 \mathrm{~mm}$ & 7.8 & 10.6 & 9.0 & 14.5 & 7.8 & 2.7 & 19.4 & 10.1 \\
\hline
\end{tabular}

a Materials were exposed on minicollectors. Transmittance measurements were made on a Cary 17D integrating sphere spectrophotometer according to ASTM E 424-71, Method A. The solar energy transmittance for air mass 2 at sea level was obtained by integrating over Parry Moon's standard solar energy distribution curve using weighted ordinates. Each transmittance value represents a separate test specimen.

Transmittance is expressed in percentage.

b/ The solar energy transmittance loss is the difference between the average for the control test specimens (Table 11) and the value obtained after the test specimen was washed. Negative values represent a gain in comparison with the average for the controls. This solar energy transmittance loss does not include the loss due to dirt on the surface. Losses due to dirt are tabulated in Table 30.

ᄃ Two sets of minicollectors were exposed for the same length of time but different dates.

d) Solar radiation values in $\mathrm{GJ} / \mathrm{m}^{2}$ are converted to $\mathrm{Btu} / \mathrm{ft}^{2}$ by: $\mathrm{Btu} / \mathrm{ft}^{2}=\left(\mathrm{GJ} / \mathrm{m}^{2} \times 1.135 \times 10^{13}\right)$.

I Material failed prior to this time. 
Table 29

Solar Energy Transmittance Loss Due to Dirt on the Surface of Cover Plate Materials After a Single Cover Exposure in New River, Arizonaa

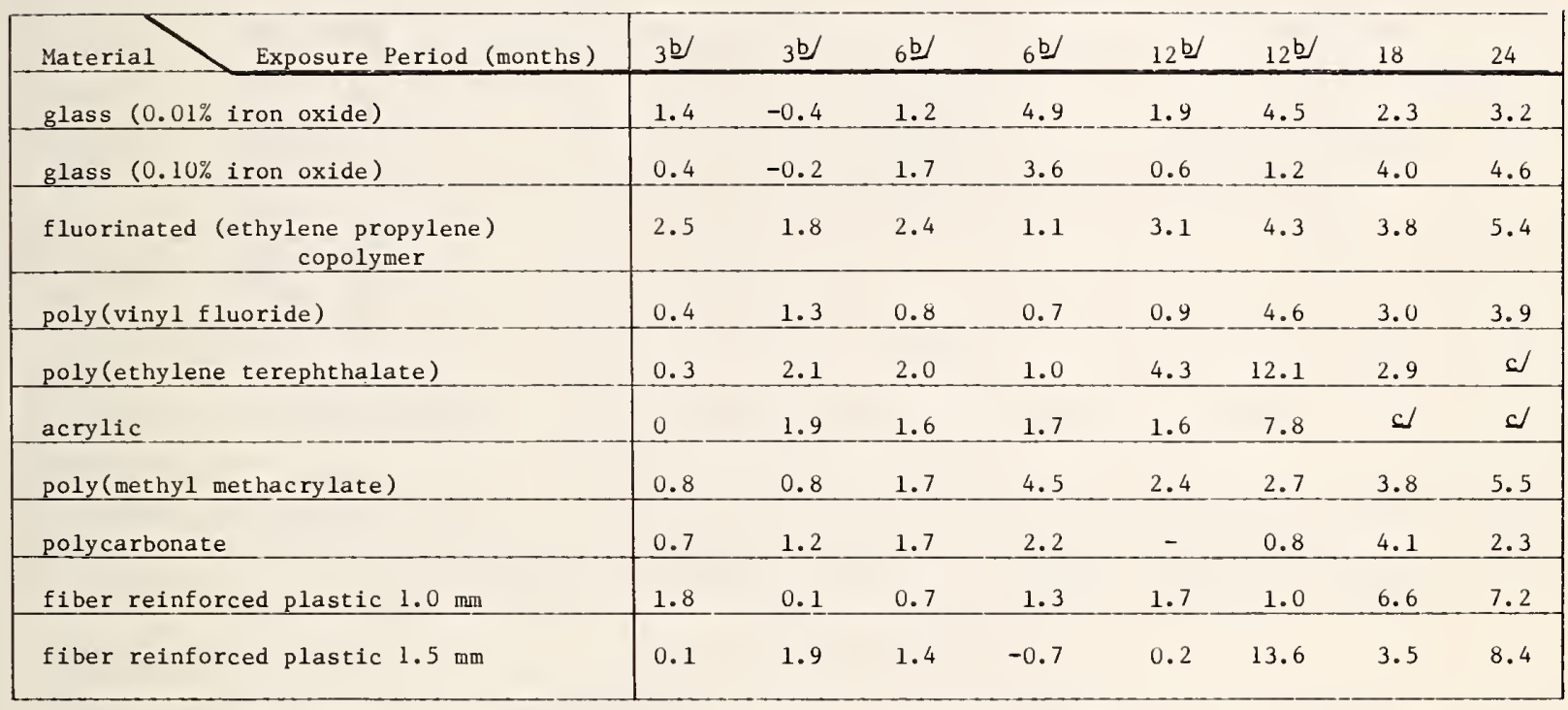

a Materials were exposed to natural weathering on minicollectors. Transmittance measurements were made on a Cary 17D integrating sphere spectrophotometer according to ASTM E 424-71, Method A. The solar energy transmittance for air mass 2 at sea level was obtained by integrating over Parry Moon's standard solar energy distribution curve using weighted ordinates. Each transmittance represents a separate test specimen. The solar energy transmittance loss due to dirt is to the difference between the solar energy transmittance measurements made before and after washing the test specimen. Negative values represent a loss in transmittance after washing. Transmittance is expressed in percentage.

$\mathrm{b}$ Two sets of minicollectors were exposed for the same length of time but different dates.

c/ Material failed prior to this time. 
Table 30

Solar Energy Transmittance Loss Due to Dirt on the Surface of Cover

Plate Materials After Double Cover Exposure in New River, Arizona

\begin{tabular}{|c|c|c|c|c|c|c|c|c|}
\hline & \multicolumn{8}{|c|}{ Outer Cover } \\
\hline Exposure Period (months) & $3 \mathrm{~b} /$ & 3 b & $6 \mathrm{~b} /$ & $6 \mathrm{~b}$ & $12 \mathrm{~b}$ & $12 \mathrm{~b}$ & 18 & 24 \\
\hline glass $(0.01 \%$ iron oxide) & 0.2 & 0.1 & 1.9 & 5.8 & 0.3 & 2.1 & 3.0 & 5.4 \\
\hline glass (0.10\% iron oxide) & 0.2 & 0.5 & $1.0^{\circ}$ & 4.6 & 1.8 & 3.5 & 2.8 & 4.1 \\
\hline $\begin{array}{c}\text { fluorinated (ethylene propylene) } \\
\text { copolymer }\end{array}$ & 2.5 & 1.7 & 2.2 & 1.2 & 2.8 & 4.0 & 3.4 & 1.1 \\
\hline poly(vinyl fluoride) & 0.8 & 0 & 0.7 & 1.2 & 2.0 & 3.8 & $=$ & 2.3 \\
\hline poly (ethylene terephthalate) & 0.1 & 0.9 & 1.9 & 1.2 & 1.4 & c & 7.6 & c/ \\
\hline acrylic & 1.6 & 1.8 & 1.3 & 2.3 & 0.4 & c) & c) & c/ \\
\hline poly(methyl methacrylate) & 0 & 2.0 & 1.4 & 3.1 & 3.5 & 2.0 & 2.9 & 4.8 \\
\hline polycarbonate & 1.1 & 1.7 & 1.4 & 2.0 & 2.0 & 1.0 & 3.4 & 2.6 \\
\hline fiber reinforced plastic $1.0 \mathrm{~mm}$ & 0.8 & 1.1 & 0.5 & 3.7 & 0.7 & 5.5 & 3.5 & 4.8 \\
\hline fiber reinforced plastic $1.5 \mathrm{~mm}$ & 0.8 & 0.8 & 3.8 & 2.9 & 2.0 & 3.0 & 3.8 & 9.1 \\
\hline
\end{tabular}

\begin{tabular}{|c|c|c|c|c|c|c|c|c|}
\hline & \multicolumn{8}{|c|}{ Inner Cover } \\
\hline Material Exposure Period (months) & $3 \mathrm{~b} /$ & $3 \mathrm{~b}$ & $6 \mathrm{~b}$ & $6 \mathrm{~b}$ & $12^{\mathrm{b} /}$ & $12 \mathrm{~b}$ & 18 & 24 \\
\hline glass $(0.01 \%$ iron oxide) & -0.5 & -1.0 & 0.9 & 3.3 & 3.2 & 0.2 & 0.8 & 1.9 \\
\hline glass $(0.10 \%$ iron oxide) & -0.4 & 0.7 & -0.1 & 2.5 & 1.7 & 0.5 & 0.1 & 0.6 \\
\hline $\begin{array}{c}\text { fluorinated (ethylene propylene) } \\
\text { copolymer }\end{array}$ & 0 & 0.4 & 0.3 & 0 & 2.1 & 0.8 & 0.7 & 2.2 \\
\hline poly(vinyl fluoride) & 0.3 & 1.0 & 0.6 & 0 & 2.3 & 0.4 & - & $=$ \\
\hline poly (ethylene terephthalate) & 0.1 & 0.2 & -0.5 & -0.1 & 1.7 & c & 0.4 & c) \\
\hline acrylic & 0.9 & 1.2 & 0.8 & 0.2 & 1.9 & c) & 1.8 & c \\
\hline poly(methyl methacrylate) & -0.8 & 1.0 & 0 & 1.7 & 1.5 & 0.5 & 1.0 & 2.8 \\
\hline polycarbonate & 0.2 & 0.6 & 0.4 & 0.7 & 2.1 & 0.4 & 1.7 & 4.1 \\
\hline fiber reinforced plastic $1.0 \mathrm{~mm}$ & 0 & -1.2 & 0.3 & 0 & 0.8 & 0 & 3.7 & 5.9 \\
\hline fiber reinforced plastic $1.5 \mathrm{~mm}$ & -0.7 & -1.1 & 0.9 & -0.2 & 6.4 & 9.4 & 2.2 & 4.3 \\
\hline
\end{tabular}

a/ Materials were exposed to natural weathering on minicollectors. Transmittance measurements were made on a Cary 17D integrating sphere spectrophotometer according to ASTM E 424-71, Method A. The solar energy transmittance for air mass 2 at sea level was obtained by integrating over Parry Moon's standard solar energy distribution curve using weighted ordinates. Each transmittance value represents a separate test specimen. The solar energy transmittance loss due to dirt is the difference between the solar energy transmittance measurements made before and after washing the test specimen. Negative values represent a loss in transmittance after washing. Transmittance is expresed in percentage.

b Two sets of minicollectors were exposed for the same length of time but different dates.

c) Material failed prior to this time. 
Figure 17a Spectral Transmittance of Washed 3.2Mm(1/81n) Glass $(0.01 \%$ IRON OXIDE) After TWO YeARS OUTDOOR WEATHERING
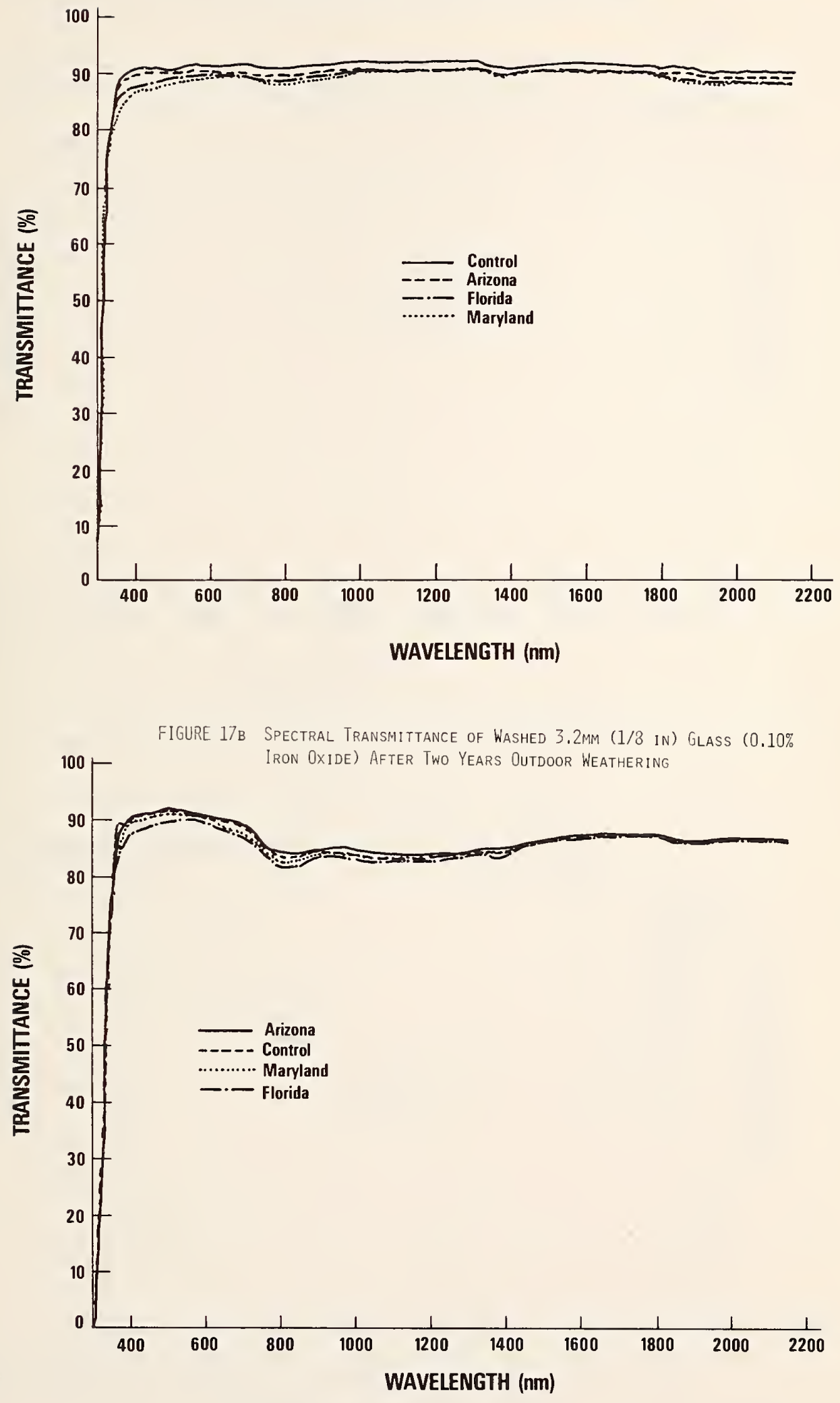
Figure $17 \mathrm{C}$ upectpal Transmittance of Washed 0.025mm(0.001in) Fluorinated

(E:HYLENE PROPYLENE) COPOLymer AFTER TWO YeARS DUtdoOR WEATHERING

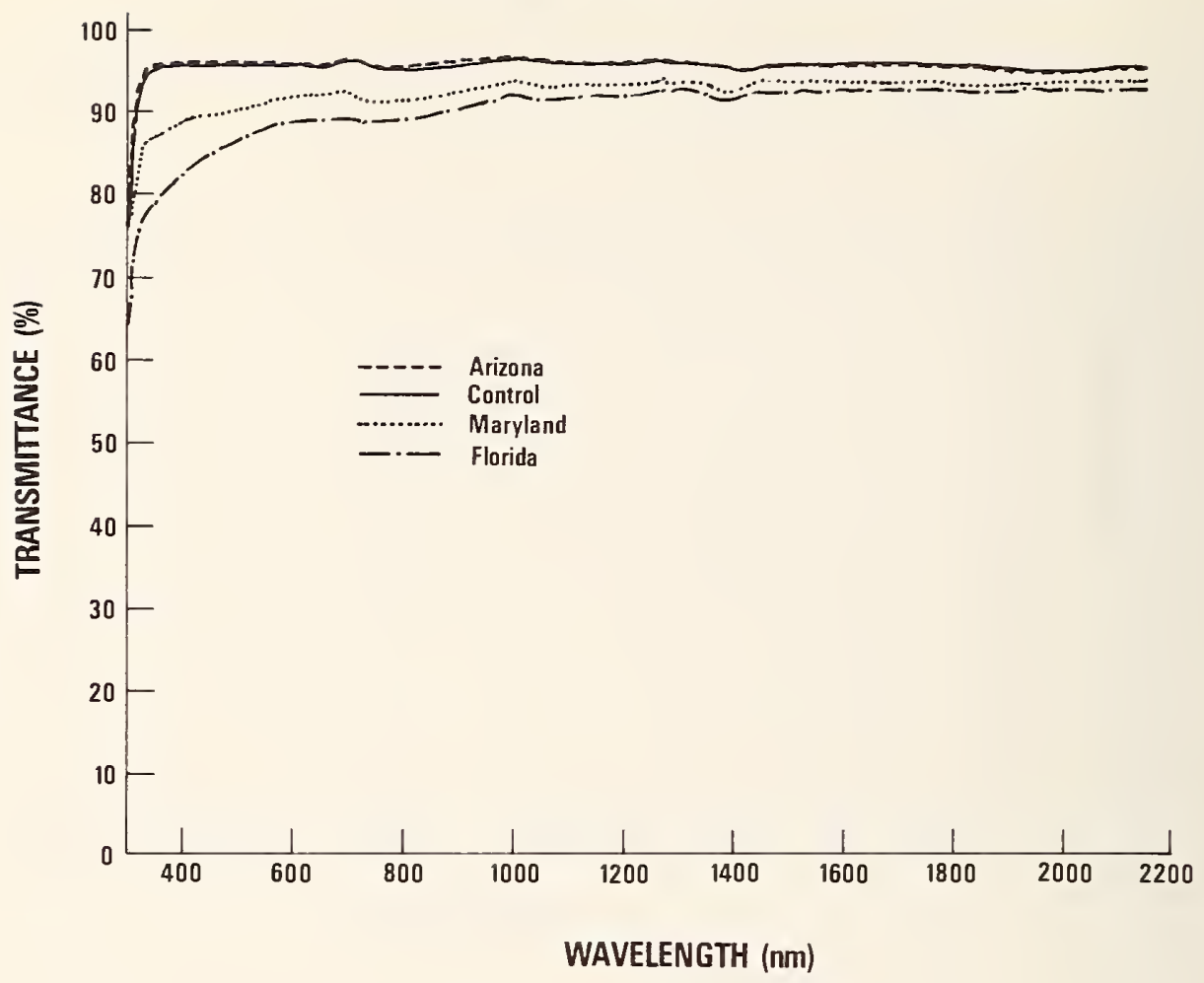

Figure 17d Spectral Transmittance of Washed 0.10mm(0.004in) Poly (vinyl FLUORIDE) AFTER TWO YEARS DUTDOOR WEATHERING

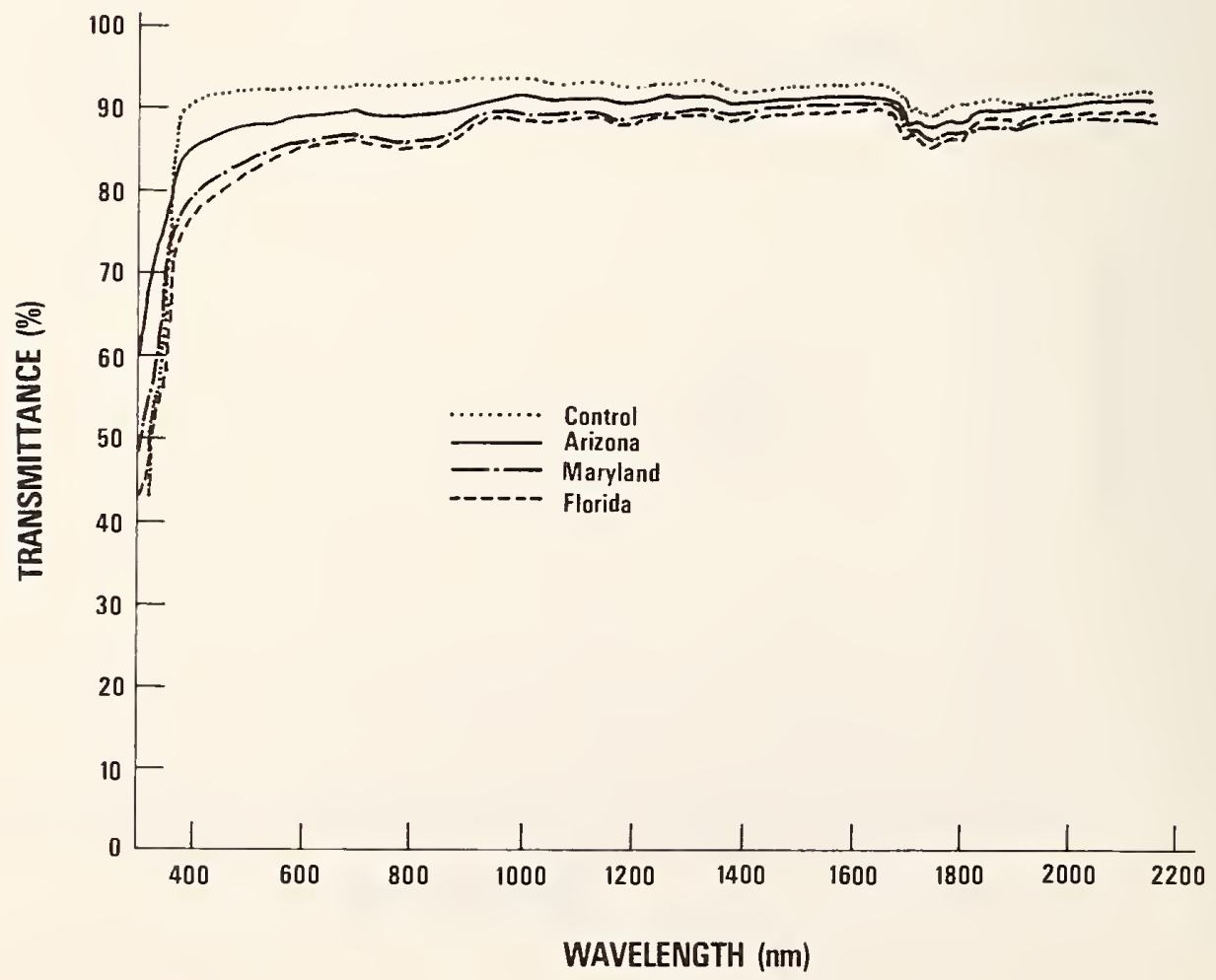


Figure 17e Spectral Transmittance of Washed $0.13 \mathrm{~mm}(0.005$ in) Poly(ethylene terephthalate) After Two Years Outdoor. Weathering

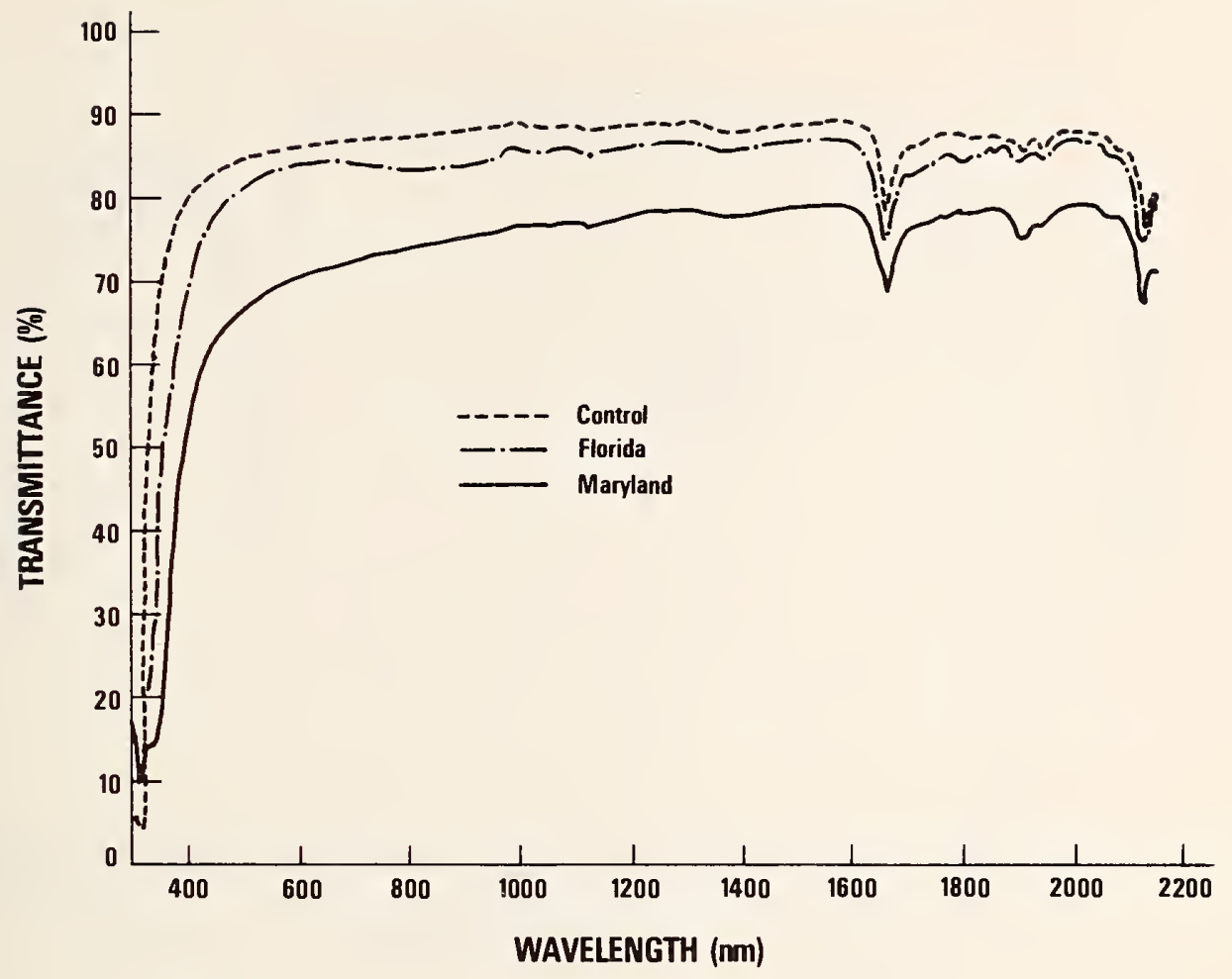

Figure $17 \mathrm{~F}$ Spectral Transmittance of Washed 1.5mm(0.06in) Poly(methyl methacrylate) After Tiwo Years Outdoor Weathering

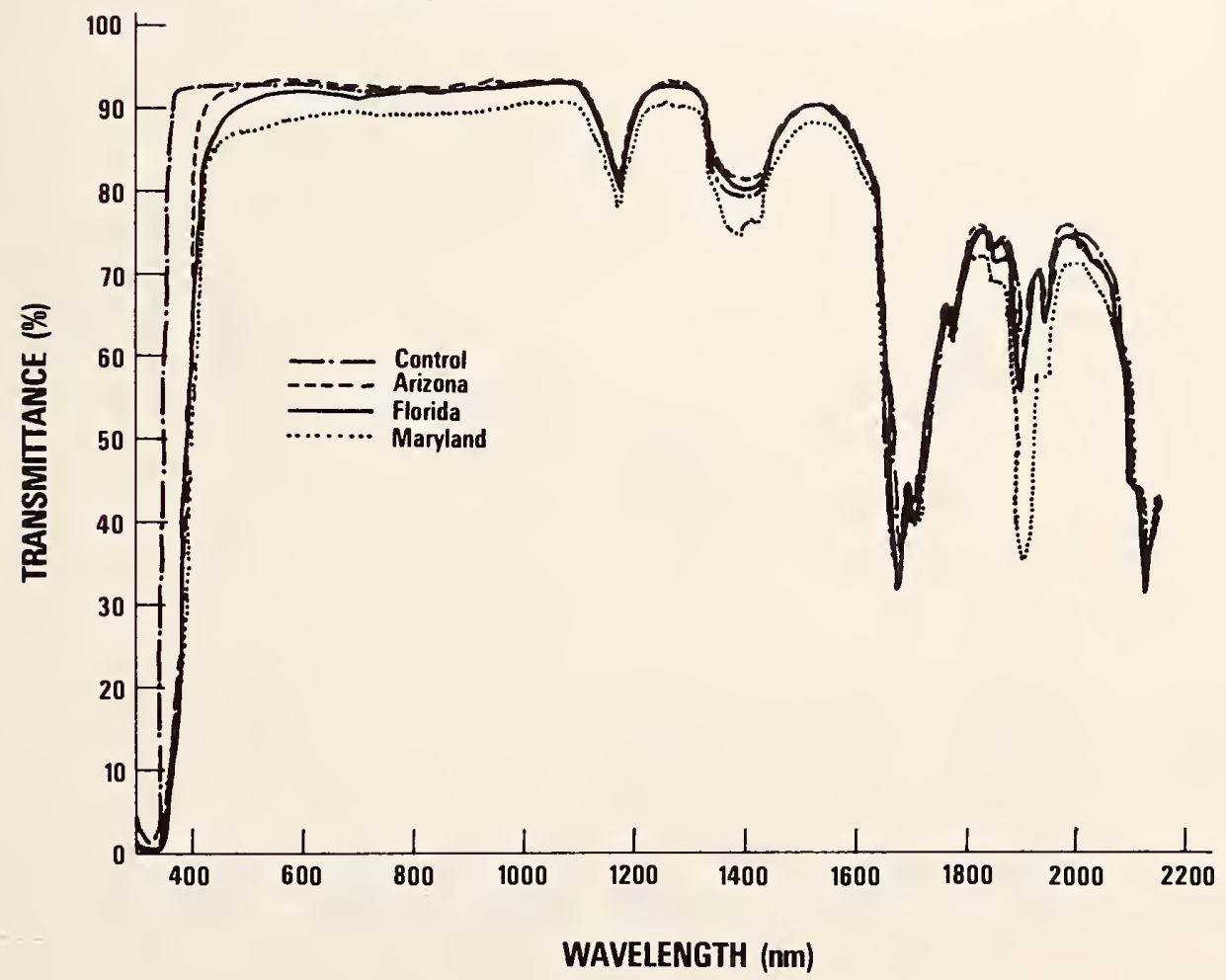


Figure 17g Spectral Transmittance of Washed 1.0mm(0.04in) Polycarbonate After Two Years Outdoor Weathering

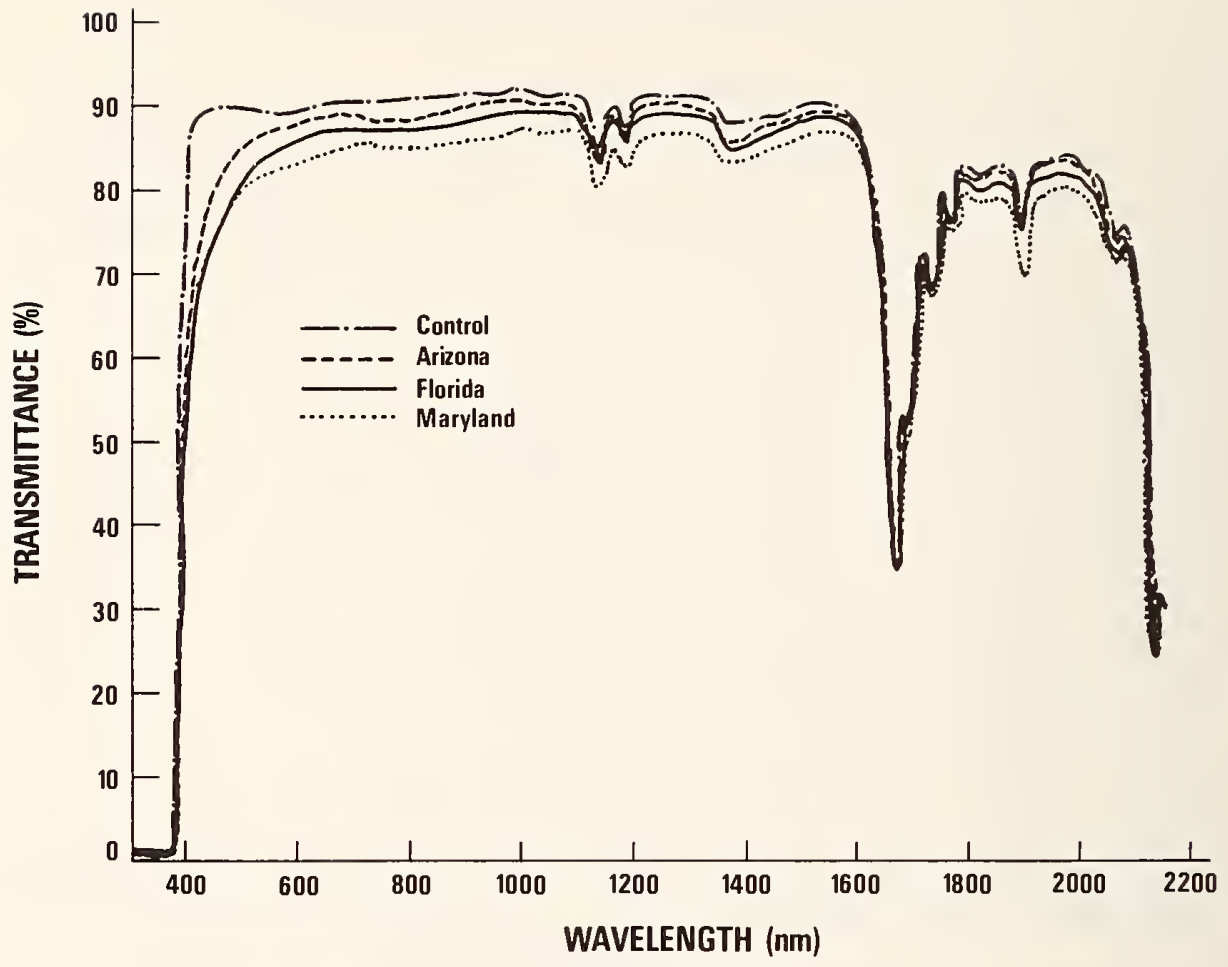

Figure $17 \mathrm{H}$ Spectral Transmittance of Washed 1.,0mm(0 04in) Fiber Reinforced Plastic After Two Years Outdoor Heathering

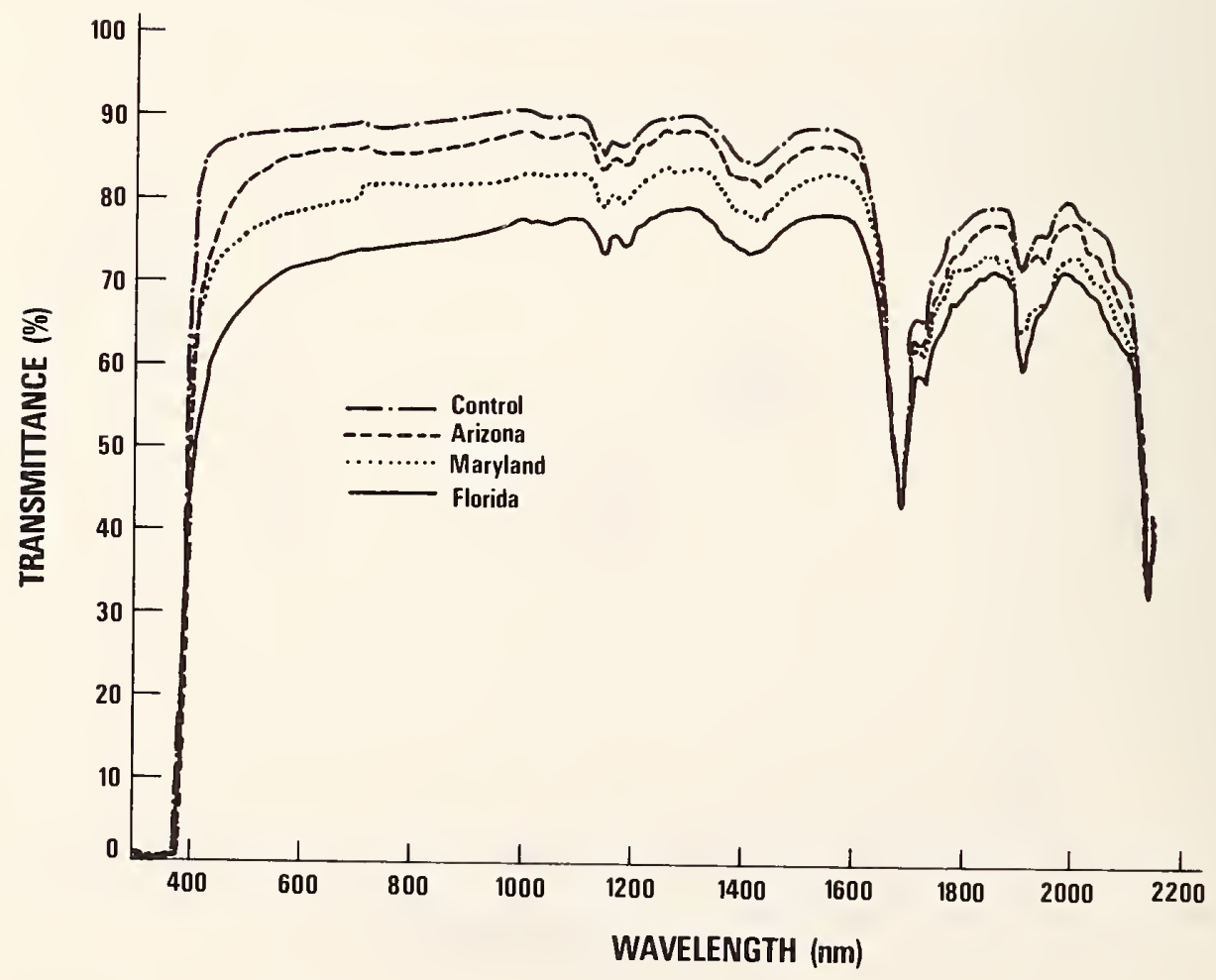




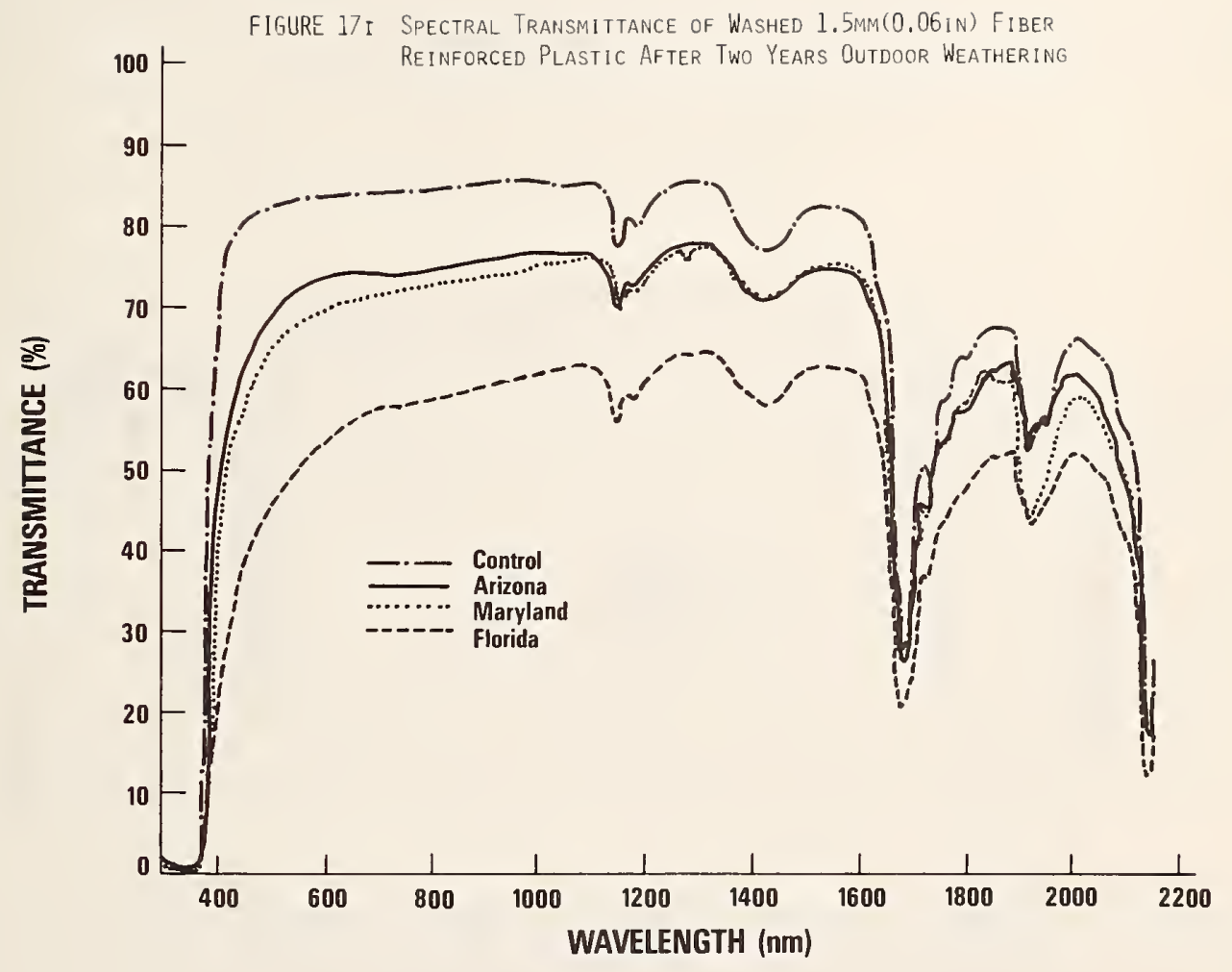


FIgURE 18 Comparison of SPECtral Transmittance of $1.0 \mathrm{~mm}(0.04$ in)

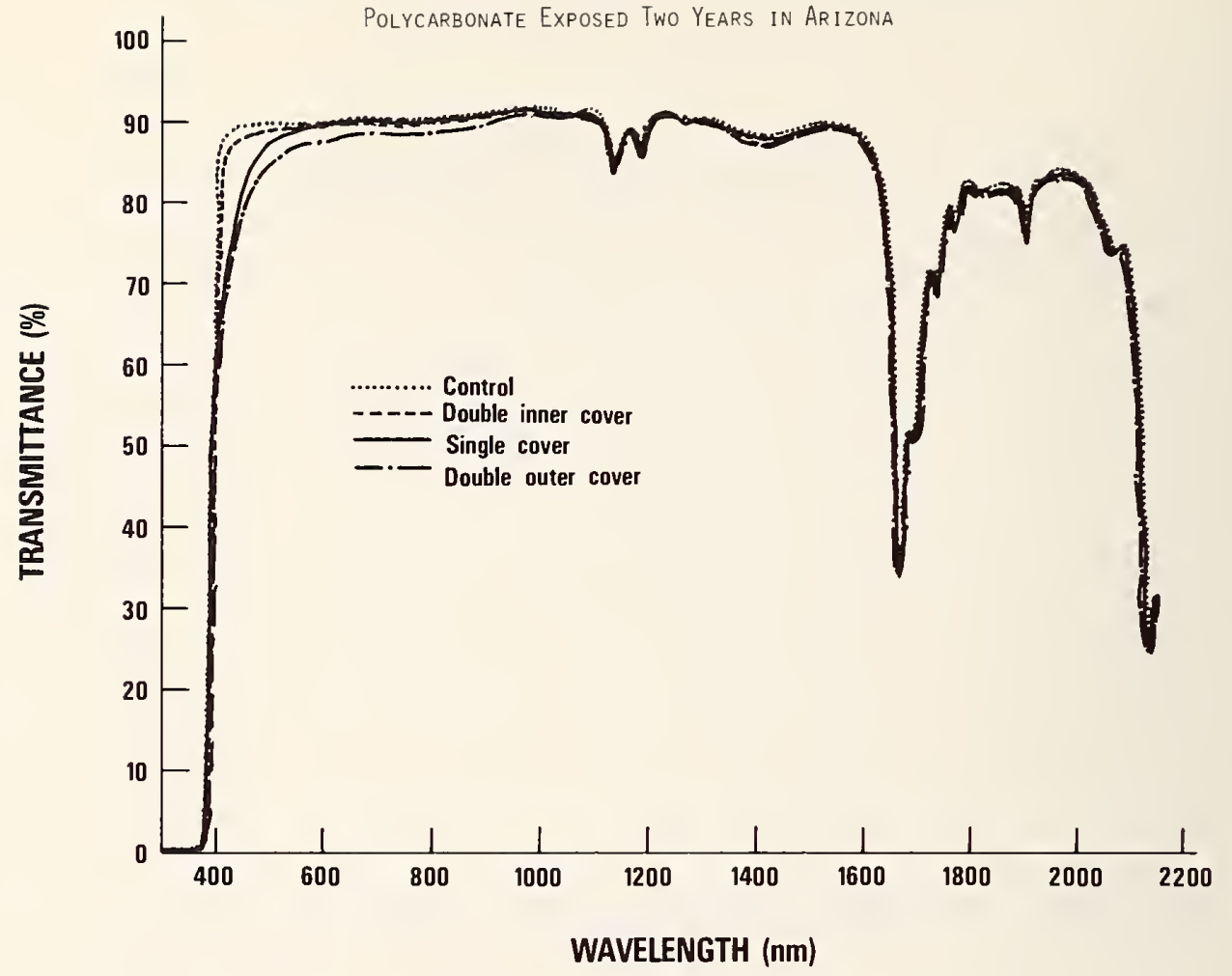

FIGURE 19 Comparision of Spectral Transmittance of $1.0 \mathrm{~mm}(0,04)$ Polycarbonate Single Covers Exposed in Florida

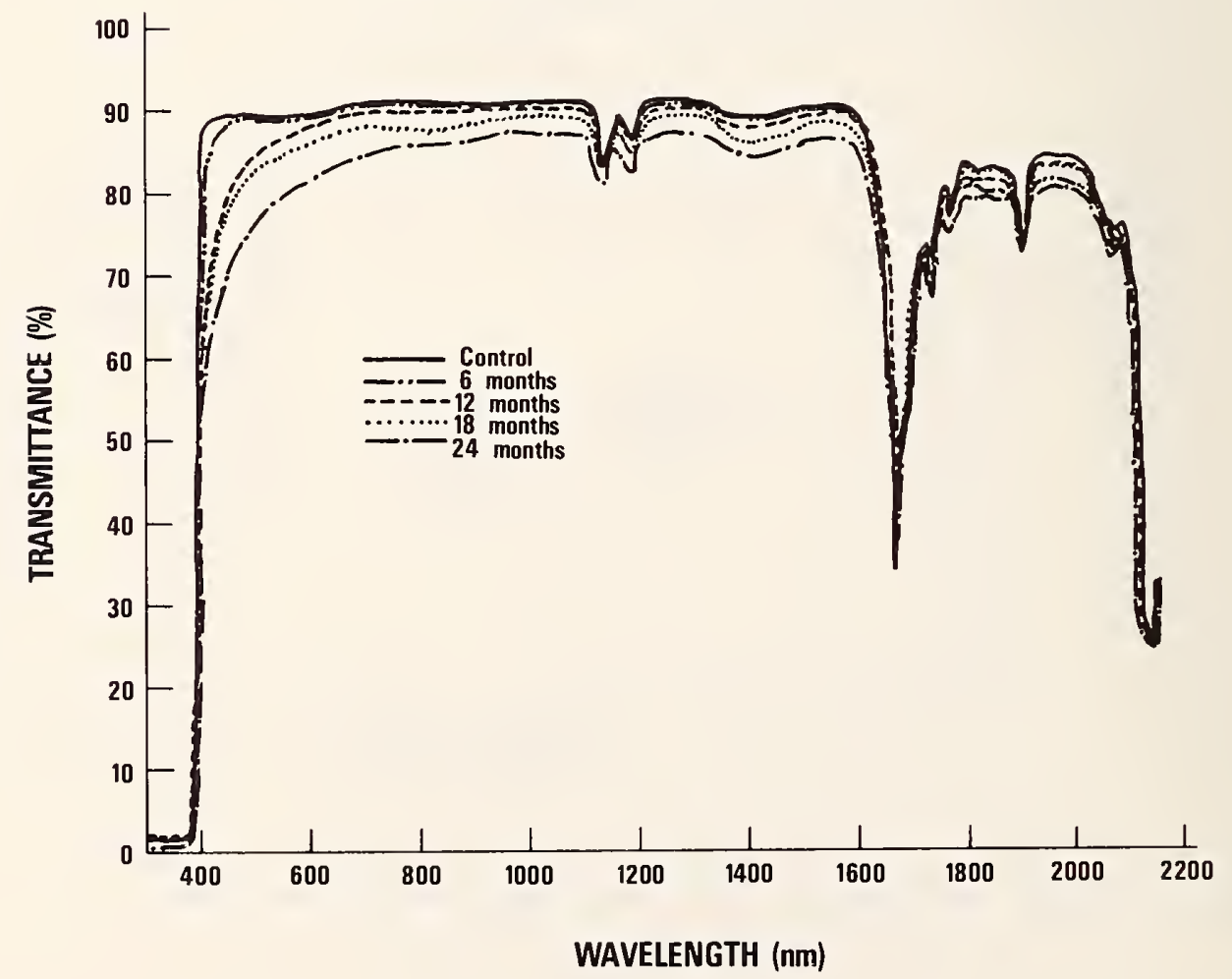


plate materials in outer cover and single cover applications. Some cover materials have even greater losses, e.g. poly (ethylene terephthalate) in Miami, fluorinated (ethylene propylene) copolymer in Gaithersburg, both fiber reinforced plastics in Miami and New River.

Although the inner cover was not expected to accumulate dirt, the data indicate that in some cases the inner cover does get dirty and lose solar energy transmittance. This was particularly true after 18 and 24 months in Miami and New River. This could result from decomposition of the wood during the exposures or from infiltration of dirt into boxes which were not well sealed or where the cover had loosened.

\subsubsection{Warpage}

Warpage was observed on some of the test specimens after outdoor exposures. The warpage occurred with the inner cover in the double cover minicollectors. Since the test specimens were adhered to the box on all four edges, the warpage occured primarily as sagging below the plane of the cover, although slight buckling above the plane was also observed. Although the edges were constrained, many test specimens of poly(methyl methacrylate) sagged in the center. For example, the test specimens exposed in a double cover box in Arizona for six months had a warpage of $6.4 \mathrm{~mm}(1 / 4 \mathrm{in})$ near the center. The polycarbonate exhibited slight sagging and buckling similar to warpage observed on full size solar collectors. Some fiber reinforced test specimens had a slight shape distortion after exposure. This may account for the waviness reported for some collectors glazed with fiber reinforced plastics.

\section{CONCLUSIONS}

\subsection{MEASUREMENT OF TRANSMITTANCE}

1. Method A (spectrophotometer) of ASTM E424 has better precision and repeatability than Method B (outdoor) and is therefore preferrable to Method B for determining solar energy transmittance of cover plate materials. Method A has a constant energy source whereas with Method B the sun's energy varies with time of day and year, weather conditions, sky conditions and geographic location. The range in solar energy transmittance values of the control specimens was greater using Method B (Table 3) than Method A (Table 2). Small solar energy transmittance changes of less than one percent can be easily measured with Method A whereas, with Method B, this is not possible. For example, in this study, there was frequently a variation of greater than one percent among the results for the controls when using Method B.

2. When the integrated solar energy transmittance loss is less than three percent, the spectral transmittance curve should be reviewed to determine the cause of the transmittance loss. While integrated solar transmittance values are helpful in evaluating material changes, when the solar transmittance change is small it is difficult to interpret the results. The 
spectral transmittance should be examined to determine if there is a shift in the absorption band in the UV-VIS region, or whether the transmittance curve has declined across the entire spectrum.

\subsection{ACCELERATED LABORATORY TESTING}

1. Accelerated laboratory testing procedures, such as those performed in this study and included in the proposed standard (Appendix C), offer an effective means of screening candidate cover plate materials.

2. Heat aging at an elevated temperature $\left(150^{\circ} \mathrm{C}\left(302^{\circ} \mathrm{F}\right)\right.$ ) for a relatively short time ( 500 hours) is an effective means of identifying materials which will develop problems in outdoor weathering. The cover plate materials having solar energy transmittance losses greater than two percent after only 500 hours at $150^{\circ} \mathrm{C}\left(302^{\circ} \mathrm{F}\right.$ ) (i.e. poly(vinyl fluoride), poly(ethylene terephthalate), acrylic film and fiber reinforced plastics) also developed problems in natural weathering. The poly(vinyl fluoride) inner covers cracked and disintegrated in less than 24 months at all three outdoor exposure sites. As outer and single covers, the solar energy transmittance loss of poly(vinyl fluoride) was generally greater than four percent after 24 months. The poly(ethylene terephthalate) turned white in Florida and also became very brittle at all three sites. The acrylic film cracked and disintegrated in 12-18 months at each site. Both the 1.5 and the $1.0 \mathrm{~mm}$ fiber reinforced plastics yellowed and lost transmittance at all three sites.

3. The heat aging had little effect on the glass and the fluorinated (ethylene propylene) copolymer.

4. For the materials included in this study other than the glass and fluorinated (ethylene propylene) copolymer, the rate of transmittance loss was related to the aging temperature and was accelerated by higher temperatures. The solar energy transmittances decreased as the cover plate materials were exposed to longer periods of heating aging. Also, as the temperature was increased the solar energy transmittances decreased.

5. Measurement of linear dimensions after ten hours exposure at a specific temperature is sufficient to establish trends and determine approximate dimensional changes due to that specific temperature.

6. Artificial weathering with a xenon arc light is helpful in distinguishing materials sensitive to solar radiation. Polycarbonate, the fiber reinforced plastics, poly(ethylene terephthalate), and the acrylic film suffered transmittance losses in the artificial weathering. In the natural weathering the polycarbonate and the fiber reinforced materials yellowed and lost transmittance. The poly(ethylene terephthalate) and acrylic showed smaller decreases due to the xenon arc exposure but significant changes in physical and mechanical properties when exposed outside. 
1. The minicollectors increased the temperature of the cover plate materials adequately to simulate operating collector temperatures and to approach stagnation temperatures of some flat plate solar collectors. They proved to provide data which were useful in evaluating candidate cover plate materials.

2. Solar radiation is not the only weathering factor causing solar energy transmittance losses. Although Arizona specimens received the most solar radiation and experienced the highest temperatures, the cover plate materials from the Arizona exposures did not have the greatest solar transmittance losses. Apparently moisture, air pollutants, and possibly other weather factors caused greater permanent transmittance losses at the Florida and Maryland locations. In addition, the dirt and dust caused greater temporary transmittance losses (which can be regained after cleaning) at these sites.

3. Dirt and dust retention is a major cause of solar energy transmittance decrease in a11 cover plate materials. Solar transmittance losses due to dirt and dust (which can be washed off) are generally from three to five percent and occassionally higher. These transmittance losses frequently equalled or exceeded losses due to natural weathering factors. Dirt and dust accumulation seemed somewhat material dependent (e.g. fluorinated (ethylene propylene) copolymer usually had higher transmittance losses due to dirt than other materials). Also, as the surface of a material roughened during exposure the dirt retained on the surface increased.

4. Decreases in the mechanical and physical properties of materials included in this study seemed related to solar radiation dosage. For example, the deterioration of the acrylic film, poly(vinyl fluoride) as the inner cover, and the poly(ethylene terephthalate) occured most rapidly at Arizona followed by the other sites.

\section{ADDITIONAL RESEARCH NEEDS}

In addition to these studies reported here, other valuable data could be obtained by further studies. The following research needs are identified:

1. Artificial weathering exposures with xenon arc light should be performed at higher temperatures to simulate the temperatures encountered in stagnating collectors. This experiment would combine the two major factors causing degradation of plastics in solar collectors. The data should be particularly useful in correlating with outdoor exposures.

2. The effect of moisture on cover plate materials should be studied and a laboratory procedure to evaluate this effect should be identified or developed. 
3. Various methods for cleaning cover plate materials should be evaluated and a standard practice for cleaning cover plate materials and collectors should be developed.

4. Studies to further evaluate the interaction of dirt and dust with the cover plate materials should be performed.

5. The surfaces of materials exposed in Maryland and Florida should be examined to better characterize them and to determine if the increased transmittance losses are due to deposits on the surfaces or to degradation of the materials by weathering factors.

\section{PROPOSED STANDARDS}

Based upon the laboratory work reported in Chapters 3 and 4, two standards for use in evaluation of cover plate materials for flat plate solar collectors were drafted and submitted for consideration for acceptance as consensus standards by ASTM Committee E44 on Solar Energy Conversion, Subcommittee E44.04 on Materials Performance. The proposed standards are included in Appendices $B$ and $C$ of this report.

These proposed standards, while based upon NBS laboratory studies, incorporate the comments of many $\mathrm{E} 44$ members and reflect the results of many hours of discussion of the E44.04.02 Cover Plate Task Group.

7.1 STANDARD PRACTICE FOR EXPOSURE OF COVER MATERIALS FOR SOLAR COLLECTORS TO NATURAL WEATHERING UNDER CONDITIONS SIMULAT ING STAGNATION MODE (APPENDIX B).

This is a proposed standard practice for the exposure of cover materials to natural weathering. It provides a procedure for the natural weathering of cover materials for flat plate solar collectors on a box which has heat loss coefficients similar to a flat plate collector. The box should elevate the cover plate temperature to approximate stagnation conditions of a solar collector. A variable angle exposure is used. Provisions are made for exposure of single and double cover assemblies to accomodate the need for exposure of both inner and outer solar collector cover materials. This document is based upon the concept of the minicollector (with modifications) described in Section 3.2.3. The standard practice provides guidelines for the calculation of the heat loss coefficient and guidelines for determining a variable angle exposure schedule.

\subsection{STANDARD PRACTICE FOR EVALUATION OF COVER MATERIALS FOR FLAT PLATE} SOLAR COLLECTORS (APPENDIX C)

This is a proposed standard practice for evaluation of cover materials for flat plate solar collectors. Much of this proposed standard practice is based upon the studies described in this report. The proposed standard includes both aging procedures and material property measurement tests. It describes evaluation procedures for assessment of the durability of solar collector covers by 
comparison of initial material property values with those obtained after exposure to aging procedures. The aging procedures encompass exposures for heat stability, natural weathering and accelerated weathering. Property test methods are included for measurements of solar energy transmittance, linear dimensional stability, warpage, impact resistance, tensile strength and the effect of dirt retention.

\section{REFERENCES}

[1] Grimmer, D. P. and Moore, S. W., "Practical Aspects of Solar Heating: A Review of Materials Use in Solar Heating Applications," presented at Society for the Advancement of Materials and Process Engineering, Oct. $14-16,1975$.

[2] "Component Spotlight - Glazing," Solar Heating and Cooling, Vol. 5, No. 1, p. 16, (January 1980).

[3] Skoda, L. F. and Masters, L. W., "Solar Energy Systems - Survey of Materials Performance," National Bureau of Standards Report, NBSIR 77-1314, (1977). Available from NTIS, Order No. PB 273305.

[4] Lorriman, D. B., "An Assessment of Problems Experienced With Operating Solar Systems in Canada and the Northern United States", National Research Council Technical Series No. 1, (1978). Available from Canadian Government Publishing Centre, Supply and Services Canada, Hu11, Quebec, Canada.

[5] Hobbs, Norman P., "Investigation of Glass Breakage in Solar Panels at Timonium School", Burlington, Mass., Kaman Avidyne, A Division of Kaman Sciences Corp, prepared for the U.S. Dept. of Energy Research and Development Administration under contract NSF-C871, P.0. WA-76-5330, (1976).

[6] Löf, G.0. and French, R.R., "Hail Resistance of Solar Collectors with Tempered Glass Covers", Preconference Proceedings - Solar Heating and Cooling Systems - Opertional Results, Colorado Springs, Co, November 27-30, 1979. Available from Solar Energy Research Institute Report No. TP-245-430.

[7] Baldwin, J. L., Climates of the United States, National Oceanic and Atmospheric Administration, Washington, D.C., (1973). Available from the Government Printing Office, Washington, D.C. 20402.

[8] Mendelsohn, M.A., Yeoman, F.A., Luck, R.M., Navish, R.W. and Meier, J.F., "Collector Sealants and Breathing", Westinghouse Electric Corporation, Pittsburgh, PA, Mid-Term Report Sept. 1978 - May 1979, for U.S. Dept. of Energy, Report No. ALD-153624.

[9] "Intermediate Minimum Property Standards Supplement-Solar Heating and Domestic Hot Water Systems", U.S. Department of Housing and Urban and 
[10] Holton, J. K., et al., "Interim Performance Criteria for Solar Heating and Cooling Systems in Residential Buildings, Second Edition", National Bureau of Standards Report NBSIR 78-1562, (1978). Available from National Technical Information Service, Springfield, VA 22161, Order No. PB 289767 .

[11] "Interim Performance Criteria for Solar Heating and Cooling Systems in Commercial Buildings", National Bureau of Standards Report NBSIR 76-1187, (1976). Available from National Technical Information Service, Springfield, VA 22161, Order No. PB 262114.

[12] Mathey, R. G., "Hail Resistance Tests of Aluminum Skin Honeycomb Panels for the Relocatable Lewis Building, Phase II", National Bureau of Standards Report 10193 (1970). Available from National Bureau of Standards, Washington, D.C. 20234 .

[13] Fuchs, E. R., "Hailstorm in Montana", American Roofer, (Nov• 1955).

[14] Kalmal, M. R. and Saxon, R., "Recent Developments in the Analysis and Prediction of the Weatherability of Plastics", in Applied Polymer Symposia No. 4, Weatherability of Plastics, M. R. Kalmal Ed., pp. 1-28, (Interscience, New York, N.Y. 1967).

[15] Jellinek, H. H. G., "Fundamental Degradation Processes Relevant to Outdoor Exposure of Polymers", in Applied Polymer Symposia No. 4, Weathering of Plastics, M. R. Kamal, Ed., pp. 41-59, (Interscience, New York, N.Y. 1967).

[16] Winslow, F. H., and Hawkins, W. L., "Some Weathering Characteristics of Plastics", in Applied Polymer Symposia No. 4, Weatherability of Plastics, M. R. Kamal, Ed., pp. 29-39, (Interscience, New York, N.Y. 1967 ).

[17] Gray, V.E. and Cadoff, B.C., "Survey of Techniques for Evaluating Effects of Weathering on Plastics", in Applied Polymer Symposia No. 4, Weathering of Plastics, M.R. Kamal, Ed., pp. 85-95, (Interscience, New York, N.Y. 1967 ).

[18] Carlson, D.J. and Wiles, D.M., "The Photooxidative Degradation of Polypropylene. Part I. Photooxidation and Photoinitiation Processes", J. Macromol. Sci., Rev. Macromol. Chem., C14, 65 (1976).

[19] Day, M. and Wiles, D.M., "Photochemical Degradation of Poly(ethylene terephthalate)", I., II., and III. J. App1. Polymer Sci., 16, 175, 191, 203 (1972).

[20] Zerlaut, G. A., "Fundamental Materials Considerations for Solar Collectors", Chpt. 13, Critical Materials Problems in Energy Production, Academic Press, (New York: 1976). 
[21] ASTM D 794, Recommended Practice for Determining Permanent Effect of Heat on Plastics, Annual Book of ASTM Standards, Book 35, American Society for Testing on Materials, 1916 Race Street, Philadelphia, PA 19103.

[22] Searle, N. Z. Giesecke, P., Kinmonth, R. and Hirt, R. "Ultraviolet Spectral Distributions and Aging Characteristics of Xenon Arcs and Filters", Applied Optics, APOPA, Vol. 3, No. 8, pp. 923-27, (August $1964)$.

[23] Boettner, E. A. and Miedler, L. J., "Simulating the Solar Spectrum with Filtered High Pressure Xenon Lamp", Applied Optics, APOPA, Vol. 2, No. 1, pp. 105-108, (January 1963).

[24] Hirt, R. C., Schmitt, R. G. Searle, N. Z. and Sullivan, A. P., "Ultraviolet Spectral Distribution of Natural Sunlight and Accelerated Test Light Sources," Journal of the Optical Society of America, JOSAA, Vol. 50, No. 7, pp. 706-13, (1960).

[25] ASTM D 2565, Recommended Practice for Operating Xenon Arc-Type (Water-Cooled) Light-and Water-Exposure Apparatus for Exposure of Plastics, Annual Book of ASTM Standards, Book 35, American Society of Testing and Materials, 1916 Race Street, Philadelphia, PA 19103.

[26] ASTM D 1435, Recommended Practice for Outdoor Weathering of Plastics, Annual Book of ASTM Standards, Book 35, American Society of Testing and Materials, 1916 Race Street, Philadelphia, PA 19103.

[27] ASTM E 424, Standard Test Methods for Solar Energy Transmittance and Reflectance (Terrestrial) of Sheet Materials, Annual Book of ASTM Standards Book 46, American Society of Testing and Materials, 1916 Race Street, Philadelphia, PA 19103.

[28] Smithsonian Physical Tables, Table 1, Vol. 815, p. 273, (1954).

[29] ASTM D 1042, Standard Test Method for Linear Dimensional Changes of Plastics, Annual Book of ASTM Standards, Book 35, American Society of Testing and Materials, 1916 Race Street, Philadelphia, PA 19103.

[30] ASTM D 1204, Standard Test Method for Linear Dimensional Changes of Nonrigid Thermoplastic Sheeting of Film at Elevated Temperatures, Annual Book of ASTM Standards, Book 35, American Society of Testing and Materials, 1916 Race Street, Philadelphia, PA 19103. 
I 


\section{A.1 Introduction}

Prior to performing heat aging exposures in the laboratory, it was necessary to determine the temperatures to which cover plate materials are exposed on $f l a t$ plate solar collectors. Two approaches were used to determine the temperatures. The first involved the installation of thermocouples on a collector to measure cover plate temperatures. The second involved computer simulations of collectors to estimate the temperatures reached.

\section{A.2 Measurement of Cover Plate Temperatures}

To measure material temperatures, thermocouples were installed at various locations on a typical flat plate solar collector. A description of the collector is contained in table Al and the collector is shown in figures A1 and A2. Type ' $\mathrm{T}$ ', copper constantan thermocouples were installed on the cover plate and the absorber in the locations indicated in figure A2.

\section{Table Al}

Description of Collector on Which Temperatures Were Measured

\begin{tabular}{|l|l|}
\hline $\begin{array}{l}\text { Exterior Size } \\
\begin{array}{l}\text { Two Cover Plates, } \\
\text { each cover: }\end{array}\end{array}$ & $1.93 \times 0.86 \mathrm{~m}(76 \times 34 \mathrm{in})$ \\
$\begin{array}{l}\text { Absorber Coating } \\
\begin{array}{l}\text { Insulation } \\
\text { Spacing between Absorber } \\
\text { and Inner Cover }\end{array}\end{array}$ & $\begin{array}{l}\text { (n) } \\
\text { Spacing between Covers }\end{array}$ \\
\hline
\end{tabular}

Thermocouples were attached to the cover plates using aluminum foil backed adhesive tape. The size of the strip of tape used was just large enough to provide secure contact with the surface of the cover plate. By proper positioning of the foil backed tape, the thermocouple junctions were protected from direct exposure to either the reradiation of heat from the absorber plate or direct solar radiation. Installation of the thermocouples on the absorber plate was accomplished by embedding the thermocouple junction in the back of the $3.2 \mathrm{~mm}(0.125 \mathrm{in})$ thick aluminum absorber. The thermocouple was inserted into a hole drilled at an angle in the absorber and it was held in place by peening. 


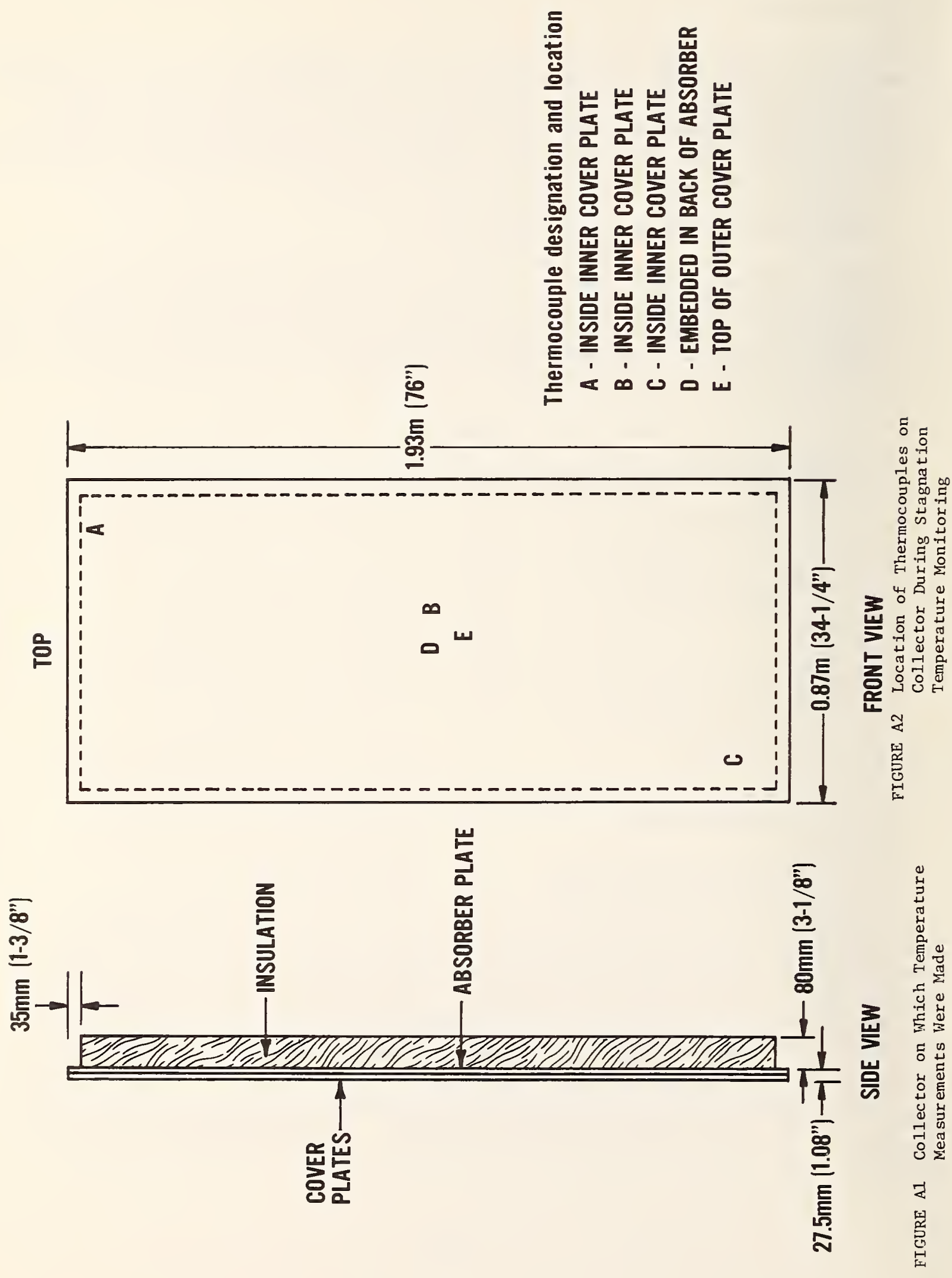


Solar radiation was recorded by a pyranometer mounted at the same tilt angle as the solar collector. A Class 1 pyranometer, as classified by the World Meteorological Organization, was used. The solar radiation data from the pyranometer was collected with an integrator. Monitoring the test was accomplished by scanning the thermocouples and solar radiation integrator at intervals (e.g., 10 or 15 minutes) using an automatic data logging system.

The solar collector was exposed at Gaithersburg, Maryland facing south. Temperatures were monitored with the collector in a stagnation condition. Figure $\mathrm{A} 3$ is an illustration of the cover plate temperatures on June 23, 1977. The highest inner cover plate temperature measured was about $120^{\circ} \mathrm{C}$ $\left(248^{\circ} \mathrm{F}\right)$, while the maximum outer cover plate temperature was $70^{\circ} \mathrm{C}\left(158^{\circ} \mathrm{F}\right)$. The slight wind during the day would have had some cooling effect, especially on the outer cover plate. Examination of the temperatures across the diagonal of the inner cover plate indicated a temperature differential of approximately $30^{\circ} \mathrm{C}\left(55^{\circ} \mathrm{F}\right)$ from the center of the collector to the upper right or lower left corners of the cover plate. This provides an indication of the temperature differences to which the inner cover was exposed.

Figure A4 illustrates the temperatures on September 18, 1977 of the absorber plate along with the inner and outer cover plates in a stagnating collector and the ambient air. The temperatures were measured at positions $B, D$ and $E$ shown in Figure A2. The maximum absorber plate temperature reached on this day was approximately $150^{\circ} \mathrm{C}\left(302^{\circ} \mathrm{F}\right)$ while the corresponding inner and outer cover plate temperatures were $130^{\circ} \mathrm{C}\left(265^{\circ} \mathrm{F}\right)$ and $75^{\circ} \mathrm{C}\left(167^{\circ} \mathrm{F}\right)$. When the maximum temperatures were measured, the instantaneous solar irradiance was approximately $945 \mathrm{~W}^{\circ} \mathrm{h} / \mathrm{m}^{2}\left(300 \mathrm{Btu} / \mathrm{ft}^{2}\right)$, the average wind speed was 10.9 $\mathrm{km} / \mathrm{h}(6.8 \mathrm{mph})$ and the ambient air temperature was $28^{\circ} \mathrm{C}\left(82^{\circ} \mathrm{F}\right)$.

The data in figure A4 show that the inner cover plate was approximately $20^{\circ} \mathrm{C}\left(37^{\circ} \mathrm{F}\right)$ cooler than the adjacent absorber while the difference between the inner and outer cover plates was approximately $55^{\circ} \mathrm{C}\left(98^{\circ} \mathrm{F}\right)$. The outer cover plate was also about $47^{\circ} \mathrm{C}\left(85^{\circ} \mathrm{F}\right)$ above the ambient temperature. Similar temperature differences were also found in the data in figure A3.

\section{A. 3 Computer Simulations to Estimate Cover Plate Temperatures}

\section{A.3.1 Interim Performance Criteria Calculations}

The Interim Performanç Criteria for Solar Heating and Cooling Systems in Residential Buildings contains computer generated graphs representing maximum temperatures for cover plate and absorber plate materials under

1/ Holton, J.K. et al., "Interim Performance Criteria for Solar Heating and Cooling Systems in Residential Buildings, Second Edition", National Bureau of Standards Reprot NBSIR 78-1562, (1978). Available from National Technical Information Service, Springfield, VA 22161 , Order No. PB 289967. 


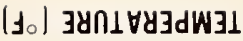

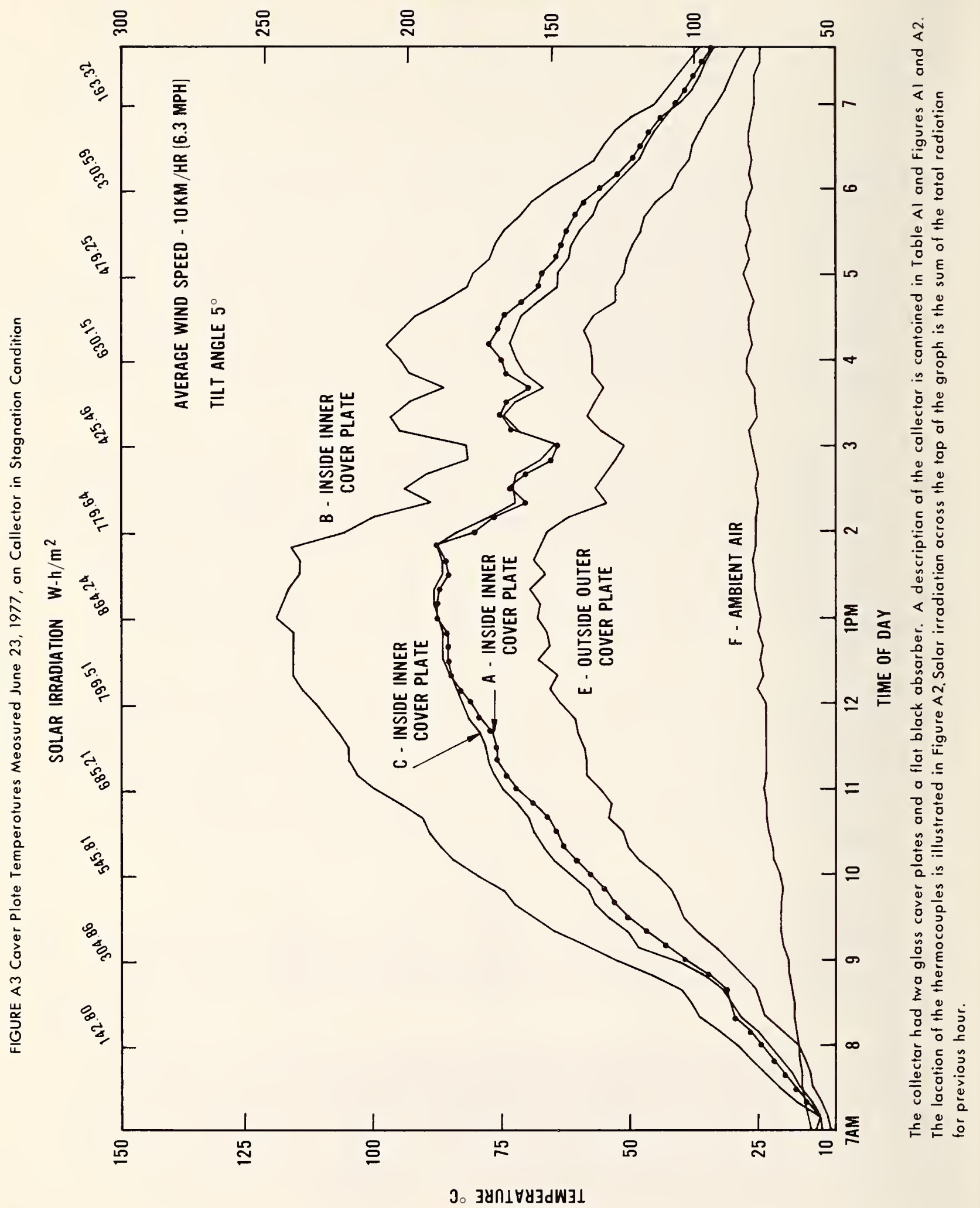




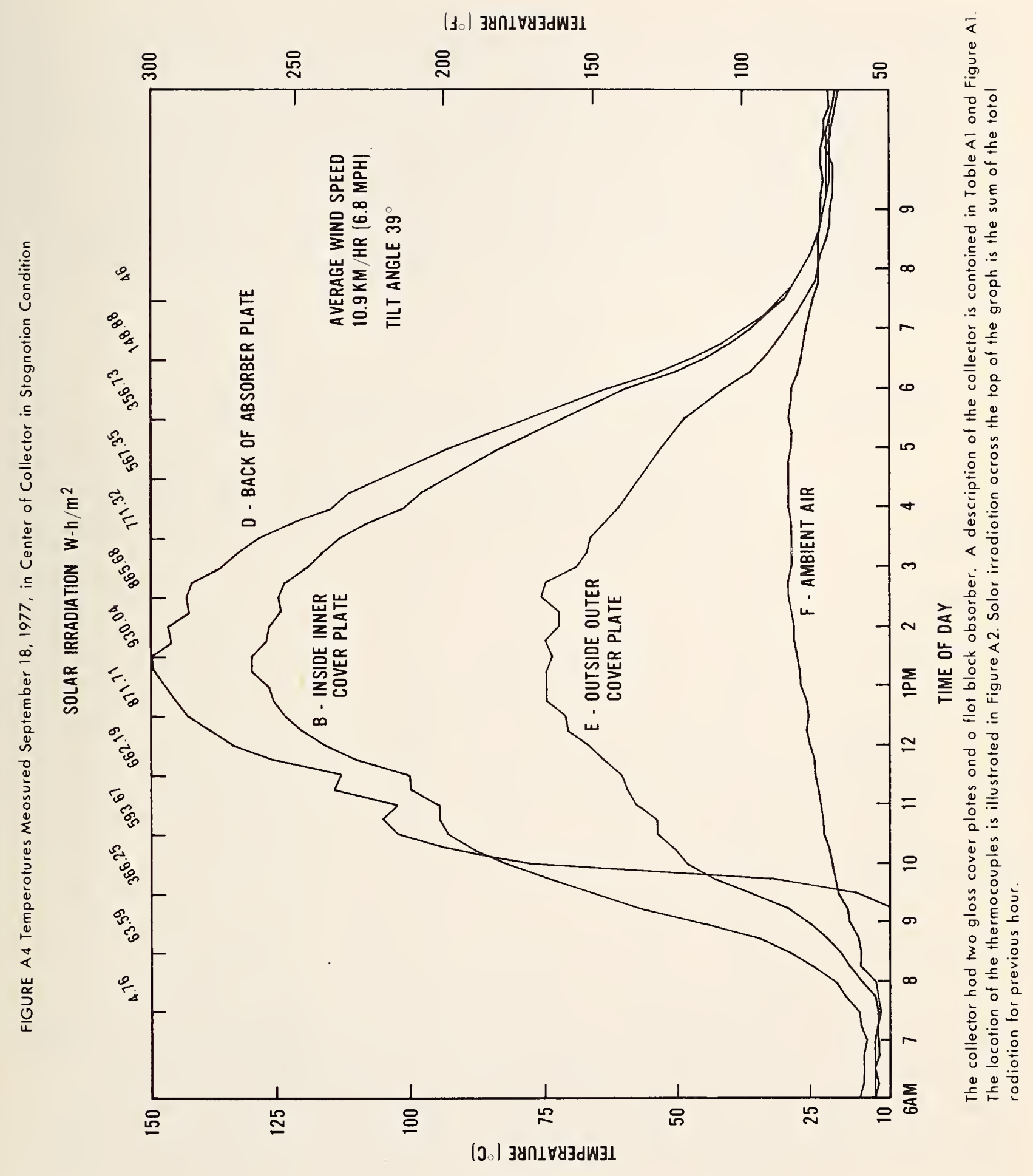


stagnation conditions. The graphs were based upon calculations for typical flat plate solar collectors having two types of cover plates, i.e., a typical window glass and a more transparent glass with a low iron oxide content.

Temperatures of glass cover plates and absorber plates were plotted as a function of ambient temperature for exposure to a solar radiation flux of $1070 \mathrm{~W} / \mathrm{m}^{2}\left(340 \mathrm{Btu} / \mathrm{ft}^{2} \cdot \mathrm{h}\right)$. Data were shown for collectors with one and two cover plates for the two cover glass materials and with spectrally flat and selective black absorber coatings. The calculations were performed with a transient thermal analysis model using the following conditions: 1) air space thickness of $9.5 \mathrm{~mm}$ ( $3 / 8 \mathrm{in})$ between the two cover plates and between the absorber surface and inner cover plate; 2) zero edge and back losses; 3 ) incident solar radiation normal to the collector; and 4 ) the properties of glass cover plates contained in table A2. Four graphs, figures A5a-A5d, illustrate the cover plate temperatures estimated by this computer simulation.

Table A2

Properties of Glass Cover Plates Used in Computer Simulation of Maximum Collector Temperatures in Interim Performance Criteria

\begin{tabular}{|c|c|c|}
\hline & $\begin{array}{l}\text { Conventional Glass } \\
(0.1 \% \text { iron oxide) }\end{array}$ & $\begin{array}{c}\text { Low Iron Oxide Glass } \\
(0.01 \% \text { iron oxide })\end{array}$ \\
\hline thickness & $3.2 \mathrm{~mm}(1 / 8 \mathrm{in})$ & $3.2 \mathrm{~mm}(1 / 8 \mathrm{in})$ \\
\hline aborptance $(\alpha)$ & 0.06 & 0.02 \\
\hline extinction coefficient & $\begin{array}{l}2.76 \times 10^{-2} / \mathrm{mm} \\
(0.70 / \mathrm{in})\end{array}$ & $\begin{array}{c}7.87 \times 10^{-3} / \mathrm{mm} \\
(0.20 / \mathrm{in})\end{array}$ \\
\hline index of refraction & 1.52 & 1.52 \\
\hline thermal conductivity & $\begin{array}{c}1.019 \mathrm{~W} / \mathrm{m}^{\circ} \mathrm{C} \\
\left(0.589 \mathrm{Btu} /\left(\mathrm{ft} \cdot \mathrm{h} \cdot{ }^{\circ} \mathrm{F}\right)\right)\end{array}$ & $\begin{array}{c}1.019 \mathrm{~W} / \mathrm{m} \cdot{ }^{\circ} \mathrm{C} \\
\left(0.589 \mathrm{Btu} /\left(\mathrm{ft} \cdot \mathrm{h}^{\circ}{ }^{\circ} \mathrm{F}\right)\right)\end{array}$ \\
\hline $\begin{array}{l}\text { solar energy } \\
\text { transmittance }\end{array}$ & $86 \%$ & $90 \%$ \\
\hline emittance $(\varepsilon)$ & 0.86 & 0.86 \\
\hline
\end{tabular}

With the ambient temperature at $27^{\circ} \mathrm{C}\left(81^{\circ} \mathrm{F}\right)$, the maximum temperature estimated for the conventional glass cover plates was $130-135^{\circ} \mathrm{C}\left(266-275^{\circ} \mathrm{F}\right)$ as an inner cover, $80-85^{\circ} \mathrm{C}\left(176-185^{\circ} \mathrm{F}\right)$ as an outer cover and $88-93^{\circ} \mathrm{C}\left(190-200^{\circ} \mathrm{F}\right)$ as a single cover plate. The temperatures of the conventional glass and the low iron glass varied by less than $5^{\circ} \mathrm{C}\left(9^{\circ} \mathrm{F}\right)$. Comparing the temperatures of the single and double glazed collectors, the data indicate that the cover plate on 


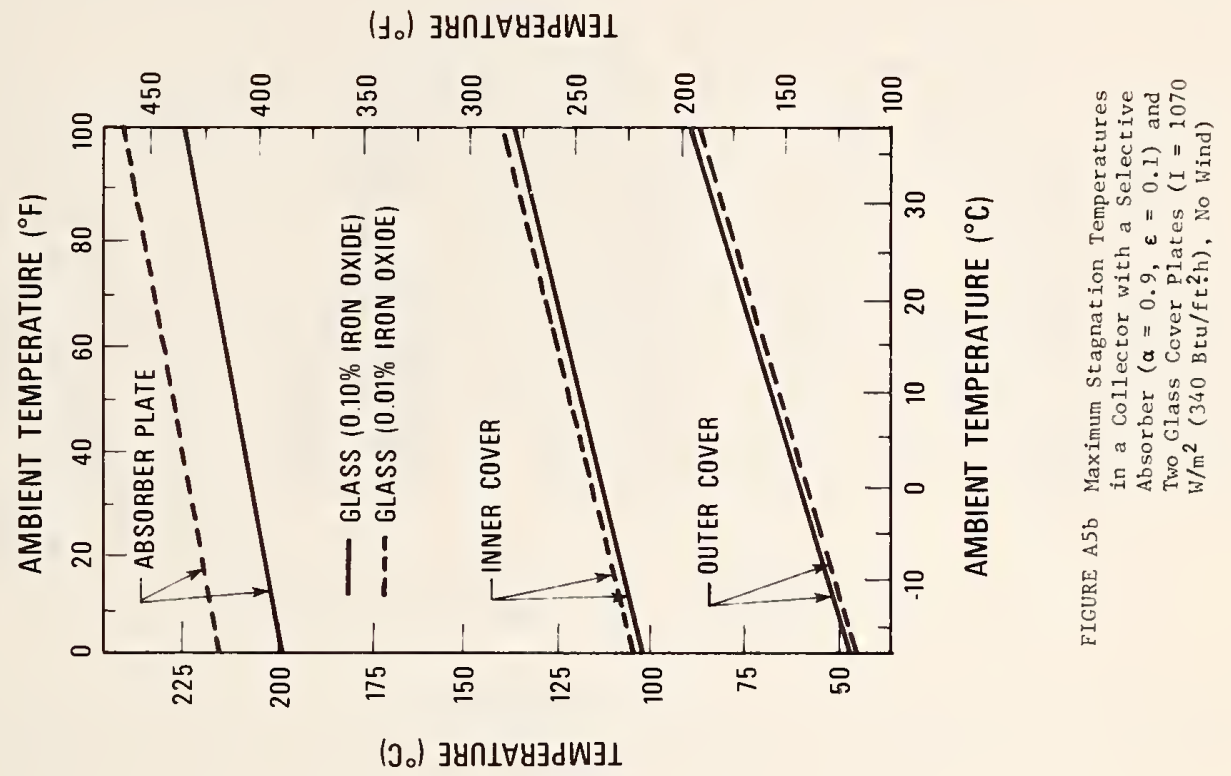

(ヨ。) $\exists y n \perp \forall y \exists d W \exists \perp$

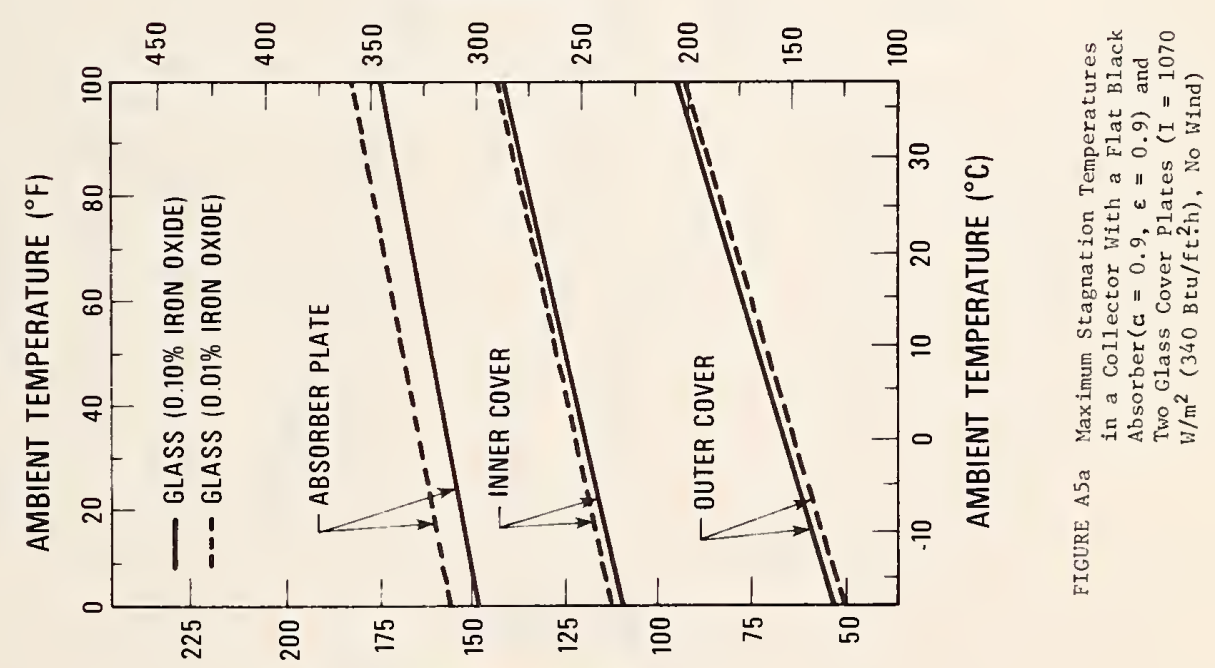

(ว.) $\exists y n \perp \forall y \exists d W \exists \perp$ 

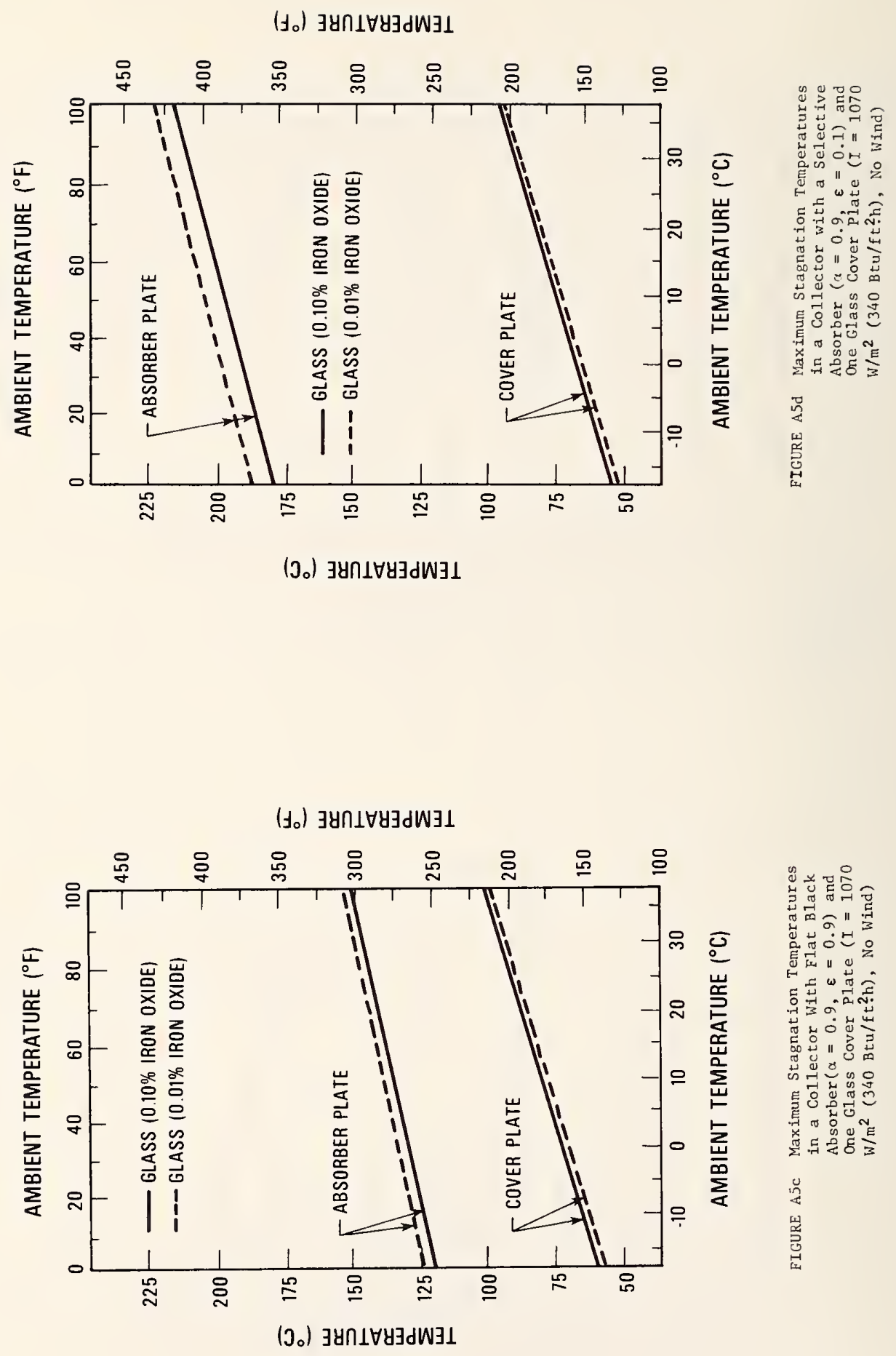
a single glazed collector is approximately the same temperature as the outer cover plate on the double glazed collector, with the outer cover plate being perhaps $10^{\circ} \mathrm{C}\left(18^{\circ} \mathrm{F}\right)$ lower. Note that the temperature of the cover plates on collectors having flat black absorbers were only about $5-10^{\circ} \mathrm{C}$ higher than cover plates on similar collectors having selective absorber surfaces.

This appears to be the case for both single and double glazed collectors. This temperature difference can be attributed to the selective surface reradiating less of the thermal energy than the flat black absorber.

It should be noted that the exposure conditions used for these comparisons represent typical maximum conditions. Higher solar radiation flux can be experienced under some atmospheric conditions or by the use of external reflectors. The cover plate temperature would also increase as the ambient temperature rises. For example, if the ambient temperature rose from $27^{\circ} \mathrm{C}$ $\left(81^{\circ} \mathrm{F}\right)$ to $38^{\circ} \mathrm{C}\left(100^{\circ} \mathrm{F}\right)$, these graphs predict the temperature of the cover would rise $5-8^{\circ} \mathrm{C}\left(9-14^{\circ} \mathrm{F}\right)$.

\section{A.3.2 Calculations for Plastic Cover Plate Materials}

Plastic cover plate materials have different material properties than those used for the glass covers in the computer calculations described in the preceding section. To estimate the temperatures reached by various types of plastic cover plate materials, additional computer calculations were made. Cover plate and absorber plate temperatures were determined for two sets of weather conditions for stagnating collectors having single and double cover plates and with spectrally flat and selective black absorber surfaces. Temperatures were calculated for seven cover materials which included three plastic films, (i.e., fluorinated(ethylene propylene) copolymer, poly(vinyl fluoride), and poly(ethylene terephthalate)), three plastic sheet materials, (i.e., poly(methyl methacrylate), polycarbonate, and fiber reinforced plastic) and one glass. Temperatures were calculated for each cover plate material on a single cover collector and for double cover collectors having both covers made of the same material. Additional, calculations were made using glass as the outer cover with each of the three films as the inner cover. A computer analysis technique was used to determine the temperatures. Collector and weather parameters which were utilized in the calculations are contained in table A3. The cover plate materials and their properties are listed in table A4. 
Collector and Weather Parameters Used in Computer Calculations

Collector Slope

Incident Angle

Number of Covers

Space Between Absorber

and Cover

Space between Inner and Outer Covers $\mathrm{K}$-Insulation

Insulation Thickness

Plate Absorptance $(\alpha)$

Plate Emittance $(\varepsilon)$

Solar Radiation

Diffuse Fraction

Ambient Temperature

Sky Temperature

Wind Speed $45^{\circ}$

$0.0^{\circ}$

One or Two

$25 \mathrm{~mm}$ (1 in)

$25 \mathrm{~mm}$ ( 1 in)

$0.035 \mathrm{~W} / \mathrm{m} \cdot{ }^{\circ} \mathrm{C}\left(0.20 \mathrm{Btu} /\left(\mathrm{ft} \cdot \mathrm{h} \cdot{ }^{\circ} \mathrm{F}\right)\right)$

(No Edge Losses)

$76.2 \mathrm{~mm}$ ( $3 \mathrm{in}$ )

0.95

0.20 or 0.90

$945 \mathrm{~W} / \mathrm{m}^{2}\left(300 \mathrm{Btu} / \mathrm{ft}^{2} \cdot \mathrm{h}\right)$

or $1070 \mathrm{~W} / \mathrm{m}^{2}\left(340 \mathrm{Btu} / \mathrm{ft}^{2} \cdot \mathrm{h}\right)$

0.10

$25^{\circ} \mathrm{C}\left(77^{\circ} \mathrm{F}\right)$ or $38^{\circ} \mathrm{C}\left(100^{\circ} \mathrm{F}\right)$

Ambient Temperature

$0.0 \mathrm{~m} / \mathrm{s}$

Table A5 represents the cover plate and absorber temperatures expected for a stagnating collector with an ambient temperature of $38^{\circ} \mathrm{C}\left(100^{\circ} \mathrm{F}\right)$ and a solar irradiance of $1070 \mathrm{~W} / \mathrm{m}^{2}\left(340 \mathrm{Btu} / \mathrm{ft}^{2} \cdot \mathrm{h}\right)$. These conditions represent clear sky conditions which can be reached in most parts of the United States, although a higher solar irradiance may be achieved, especially if reflectors are used. From the data in table A5, the highest predicted cover plate temperatures for a collector under these stagnation conditions would occur with low iron glass, although generally the temperatures of the plastic sheet materials were just a few degrees lower. Since film materials are generally transparent to reradiated long wavelength energy, film temperatures are lower than the corresponding temperatures for glass and plastic sheet materials (which are opaque to the long wavelength radiation).

For single cover applications, glass and plastic sheet materials had essentially the same maximum temperatures with the range being from $98-102^{\circ} \mathrm{C}$ $\left(208-216^{\circ} \mathrm{F}\right)$. The films had lower temperatures spanning from $81-96^{\circ} \mathrm{C}$ (178$205^{\circ} \mathrm{F}$ ). For the double cover collector, the maximum temperature of the inner cover ranged from $143-153^{\circ} \mathrm{C}\left(289-307^{\circ} \mathrm{F}\right)$ for the glass and plastic sheet materials while the film temperatures varied between $110^{\circ}$ and $131^{\circ} \mathrm{C}$ $\left(230^{\circ}\right.$ and $\left.268^{\circ} \mathrm{F}\right)$. The outer cover temperatures ranged from $93^{\circ}-98^{\circ} \mathrm{C}$ $\left(199-208^{\circ} \mathrm{F}\right)$ for glass and plastic sheet materials and from $76-87^{\circ} \mathrm{C}(169-$ $189^{\circ} \mathrm{F}$ ) for films. Comparing the double cover collectors having the glass/ film cover plate combination with those having two glass covers, the outer glass cover plate remained essentially the same temperature, while the inner film cover plate was $3-14^{\circ} \mathrm{C}\left(5-25^{\circ} \mathrm{F}\right)$ lower. Table A6 1ists the range of maximum stagnation temperatures along with average temperatures and the 


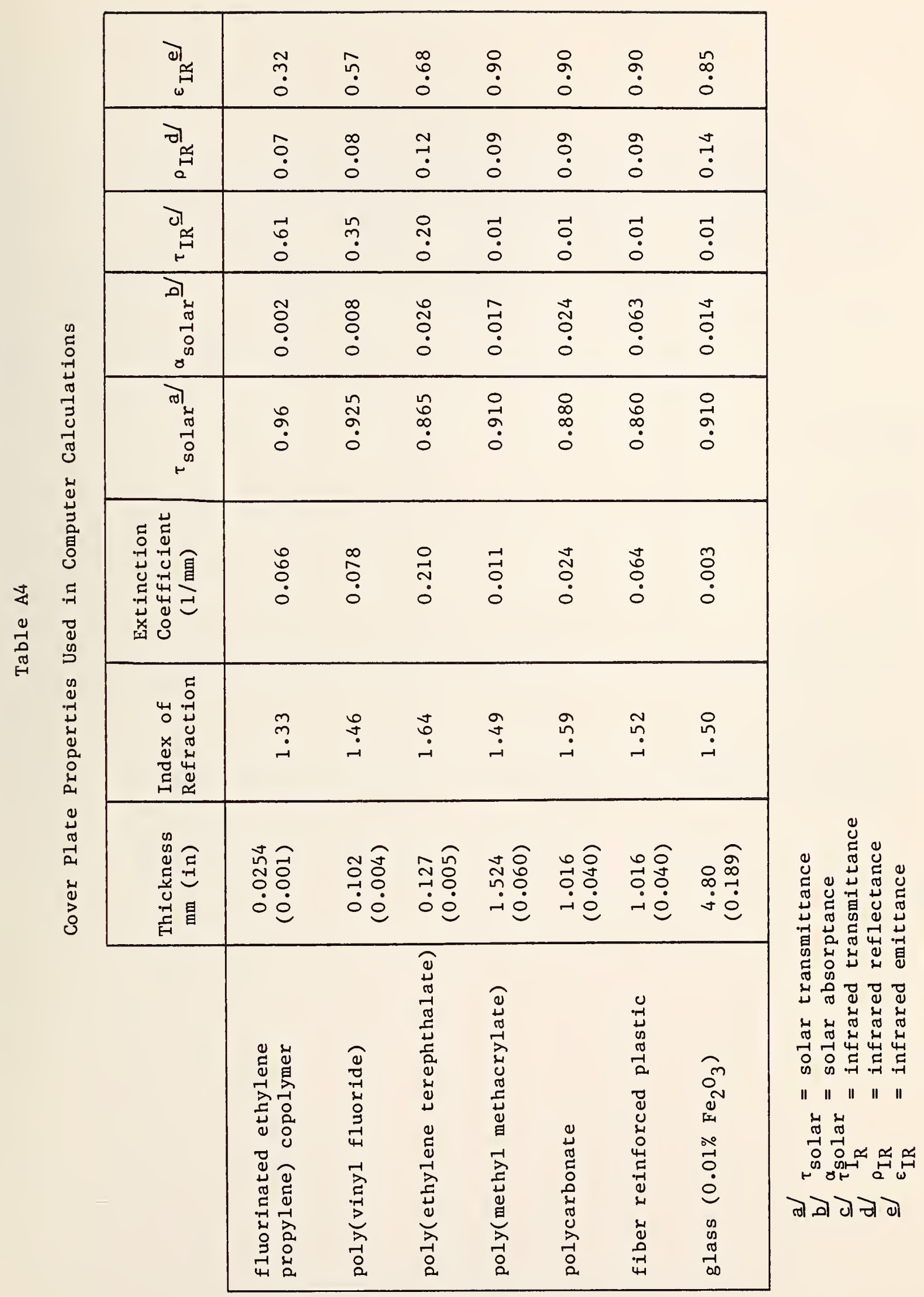


Table A5

Cover Plate and Absorber Plate Temperatures ${ }^{2 /}$ Reached on Stagnating Collectors with an Ambient Air Temperature of $38^{\circ} \mathrm{C}\left(100^{\circ} \mathrm{F}\right)$ and a Solar Irradiance of $1070 \mathrm{~W} / \mathrm{m}^{2}\left(340 \mathrm{Btu} / \mathrm{ft}^{2} \cdot \mathrm{h}\right)$

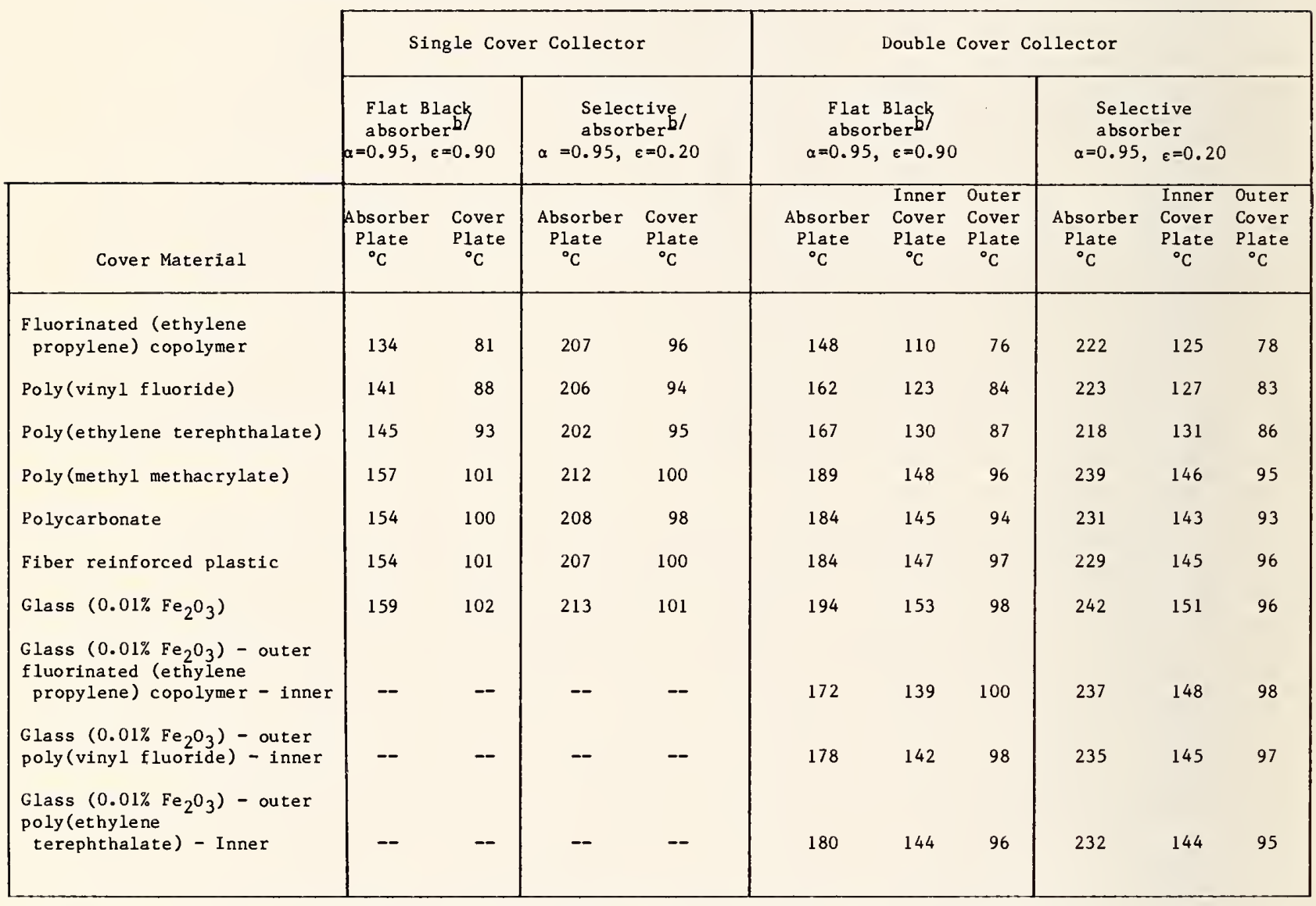

a/ Temperatures in Centigrade may be converted to Fahrenheit using the formula: ${ }^{\circ} \mathrm{F}=\left({ }^{\circ} \mathrm{C} x \frac{9}{5}\right)+32^{\circ}$.

b/ $\alpha=$ solar absorptance

$\varepsilon=$ emittance 
Summary of Cover Plate Temperature Data for Stagnation Conditions $\underline{a, b /}$

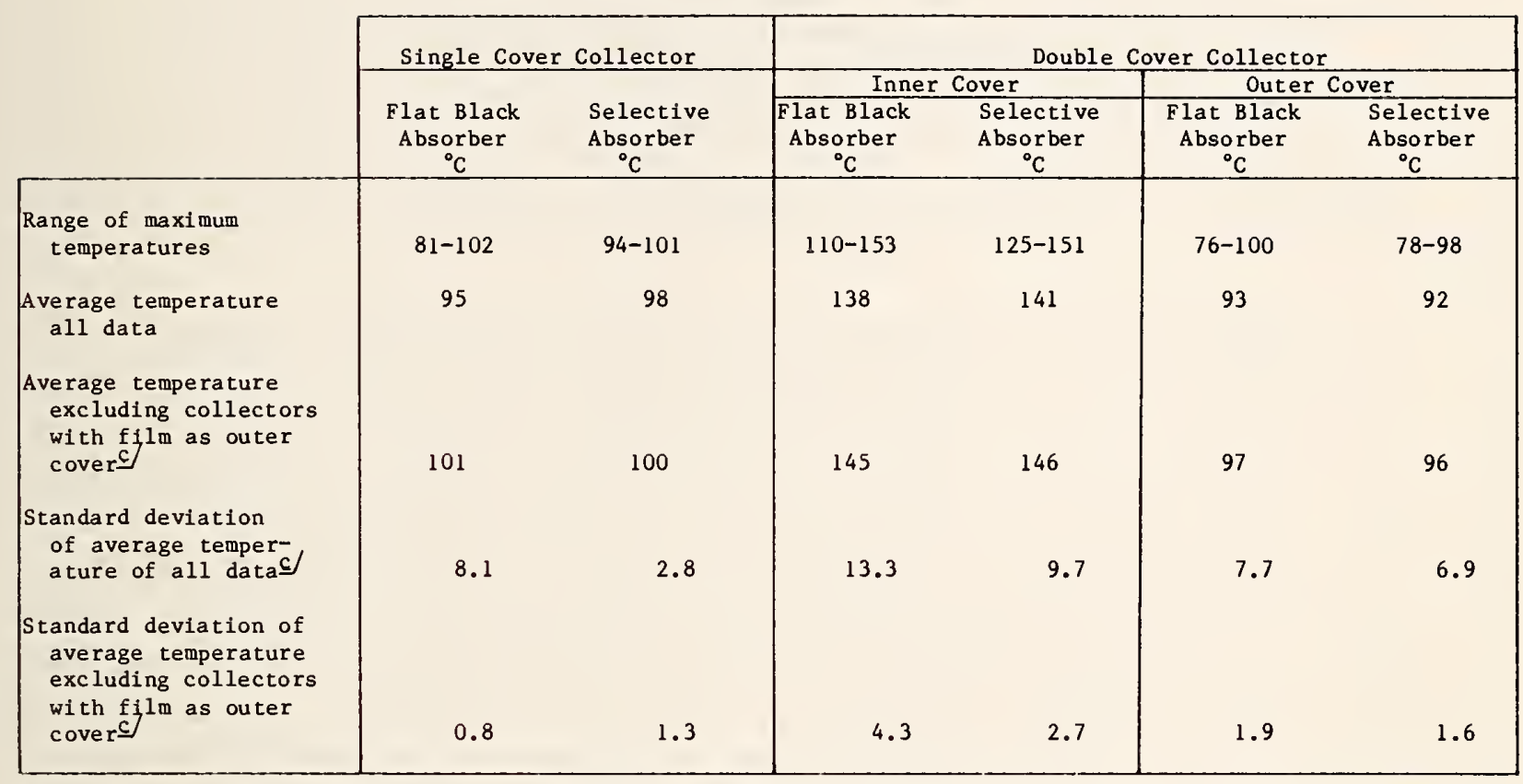

a/ These temperatures are extracted from table A5. Temperatures are based upon a solar irradiance of $1070 \mathrm{~W} / \mathrm{m}^{2}$ $\left(340 \mathrm{Btu} / \mathrm{ft}^{2} \mathrm{~h}\right)$ at an ambient temperature of $38^{\circ} \mathrm{C}\left(100^{\circ} \mathrm{F}\right)$. For the flat black absorber $a=.95, \varepsilon=.90$, while for the selective absorber $\alpha=.95, \varepsilon=.20$.

b/ Centigrade temperatures can be converted to Fahrenheit by the formula: ${ }^{\circ} \mathrm{F}=\left({ }^{\circ} \mathrm{C} \times \frac{9}{5}\right)+32^{\circ}$.

c/ Films are generally not used in outer cover applications as their resistance to puncture and impact is very low. This average temperature data excludes the use of fluorinated (ethylene propylene) copolymer, poly(vinyl fluoride) and poly(ethylene terephthalate) in applications as single covers and outer double covers. 
standard deviations. Since films are generally not used in outer cover applications, the average temperatures were calculated for all collector cover plate combinations and for the collector cover combinations that excluded films in applications as a single cover or outer double cover. When the temperature data for films in these applications was excluded, the average cover plate temperature increased but the standard deviation of the average temperatures significantly decreased. Thus, these average temperatures (excluding films as outer or single covers) are probably the temperatures typically reached by most collectors. It can be noted from table A6 that the type of absorber (i.e., flat black or selective) has no significant effect on the cover plate temperature. It can also be observed that single covers are only about $4^{\circ} \mathrm{C}\left(7^{\circ} \mathrm{F}\right)$ higher than the outer double cover.

Table A7 represents cover plate and absorber plate temperatures expected from a stagnating collector with an ambient temperature of $25^{\circ} \mathrm{C}\left(77^{\circ} \mathrm{F}\right)$ and a solar irradiance of $945 \mathrm{~W} / \mathrm{m}^{2}\left(300 \mathrm{Btu} / \mathrm{ft}^{2} \cdot \mathrm{h}\right)$. Table A7 has cover plate temperatures similar to the data in table A5, however, the ambient temperature and solar irradiance are lower. These conditions are typical of average summer weather for larger parts of the United States but do not produce maximum stagnation temperatures obtained under the higher ambient temperatures and solar irradiance. These calculations were done to compare the calculated temperatures with those which were measured on the stagnating collector (Section A.2) and to determine the effect of changing both the ambient temperature and solar irradiance. The variation in cover plate temperatures obtained by increasing the ambient temperature from $25^{\circ}$ to $38^{\circ} \mathrm{C}\left(77-100^{\circ} \mathrm{F}\right)$ and the solar irradiance from 945 $\mathrm{W} / \mathrm{m}^{2}$ to $1070 \mathrm{~W} / \mathrm{m}^{2}\left(300 \mathrm{Btu} / \mathrm{ft}^{2} \cdot \mathrm{h}\right.$ to $\left.340 \mathrm{Btu} / \mathrm{ft}^{2} \cdot \mathrm{h}\right)$ is summarized in table A8. Although the ambient, temperature, was increased $13^{\circ} \mathrm{C}\left(23^{\circ} \mathrm{F}\right)$ and the solar irradiance by $125 \mathrm{~W} / \mathrm{m}^{2}\left(40 \mathrm{Btu} / \mathrm{ft}^{2} \cdot \mathrm{h}\right)$, the estimated increase in the cover plate temperature was only $14-19^{\circ} \mathrm{C}\left(25-34^{\circ} \mathrm{F}\right)$.

\section{A. 4 Comparison of Cover Plate Temperature Data}

Glass cover plate temperatures measured and those obtained from the computer simulations are summarized in table A9. Although the weather parameters varied somewhat, the temperatures measured for the glass cover plates on the double cover collector are in the range of those predicted by the computer models when the ambient temperatures were comparable. The slightly lower outer cover plate temperature in the measured data can be explained by the $10.9 \mathrm{~km} / \mathrm{h}(6.3 \mathrm{mph})$ wind while the computer simulations had no wind conditions. The bottom line of temperatures in table A9 probably represents the maximum stagnation cover plate temperatures that would be achieved in most parts of the United States. 
Table A7

Cover Plate and Absorber Plate Temperatures ${ }^{2}$ Reached on Stagnating Collectors with an Ambient Air Temperature of $25^{\circ} \mathrm{C}\left(77^{\circ} \mathrm{F}\right)$ and a Solar Irradiance of $945 \mathrm{~W} / \mathrm{m}^{2}\left(300 \mathrm{Btu} / \mathrm{ft}{ }^{2} \mathrm{~h}\right)$

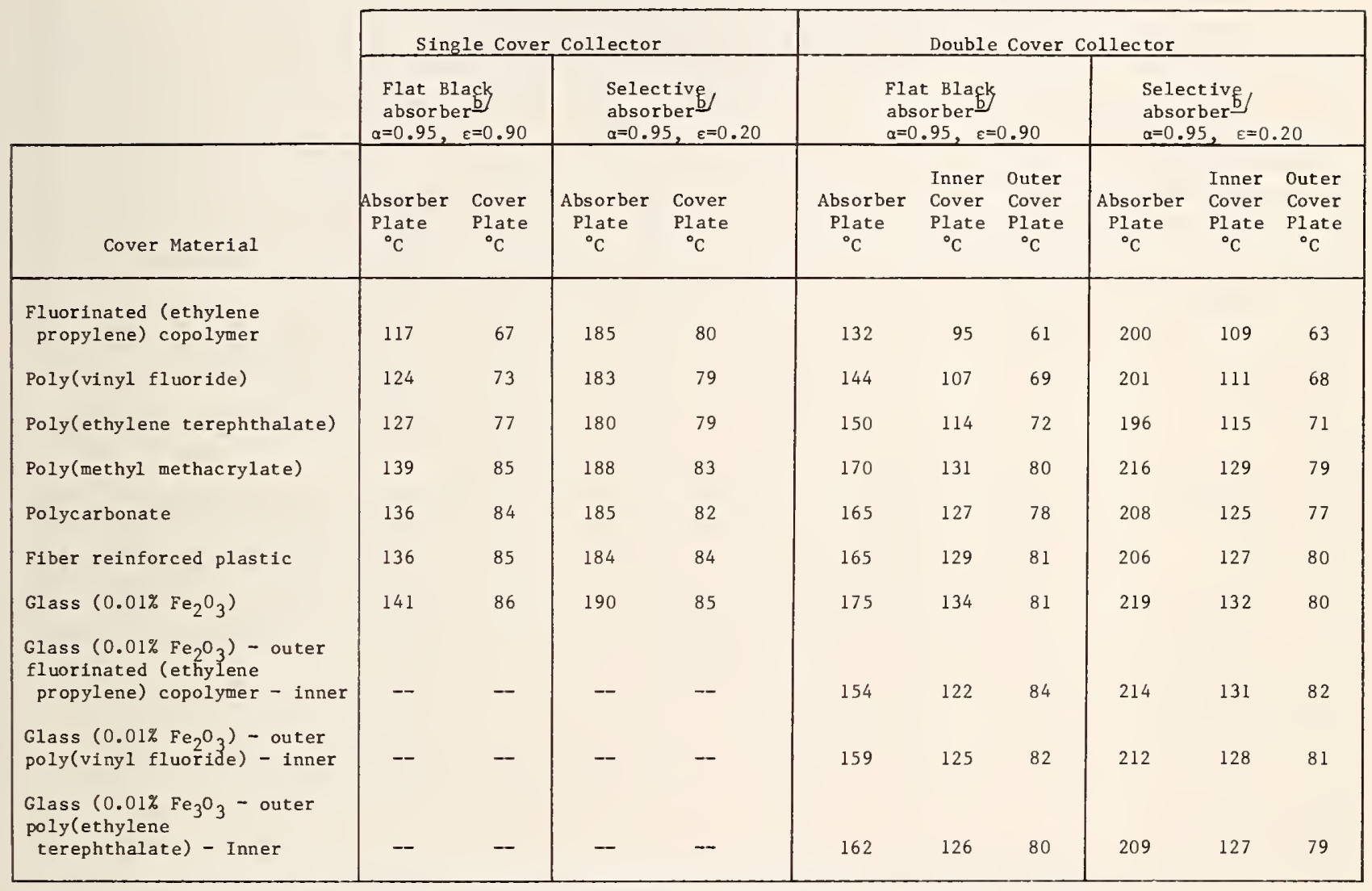

a) Temperature in Centigrade may be converted to Fahrenheit by the formula: ${ }^{\circ} \mathrm{F}=\left({ }^{\circ} \mathrm{C} \times \frac{9}{5}\right)+32^{\circ}$.

b/ $a=$ solar absorptance

$\varepsilon=$ emittance 
Table A8

Variation in Cover Plate Temperatures for Stagnating Collectors

with No Wind When the Weather Conditions Are Altered

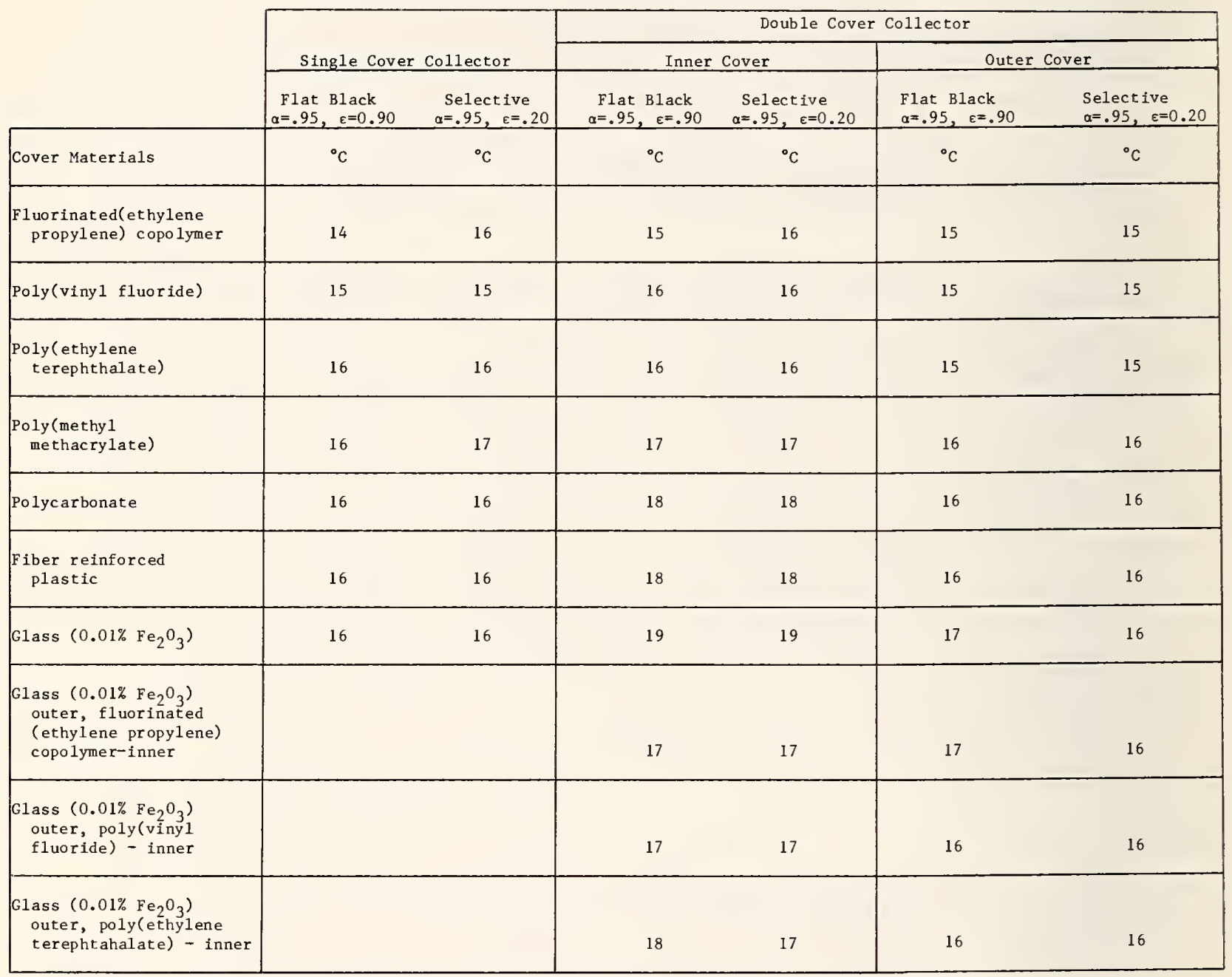

a These data were obtained by comparing the temperatures in Tables A5 and A7. The weather conditions were altered from $25^{\circ} \mathrm{C}\left(77^{\circ}\right)$ ambient temperature with $945 \mathrm{~W} / \mathrm{m}^{2}$ ( $300 \mathrm{Btu} / \mathrm{ft}^{2}{ }^{\circ} \mathrm{h}$ ) solar irradiance to $38^{\circ} \mathrm{C}$ ( $100^{\circ} \mathrm{F}$ ) ambient temperature with $1070 \mathrm{~W} / \mathrm{m}^{2}\left(340 \mathrm{Btu} / \mathrm{ft}^{2} \cdot \mathrm{h}\right)$ solar irradiance. 
Table A9

Comparison of Measured Temperatures of Glass Cover Plates on Flat Plate Solar Collectors under Stagnation Conditions with Estimated Temperatures from Computer Simulations

\begin{tabular}{|c|c|c|c|}
\hline & Single Cover Temperatures & \multicolumn{2}{|c|}{ Double Cover Temperatures } \\
\hline & ${ }^{\circ} \mathrm{C}$ & $\begin{array}{l}\text { Outer } \\
{ }^{\circ} \mathrm{C}\end{array}$ & $\begin{array}{l}\text { Inner } \\
{ }^{\circ} \mathrm{C}\end{array}$ \\
\hline $\begin{array}{l}\text { Measured on a flat plate } \\
\text { collector at } 28^{\circ} \mathrm{C}\left(820^{\circ} \mathrm{C}\right) \\
\text { ambient air } 930 \mathrm{~W} / \mathrm{m}^{2} \\
\left(295 \mathrm{Btu} / \mathrm{ft}^{2} \cdot \mathrm{h}\right) \mathrm{solar} \\
\text { irradiance, } 10.9 \mathrm{~km} / \mathrm{h} \\
(6.3 \mathrm{mph}) \text { wind, flat black } \\
\text { absorber (see figure A4). }\end{array}$ & -- & 75 & 130 \\
\hline $\begin{array}{l}\text { From computer simulations, } \\
\text { in IPC described in } \\
\text { section } \mathrm{A} \cdot 3.2 .3 .27^{\circ} \mathrm{C} \\
\left(81^{\circ} \mathrm{F} \text { ) ambient aif } 1070\right. \\
\mathrm{W} / \mathrm{m}^{2}\left(340 \mathrm{Btu} / \mathrm{ft}^{2} \cdot \mathrm{h}\right) \text { solar } \\
\text { irradiance, no wind (see } \\
\text { figure A5). }\end{array}$ & $85-86$ & $80-81$ & $132-134$ \\
\hline $\begin{array}{l}\text { From computer simulations } \\
\text { described in section } \mathrm{A} .3 .2 \text {. } \\
25^{\circ} \mathrm{C}\left(77^{\circ} \mathrm{F}\right) \text { ambient air, } \\
\left.945 \mathrm{~W} / \mathrm{m}^{2} \text { ( } 300 \mathrm{Btu} / \mathrm{ft}^{2} \cdot \mathrm{h}\right) \\
\text { solar irradiance, no wind } \\
(\text { see table } \mathrm{A} 7) \text {. }\end{array}$ & $88-93$ & $80-85$ & $130-135$ \\
\hline $\begin{array}{l}\text { From computer simulations } \\
\text { described in section A.3.2. } \\
38^{\circ}\left(100^{\circ} \mathrm{F}\right) \text { ambient ajr, } \\
\left.1070 \mathrm{~W} / \mathrm{m}^{2} \text { ( } 340 \mathrm{Btu} / \mathrm{ft}^{2} \cdot \mathrm{h}\right) \\
\text { solar irradiance, no wind } \\
\text { (see table A5). }\end{array}$ & $101-102$ & $96-98$ & $151-153$ \\
\hline
\end{tabular}

a/ Temperatures in Centigrade may be converted to Fahrenheit by the formula: ${ }^{\circ} \mathrm{F}=\left({ }^{\circ} \mathrm{C} \times 9 / 5\right)+32^{\circ}$. 

PROPOSED STANDARD PRACTICE FOR EXPOSURE OF COVER MATERIALS FOR SOLAR COLLECTORS TO NATURAL WEATHERING UNDER CONDITIONS SIMULATING STAGNATION MODE

1. SCOPE

1.1 This standard practice provides a procedure for the exposure of cover materials for flat plate solar collectors to the natural weather environment at temperatures which are elevated to approximate stagnation conditions.

1.2 This standard practice is suitable for exposure of both glass and plastic solar collector cover materials. Provisions are made for exposure of single and double cover assemblies to accomodate the need for exposure of both inner and outer solar collector cover materials.

1.3 This standard practice does not apply to cover materials for evacuated collectors or photovoltaics.

2. APPLICABLE DOCUMENTS

2.1 ASTM Standards

D 883 Definitions of Terms Relating to Plastics

D 1435 Recommended Practice for Outdoor Weathering of Plastics

E XXX Standard Practice for Evaluation of Cover Materials for Flat Plate Solar Collectors $1 /$

2.2 Other Documents:

Federal Specification HH-I-558B, Amendment 3, Insulation Blocks, Boards, Felts, Sleeving (Pipe and Tube Covering), and Pipe Fitting Covering Thermal (Mineral Fiber, Industrial Type) August 1976.2/

3. SIGNIFICANCE AND USE

3.1 This standard practice describes a weathering box test fixture and establishes limits for the heat loss coefficients. Uniform exposure guidelines are provided to minimize the variables encountered during outdoor exposure testing.

1/ A copy of this proposed Standard Practice is contained in Appendix C of this report.

2/ Available from General Services Administration. 
3.2 Since the combination of elevated temperature and solar radiation may cause some solar collector cover materials to degrade more rapidly than either alone, a weathering box which elevates the temperature of the cover materials is utilized.

3.3 This standard practice is intended to assist in the evaluation of solar collector cover materials in the stagnation mode. Insufficient data exist to obtain exact correlation between the behavior of materials exposed according to this recommended practice and actual in-service performance.

3.4 This standard practice may also be useful in comparing the performance of different materials at one site and/or the performance of the same material at different sites.

3.5 Means of evaluation of effects of weathering are provided in Method E XXX, Standard Practice for Evaluation of Cover Materials for Flat Plate Solar Collectors and in other ASTM test methods which evaluate material properties.

3.6 Exposures of the type described in this standard practice may be used to evaluate the stability of solar collector cover materials when exposed outdoors to the varied influences which comprise weather. Exposure conditions are complex and changeable. Important factors are material temperature, climate, time of year, presence of industrial atmosphere, etc. Generally, because it is difficult to define or measure precisely the factors influencing degradation due to weathering, results of outdoor exposure tests must be taken as indicative only. Repeated exposure testing at different seasons and over a period of more than one year is required to confirm exposure tests at any one location. Control samples must always be utilized in weathering tests for comparative analysis.

\section{WEATHERING BOX TEST FIXTURE}

\subsection{Test Fixture Requirements}

4.1.1 The weathering box test fixture should be constructed such that the combined back and edge loss coefficient is less than $1.5 \mathrm{~W} / \mathrm{m}^{2} \cdot{ }^{\circ} \mathrm{C}$ $\left(0.264 \mathrm{Btu} /\left(\mathrm{ft}^{2} \cdot \mathrm{h} \cdot{ }^{\circ} \mathrm{F}\right)\right)$. (Note 1 ) (The method for determining this coefficient is outlined in Appendix XI of this Standard). The distance between the absorber and the closest cover plate should be between 13 and $38 \mathrm{~mm}(1 / 2$ and $1-1 / 2 \mathrm{in})$. For a double cover exposure the separation between the inner and outer cover should be between 13 and $38 \mathrm{~mm}(1 / 2$ and $1-1 / 2$ in). Not more than 10 percent of the absorber plate area should be shaded when the sun is at a $30^{\circ}$ angle with the plane of the front surface of the exposure box.

4.1.2 Boxes that meet the requirements of Section 4.1 .1 are described in Table Bl. Figures B1 and B2 illustrate the exposure test fixtures. Although figure $B l$ shows a square box, any shape is permitted if the 
Table Bl. Examples of Exposure Test Fixtures with Combined Heat Loss Coefficient for Back and Edge Losses Less than $1.5 \mathrm{~W} / \mathrm{m}^{2}{ }^{\circ} \mathrm{C}$ $\left(0.264 \mathrm{Btu} /\left(\mathrm{ft}^{\left.\left.2 \cdot h \cdot{ }^{\circ} \mathrm{F}\right)\right)}\right.\right.$

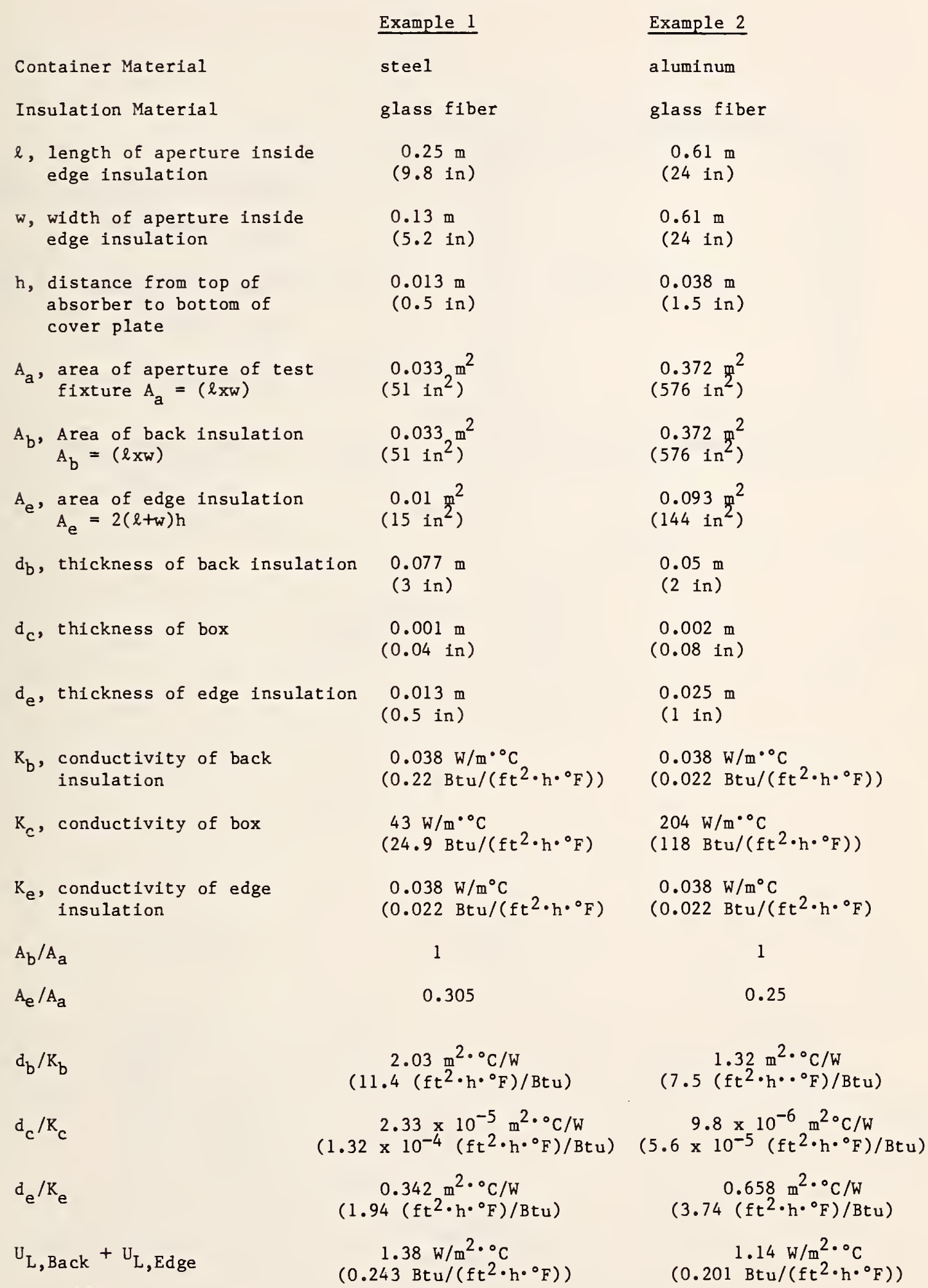


Figure B1 Top View of Exposure Test Fixture

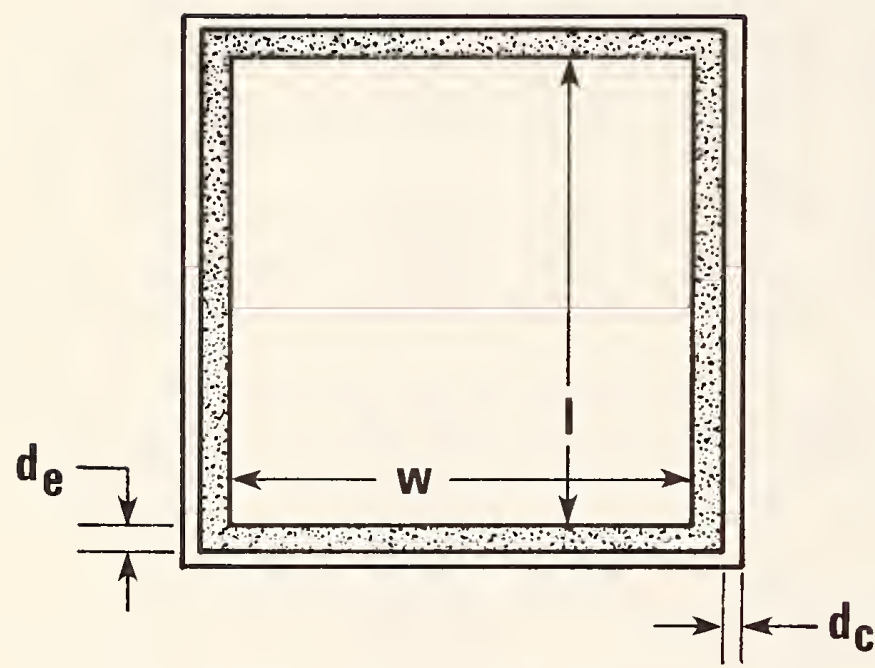

I = length of aperture inside edge insulation

w = width of aperture inside edge insulation

$d_{c}=$ thickness of box

$d_{e}=$ thickness of edge 
Figure B2 Natural Weathering Box Assembly

\section{DOUBLE GLAZED}

\section{SINGLE GLAZED}
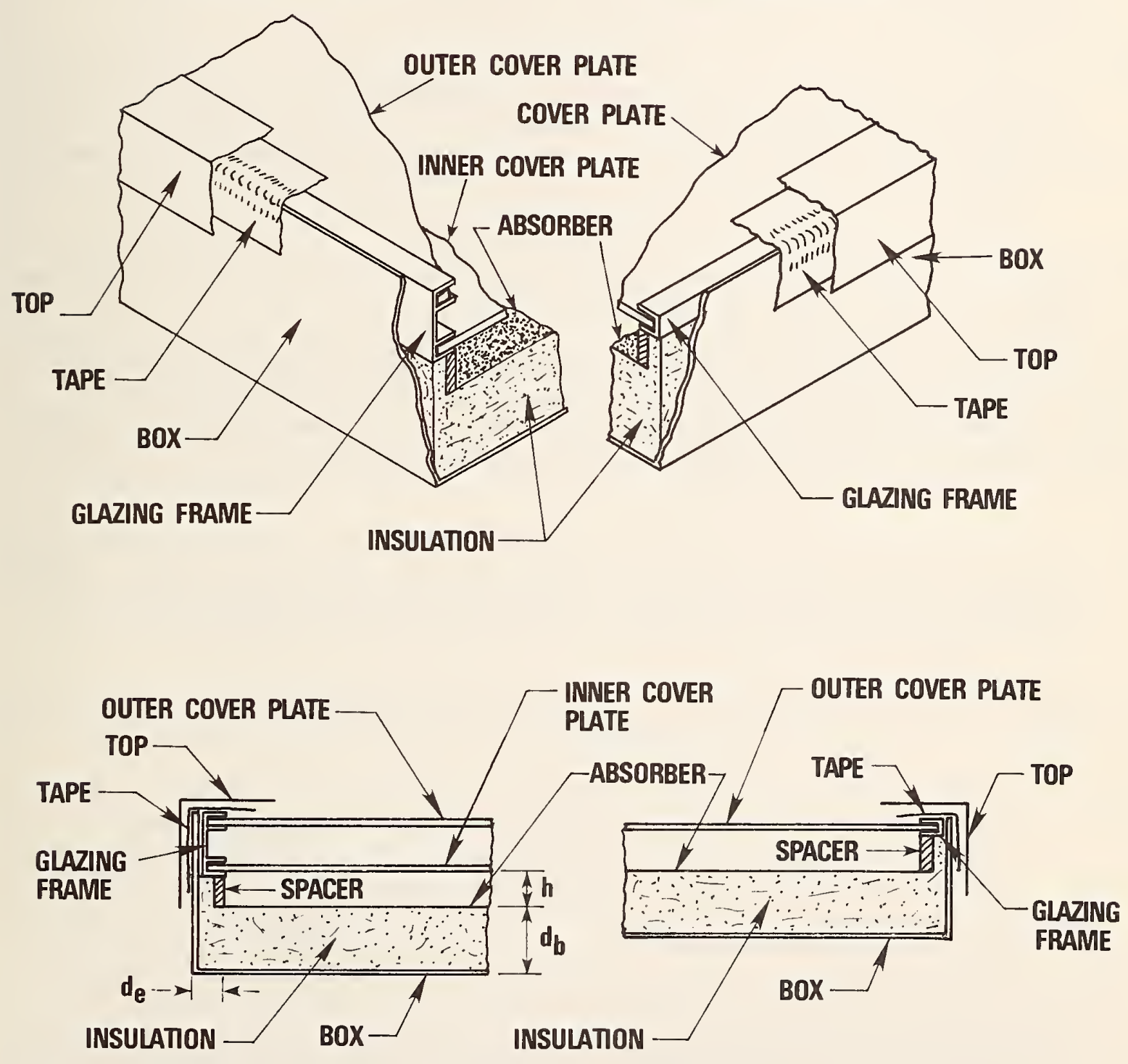
requirements in Section 4.1 .1 are met. Appendix X1 of this standard describes the method for determining the combined back and edge loss coefficients.

NOTE 1: A good flat plate solar collector has a combined back and edge loss coefficient of less than about $1.5 \mathrm{~W} / \mathrm{m}^{2}{ }^{\circ} \mathrm{C}\left(0.264 \mathrm{Btu} /\left(\mathrm{ft}^{2} \cdot \mathrm{h} \cdot{ }^{\circ} \mathrm{F}\right)\right)$.

4.2 The weathering box test fixture should consist of 1) a box, 2) insulation, 3) absorber, 4) a box top, 5) a spacer, 6) a glazing frame, and 7) adhesive tapes.

4.2.1 The box may have any dimensions and be made of any material as long as the requirements in Section 4.1 .1 are met. A weephole should be drilled at the lower end of the bottom of the box to provide drainage and to minimize moisture accumulation.

NOTE 2: It is desirable that the box and box top be made of a material which will be unaffected by the exposure environment. A metal resistant to corrosion encountered the environment would be suitable. If wood is used, it should be painted or treated on the exterior to make it impervious to moisture. In certain climates only rot resistant wood should be utilized to minimize deterioration during exposure.

4.2.2 The insulation should be a material suitable for use at high temperatures, $\left(\mathrm{e} . \mathrm{g} \cdot, 150^{\circ} \mathrm{C}\left(302^{\circ} \mathrm{F}\right)\right) .11$

NOTE 3: Insulation materials having resins or binders should not be used because elevated temperatures may cause the resin or binder to deteriorate and outgas. Outgassing products condense on the cover material causing changes in the solar transmittance of the solar collector cover material.

4.2.3 The absorber should be of an adequate size to cover the interior surface of the weathering box aperture. The absorber shall have a flat black nonselective coating having an absorptance not less than 0.90 after exposure.

4.2.4 The box top should be of an adequate size to fit over the top of the box.

NOTE 4: The box top is intended to protect the edges of the test specimen in contact with the box from reaching excessively high temperatures, to minimize exposure of the adhesive tape to sunlight, and to minimize moisture penetration into the exposure test fixture.

1/ Federal Specification $H H-I-558 B$ has several classes of insulation material intended for high temperature use. 
4.2.5 The glazing frame in intended to hold the cover plate material. The glazing frame should have dimensions similar to the perimeter of the container. For a double cover exposure the frame should provide a separation between the two cover plates of not less than $13 \mathrm{~mm}$ (1/2 in) nor greater than $38 \mathrm{~mm}(1-1 / 2 \mathrm{in})$. Exact dimensions of the frame are related to the requirements in Section 4.1.1. A vent hole may be drilled at one end of the spacer to provide drainage and to minimize moisture accumulation.

4.2.6 The spacer is intended to provide a separation of 13 to $38 \mathrm{~mm}$ ( $1 / 2$ to 1-1/2 in) between the absorber and the closest cover plate. Exact dimensions of the spacer are related to the requirements in Section 4.1 .1 .

NOTE 5: Certain designs of weathering boxes may eliminate the need for the spacer.

4.2.7 The adhesive tapes ${ }^{1 /}$ should be stable when exposed to moisture and elevated temperatures. They should be compatible with the specific materials from which the box, glazing frame, box top, and cover plate are made.

4.2.8 Organic materials are potential sources of outgassing and should be eliminated from the interior of the weathering box where possible. For example, metallic parts should be cleaned to remove traces of grease or other foreign matter. Other possible sources of outgassing include coatings and sealants. Test fixture components containing organic materials (e.g. absorber coatings or insulation) should be heated in an over at $150^{\circ} \mathrm{C}\left(302^{\circ} \mathrm{F}\right)$ for 24 hours before the test fixture is assembled. This should minimize outgassing which results from deterioration of the organic components exposed to elevated temperatures.

\subsection{Test Specimen}

4.3.1 The test specimen should be of an adequate size to cover the aperture of the box or glazing frame and to permit suitable attachment.

NOTE 6: Adequate allowances should be made for materials that will undergo dimensional changes due to temperature.

1/ 3M Weather Resistant Adhesive Tape $\$$ 棌38 or its equivalent has been found suitable for attaching the box top to the box. 3M Adhesive Transfer Tape and Densil Silicone Pressure Sensitive Tape 非2078 or the equivalent have been found suitable for attaching glazings to the glazing frame in solar collectors. The $3 \mathrm{M}$ tape is available from the 3M Company, 3M Center, St. Pau1, MN 55101. The Densil tape is available from the Dennison Manufacturing Company, Coated Paper Division, Framingham, MA 001701. 
4.3.2 The test specimen identification marks shall not interfere with either the exposure or the subsequent testing.

4.4 Sample Mounting

4.4.1 Rigid and Semirigid Glazings

4.4.1.1 Test specimens for single cover exposure may be laid directly on either the spacer or the glazing frames. If used, the frame is then placed on the spacer in the weathering box (see figure B2).

4.4.1.2 Test specimens for inner cover exposure on a double cover assembly should be either laid on the spacer or attached to the glazing frame before the glazing frame is placed in the box (see figure B2).

4.4.1.3 Test specimens for outer cover exposure on a double cover assembly should be laid on the top of the glazing frame (see figure B2).

4.4.2 Films

4.4.2.1 Film test specimens should be placed on the glazing frame using adhesive transfer tape to hold the test specimens taut. The frame should then be placed in the box similar to Sec. 4.4.1.1, 4.4.1.2 and 4.4 .1 .3 .

4.5 Assembly of Weathering Box

4.5.1 The various parts of the weathering box test fixture should be slid into position. The outer glazing must be roughly flush with the top side of the box. The position of an inner glazing, if used, will be nearest the bottom of the box.

4.5.2 After assembly, the frame and outer glazing should be sealed in place with an adhesive tape to prevent moisture intrusion. The box top is then placed on the box covering the tape (see figure B2).

5. NATURAL WEATHERING EXPOSURE

5.1 The weathering boxes shall be mounted in a backed condition on weathering racks such as those described in ASTM D 1435. The racks should be capable of having the angles adjusted and have their axis of rotation on an east/ west line.

5.2 A variable angle exposure should be utilized to maximize solar radiation incident upon the weathering box. Racks shall be adjusted according to the schedule given in Table B2. Positive rack angles face south. The angles shall be so chosen that the weathering boxes are never closer to the horizontal than by 5 degrees. Other variable exposure schedules utilizing more than four adjustments per year may be utilized. The method to determine the variable angle exposure schedule is described in Appendix X2 of this standard. 
5.3 When a number of weathering boxes are exposed simultaneously, the boxes should be mounted side by side with the sides not touching.

5.4 The solar collector cover materials should not be cleaned during exposure.

Table B2. Variable Angle Rack Adjustment Schedule Utilizing Four Changes Per Yeara,b/

\begin{tabular}{|l|c|c|}
\cline { 2 - 3 } \multicolumn{1}{c|}{} & \multicolumn{2}{c|}{ Calendar Period } \\
\hline $\begin{array}{c}\text { Rack Tilt Angle } \\
\text { Degrees }\end{array}$ & Dates & Days of Year \\
\hline Latitude $\pm 2.5^{\circ}$ & $3 / 2$ to $4 / 11$ & 61 to 101 \\
$\left(\right.$ Latitude $\left.-16^{\circ}\right) \pm 2.5^{\circ}$ & $4 / 12$ to $8 / 31$ & 102 to 243 \\
Latitude $\pm 2.5^{\circ}$ & $9 / 1$ to $10 / 10$ & 244 to 283 \\
(Latitude $\left.+16^{\circ}\right) \pm 2.5^{\circ}$ & $10 / 11$ to $3 / 1$ & 284 to 60 \\
\hline
\end{tabular}

a) This exposure schedule may be used in both northern and southern hemispheres. The latitude in the southern hemisphere is negative. Positive rack angles face south.

b) The incident angle of beam radiation $(\theta)$ at solar noon for a south facing collector is $\leq 8^{\circ}$.

6. REPORT

6.1 The report shall include the following:

6.1.1 Description of the weathering box test fixture and its calculated combined back and edge loss coefficient.

6.1.2 Complete identification of the solar collector cover material.

6.1.3 Whether the solar collector cover materials are exposed as a single or double cover configuration and whether the test specimen was the inner or outer cover.

6.1.4 A description of the test specimen attachment and mounting procedures.

6.1.5 Latitude, longitude, altitude and address of the testing site including a description of the type of climate.

6.1.6 Exposure data. 
6.1.6.1 Calendar dates of exposure.

6.1.6.2 Variable angle rack adjust schedule.

6.1.7 Climatological data.

6.1.7.1 Radiant exposure $\left(\mathrm{GJ} / \mathrm{m}^{2}\right)$ measured in the plane of the weathering boxes.

6.1.7.2 Monthly maximum, minimum and mean temperatures.

6.1.8 A visual inspection of test specimens, noting any obvious changes in appearance should be made at regular scheduled intervals (once per month minimum).

6.1.9 Description of control specimens.

6.1.10 Any deviation from this standard practice.

6.2 Other data which are desirable to report, if available are:

6.2.1 Optional climatological data.

6.2.1.1 Daily maximum, minimum and mean percent relative humidity.

6.2.1.2 Daily hours of wetness, both dew and rain.

6.2.1.3 Daily total inches of rainfall.

6.2.1.4 Daily maximum and minimum ambient temperature.

6.2.1.5 Daily radiant energy.

6.2.1.6 Wind direction and velocity.

6.2.2 Type of atmosphere, e.g., industrial, and level of air pollutants.

6.2.3 U1traviolet radiation.

6.2.4 Maximum absorber plate temperature. 


\section{APPENDIX XI \\ CALCULATION OF EXPOSURE TEST FIXTURE HEAT LOSSES}

\section{X1.1 SCOPE}

X1.1.1 This appendix outlines the method for determining the combined back and edge loss coefficients for an exposure test fixture as referenced in Section 4.1 .1 of this standard.

\section{X1.2 PROCEDURE}

\section{$\mathrm{X} 1.2 .1$ Assumptions:}

1. One-dimensional heat transfer (neglect corner effects)

2. The outside surface of the container is equal to the ambient temperature.

3. The inside surface of the edge insulation is equal to the absorber plate temperature. (A conservative assumption; the inside edge temperature would average less than the absorber plate temperature.)

\section{X1.2.2 Abbreviations}

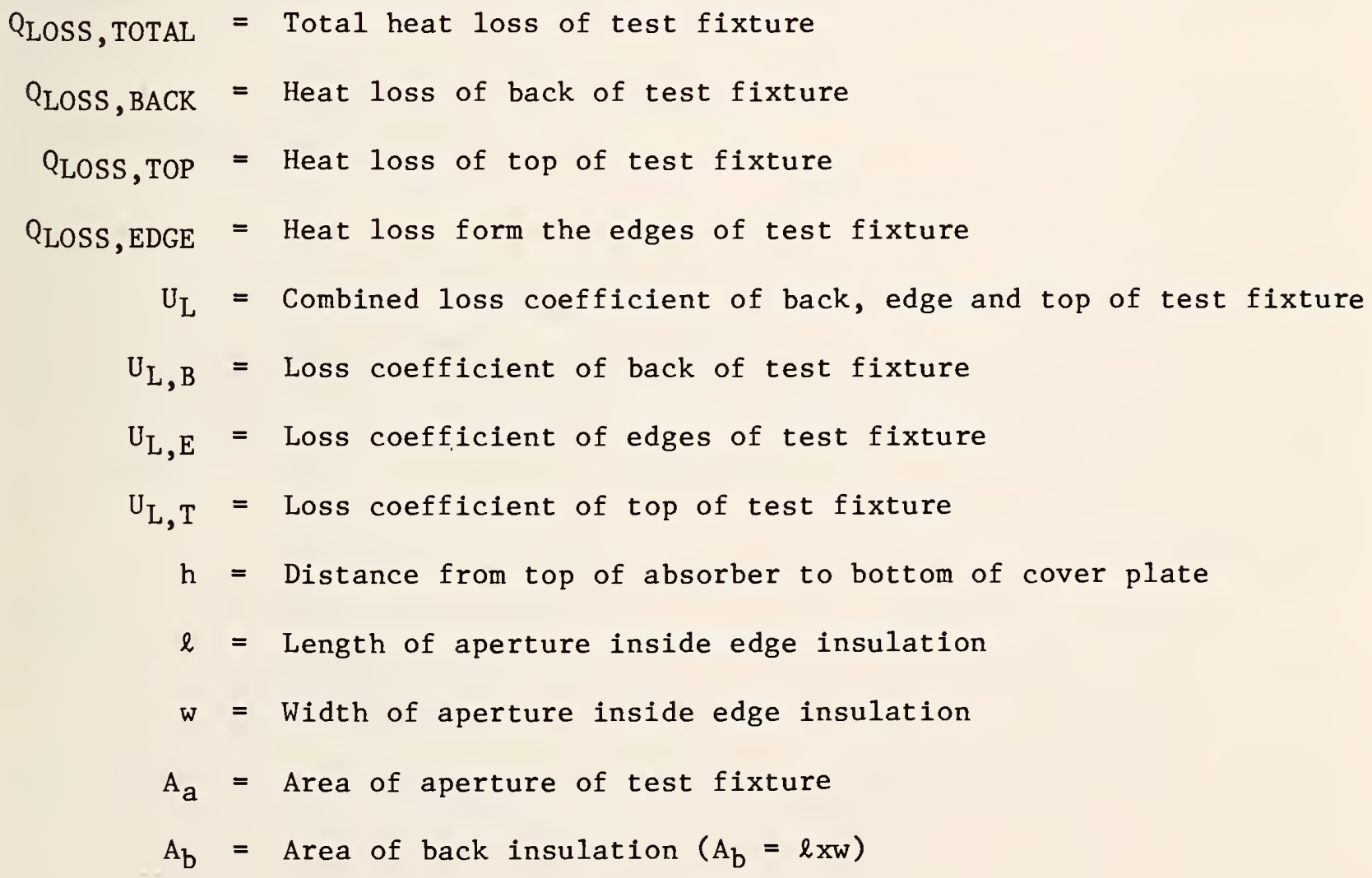




$$
\begin{aligned}
& A_{e}=\text { Area of edge insulation }\left(A_{e}=2(\ell+w) h\right) \\
& d_{b}=\text { Thickness of back insulation } \\
& d_{e}=\text { Thickness of edge insulation } \\
& d_{c}=\text { Thickness of container } \\
& \mathrm{K}_{b}=\text { Thermal conductivity of back insulation } \\
& \mathrm{K}_{e}=\text { Thermal conductivity of edge insulation } \\
& \mathrm{K}_{\mathrm{c}}=\text { Thermal conductivity of container } \\
& \mathrm{T}_{\mathrm{p}}=\text { Temperature of absorber plate } \\
& \mathrm{T}_{\mathrm{a}}=\text { Temperature of ambient air } \\
& \mathrm{T}_{\mathrm{c}}=\text { Temperature of container }
\end{aligned}
$$

\section{X1.2.3 Heat Losses}

\section{X1.2.3.1 General Equations}

$$
\mathrm{Q}_{\text {LOSS }, \text { TOTAL }}=\mathrm{Q}_{\mathrm{LOSS}, \mathrm{BACK}}+\mathrm{Q}_{\mathrm{LOSS}, \mathrm{EDGE}}+\mathrm{Q}_{\mathrm{LOSS}, \mathrm{TOP}}
$$

or

$$
A_{a} U_{L}\left(T_{p}-T_{a}\right)=A_{a} U_{L, B}\left(T_{p}-T_{a}\right)+A_{a} U_{L, E}\left(T_{P}-T_{a}\right)+A_{a} U_{L, T}\left(T_{P}-T_{a}\right)(E q \cdot 1.1)
$$

Dividing by $\mathrm{A}_{\mathrm{a}}\left(\mathrm{T}_{\mathrm{P}}-\mathrm{T}_{\mathrm{a}}\right)$,

$$
\mathrm{U}_{\mathrm{L}}=\mathrm{U}_{\mathrm{L}, \mathrm{B}}+\mathrm{U}_{\mathrm{L}, \mathrm{E}}+\mathrm{U}_{\mathrm{L}, \mathrm{T}}
$$

To keep different sizes of the test fixtures thermally equivalent, the sum of the loss coefficients, $\mathrm{U}_{\mathrm{L}, \mathrm{B}}, \mathrm{U}_{\mathrm{L}, \mathrm{E}}$, and $\mathrm{U}_{\mathrm{L}, \mathrm{T}}$ must remain constant. The top loss coefficient can be held fairly constant by keeping the cover distance above the absorber plate between 13 and $38 \mathrm{~mm}$ ( $1 / 2$ and $1-1 / 2 \mathrm{in})$. With this constraint, the sum of the edge loss coefficient, $U_{L, E}$, and the back loss coefficient, $\mathrm{U}_{\mathrm{L}, \mathrm{B}}$, must remain constant.

Therefore,

$$
\mathrm{U}_{\mathrm{L}, \mathrm{B}}+\mathrm{U}_{\mathrm{L}, \mathrm{E}}=\text { Constant }
$$

X1.2.3.2 Determination of Heat Loss Coefficient ( $U_{L, B}$ ) for Back of Test Fixture

The heat loss through the back of a test fixture is equal to: 


$$
\begin{aligned}
Q_{\text {LOSS, BACK }} & =A_{a} U_{L}, B\left(T_{p}-T_{a}\right)=A_{b}\left(K_{b} / d_{b}\right)\left(T_{P}-T_{c}\right) \\
& =A_{b}\left(K_{c} / d_{c}\right)\left(T_{c}-T_{a}\right)
\end{aligned}
$$

Reduction of equation 3.0 yields

$$
\mathrm{U}_{\mathrm{L}, \mathrm{B}}=\frac{\mathrm{A}_{\mathrm{b}} / \mathrm{A}_{\mathrm{a}}}{\left(\mathrm{d}_{\mathrm{b}} / \mathrm{K}_{\mathrm{b}}\right)+\left(\mathrm{d}_{\mathrm{c}} / \mathrm{K}_{\mathrm{c}}\right)}
$$

This reduction is accomplished by:

$$
\left(\mathrm{T}_{\mathrm{P}}-\mathrm{T}_{\mathrm{a}}\right)=\left(\mathrm{T}_{\mathrm{p}}-\mathrm{T}_{\mathrm{c}}\right)+\left(\mathrm{T}_{\mathrm{c}}-\mathrm{T}_{\mathrm{a}}\right)
$$

Substituting quantities from equation 3.0 into equation 3.2

$$
\frac{Q_{\text {LOSS, BACK }}}{A_{a} U_{L}, B}=\frac{Q_{L O S S, B A C K}}{A_{b}\left(K_{b} / d_{b}\right)}+\frac{Q_{\text {LOSS, BACK }}}{A_{b}\left(K_{c} / d_{c}\right)}
$$

Dividing by QLOSS,BACK

$$
\frac{1}{\mathrm{~A}_{\mathrm{a}} \mathrm{U}_{\mathrm{L}, \mathrm{B}}}=\frac{\mathrm{d}_{\mathrm{b}}}{\mathrm{A}_{\mathrm{b}} \mathrm{K}_{\mathrm{b}}}+\frac{\mathrm{d}_{\mathrm{c}}}{\mathrm{A}_{\mathrm{b}} \mathrm{K}_{\mathrm{c}}}
$$

Then,

$$
\mathrm{U}_{\mathrm{L}, \mathrm{B}}=\frac{\mathrm{A}_{\mathrm{b}} / \mathrm{A}_{\mathrm{a}}}{\left(\mathrm{d}_{\mathrm{b}} / \mathrm{K}_{\mathrm{b}}\right)+\left(\mathrm{d}_{\mathrm{c}} / \mathrm{K}_{\mathrm{c}}\right)}
$$

X1.2.3.3 Determination of Heat Loss Coefficient $\left(U_{L, E}\right)$ for Edge of Test Fixture The heat loss through the edge of the test fixture is equal to:

$$
\begin{aligned}
\text { QLOSS,EDGE } & =A_{a} U_{L}, E\left(T_{p}-T_{a}\right)=A_{e}\left(K_{e} / d_{e}\right)\left(T_{p}-T_{c}\right) \\
& =A_{e}\left(K_{c} / d_{c}\right)\left(T_{c}-T_{a}\right)
\end{aligned}
$$

Reduction of equation 4.0 yields:

$$
\mathrm{U}_{\mathrm{L}, \mathrm{E}}=\frac{\mathrm{A}_{\mathrm{e}} / \mathrm{A}_{\mathrm{a}}}{\left(\mathrm{d}_{\mathrm{e}} / \mathrm{K}_{\mathrm{e}}\right)+\left(\mathrm{d}_{\mathrm{c}} / \mathrm{K}_{\mathrm{c}}\right)}
$$

This reduction is accomplished by

$$
\left(T_{p}-T_{a}\right)=\left(T_{p}-T_{c}\right)+\left(T_{c}-T_{a}\right)
$$


Substituting quantities from equation 4.0 into equation 4.2

$\frac{\mathrm{Q}_{\mathrm{LOSS}, \text { EDGE }}}{\mathrm{A}_{\mathrm{a}} \mathrm{U}_{\mathrm{L}, \mathrm{E}}}=\frac{\mathrm{Q}_{\mathrm{LOSS}, \text { EDGE }}}{\mathrm{A}_{\mathrm{e}}\left(\mathrm{K}_{\mathrm{e}} / \mathrm{d}_{\mathrm{e}}\right)}+\frac{\mathrm{Q}_{\mathrm{LOSS}, \text { EDGE }}}{\mathrm{A}_{\mathrm{e}}\left(\mathrm{K}_{\mathrm{c}} / \mathrm{d}_{\mathrm{c}}\right)}$

Dividing by QLOSS,EDGE

$$
\begin{aligned}
& \frac{1}{A_{a} U_{L, E}}=\frac{d_{e}}{A_{e} K_{e}}+\frac{d_{c}}{A_{e} K_{c}} \\
& U_{L, E}=\frac{A_{e} / A_{a}}{\left(d_{e} / K_{e}\right)+\left(d_{c} / K_{c}\right)}
\end{aligned}
$$

X1.2.3.4 Combined Heat Loss Coefficient for Back and Edge Losses from Test Fixture

The combined heat loss coefficient for back and edge losses from the test fixture is found by adding equations 3.1 and 4.1 .

Then

$$
\mathrm{U}_{\mathrm{L}, \mathrm{B}}+\mathrm{U}_{\mathrm{L}, \mathrm{E}}=\frac{\mathrm{A}_{\mathrm{b}} / \mathrm{A}_{\mathrm{a}}}{\left(\mathrm{d}_{\mathrm{b}} / \mathrm{K}_{\mathrm{b}}\right)+\left(\mathrm{d}_{\mathrm{c}} / \mathrm{K}_{\mathrm{c}}\right)}+\frac{\mathrm{A}_{\mathrm{e}} / \mathrm{A}_{\mathrm{a}}}{\left(\mathrm{d}_{\mathrm{e}} / \mathrm{K}_{\mathrm{e}}\right)+\left(\mathrm{d}_{\mathrm{c}} / \mathrm{K}_{\mathrm{c}}\right)}
$$

For most designs $A_{b} / A_{a} \approx 1$, and $d_{b} / K_{b}$ and $d_{e} / K_{e} \gg d_{c} / K_{c} \cdot$

The refore, $U_{L, B}+U_{L, E}=\left(K_{b} / d_{b}\right)+\left(A_{e} / A_{a}\right)\left(K_{e} / d_{e}\right)$

\section{X1.2.3.5 Examples:}

This is an example of how to determine the combined heat loss coefficients and shading factor for the exposure test fixtures described in Table Bl in Section 4.1 .2 of the standard.

X1.2.3.5.1 For Example 1 Test Fixture from Table Bl,

$$
U_{L, B}+U_{L, E}=\frac{A_{b} / A_{a}}{\left(d_{b} / K_{b}\right)+\left(d_{c} / K_{c}\right)}+\frac{A_{e} / A_{a}}{\left(d_{e} / K_{e}\right)+\left(d_{c} / K_{c}\right)}
$$

If $A_{b} / A_{a}=1, A_{e} / A_{a}=0.305$, and $d_{b} / K_{b}=2.03 \mathrm{~m}^{2} \cdot{ }^{\circ} \mathrm{C} / \mathrm{W}\left(11.4\left(\mathrm{ft}^{2} \cdot \mathrm{h} \cdot{ }^{\circ} \mathrm{F}\right) / \mathrm{Btu}\right)$,

$$
\mathrm{d}_{\mathrm{c}} / \mathrm{K}_{\mathrm{c}}=2.33 \times 10^{-5} \mathrm{~m}^{2} \cdot{ }^{\circ} \mathrm{C} / \mathrm{W},\left(1.32 \times 10^{-4}\left(\mathrm{ft}^{2} \cdot \mathrm{h} \cdot{ }^{\circ} \mathrm{F}\right) / \mathrm{Btu}\right),
$$$$
\mathrm{d}_{\mathrm{e}} / \mathrm{K}_{\mathrm{e}}=0.342 \mathrm{~m}^{2} \cdot{ }^{\circ} \mathrm{C} / \mathrm{W}\left(1.94\left(\mathrm{ft}^{2} \cdot \mathrm{h} \cdot{ }^{\circ} \mathrm{F}\right) / \mathrm{Btu}\right)
$$ 
Then $d_{b} / K_{b} \gg d_{c} / K_{c}$ and $d_{e} / K_{e} \gg d_{c} / K_{c}$

Therefore, equation 5.1 can be used.

$$
\begin{aligned}
\mathrm{U}_{\mathrm{L}, \mathrm{B}}+\mathrm{U}_{\mathrm{L}, \mathrm{E}}= & \left(\mathrm{K}_{\mathrm{b}} / \mathrm{d}_{\mathrm{b}}\right)+\left(\mathrm{A}_{\mathrm{e}} / \mathrm{A}_{\mathrm{a}}\right)\left(\mathrm{K}_{\mathrm{e}} / \mathrm{d}_{\mathrm{e}}\right) \\
= & 0.49 \mathrm{~W} / \mathrm{m}^{2} \cdot{ }^{\circ} \mathrm{C}\left(0.088 \mathrm{Btu} /\left(\mathrm{ft}^{2} \cdot \mathrm{h} \cdot{ }^{\circ} \mathrm{F}\right)\right. \\
& +0.89 \mathrm{~W} / \mathrm{m}^{2}{ }^{\circ} \mathrm{C}\left(0.155 \mathrm{Btu} /\left(\mathrm{ft}^{2} \cdot \mathrm{h} \cdot{ }^{\circ} \mathrm{F}\right)\right) \\
\mathrm{U}_{\mathrm{L}, \mathrm{B}}+\mathrm{U}_{\mathrm{L}, \mathrm{E}}= & 1.38 \mathrm{~W} / \mathrm{m}^{2} \cdot{ }^{\circ} \mathrm{C}\left(0.243 \mathrm{Btu} /\left(\mathrm{ft}^{2} \cdot \mathrm{h} \cdot{ }^{\circ} \mathrm{F}\right)\right)
\end{aligned}
$$

To determine the shading of the absorber:

$$
\% \text { shade }=\frac{z \cdot h \cdot \tan \theta \cdot 100 \%}{z \cdot y}
$$

where

$$
\begin{aligned}
& z=\text { north-south dimension of absorber } \\
& y=\text { east-west dimension of absorber } \\
& h=\text { height from absorber to top of outer cover plate } \\
& \theta=\text { solar beam angle of incidence }\left(15^{\circ} \cong 1\right. \text { hour from solar noon) }
\end{aligned}
$$

$$
\begin{aligned}
& \text { If } \theta=30^{\circ}, z=0.25 \mathrm{~m}(9.8 \text { in) } \\
& y=0.13 \mathrm{~m}(5.2 \mathrm{in}) \\
& \mathrm{h}=0.013 \mathrm{~m}(0.5 \mathrm{in}) \\
& \% \text { shade }=\frac{(0.25 \mathrm{~m})(0.013 \mathrm{~m}) \tan 30}{(0.25 \mathrm{~m})(0.13 \mathrm{~m})} \times 100 \% \\
& \% \text { shade }=5.8 \%
\end{aligned}
$$

X1.2.3.5.2 For Example 2 Test Fixture from Table $B 1$,

$$
\mathrm{U}_{\mathrm{L}, \mathrm{B}}+\mathrm{U}_{\mathrm{L}, \mathrm{E}}=\frac{\mathrm{A}_{\mathrm{b}} / \mathrm{A}_{\mathrm{a}}}{\left(\mathrm{d}_{\mathrm{b}} / \mathrm{K}_{\mathrm{b}}\right)+\left(\mathrm{d}_{\mathrm{c}} / \mathrm{K}_{\mathrm{c}}\right)}+\frac{\mathrm{A}_{\mathrm{e}} / \mathrm{A}_{\mathrm{a}}}{\left(\mathrm{d}_{\mathrm{e}} / \mathrm{K}_{e}\right)+\left(\mathrm{d}_{c} / \mathrm{K}_{\mathrm{c}}\right)}
$$

If $A_{b} / A_{a}=1, A_{e} / A_{a}=0.25$ and $d_{b} / K_{b}=1.32 \mathrm{~m}^{2} \cdot{ }^{\circ} \mathrm{C} / \mathrm{W}\left(7.5\left(\mathrm{ft}^{2} \cdot \mathrm{h} \cdot{ }^{\circ} \mathrm{F}\right) / \mathrm{Btu}\right)$,

$$
\begin{aligned}
& \mathrm{d}_{\mathrm{c}} / \mathrm{K}_{\mathrm{c}}=9.8 \times 10^{-6} \mathrm{~m}^{2} \cdot{ }^{\circ} \mathrm{C} / \mathrm{W}\left(5.6 \times 10^{-5}\left(\mathrm{ft}^{2} \cdot \mathrm{h} \cdot{ }^{\circ} \mathrm{F}\right) / \mathrm{Btu}\right), \\
& \mathrm{d}_{\mathrm{e}} / \mathrm{K}_{\mathrm{e}}=0.658 \mathrm{~m}^{2} \cdot{ }^{\circ} \mathrm{C} / \mathrm{W}\left(3.74\left(\mathrm{ft}^{2} \cdot \mathrm{h} \cdot{ }^{\circ} \mathrm{F}\right) / \mathrm{Btu}\right)
\end{aligned}
$$

Then $d_{b} / K_{b} \gg d_{c} / K_{c}$, and $d_{e} / K_{e} \gg d_{c} / K_{c}$ 
Therefore, equation 5.1 can be used.

$$
\begin{aligned}
\mathrm{U}_{\mathrm{L}, \mathrm{B}}+\mathrm{U}_{\mathrm{L}, \mathrm{E}}= & \mathrm{K}_{\mathrm{b}} / \mathrm{d}_{\mathrm{b}}+\left(\mathrm{A}_{\mathrm{e}} / \mathrm{A}_{\mathrm{a}}\right)\left(\mathrm{K}_{\mathrm{e}} / \mathrm{d}_{\mathrm{e}}\right) \\
& =0.7 \mathrm{~S} / \mathrm{m}^{2} \cdot{ }^{\circ} \mathrm{C}\left(0.134 \mathrm{Btu} /\left(\mathrm{ft}^{2} \cdot \mathrm{h} \cdot{ }^{\circ} \mathrm{F}\right)\right) \\
& +0.38 \mathrm{~W} / \mathrm{m} \cdot{ }^{\circ} \mathrm{C}\left(0.067 \mathrm{Btu} /\left(\mathrm{ft}^{2} \cdot \mathrm{h} \cdot{ }^{\circ} \mathrm{F}\right)\right) \\
\mathrm{U}_{\mathrm{L}, \mathrm{B}}+\mathrm{U}_{\mathrm{L}, \mathrm{E}}= & 1.14 \mathrm{~W} / \mathrm{m}^{2} \cdot{ }^{\circ} \mathrm{C}\left(0.201 \mathrm{Btu} /\left(\mathrm{ft}^{2} \cdot \mathrm{h} \cdot{ }^{\circ} \mathrm{F}\right)\right)
\end{aligned}
$$

To determine the shading of the absorber, equation 6.0 is used.

$$
\begin{aligned}
\text { If } \theta=30^{\circ}, z & =0.61 \mathrm{~m}(24 \mathrm{in}) \\
\mathrm{y} & =0.61 \mathrm{~m}(24 \mathrm{in}) \\
\mathrm{h} & =0.038 \mathrm{~m}(1.5 \mathrm{in}) \\
\% \text { shade }= & \frac{(0.61 \mathrm{~m})(0.038 \mathrm{~m}) \tan 30 \mathrm{x} 100 \%}{(0.61 \mathrm{~m})(0.61 \mathrm{~m})} \\
\% \text { shade }= & 3.6 \%
\end{aligned}
$$


The direction of beam solar radiation can be determined by equations provided in Duffie and Beckman.1/ The geometric relationships between a plane of any particular orientation relative to the earth at any time (whether that plane is fixed or moving relative to the earth) and the incoming beam solar radiation, that is, the position of the sun relative to that plane, can be described in terms of several angles. These angles, and the relationship between them are:

$\phi \quad=$ latitude (north positive);

$\delta=$ declination (i.e., the angular position of the sun at solar noon with respect to the plane of the equator) (north positive);

$\mathrm{s}=$ the angle betwen the horizontal and the plane (i.e., the slope) (facing south is positive);

$\gamma=$ the surface azimuth angle, that is, the deviation of the normal to surface from the local meridian, the zero point being due south, east positive, and west negative;

$\omega=$ hour angle, solar noon being zero, and each hour equaling $15^{\circ}$ of longitude with mornings positive and afternoons negative (e.g., $\omega=+15$ for $11: 00$, and $\omega=-37.5$ for 14:30);

$\theta=$ the angle of incidence of beam radiation, the angle being measured between the beam and the normal to the plane.

The declination, $\delta$, can be found from the approximate equation

$$
\delta=23.45 \sin \left[360\left(\frac{284+n}{365}\right)\right]
$$

where $\mathrm{n}$ is the day of the year. $2 /$

1/ Duffy, John and Beckman, William, Solar Energy Thermal Processes, New York, John Wiley and Sons, (1974).

2/ Declination can also be conveniently determined from charts. 
The relation between $\theta$ and the other angles is given by

$$
\begin{aligned}
\cos \theta & =\sin \delta \sin \phi \cos s-\sin \delta \cos \phi \sin s \cos \gamma \\
& +\cos \delta \cos \phi \cos s \cos \omega \\
& +\cos \delta \sin \phi \sin s \cos \gamma \cos \omega \\
& +\cos \delta \sin s \sin \gamma \sin \omega
\end{aligned}
$$

Equation 2 reduces to the following for a south facing collector:

$$
\cos \theta=\sin (\phi-s) \sin \delta+\cos (\phi-s) \cos \delta \cos \omega
$$

At solar noon $\omega=0$ and $\cos \omega=1$, therefore

$$
\cos \theta=\sin (\phi-s) \sin \delta+\cos (\phi-s) \cos \delta
$$

Using the identity: $\cos (A-B)=\sin A \sin B+\cos A \cos B$, equation 2.2 becomes:

$$
\cos \theta=\cos [(\phi-s)-\delta]
$$

Therefore, $\theta=\phi-s-\delta$

In order to make $\theta=0$, the following must be true

$$
\begin{aligned}
\mathrm{S}_{\text {opt }}=\phi & -\delta \text { where } \\
\mathrm{S}_{\text {opt }} & =\text { optima1 collector slope } \\
\phi & =\text { latitude } \\
\delta & =\text { declination of sun }
\end{aligned}
$$

To maximize the incident solar radiation upon the cover plate materials, the angle of incidence of the beam solar radiation, $\theta$, should be as close to 0 as possible at solar noon. This can be achieved by periodically adjusting the slope of the exposure fixture. The optimal slope may be determined by equation 3 .

Example:

Find optimum slope for Gaithersburg, Md. on May 3 .

$$
\begin{aligned}
& \phi=39.1^{\circ} \text { (latitude) } \\
& n=123 \text { (day of year for May 3) }
\end{aligned}
$$


From Equation 1,

$$
\begin{aligned}
& \delta=23.45 \sin \left[\frac{360}{365}(284+123)\right] \\
& \delta=15.5^{\circ}
\end{aligned}
$$

Therefore,

$$
\mathrm{S}_{\text {opt }}=\phi-\delta=39.1^{\circ}-15.5^{\circ}=23.6^{\circ}
$$

Using equation 3, Tables B3 and B4 were developed for variable angle exposure schedules necessary to keep the angle of incidence of the beam solar radiation, $(\theta)$, less than $4^{\circ}$ and $6^{\circ}$. Other exposure schedules may be calculated using this approach. 
Table B3. Variable Angle Rack Adjustment Schedule Utilizing Ten Changes per Yeara, b/

\begin{tabular}{|l|l|l|}
\hline \multirow{2}{*}{ Rack Angle (Degrees) } & \multicolumn{2}{|c|}{ Calendar Period } \\
\cline { 2 - 3 } & \multicolumn{1}{|c|}{ Dates } & Days of Year \\
latitude $+12^{\circ}$ & $2-7$ to $3-1$ & 38 to 60 \\
latitude $+4^{\circ}$ & $3-2$ to $3-21$ & 61 to 80 \\
latitude $-4^{\circ}$ & $3-22$ to $4-11$ & 81 to 101 \\
latitude $-12^{\circ}$ & $4-12$ to $5-4$ & 102 to 124 \\
latitude $-20^{\circ}$ & $5-5$ to $8-7$ & 125 to 219 \\
latitude $-12^{\circ}$ & $8-8$ to $8-31$ & 220 to 243 \\
latitude $-4^{\circ}$ & $9-1$ to $9-20$ & 244 to 263 \\
latitude $+4^{\circ}$ & $9-21$ to $10-10$ & 264 to 283 \\
latitude $+12^{\circ}$ & $10-11$ to $11-2$ & 284 to 306 \\
latitude $+20^{\circ}$ & $11-3$ to $2-6$ & 307 to 37 \\
\hline
\end{tabular}

a/ This exposure schedule may be used in both northern and southern hemispheres. The latitude in the southern hemispheres is negative. Positive rack angles face south.

b/ The incident angle of beam radiation ( $\theta$ ) at solar noon for a south facing collector is $\leq 4^{\circ}$.

Table B4. Variable Angle Rack Adjustment Schedule Utilizing Six Changes per Yeara, b/

\begin{tabular}{|l|l|l|}
\hline \multirow{2}{*}{ Rack Angle (Degrees) } & \multicolumn{2}{|c|}{ Calendar Period } \\
\cline { 2 - 3 } & Dates & Days of Year \\
\hline latitude $+6^{\circ}$ & $2-19$ to $3-21$ & 50 to 80 \\
latitude $-6^{\circ}$ & $3-22$ to $4-22$ & 81 to 112 \\
latitude $-18^{\circ}$ & $4-23$ to $8-20$ & 113 to 232 \\
latitude $-6^{\circ}$ & $8-21$ to $9-20$ & 233 to 263 \\
latitude $+6^{\circ}$ & $9-21$ to $10-22$ & 264 to 294 \\
latitude $+18^{\circ}$ & $10-22$ to $2-18$ & 295 to 49 \\
\hline
\end{tabular}

a This exposure schedule may be used in both northern and southern hemispheres. The latitude in the southern hemisphere is negative. Positive rack angles face south.

b/ The incident angle of beam radiation ( $\theta$ ) at solar noon for a south facing collector is $\leq 6^{\circ}$. 
PROPOSED STANDARD PRACTICE FOR EVALUATION OF COVER MATERIALS FOR FLAT PLATE SOLAR COLLECTORS

1. SCOPE

1.1 This standard practice is intended for the evaluation of cover materials for flat plate solar collectors.

1.2 This standard practice includes evaluation procedures for the measurement of primary properties of materials and for the assessment of durability of solar collector covers by comparison of initial primary property values with those obtained after exposure to aging procedures.

1.3 This standard practice includes both primary property measurement tests and aging procedures. Property test methods are included for measurments of: solar transmittance, dimensional stability, impact resistance, tensile strength, and the effect of dirt retention on solar tramsmittance. Aging procedures are included for exposure to: heat, natural weathering, and accelerated weathering.

2. APPLICABLE DOCUMENTS

\subsection{ASTM STANDARDS}

D 618 Conditioning Plastics and Electrical Materials for Testing

D 638 Tensile Properties of Plastics

D 794 Recommended Practice for Determining the Permanent Effect of Heat on Plastics

D 882 Tensile Properties of Thin Plastic Sheeting

D 1042 Linear Dimensional Changes of Plastics Under Accelerated Service Conditions

D 1181 Warpage of Sheet Plastics

D 1204 Linear Dimensional Changes of Nonrigid Thermoplastic Sheeting or Film at Elevated Temperature

D 2565 Recommended Practice for Operating Xenon Arc-Type (Water-Cooled) Light-Exposure Apparatus With and Without Water for Exposure of Plastics

E 424 Solar Energy Transmittance and Reflectance (Terrestria1) of Sheet Materials

E XXX Standard Practice for Determining Resistance of Solar Collector Covers to Impact by Haill/

1/ A copy of this proposed standard is contained in National Bureau of Standards Report, by D.R. Jenkins and R.G. Mathey which is in preparation. 
E XXX Standard Practice for Exposure of Cover Materials for Solar Collectors to Natural Weathering Under Conditions Simulating Stagnation Mode ${ }^{1 /}$

\subsection{ANSI STANDARDS}

ANSI 297.1-1975 Safety Performance Specifications and Methods of Test for Safety Glazing Material Used in Buildings.2\%

\subsection{OTHER DOCUMENTS}

Recommendations for the Integrated Irradiance and Spectra 1 Distribution of Simulated Radiation for Test Purposes, CIE Publication No. 20 (TC-2.2), $1972.3 /$

\section{SIGNIFICANCE AND USE}

3.1 While this standard practice is addressed to testing of covers for flat plate collectors, it may be used for testing covers for other solar collectors where applicable.

3.2 This standard practice is intended to aid the prediction of in-service performance by short term testing.

3.3 Insufficient data exist to obtain exact correlation between the results of accelerated weathering tests and actual in service performance.

3.4 Primary properties and their long term stability are critical to the performance of a solar collector. Property measurement tests provide for measurement of material properties of solar collector covers. Aging procedures provide for exposure of solar collector covers to environments which may induce changes in material properties as shown in property measurement tests. Property measurement tests performed before and after aging procedures provide a means of determining the effect of the aging procedures on the solar collector cover material and assist in estimating the durability of solar collector covers.

3.5 These tests include only those considered most critical to the performance of the solar collector. Other tests to evaluate materials may also be performed.

1/ A copy of this proposed standard is contained in Appendix B of this report.

2/ Available from American National Standards Institute, 1430 Broadway, New York, NY 10018

3/ Available from Dr. Jack L. Tech, Secretary of U.S. National Committee of International Commission on Illumination, National Bureau of Standards, 220 B-306, Washington, DC 20234 
3.6 This standard practice is intended for use by material manufacturers, solar collector manufacturers, testing laboratories and others. The use of this standard practice will provide material property data and durability data by which a material's suitability for a solar collector cover can be assessed. It will also provide data for comparing the durability of various collector cover materials. However, when using the data for comparison of materials, the user should be aware that the many factors influencing degradation due to weathering vary from location to location as well as time of test. Because of this, outdoor exposure data should be taken as indicative only. For direct comparisons the materials should undergo the identical exposure conditions. Control samples must be used in weathering exposures when identical exposure conditions cannot be used.

\section{TEST SPECIMENS}

4.1 The numbers and types of tests required and the preferred testing sequence are specified in Table $\mathrm{Cl}$ and Figure $\mathrm{Cl}$.

4.2 Except for thickness, the geometry of the test specimens used to evaluate the properties of cover materials shall be in accordance with that specified in the applicable documents listed in Section 2. The thickness of the specimens shall be that thickness intended for use in solar collector covers. Warpage specimens will be $15 \mathrm{~cm}$ by $15 \mathrm{~cm}$ ( 6 in by 6 in) (See Section 6.1.3).

4.3 Tensile test specimens used for evaluating the effects of aging procedures shall be cut from a larger piece of material that was subjected to the aging procedure.

4.4 Separate test specimens shall be used for the physical property tests if the physical property test could change the test specimen prior to measurement of solar transmittance or dirt retention. Optical property tests shall not be performed on test specimens damaged by physical property tests.

\section{RECOMMENDED CONDITIONING FOR PHYSICAL PROPERTY TESTS}

5.1 Conditioning - Unless otherwise specified, the test specimens for physical property tests shall be conditioned at $23^{\circ} \pm 2^{\circ} \mathrm{C}\left(73^{\circ} \pm 4^{\circ} \mathrm{F}\right)$ and $50 \pm$ 5 percent relative humidity for not less than 40 hours prior to test in accordance with Procedure A of ASTM D 618.

5.2 Test Conditions - Conduct tests in the Standard Laboratory Atmosphere of $23^{\circ} \pm 2^{\circ} \mathrm{C}\left(73^{\circ} \pm 4^{\circ} \mathrm{F}\right)$ and $50 \pm 5$ percent relative humidity, unless other-

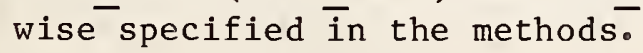

NOTE 1: In actual practice collector cover materials must have acceptable physical properties over a wide range of temperature and humidity conditions. However performing physical property tests above or below ambient conditions is difficult to implement. 

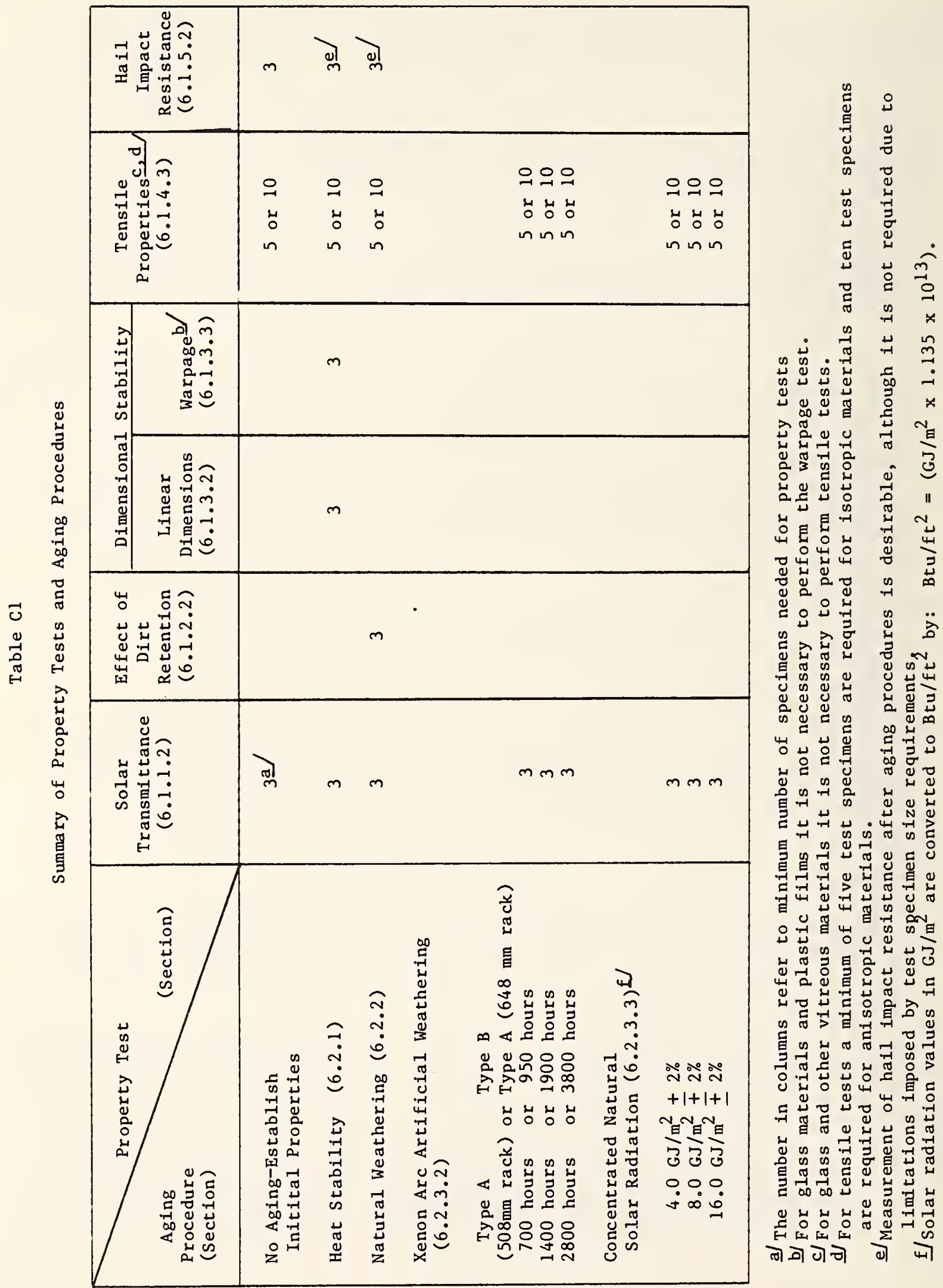

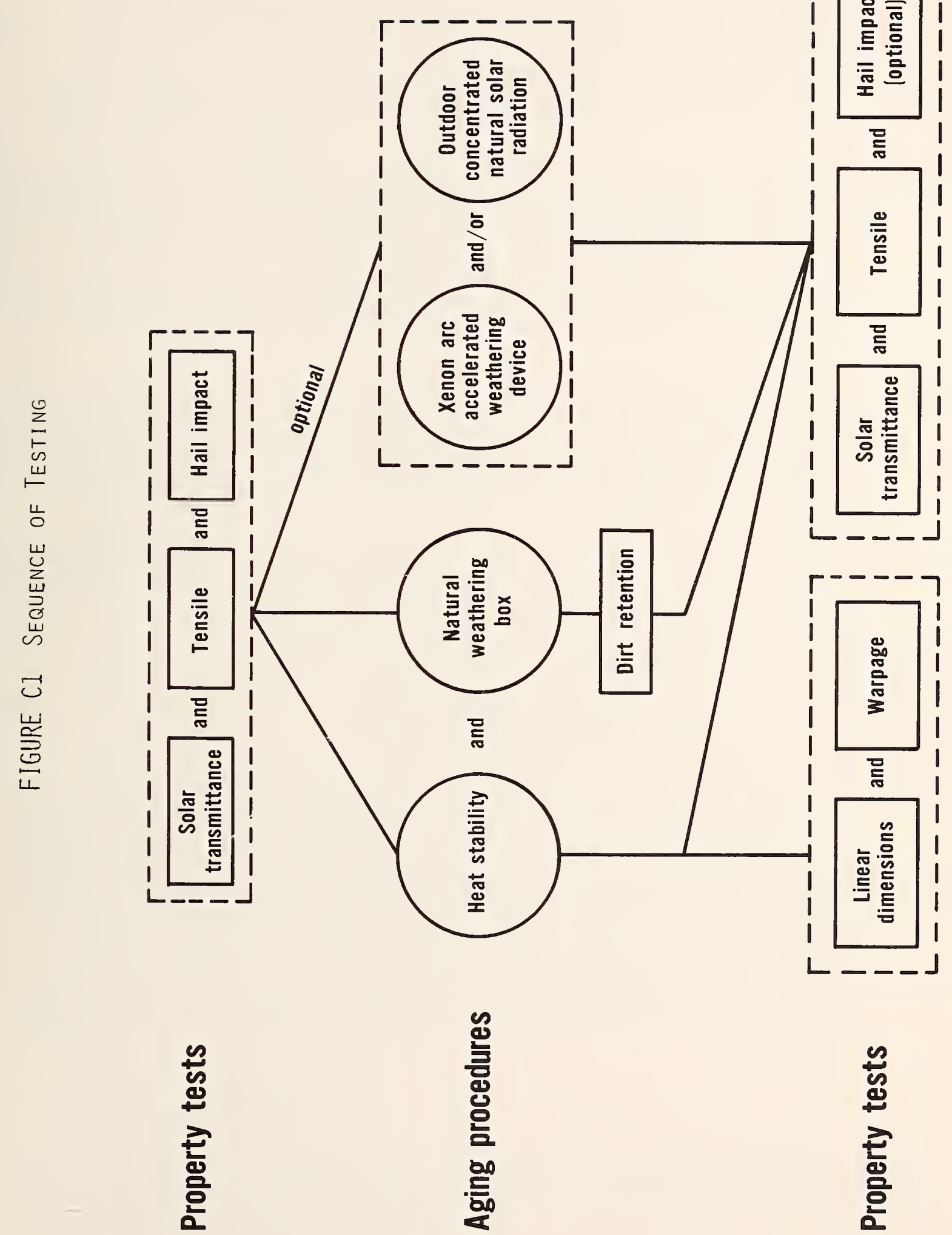


\subsection{PROPERTY MEASUREMENT TESTS}

\section{1 .1 SOLAR TRANSMITTANCE}

6.1.1.1 Transmittance is an important factor in the admittance of energy through the solar collector cover.

6.1.1.2 Determine solar energy transmittance by the appropriate method described in ASTM E 424. The same method shall be used for the initial and final measurements. Four measurements shall be made, rotating the test specimen $90^{\circ}$ after each measurement. The average of the four values shall be considered the solar transmittance of the material. If Method $A$ is used, a representative sample of the material must be supplied for transmittance measurements to establish initial properties.

NOTE 2: Method A of ASTM E 424 uses a spectrophotometer with an integrating sphere, and is especially useful for precise determinations of minor changes in clear or uniformly diffusing cover materials. Method B of ASTM E 424 using a pyranometer may be used for nonuniformly diffusing thick cover materials.

6.1.1.3 These methods provide a means for measuring solar transmittance under fixed conditions of incidence and viewing and have been found practical for both transparent and translucent materials.

\subsubsection{EFFECT OF DIRT RETENTION ON SOLAR TRANSMITTANCE}

6.1.2.1 Dirt on a solar collector cover will block the passage of solar energy and reduce solar energy transmittance.

6.1.2.2 The effect of dirt retention on the solar transmittance of a solar collector cover material may be determined on a test specimen exposed to natural weathering ( $\mathrm{Sec}, 6.2 .2$ ). Measure solar transmittance as described in Sec.6.1.1.2. Then using a very soft brush, clean both sides of the sample with a 0.1 percent solution of nonionic detergent (Note 3) in distilled water. Rinse with distilled water, blot remaining water and air dry. Care should be taken to avoid scratching or stretching plastic materials. Remeasure the total solar transmittance. The difference in solar transmittance before and after cleaning is an indication of the amount of dirt retained during natural weathering. 
NOTE 3: Suitable nonionic detergents include Alconox, Triton DF 16 and Triton $\mathrm{x} 100.11$

NOTE 4: Since dirt retention in natura1 outdoor weathering is dependent on when the last rainfall took place, it is difficult to compare dirt retention on materials that have not undergone identical, simultaneous weathering.

\subsubsection{DIMENSIONAL STABILITY}

6.1.3.1 Changes in the shape of a solar collector cover may result from exposure to service conditions. A material may sag, shrink or warp.

6.1.3.2 Changes in linear dimensions shall be determined for rigid and semirigid materials as described in ASTM D 1042, and for nonrigid materials as described in ASTM D 1204.

6.1.3.3 Determine warpage of rigid and semirigid plastic materials using the apparatus described in ASTM D 1181, or an equivalent apparatus. During heat aging the test specimens shall be suspended vertically from a single point at the center of the top edge. Measure at the location having the greatest deviation from flatness. Specimens for this test shall be $15 \mathrm{~cm}$ by $15 \mathrm{~cm}$ ( 6 in by 6 in). Specimens must be cut to size prior to heat aging.

\subsubsection{TENSILE PROPERTIES}

6.1.4.1 Tensile properties are an indication of the mechanical properties of a material. During environmental exposure a material may soften or become more brittle. Tensile properties include tensile strength, percent elongation at yield and at break, and modulus of elasticity.

6.1.4.2 Since tensile properties are influenced by temperature and humidity, the test specimens shall be carefully conditioned as per Sec. 5.1 and 5.2 prior to each test.

6.1.4.3 Determine tensile properties of rigid and semi-rigid plastic materials as described in ASTM D 638 using Speed B with a Type IV specimen. For flexible membrane materials use ASTM D 882.

1/ Alconox is available from Alconox Inc., 217 Park Ave S., New York, N.Y. Triton DF16 and Triton X100 are available from Rohm and Haas, Industrial Chemical Dept., Philadelphia, PA 19105. 
6.1.5.1 Impact resistance is the ability of a material to resist fracture under shock force.

6.1.5.2 Determine hail impact resistance of solar collector cover materials using ASTM E XXX, Standard Practice for Determining Resistance of Cover Plates for Solar Energy Collectors to Hail Impact.

6.1.5.3 Collector covers are also subject to impact by thrown and wind-blown solid objects. The evaluation of impact resistance to these objects will require different Standard Practices than that for hail impact resistance.

\subsection{AGING PROCEDURES}

\section{2 .1 HEAT STABILITY}

6.2.1.1 The elevated temperatures reached by solar collector covers may cause changes in properties of the material. The design of the solar collector will influence the temperatures attained by the collector covers. This heat stability test is intended to be an early screening device to discriminate between materials that are probably not suitable for solar collector covers and those that may have value in this application.

6.2.1.2 Using an oven and a specimen rack described in ASTM D 794, Sections 3 and 4 , expose the test specimens for 500 hours to $150^{\circ} \mathrm{C}\left(302^{\circ} \mathrm{F}\right)$.

6.2.2 NATURAL WEATHERING

6.2.2.1 On a solar collector the cover is simultaneously exposed to elevated temperature and solar radiation. The combination may have a more severe effect on materials than either would independently.

6.2.2.2 Expose solar collector cover test specimens for a minimum period of twelve months using ASTM E XXX, Standard Practice for Exposure of Cover Materials for Solar Collectors to Natural Weathering under Conditions Simulating Stagnation Mode.

\section{2 .3 ACCELERATED WEATHERING}

6.2.3.1 Accelerated weathering exposure procedures shall not replace the Natural Weathering exposure procedure in Sec.6.2.2.2. They may be used as a screening test for cover materials. It is noted that where correlation to natural weathering is or can be established for a candidate cover material, accelerated testing using simulated weathering devices may be an effective means for obtaining reliable long-term durability information in short periods of time. 
NOTE 5: When two or more materials are being compared, all materials must be exposed in the same test.

\subsubsection{Laboratory Procedure}

6.2.3.2.1 Expose the test specimens according to Procedure A of ASTM D 2565 . With the Type A or AH apparatus having a $508 \mathrm{~mm}$ (20 in) diameter rack, the exposure periods sha11 be 700,1400 and 2800 hours. With the Type $\mathrm{B}$ or $\mathrm{BH}$ apparatus or with the Type A or AH apparatus having a $648 \mathrm{~mm}$ ( $25.5 \mathrm{in})$ inclined rack, the exposure periods shall be 950 , 1900 , and 3800 hours. The black panel temperature should be $70^{\circ} \pm$ $2^{\circ} \mathrm{C}\left(158^{\circ} \mathrm{F} \pm 4^{\circ} \mathrm{F}\right)$ with a relative humidity of $55 \pm 5$ percent. Solar Solar collector cover materials exposed to moisture in service shall be subjected to an exposure cycle of 90 minutes of light only followed by 30 minutes of light with water spray.

NOTE 6: In order to approximate the equivalence of hours of exposure in ASTM D 2565 to years of exposure to natural solar irradiance, Tables C2 and C3 in Appendix XI of this standard are provided.

\subsubsection{Outdoor Exposure Using Concentrated Natural Solar Radiation}

6.2.3.3.1 Outdoor weathering can be accelerated by concentrating natural sunlight using reflectors.

6.2.3.3.2 Using concentrated natural solar radiation machines such as those referenced in ANSI 297.1-1975, paragraph 4.3.2, expose the test specimens to concentrated natural solar radiation. The test specimens shall be framed and off-mounted (between 0.5 and $1 \mathrm{~cm}(1 / 4$ and $1 / 2$ inch) from the target board. The cooling of the test specimens shall be adjusted to maintain the surface temperature of the test specimens to within $15^{\circ} \mathrm{C}\left(27^{\circ} \mathrm{F}\right)$ of identical test specimens exposed to the nonconcentrated irradiance at a standard fixed angle. The framing or mounting of the relevant test specimens must be identical. The test specimens shall be exposed until they have received a total incident radiant exposure of $4.0 \mathrm{GJ} / \mathrm{m}^{2}+2$ percent, 8.0 $\mathrm{GJ} / \mathrm{m}^{2} \pm 2$ percent and $16.0 \mathrm{GJ} / \mathrm{m}^{2} \pm 2$ percent. $1 /$ Solar collector cover materials exposed to moisture in service shall be subjected to water spray for a period of 8 minutes during each 60 minutes of sunlight exposure, and four eight minute spray cycles per night. The water spray should be at a rate of $1.2 \times 10^{-2} \mathrm{l} / \mathrm{s} \cdot \mathrm{m}^{2}\left(1.8 \times 10^{-2}\right.$ gal/min $\left.\cdot f t^{2}\right)+20$ percent.

$1 /$ These values are based on a solar exposure of 6 months, 12 months, and 24 months, assuming an average annual radiant exposure of $8.0 \mathrm{GJ} / \mathrm{m}^{2}$ $\left(9.1 \times 10^{13} \mathrm{Btu} / \mathrm{ft}^{2}\right) \pm 2$ percent. 
7. PROCEDURE

7.1 Some of the property measurement tests are to be performed before the aging procedures, some after, and some both before and after.

7.1.1 Solar transmittance, tensile strength, impact resistance, initial warpage and the initial dimensions for the linear dimensional stability test shall be measured before aging to establish the initial material properties of a solar collector cover material.

7.1.2 Solar transmittance, tensile strength, the effect of dirt retention, warpage and final dimensions for the linear dimensional stability test shall be measured after aging to assess the durability of a solar collector cover material.

7.1.3 After natural weathering exposure, specimens for testing shall be taken from the center of the test specimen.

7.1.4 The impact resistance may be measured after the aging procedures, unless sample size limitations prevent this determination.

NOTE 7: Many materials lose resistance to impact after exposure to aging procedures. A remeasurement of impact resistance after exposure to the elements should detect this loss.

7.2 Tests conducted in accordance with this standard practice shall be as summarized in Table $\mathrm{Cl}$ and in the sequence as shown in Figure $\mathrm{Cl}$.

7.3 The solar transmittance, impact resistance, dimensional stability, and the effect of dirt retention shall be measured on a minimum of three separate specimens at each exposure increment of each aging procedure indicated in Table Cl.

7.4 At each exposure test increment, tensile test specimens may be cut from a single piece of cover plate material. At least five test specimens shall be tested for each material in the case of isotropic materials. At least ten specimens, five normal to and five parallel with the principal axis of anisitropy, shall be tested for each material in the case of anisotropic materials.

8. REPORT

8.1 The test report shall include the following:

8.1.1 Any deviation from the conditions described in this standard practice.

8.1.2 Complete identification of the solar collector cover material tested.

8.1.3 Indicate the method used for measuring solar transmittance. 
8.1.4 For the effect of dirt retention, report the original solar energy transmittance and the solar transmittance before and after cleaning. Report the exposure period (dates).

8.1.5 For linear dimensional stability, the test specimen size and the average percentage change-in linear dimensions.

8.1.6 For warpage, the greatest deviation from flatness.

8.1.7 For tensile properties, whether the material is isotropic or anisotropic and the data required for the report in ASTM D 638 or D 882.

8.1.8 For impact resistance.

8.1.8.1 The type and size of the test specimen.

8.1.8.2 The size, mass and velocity of each ice sphere and the results of each impact, e.g., breakage, rupture, tear.

8.1.9 For Natural Weathering, the data required for the report in Method EXXX, Standard Practice for Exposure of Cover Materials for Solar Collectors to Natural Weathering Under Condiitons Simulating Stagnation Mode.

8.1.10 For the Accelerated Weathering Laboratory Procedure, the type of artificial weathering apparatus, length of time of exposure and whether water spray was utilized.

8.1.11 For the Outdoor Exposure Procedure using Concentrated Natural Solar Radiation, the radiant exposure, i.e, total energy incident during the time of exposure, period (dates) of exposure, and whether water spray was utilized.

8.1.12 Description of visible changes in test specimens after exposure to aging procedures.

8.1.13 Number of specimens tested.

8.1.14 Results of initial property measurement values and property measurement values determined after each aging procedure. 
ENERGY BELOW $400 \mathrm{~nm}$ FOR ARTIFICIAL WEATHERING APPARATUS WITH XENON ARC LIGHT AND NATURAL SOLAR IRRADIANCE

Table $\mathrm{C} 2$

Total Energy Below $400 \mathrm{~nm}$ for Artificial Weathering Apparatus with Xenon Arc Light

\begin{tabular}{|c|c|c|}
\cline { 2 - 3 } \multicolumn{1}{c|}{} & \multicolumn{2}{c|}{ Type of Apparatus $/$} \\
\hline Hours of Exposureb/ & $\begin{array}{r}25 \mathrm{~K} \text { Xenon } \\
\mathrm{A} \text { or AH } \\
\mathrm{MJ} / \mathrm{m}^{2}\end{array}$ & $\begin{array}{c}65 \mathrm{~K} \text { Xenon } \\
\mathrm{B} \text { or BH } \\
\mathrm{MJ} / \mathrm{m}^{2}\end{array}$ \\
\hline 1 & 0.356 & 0.261 \\
700 & 249 & 248 \\
950 & 498 & 496 \\
1400 & 997 & 992 \\
\hline 900 & & \\
\hline
\end{tabular}

a The artificial weathering apparatus types are described in ASTM D 2565.

b/ These time increments correspond to the exposure times in Section 6.2.3.2.

The exposure intervals provided in Table $\mathrm{Cl}$ are predicted on constant irradiance throughout the test and are based on the spectral distribution of the light source as listed in the table. To assure these data when following Procedure A of D 2565, the $2.5 \mathrm{~kW}$ xenon lamp should be operated to provide controlled irradiance at $340 \mathrm{~mm}$ of $0.8 \mathrm{~W} / \mathrm{m}^{2}$ and the $6.5 \mathrm{~kW}$ lamp must provide $0.6 \mathrm{~W} / \mathrm{m}^{2}$. With an integrating light monitor the intervals of irradiation at $340 \mathrm{~mm}$ and $2052 \mathrm{~kJ} / \mathrm{m}^{2}$, $4104 \mathrm{~kJ} / \mathrm{m}^{2}$ and $8208 \mathrm{~kJ} / \mathrm{m}^{2}$. Irradiance, and thus time, may vary within reasonable tolerances but the total irradiation incident on the specimen remains constant. If the irradiation is not monitored and controlled, the stepped wattage alternative may be expected to lower the precision of reproducibility. 
Average Total Energy Below $400 \mathrm{~nm}$ for Natural Solar Irradiance on a South Facing Tilt Angle in Arizona and Floridal

\begin{tabular}{|c|c|c|c|c|}
\hline & \multicolumn{2}{|c|}{$\frac{\text { Total Energy }\left(\mathrm{MJ} / \mathrm{m}^{2}\right)}{45^{\circ}}$} & \multicolumn{2}{|l|}{ Below $400 \mathrm{~nm}$} \\
\hline & Phoenix, Arizona & Miami, Florida & Phoenix, Arizona & Miami, Florida \\
\hline $\begin{array}{ll}1 & \text { year } \\
2 & \text { years } \\
3 & \text { years } \\
4 & \text { years } \\
5 & \text { years }\end{array}$ & $\begin{array}{r}492 \\
984 \\
1476 \\
1968 \\
2460\end{array}$ & $\begin{array}{r}340 \\
681 \\
1022 \\
1363 \\
1704\end{array}$ & $\begin{array}{r}429 \\
859 \\
1288 \\
1718 \\
2148\end{array}$ & $\begin{array}{r}378 \\
757 \\
1135 \\
1524 \\
1892\end{array}$ \\
\hline
\end{tabular}

1) Arizona and Florida data are based on 5-year (1973-1977) averages and assume the energy below $400 \mathrm{~nm}$ (ultraviolet) is 6.1 percent of the total solar energy. This assumption is based on data from the International Commission on Illumination (CIE) published in "Recommendations for Integrated Irradiance and Spectral Distribution of Simulated Radiation for Test Purposes". 
BIBLIOGRAPHIC DATA

SHEET (See instructions) REPORT NO.

NBS TN 1132

December 1980

4. TITLE AND SUBTITLE

Solar Energy Systems - Standards for Cover Plates for Flat Plate Solar Collectors

5. AUTHOR(S)

Elizabeth J. Clark, Willard E. Roberts, John W. Grimes, Edward J. Embree

6. PERFORMING ORGANIZATION (If joint or other than NBS, see instructions)

7. Contract/Grant No.

NATIONAL BUREAU OF STANDARDS

DEPARTMENT OF COMMERCE

WASHINGTON, D.C. 20234

8. Type of Report \& Period Covered

Final

9. SPONSORING ORGANIZATION NAME AND COMPLETE ADDRESS (Street, City, State, ZIP)

Department of Energy

Office of Solar Applications for Building

Office of the Assistant Secretary, Conservation and Solar Collectors

Washington, DC 20585

10. SUPPLEMENTARY NOTES

[D Document describes a computer program; SF-185, FIPS Software Summary, is attached.

11. ABSTRACT (A 200-word or less factual summary of most significant information. If document includes a significant bibliography or literature survey, mention it here)

Laboratory studies were performed to obtain data needed for the development of standards to evaluate the performance and durability of cover plates for flat plate solar collectors used in solar heating and cooling systems. Ten cover plate materials were evaluated to assess their durability after exposure to heat aging, natural weathering and accelerated weathering. Laboratory tests included measurement of solar energy transmittance, linear dimensional stability, warpage and the effect of the dirt retention. The temperatures cover plate materials attain on solar collectors were determined by measurement and by computer simulations. A procedure was developed for the natural weathering exposure of cover plate materials at elevated temperatures which approximate stagnation conditions of solar collectors.

The results of the laboratory tests are presented and draft standards for evaluating cover plate materials for flat plate solar collectors are proposed.

12. KEY WORDS (Six to twelve entries; alphabetical order; capitalize only proper names; and separate key words by semicolons) Cover plate durability; cover plate materials; cover plate standards; standards; weathering of cover plates.

13. AVAILABILITY

X] Unlimited

For Official Distribution. Do Not Release to NTIS

$\mathrm{X}$ Order From Superintendent of Documents, U.S. Government Printing Office, Washington, D.C. 20402.

Order From National Technical Information Service (NTIS), Springfield, VA. 2216I

14. NO. OF PRINTED PAGES

157

15. Price

$\$ 5.50$ 


\section{NBS TECHNICAL PUBLICATIONS}

\section{PERIODICALS}

JOURNAL OF RESEARCH-The Journal of Research of the National Bureau of Standards reports NBS research and development in those disciplines of the physical and engineering sciences in which the Bureau is active. These include physics, chemistry, engineering, mathematics, and computer sciences. Papers cover a broad range of subjects, with major emphasis on measurement methodology and the basic technology underlying standardization. Also included from time to time are survey articles on topics closely related to the Bureau's technical and scientific programs. As a special service to subscribers each issue contains complete citations to all recent Bureau publications in both NBS and nonNBS media. Issued six times a year. Annual subscription: domestic \$13: foreign $\$ 16.25$. Single copy, $\$ 3$ domestic: $\$ 3.75$ foreign.

NOTE: The Journal was formerly published in two sections: Section A "Physics and Chemistry" and Section B "Mathematical Sciences."

DIMENSIONS/NBS-This monthly magazine is published to inform scientists, engineers, business and industry leaders, teachers, students, and consumers of the latest advances in science and technology, with primary emphasis on work at NBS. The magazine highlights and reviews such issues as energy research, fire protection, building technology, metric conversion, pollution abatement, health and safety, and consumer product performance. In addition, it reports the results of Bureau programs in measurement standards and techniques, properties of matter and materials, engineering standards and services, instrumentation, and automatic data processing. Annual subscription: domestic \$11; foreign $\$ 13.75$.

\section{NONPERIODICALS}

Monographs-Major contributions to the technical literature on various subjects related to the Bureau's scientific and technical activities.

Handbooks-Recommended codes of engineering and industrial practice (including safety codes) developed in cooperation with interested industries, professional organizations, and regulatory bodies.

Special Publications-Include proceedings of conferences sponsored by NBS, NBS annual reports, and other special publications appropriate to this grouping such as wall charts, pocket cards, and bibliographies.

Applied Mathematics Series-Mathematical tables, manuals, and studies of special interest to physicists, engineers, chemists, biologists, mathematicians, computer programmers, and others engaged in scientific and technical work.

National Standard Reference Data Series-Provides quantitative data on the physical and chemical properties of materials, compiled from the world's literature and critically evaluated. Developed under a worldwide program coordinated by NBS under the authority of the National Standard Data Act (Public Law 90-396).
NOTE: The principal publication outlet for the foregoing data is the Journal of Physical and Chemical Reference Data (JPCRD) published quarterly for NBS by the American Chemical Society (ACS) and the American Institute of Physics (AIP). Subscriptions, reprints, and supplements available from ACS, 1155 Sixteenth St., NW, Washington, DC 20056.

Building Science Series-Disseminates technical information developed at the Bureau on building materials, components, systems, and whole structures. The series presents research results, test methods, and performance criteria related to the structural and environmental functions and the durability and safety characteristics of building elements and systems.

Technical Notes-Studies or reports which are complete in themselves but restrictive in their treatment of a subject. Analogous to monographs but not so comprehensive in scope or definitive in treatment of the subject area. Often serve as a vehicle for final reports of work performed at NBS under the sponsorship of other government agencies.

Voluntary Product Standards-Developed under procedures published by the Department of Commerce in Part 10, Title 15, of the Code of Federal Regulations. The standards establish nationally recognized requirements for products, and provide all concerned interests with a basis for common understanding of the characteristics of the products. NBS administers this program as a supplement to the activities of the private sector standardizing organizations.

Consumer Information Series-Practical information, based on NBS research and experience, covering areas of interest to the consumer. Easily understandable language and illustrations provide useful background knowledge for shopping in today's technological marketplace.

Order the above NBS publications from: Superintendent of Documents, Government Printing Office, Washington, DC 20402.

Order the following NBS publications-FIPS and NBSIR's-from the National Technical Information Services, Springfield, VA 22161.

Federal Information Processing Standards Publications (FIPS PUB)-Publications in this series collectively constitute the Federal Information Processing Standards Register. The Register serves as the official source of information in the Federal Government regarding standards issued by NBS pursuant to the Federal Property and Administrative Services Act of 1949 as amende, Public Law 89-306 (79 Stat. 1127), and as implemented by F ecutive Order 11717 (38 FR 12315, dated May I1, 1973) and Paı 。 of Title 15 CFR (Code of Federal Regulations).

NBS Interagency Reports (NBSIR)-A special series of interim or final reports on work performed by NBS for outside sponsors (both government and non-government). In general, initial distribution is handled by the sponsor; public distribution is by the National Technical Information Services, Springfield, VA 22161, in paper copy or microfiche form. 


\section{U.S. DEPARTMENT OF COMMERCE}

Wational Bureau of Standards

Washington, D.C. 20234

POSTAGE ANO FEES PAIO

OFFICIAL BUSINESS TMENT OF COMMEACE COM-2I5

Penalty for Private Use, $\$ 300$

SPECIAL FOURTH-CLASS RATE BOOK 